\title{
Physiologische Untersuchungen zur \\ Regulation des Aminosäure-Stoffwechsels von Bacillus licheniformis DSM13
}

\author{
Dissertation \\ zur Erlangung des Doktorgrades \\ der Mathematisch-Naturwissenschaftlichen Fakultäten \\ der Georg-August-Universität zu Göttingen
}

vorgelegt von

Marco Schwarzer

aus Langenhagen

Göttingen 2010 
D7

Referent: $\quad$ Prof. Dr. W. Liebl

Korreferent: $\quad$ PD Dr. R. Daniel

Tag der mündlichen Prüfung: 08.07.2010 
für meine 7race und meine Kinder 
Inhaltsverzeichnis I

Abkürzungsverzeichnis .................................................................................. V

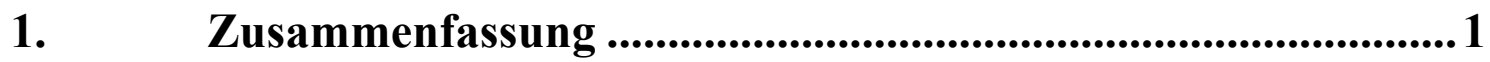

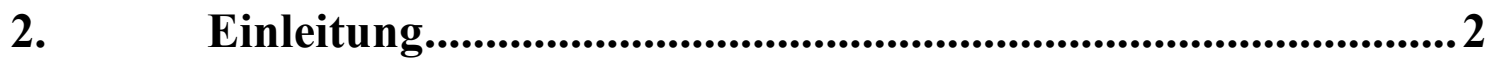

2.1. Stoffwechseländerungen zur Bewältigung unterschiedlicher

Wachstumsumstände ...................................................................................... 2

2.2. Einsatz von DNA-Microarray Technologie zur globalen

Genexpressionanalyse ..........................................................................6

2.3. Biologie von Bacillus licheniformis ........................................................................8 8

2.4. Ziele der Arbeit....................................................................................... 9

3. Material und Methoden ...................................................... 11

Organismen und Plasmide.................................................................. 11

3.2. Nährmedien, Puffer und Standardlösungen ................................................. 12

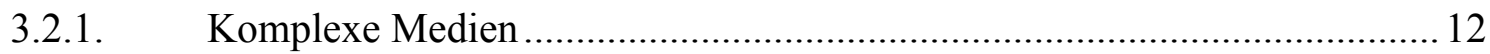

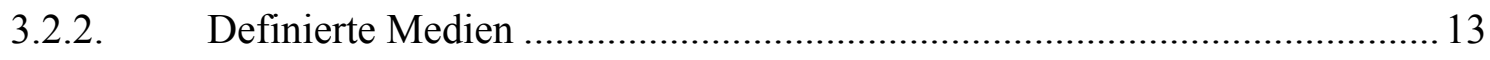

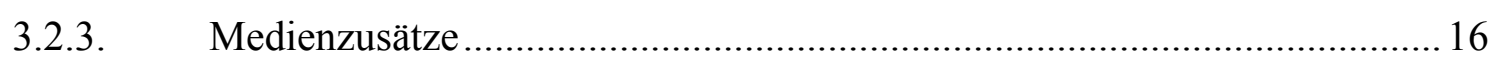

3.3. Zellanzucht und Stammhaltung............................................................. 17

3.3.1. Zellanzucht von B. licheniformis aus der Stammkultur ............................ 17

3.3.2. Zellanzucht unter anaeroben Wachstumsbedingungen .............................. 17

3.3.3. Zellanzucht unter aeroben Wachstumsbedingungen................................. 17

3.3.4. Ermittlung der maximalen Wachstumsrate ............................................... 18

3.3.5. Zellanzucht von B. licheniformis in kontinuirlicher Kultur ........................ 19

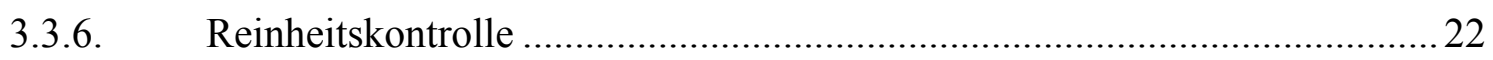

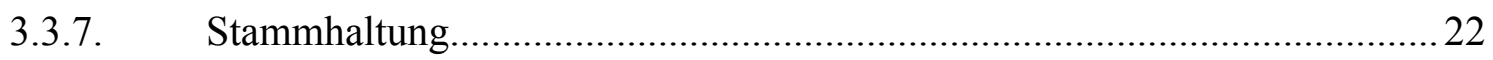

3.4. Techniken für das Arbeiten mit DNA ..............................................23

3.4.1. Lösungen und Puffer für das Arbeiten mit DNA ….................................. 23

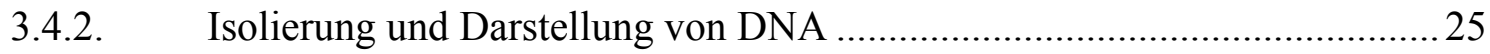

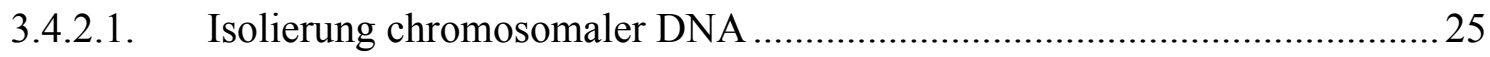

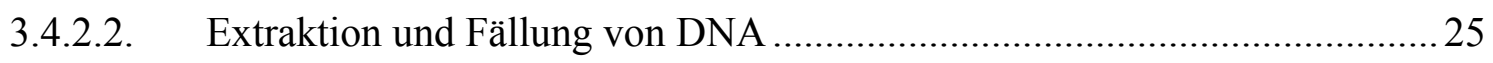

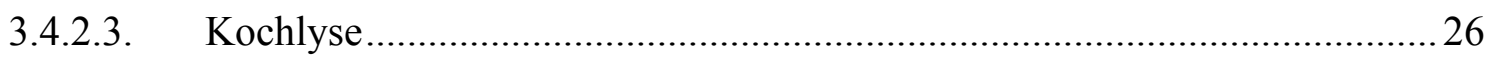

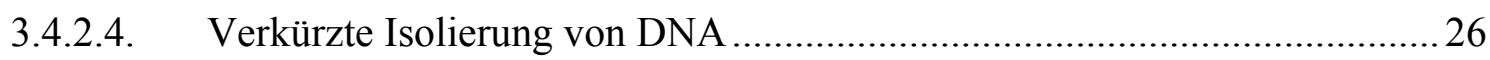




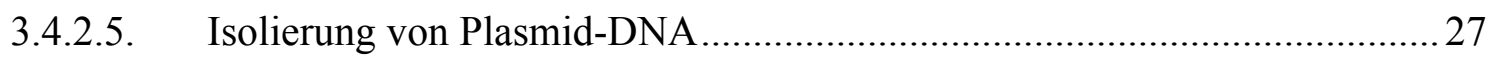

3.4.2.6. Aufreinigung von PCR-Produkten ...................................................... 27

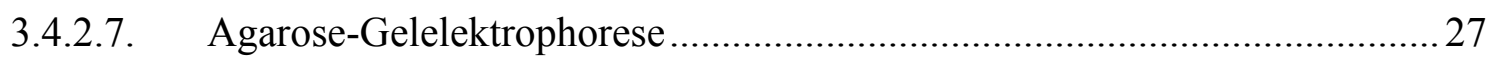

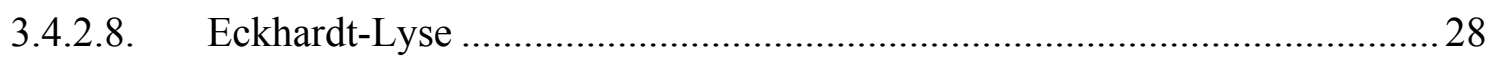

3.4.2.9. Isolierung von DNA-Fragmenten aus Agarosegelen ................................. 29

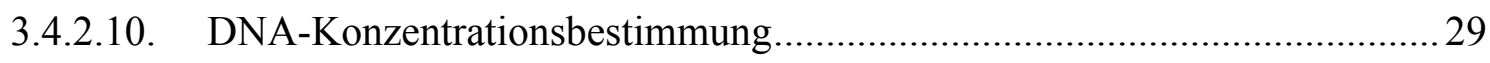

3.4.3. Restriktion und Modifikation von DNA …................................................. 30

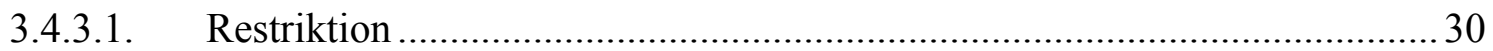

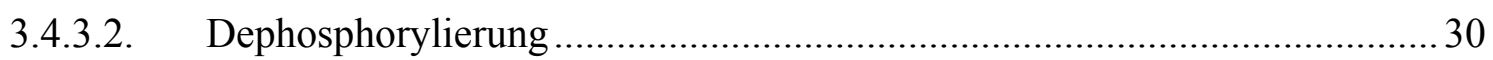

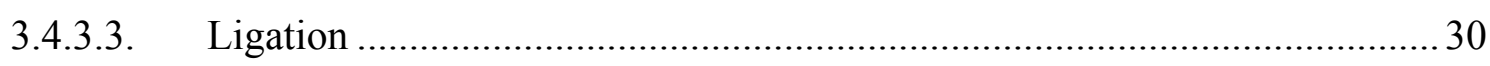

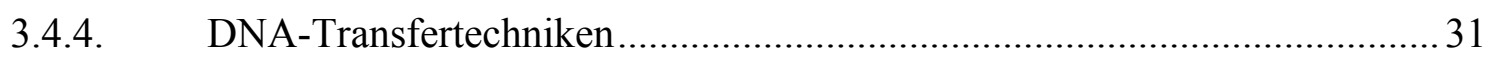

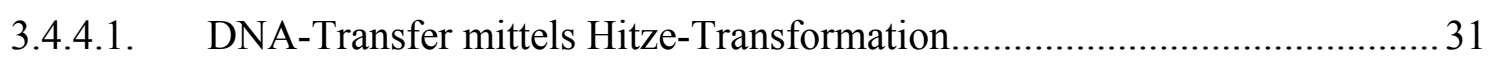

3.4.4.2. DNA-Transfer mittels Protoplasten-Transformation .................................. 32

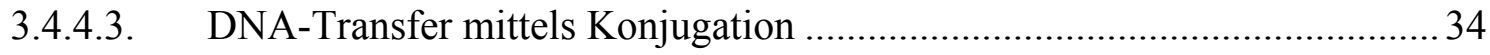

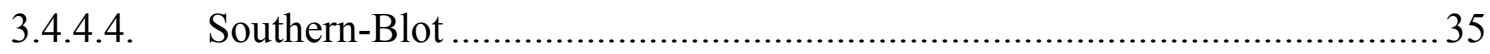

3.5. Erstellung von clean deletion - Mutanten...................................................40

3.6. Techniken für das Arbeiten mit RNA .................................................. 42

3.6.1. Lösungen und Puffer zum Arbeiten mit RNA …......................................... 42

3.6.2. Isolierung von RNA aus B. licheniformis ............................................... 43

3.6.3. DNase-Verdau und Kontrolle der RNA ...................................................... 44

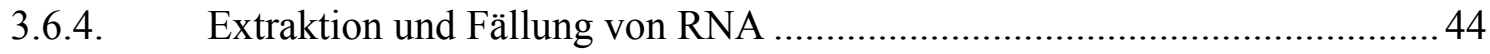

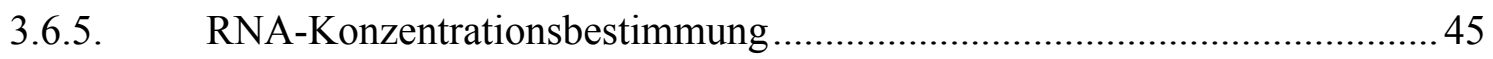

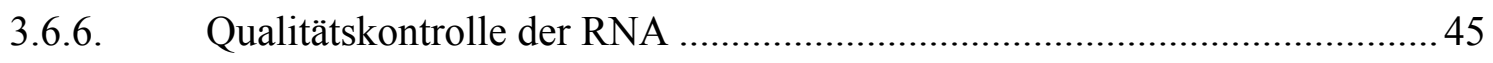

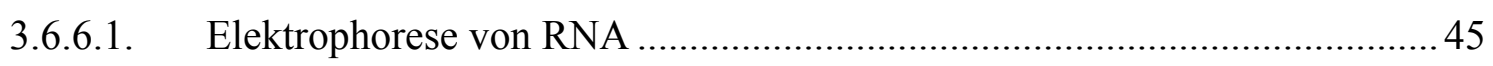

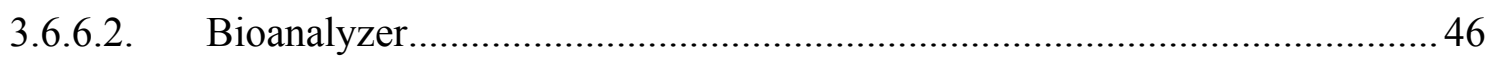

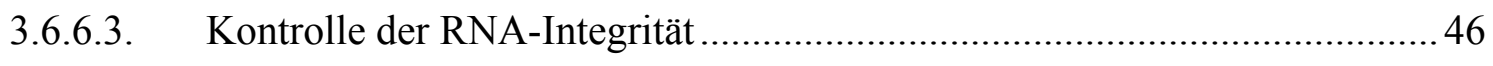

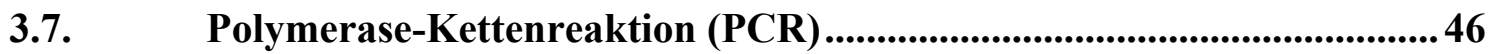

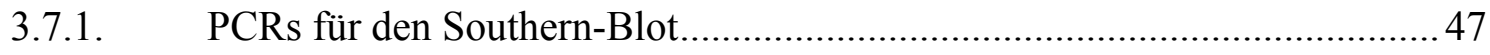

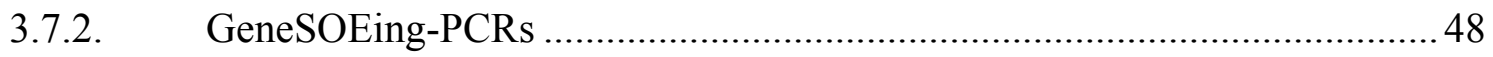

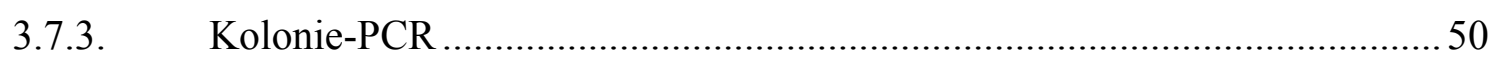

3.7.4. PCR zur Überprüfung auf DNA-Reste...................................................... 50

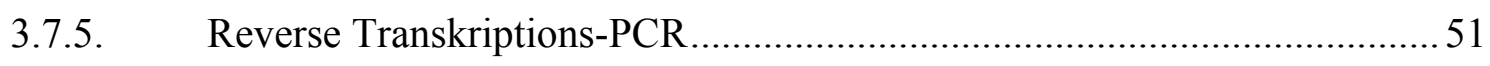

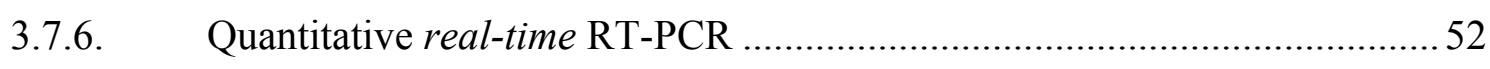


3.8. Hybridisierung und Auswertung von Microarrays ..................................54

3.8.1. Markierung von RNA mit Cy3/Cy5 Fluoreszenzfarbstoff............................55

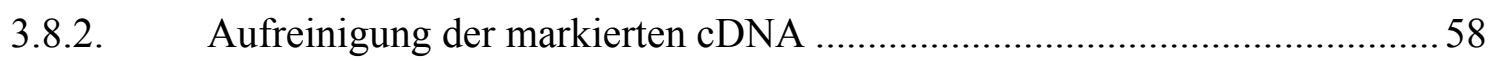

3.8.3. Überprüfung der Markierungsreaktion.......................................................... 59

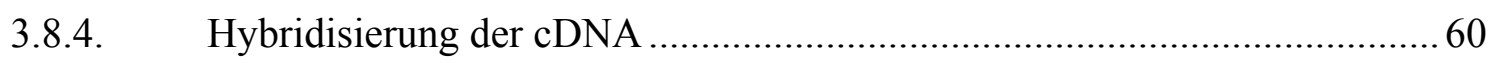

3.8.5. Quantifizierung der Microarraydaten mit GenePix Pro 6.0 ......................... 64

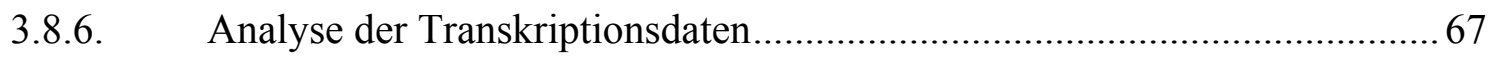

3.9. Analyse von Kulturüberständen ...............................................................6 68

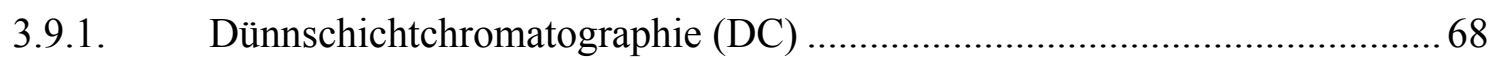

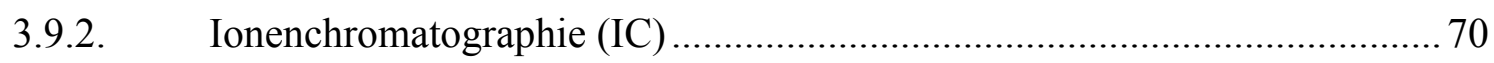

3.9.2.1. Quantitative Bestimmung von Alkoholen und Zuckern ............................. 70

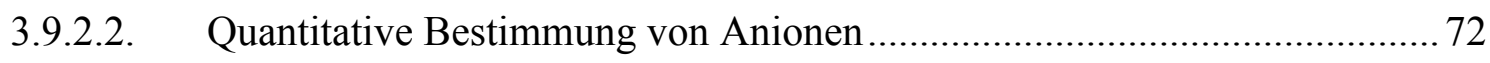

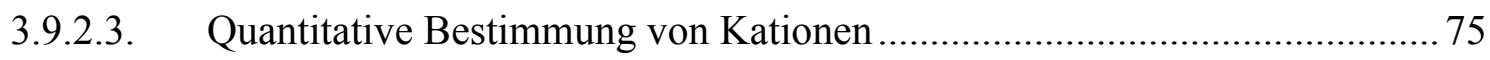

3.9.2.4. Quantitative Bestimmung von Aminosäuren ............................................ 75

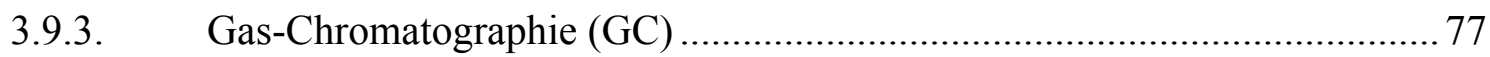

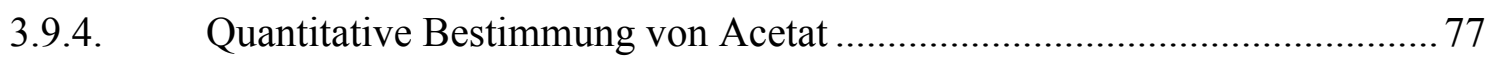

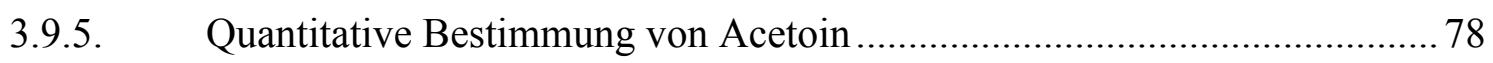

3.9.6. Quantitative Bestimmung von Ammoniak und Harnstoff ........................... 78

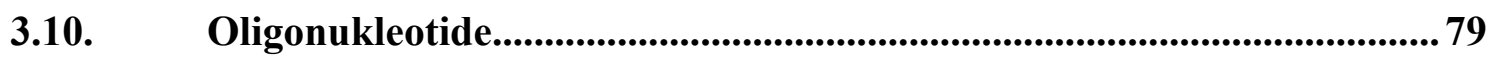

3.11. Enzyme

3.12. Chemikalien und sonstige Geräte ....................................................................... 81

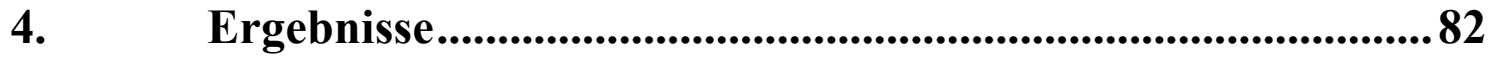

4.1. Untersuchungen zum anaeroben Wachstum ........................................... 82

4.1.1. Anaerobe Verwertung von Zuckern durch B. licheniformis ........................ 82

4.1.2. Transkriptionsanalysen zum fermentativen Wachstum ............................. 83

4.1.2.1. Vergleichende Genexpressionsanalyse des Wachstums unter aeroben

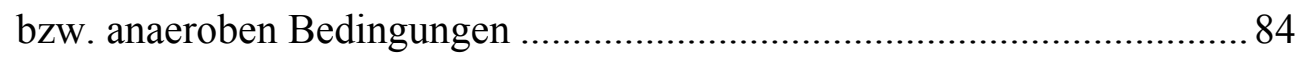

4.1.2.2. Verifizierung ausgewählter Daten der DNA-Microarray-Experimente durch real-time RT-PCR ................................................................. 97

4.1.3. Bestimmung von Fermentationsendprodukten........................................ 98

4.2. Untersuchungen zur Verwertung von C2-Metaboliten .......................... 100

4.2.1. Wachstum mit Acetat als Kohlenstoffquelle........................................... 100

4.2.2. Transkriptionsanalysen zum Wachstum mit Acetat.................................. 101 
4.2.3. Wachstum mit 2,3-Butandiol als Kohlenstoffquelle ................................ 105

4.2.4. Transkriptionsanalysen zum Wachstum mit 2,3-Butandiol ...................... 106

4.3. Untersuchungen zur Verwertung von Aminosäuren ........................... 109

4.3.1. Wachstum mit einzelnen Aminosäuren.................................................. 109

4.3.1.1. Verwertung einzelner Aminosäuren als Wachstumskomponenten............ 109

4.3.1.2. Transkriptionsanalysen zur Verwertung einzelner Aminosäuren .............. 110

4.3.1.2.1. Einmünden der Aminosäuren in den Zentralmetabolismus ....................... 111

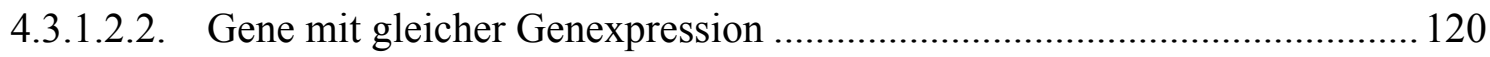

4.3.1.2.3. Gene mit unterschiedlicher Genexpression........................................... 122

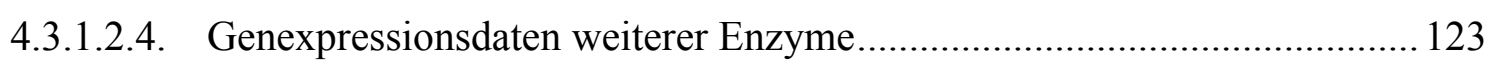

4.3.1.3. Verifizierung ausgewählter Daten aus DNA-Microarray-Experimenten durch real-time RT-PCR .................................................................... 125

4.3.2. Wachstum mit Gemischen von Aminosäuren.......................................... 127

4.3.2.1. Verwertung eines Gemisches aus sieben Aminosäuren ........................... 128

4.3.2.2. Transkriptionsanalysen zur Verwertung eines Gemisches aus sieben

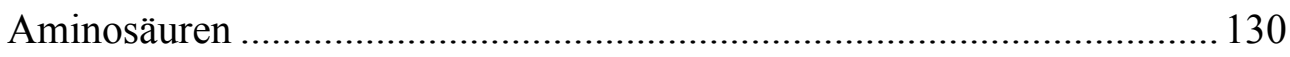

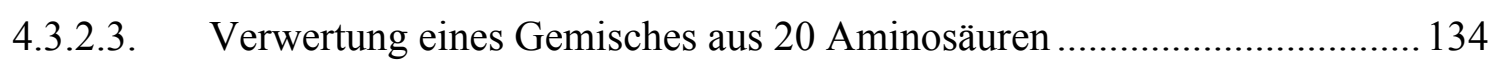

4.3.2.4. Transkriptionsanalysen zur Verwertung eines Gemisches aus 20 Aminosäuren .................................................................................... 137

4.4. Charakteristische Gene für $B$. licheniformis....................................... 146

4.5. Transkriptionsanalysen im Vergleich:

PCR-basierende Genomchips vs. Oligo-basierende Genomchips........ 150

4.6. Erstellung und phänotypische Charakterisierung von Mutanten ........ 155

5. Diskussion ........................................................................... 163

5.1. Wachstum von B. licheniformis DSM13 unter anaeroben

Kultivierungsbedingungen .............................................................................. 163

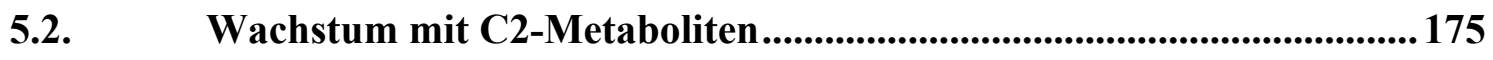

5.3. Wachstum mit Aminosäuren............................................................. 180

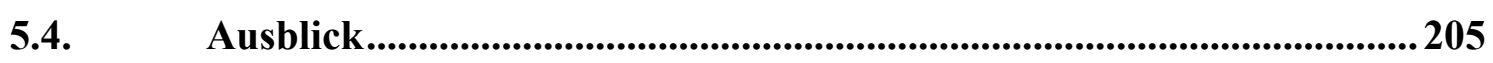

6. Literaturverzeichnis .................................................206

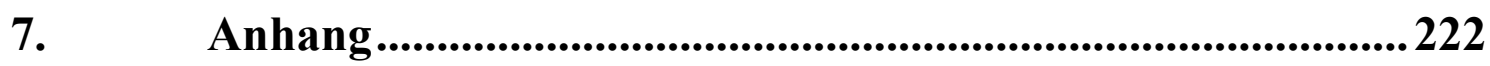




\section{Abkürzungsverzeichnis}

${ }^{\circ} \mathrm{C}$

$\mu$

A

Abb.

ADP

ATCC

ATP

$\mathrm{bp}$

BSA

bzw.

C

ca.

cDNA

$\mathrm{cm}$

$\mathrm{CoA}$

d.h.

$\mathrm{dCTP}$

DH

DIG

DMSO

DNA

DNase I

dNTP

DSMZ

DTT

Ed.

EDTA

et al.

FAD
Grad Celsius

$\operatorname{Mikro}\left(10^{-6}\right)$

Adenin

Abbildung

Adenosindiphosphat

American Type Culture Collection

Adenosintriphosphat

Basenpaare

Rinderserum-Albumin

beziehungsweise

Cytosin

circa

komplementäre Desoxyribonukleinsäure (complementary)

Zentimeter

Coenzym A

das heißt

Desoxyribocytosin-5' -triphosphat

Dehydrogenase

Digoxygenin

Dimethylsulfoxid

Desoxyribonukleinsäure

Desoxyribonuklease I

Desoxyribonukleosidtriphosphat

Deutsche Stammsammlung von Mikroorganismen

und Zellkulturen

Dithiothreitol

Editor

Ethylendiamintetraacetat

et alteri (und andere)

Flavinadenindinukleotid 


$\begin{array}{ll}\mathrm{g} & \text { Gramm } \\ \mathrm{G} & \text { Guanin } \\ \text { Glc } & \text { Glucose }\end{array}$

$\mathrm{GmbH} \quad$ Gesellschaft mit beschränkter Haftung

$\mathrm{h}$

Stunde

Hrsg. Herausgeber

k Kilo $\left(10^{3}\right)$

$\mathrm{kb} \quad$ Kilobasen

Konz. Konzentration

1 Liter

$\log \quad$ dekadischer Logarithmus

Lsg. $\quad$ Lösung

m Milli $\left(10^{-3}\right)$

M Molar (Mol/Liter)

$\min \quad$ Minute

mol Mol

mRNA Boten-Ribonukleinsäure (messenger)

n Nano $\left(10^{-9}\right)$

$\mathrm{NAD}^{+} \quad$ Nicotinamidadenindinukleotid

NAD $(\mathrm{H}) \quad$ Nicotinamidadenindinukleotid (reduzierte Form)

$\mathrm{NADP}(\mathrm{H}) \quad$ Nicotinamidadenindinukleotidphosphat (reduzierte Form)

Nr. Nummer

$\mathrm{OD}_{\mathrm{x}} \quad$ Optische Dichte bei einer Wellenlänge von $\mathrm{x} \mathrm{nm}$

ORF Offener Leserahmen (open reading frame)

ori Replikationsursprung

p Pico $\left(10^{-12}\right)$

p.A. pro analysis

PCR Polymerase-Kettenreaktion

$\mathrm{pH} \quad$ negativer dekadischer Logarithmus der Protonenkonzentration

$\mathrm{P}_{\mathrm{i}} \quad$ anorganisches Phosphat

PEP Phosphoenolpyruvat

psi Pfund-Kraft pro Quadratzoll

RNA Ribonukleinsäure (Ribonucleic Acid) 


\begin{tabular}{ll} 
RT & Raumtemperatur \\
sec & Sekunde \\
SDS & Natriumdodecylsulfat (Sodiumdodecylsulfate) \\
SSC & Saline Sodium-Citrate(-Puffer) \\
T & Thymin \\
Tab. & Tabelle \\
TAE & Tris-Acetat-EDTA \\
TE & Tris-EDTA \\
$T_{\mathrm{m}}$ & Schmelztemperatur \\
Tris & Tris-(hydroxymethyl)-aminomethan \\
U & Uracil \\
U/min & Umdrehungen pro Minute \\
UV & Ultraviolett \\
V & Volt \\
vgl. & vergleiche \\
v/v & Volumen pro Volumen \\
Vol & Volumen \\
W & Watt \\
w/v & Masse pro Volumen \\
z.B. & zum Beispiel \\
\hline
\end{tabular}

Ein- und Dreibuchstabencode für Aminosäuren
A Ala Alanin
M Met Methionin
C Cys Cystein
$\mathrm{N}$ Asn Asparagin
D Asp Aspartat
P Pro Prolin
E Glu Glutamat
Q Gln Glutamin
F Phe Phenylalanin
R Arg Arginin
G Gly Glycin
S Ser Serin
$\mathrm{H} \quad$ His Histidin
T Thr Threonin
I Ile Isoleucin
V Val Valin
K Lys Lysin
W Trp Tryptophan
L Leu Leucin
Y Tyr Tyrosin 


\section{Zusammenfassung}

Im Gegensatz zu anderen Vertretern seiner Gattung ist Bacillus licheniformis fähig durch reine Fermentation $\mathrm{zu}$ wachsen. Unter Verwendung eines definierten Mediums konnte im Rahmen dieser Arbeit gezeigt werden, dass B. licheniformis DSM13 unter anaeroben Kultivierungsbedingungen neben Glucose auch Fructose zum Wachstum nutzen kann, nicht jedoch die in diesem Kontext gewählten Pentosen. In Expressionsanalysen, welche in dieser Arbeit mittels DNA-Microarrays erfolgten, konnten für die Gene einer putativen Pyruvat-Formiat-Lyase, welche die Umsetzung von Pyruvat $\mathrm{zu}$ Formiat katalysiert, und dem offensichtlich zugehörigen Aktivierungsenzym eine erhöhte Expression unter fermentativen Wachstumsbedingungen ermittelt werden. Diese Beobachtung steht im Einklang mit der im Kulturüberstand detektierten Zunahme von Formiat. Daneben konnten in dieser Arbeit mittels Ionenchromatographie 2,3-Butandiol, Lactat, Acetat und Glycerol als Fermentationsprodukte bestimmt werden.

Neben der Verfügbarkeit von Sauerstoff beeinflussen noch weitere Faktoren den natürlichen Lebensraum von Mikroorganismen. So sind diese in der Natur einer Reihe von Kohlenstoff- und Stickstoffquellen ausgesetzt. Die in dieser Arbeit durchgeführten Untersuchungen haben gezeigt, dass B. licheniformis DSM13 sieben von 18 proteinogenen Aminosäuren als C- und N-Quelle nutzen kann. Durch sich anschließende Transkriptionsanalysen konnten charakteristische Gene im Zusammenhang mit dem Wachstum auf Aminosäuren identifiziert werden. Für eine Auswahl dieser Gene konnten diese durch DNA-Microarray-Analysen ermittelten Expressionswerte via real-time RT-PCR verifiziert werden. Im Weiteren dienten Analysen der Kulturüberstände dazu, die Verwertung von Aminosäuren in Gemischen von diesen zu untersuchen. Hierzu wurde ein definiertes Medium entworfen, welches der Aminosäurezusammensetzung der Sojabohne nachempfunden war. In diesem Zusammenhang konnte mittels Ionenchromatographie eine Akkumulation von Ammonium, Acetat, Harnstoff, Ornithin und im Weiteren ein Verbrauch des Ornithins detektiert werden. Weiterhin wurden im Einklang mit den durchgeführten Transkriptionsanalysen erste phänotypische Charakterisierungen von Mutanten eines putativen Methylcitratzyklus in B. licheniformis durchgeführt. 


\section{2. $\quad$ Einleitung}

In ihren natürlichen Habitaten sind Mikroorganismen unterschiedlichen Lebensund Umwelteinflüssen ausgesetzt. Gekennzeichnet sind diese unter anderem durch die Verfügbarkeit verschiedener Nährstoffe, an welche das Wachstum der Mikroorganismen gebunden ist. Zum einen ist hier das Vorhandensein von Nährstoffen in Form von Kohlenstoff- und Energiequellen zu nennen, aber auch das Vorhandensein von möglichen Stickstoffquellen. Ein weiterer Faktor, der das Wachstum von Mikroorganismen beeinflusst ist die Verfügbarkeit von Sauerstoff. Diese und weitere verschiedene Einflüsse führen $\mathrm{zu}$ der enormen Stoffwechselvielfalt der Mikroorganismen, mit welcher sie sich ihrem Habitat fortwährend neu anpassen können. Im Folgenden werden einige Stoffwechselleistungen herausgegriffen und einführend beschrieben, die im Rahmen dieser Dissertation von Bedeutung sind.

\subsection{Stoffwechseländerungen zur Bewältigung unterschiedlicher Wachstumsumstände}

\section{Anaerobes Wachstum}

Einer Reihe von Bakterien ist es möglich in Abwesenheit von externen Elektronenakzeptoren, wie Sauerstoff oder Nitrat, durch Fermentation zu wachsen. Dieses sind zum einen fakultativ anaerobe Bakterien, die sowohl in Gegenwart als auch in Abwesenheit von molekularem Sauerstoff wachsen können und zum anderen obligat anaerobe Mikroorganismen, für welche der Sauerstoff im allgemeinen toxisch ist.

Während der Glykolyse werden durch die Oxidation von Hexosen, wie Glucose, zu Pyruvat zwei Moleküle NADH gebildet. Bei Fermentationen wird zur Regeneration des $\mathrm{NAD}^{+}$Pyruvat zu verschiedenen Gärprodukten reduziert und diese ausgeschieden. Essenziell ist hierbei, dass die Redoxbilanz zwischen Substraten und Gärprodukten ausgeglichen ist. Ohne die Regeneration des $\mathrm{NAD}^{+}$, welches nur in geringen Mengen in der Zelle vorhanden ist, kommt die Oxidation der Hexosen und damit verbunden die Bildung von ATP zum Erliegen. Gebildet wird ATP in der Regel über Substratkettenphosphorylierungen, die mit den oxidativen Reaktionen einer Fermentation gekoppelt sind. Als ein wichtiges Enzym der Substratkettenphosphorylierung kann beispielhaft die 
Acetatkinase (Fox \& Roseman, 1986) angeführt werden. Diese katalysiert die Bildung von Acetat und ATP aus Acetylphosphat und ADP. Neben Acetat produzieren einige Enterobakterien auch 2,3-Butandiol, welches durch Reduktion von Acetoin durch die Butandiol-Dehydrogenase entsteht (Blomqvist et al., 1993). Beides sind Produkte der gemischten Säuregärung, die unter anderem auch von Vertretern der Gattung Bacillus betrieben wird (Shariati et al., 1995).

\section{Abbau von Aminosäuren}

Neben Zuckern sind Aminosäuren häufige Substrate für das Wachstum von Mikroorganismen. Sie bilden die monomeren Einheiten von Proteinen und enthalten zwei wichtige funktionelle Gruppen, eine Carboxylgruppe (-COOH) und eine Aminogruppe $\left(-\mathrm{NH}_{2}\right)$. Diese beiden Gruppen bilden unter Abspaltung eines Wassermoleküls die Peptidbindung, welche für Proteine charakteristisch ist. Aminosäuren unterscheiden sich in der Art ihrer Seitengruppen, welche zum Großteil ihre chemischen Eigenschaften bestimmen.

Bei den Aminosäuren gibt es, wie auch bei den Zuckern, Stereoisomere. Die meisten in der Natur vorkommenden Aminosäuren liegen als L-Aminosäuren vor. D-Aminosäuren, welche z.B. als Bestandteil des Mureins in Bakterien vorkommen, können durch Racemasen in ihre L-Form umgewandelt werden.

Für den ersten Schritt im Abbau von Aminosäuren, der Entfernung der $\alpha$-Aminogruppe, gibt es drei Möglichkeiten. Die einleitende Reaktion der oxidativen Desaminierung ist die Oxidation der Aminogruppe einer Aminosäure in eine Iminogruppe. Dieses Imino-Intermediat wird im Anschluss daran $\mathrm{zu} \mathrm{NH}_{3}$ und einer $\alpha$-Oxosäure hydrolysiert. Beispielhaft für Aminosäure-Dehydrogenasen, welche diese Oxidation mit $\mathrm{NAD}^{+}$als Co-Faktor katalysieren, können die Glutamat-Dehydrogenase (Hemmilä \& Mäntsälä, 1978) oder die Alanin-Dehydrogenase (O'Connor \& Halvorson, 1960) angeführt werden. Alternativ können die Aminosäuren durch relativ substratunspezifische Aminosäureoxidasen oxidiert und desaminiert werden. Die Oxidation mittels Transaminierung setzt sich aus den folgenden zwei Schritten zusammen. Zunächst überträgt die $\alpha$-Aminosäure ihre $\mathrm{NH}_{2}$-Gruppe auf 2-Oxoglutarat oder Pyruvat aus dem Zentralstoffwechsel. Durch die sich anschließende oxidative Desaminierung der gebildeten Produkte L-Glutamat oder L-Alanin wird der $\mathrm{NH}_{2}$-Akzeptor wieder regeneriert. Eine dritte Möglichkeit stellt die Desaminierung 
durch $\beta$-Eliminierung dar. Voraussetzung für diese Reaktionen ist, dass die Eliminierung am $\alpha$-C-Atom durch geeignete Substituenten am $\beta$-C-Atom erleichtert wird. Katalysiert wird die Eliminierung von Ammoniak vom $\alpha$-C-Atom bei den Aminosäuren Serin, Cystein und Threonin, welche in der $\beta$-Stellung zur Carboxylgruppe eine Hydroxyl- oder Thiolgruppe enthalten, durch Dehydratasen oder Desulfhydrasen. Bei Aminosäuren mit einer Carboxylat-, Imidazol- bzw. Benzolgruppe als Substituenten am $\beta$-C-Atom, wie Aspartat, Histidin und Phenylalanin, wird die Eliminierungsreaktion von Aminosäure-Ammoniak-Lyasen katalysiert. C-C-Lyasen katalysieren die Eliminierung von Ammoniak bei den Aminosäuren Tyrosin und Tryptophan. Sie enthalten am $\beta$-C-Atom einen aromatischen oder heterozyklischen Substituenten. Die weiteren Abbauwege der stickstofffreien Derivate der Aminosäuren führen zu Intermediaten des Zentralstoffwechsels.

\section{Zentralstoffwechsel}

Neben der Glykolyse und dem Pentosephosphat-Weg gehört auch der Tricarbonsäurezyklus zu den zentralen Stoffwechselwegen. Zu ihren Hauptfunktionen gehören die Generierung von ATP und NADH, sowie die Bereitstellung von Intermediaten für anabole Reaktionen. Im Tricarbonsäurezyklus (TCA-Zyklus, Abb. 2.1) wird die Acetyl-Gruppe des Acetyl-CoAs zu $\mathrm{CO}_{2}$ oxidiert, wobei die Reduktionsäquivalente auf $\mathrm{NAD}^{+}, \mathrm{NADP}^{+}$und $\mathrm{FAD}$ übertragen werden. Acetyl-CoA gelangt in diesen Zyklus durch eine von der Citrat-Synthase katalysierten Reaktion, in welcher Oxalacetat mit Acetyl-CoA zu Citrat kondensiert. Die Aconitat-Hydratase isomerisiert im Anschluss daran Citrat zu Isocitrat, welches durch die IsocitratDehydrogenase zu 2-Oxoglutarat oxidiert wird. Katalysiert durch den 2-OxoglutaratDehydrogenase Multienzymkomplex wird dieses unter Bildung von NADH zu Succinyl-CoA oxidiert. Die energiereiche Thioesterbindung des Succinyl-CoAs wird anschließend durch die Succinat-CoA-Synthase hydrolysiert und zur Bildung von ATP verwendet. Unter Freisetzung von $\mathrm{FADH}_{2}$ wird das gebildete Succinat, katalysiert durch die Succinat-Dehydrogenase, zu Fumarat oxidiert. Ausgehend vom Fumarat sind noch zwei weitere Reaktion zur Bildung von Oxalacetat notwendig. Zunächst hydratisiert die Fumarat-Hydratase Fumarat zu Malat, welches im Weiteren durch die MalatDehydrogenase unter Reduktion von $\mathrm{NAD}^{+}$zu dem Acetyl-CoA-Akzeptor Oxalacetat oxidiert wird. 


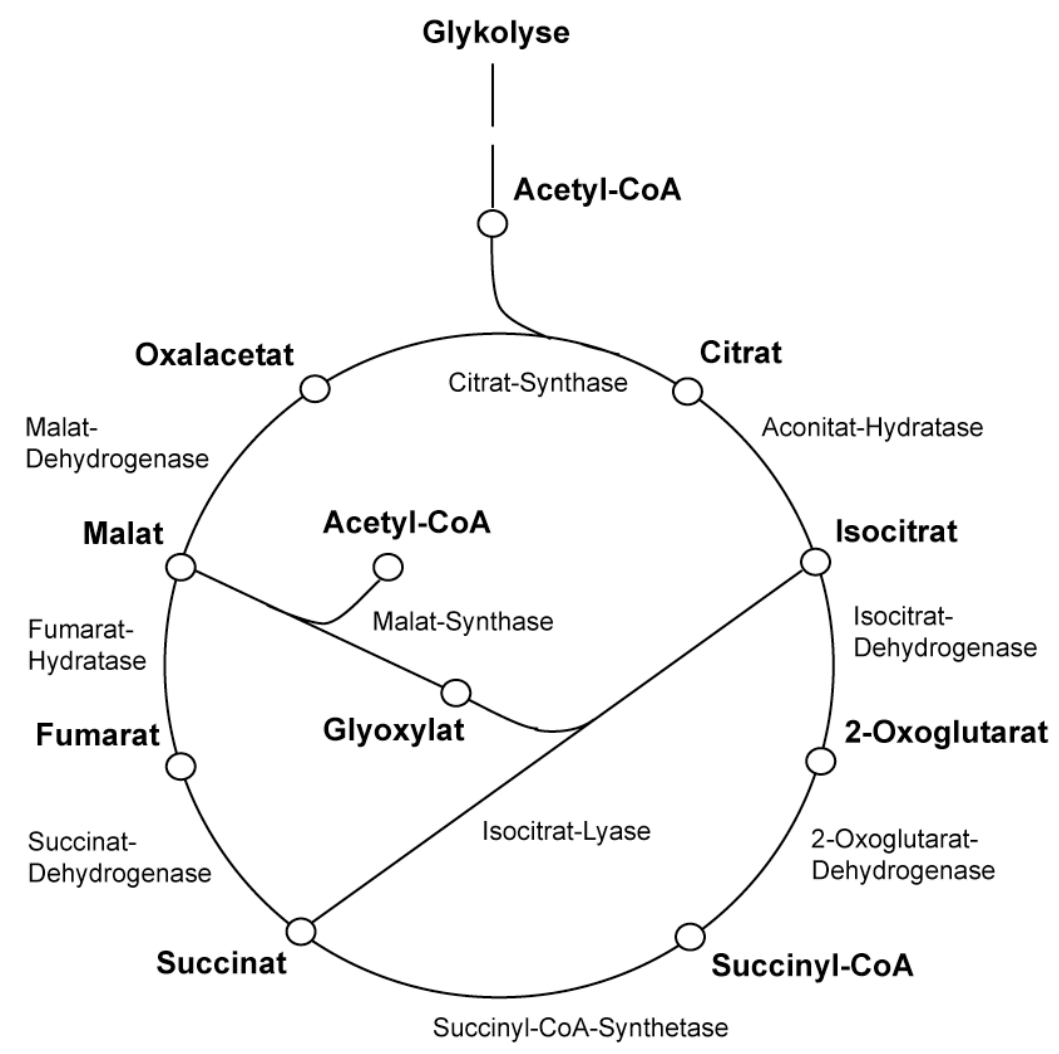

Abbildung 2.1: Schematische Darstellung des Tricarbonsäurezyklus und des Glyoxylatzyklus. Neben den ausgehend von der Glykolyse abgebildeten Intermediaten sind des Weiteren die beteiligten Enzyme dargestellt.

\section{Glyoxylatzyklus}

Gemeinsam mit weiteren Enzymen des Tricarbonsäurezyklus bilden die Enzyme Isocitrat-Lyase und Malat-Synthase den Glyoxylatzyklus. Organismen, welche diesen besitzen, sind befähigt mit C2-Substraten als alleinige Kohlenstoffquelle zu wachsen. Beispielhaft können in diesem Zusammenhang Escherichia coli (Chung et al., 1988) und Corynebacterium glutamicum (Reinscheid et al., 1994a; Reinscheid et al., 1994b) angeführt werden. Die anaplerotische Funktion des Glyoxylatzyklus liegt in der Versorgung des TCA-Zyklus mit dem Acetyl-CoA-Akzeptor Oxalacetat (Abb. 2.1). Nachdem Acetyl-CoA mit Oxalacetat zu Citrat kondensiert, wird letzteres zu Isocitrat umgesetzt. Anders als im TCA-Zyklus wird dieses nicht zu 2-Oxoglutarat umgewandelt, sondern durch die Isocitrat-Lyase zu Glyoxylat und Succinat gespalten. Das zweite Enzym des Glyoxylatzyklus, die Malat-Synthase, katalysiert im Anschluss die 
Kondensation des Glyoxylats mit einem weiteren Acetyl-CoA zu Malat, welches wiederum zu Oxalacetat oxidiert werden kann.

\section{Methylcitratzyklus}

Der im Grunde analog zum Glyoxylatzyklus verlaufende Methylcitratzyklus wurde ursprünglich in der Hefe entdeckt (Tabuchi \& Serizawa, 1975). Zwischenzeitlich konnte er aber auch bei verschiedenen Bakterien wie E. coli, Salmonella typhimurium LT2, C. glutamicum oder Ralstonia eutropha nachgewiesen werden (Textor et al., 1997; Horswill \& Escalante-Semerena, 1997; Claes et al., 2002; Brämer \& Steinbüchel, 2001). Anders als beim Glyoxylatzyklus kondensiert nicht Acetyl-CoA, sondern PropionylCoA beim Methylcitratzyklus mit Oxalacetat (Abb. 2.2). Das durch diese einleitende Reaktion gebildete Methylcitrat wird analog dem Glyoxylatzyklus zu Methylisocitrat umgesetzt. Katalysiert durch die Methylisocitrat-Lyase wird im Anschluss daran Methylisocitrat in Succinat und Pyruvat gespalten. Succinat kann durch die sich anschließenden Reaktionen des Tricarbonsäurezyklus zu dem Acetyl-CoAAkzeptormolekül Oxalacetat umgesetzt werden. Pyruvat kann wiederum über AcetylCoA in den Tricarbonsäurezyklus eingeschleust oder für biosynthetische Zwecke verwendet werden. Als Vorläufer des Propionyl-CoA kann Propionat oder ein Intermediat des Fettsäureabbaus dienen (Sonenshein, 2002).

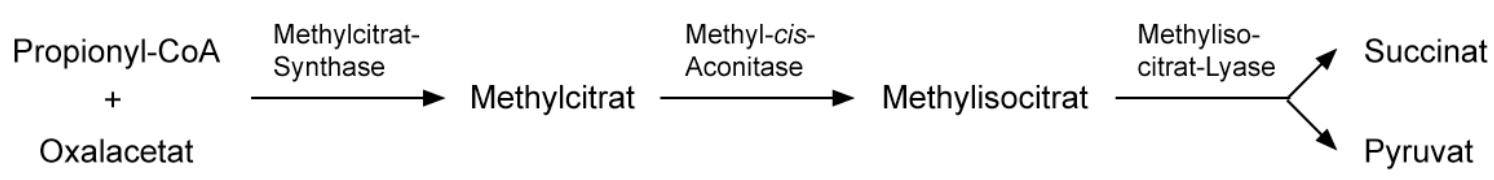

Abbildung 2.2: Putativer Abbauweg von Propionyl-CoA (nach Sonenshein, 2002). Erläuterung im Text.

\subsection{Einsatz von DNA-Microarray Technologie zur globalen Genexpressionsanalyse}

Eine wichtige Entwicklung auf dem Gebiet der globalen Genexpressionsanalyse stellt die Microarray-Technologie (Lander, 1999) dar. Zurückzuführen ist sie auf Ed Southern, der bereits in den 70er Jahren feststellte, dass markierte Nukleinsäuremoleküle mit immobilisierten Nukleinsäuremolekülen interagieren können 
(Southern, 1975). Das Prinzip der Microarrays beruht auf der komplementären Basenpaarung von Nukleinsäuren. Auf der Oberfläche des Microarrays liegen kovalent gebunden einzelsträngige Nukleotidsequenzen aus bekannten Genen vor, welche nach einem definierten Muster angeordnet sind. Wird dieser Microarray nun mit verschieden markierter cDNA eines zu untersuchenden Zustandes A bzw. Zustandes B inkubiert, kann nur der ihr komplementäre Strang binden (Abb. 2.3).

Ein Verfahren, um die Nukleinsäuren auf die Oberfläche eines Microarrays zu platzieren, ist das Kontaktprinting. Hierbei werden gereinigte Nukleinsäuren in winzigen Tröpfchen, pro Spot 100 pl, durch einen "Microarray-Spotter" auf die Glasoberfläche des Microarrays aufgebracht. Die Größe eines dieser Microarray-Chips ist etwa 2,5 x 7,5 cm, entspricht somit etwa der Größe eines Objektträgers. Es ist möglich, bis zu 20.000 Spots auf einen solchen Microarray aufzubringen, wobei die Größe eines Spots etwa $150 \mu \mathrm{m}$ und der minimale Abstand der Spots voneinander $30 \mu \mathrm{m}$ beträgt.

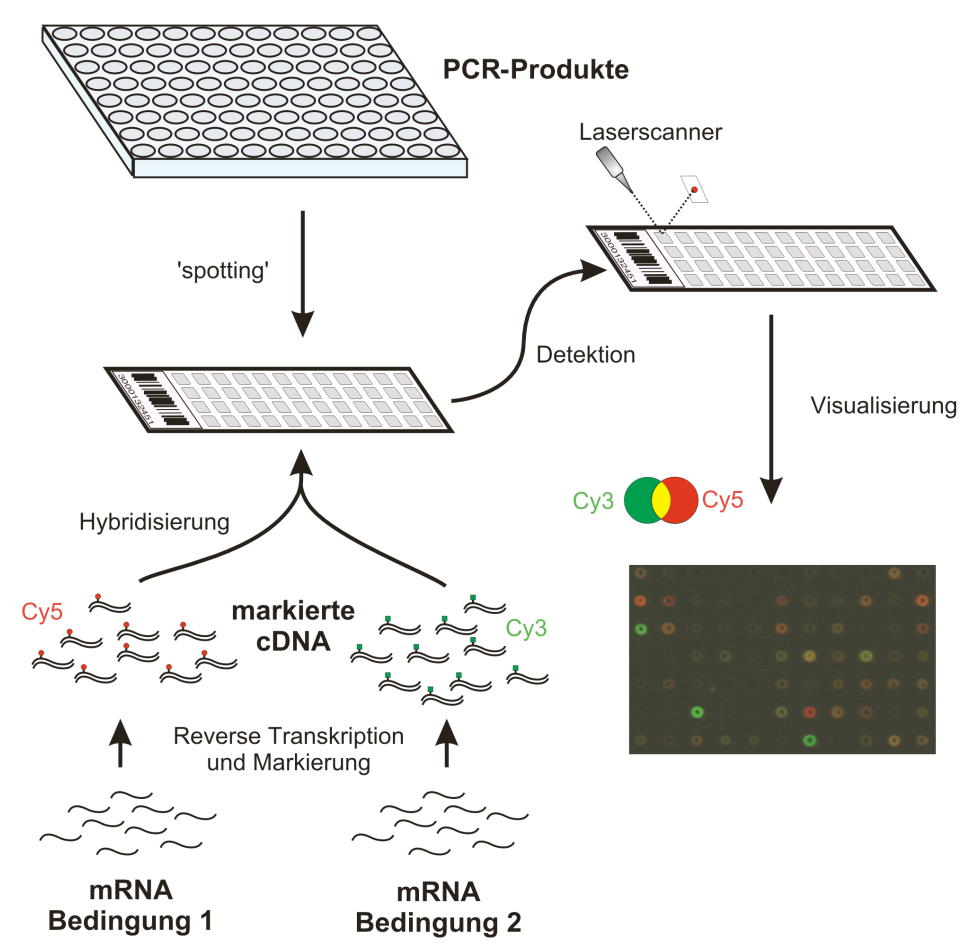

Abbildung 2.3: Schematische Übersicht des Ablaufs der DNA-Microarray-Analyse (Schmidt, 2005). Die gesamte RNA der Bedingungen 1 und 2 werden anhand der Reversen Transkription markiert und zusammen zur Hybridisierung des DNA-Microarrays eingesetzt. Die Detektion erfolgt mittels eines Laserscans mit definierten Wellenlängen und die relativen Fluoreszenzwerte werden im Anschluss daran softwaregestützt ausgewertet. 
Die Transkriptionsanalyse untersucht die qualitative und quantitative Zusammensetzung der zellulären mRNA. In einem typischen ZweikanalTranskriptionsanalyse-Experiment werden die relativen Expressionsstärken von zwei Proben, denen zwei unterschiedliche Zustände entsprechen, miteinander verglichen. Die erste Probe stellt hierbei einen Referenzwert dar, die zweite Probe wird aus Zellpopulationen gewonnen, deren Status untersucht werden soll. Es gilt zunächst die mRNA aus den Zellen der jeweiligen Probe zu isolieren und mittels der reversen Transkription in cDNA umzuschreiben. Jede dieser Proben wird währenddessen mit einem unterschiedlich fluoreszierenden Farbstoff markiert und gleiche Mengen markierter Probe werden in eine Hybridisierung mit dem Microarray eingesetzt. Die Verwendung von Fluoreszenz hat den Vorteil, dass mehrere Proben in einem Experiment gleichzeitig ausgewertet werden können. Nach der Hybridisierung wird das mit jedem der beiden eingesetzten Farbstoffe korrespondierende Fluoreszenzsignal unabhängig voneinander gemessen. Im Anschluss an eine Normalisierung kann die Intensität der beiden Hybridisierungssignale miteinander verglichen werden (Blalock, 2003).

\subsection{Biologie von Bacillus licheniformis}

Zur Gattung Bacillus zählen in erster Linie chemoorganotrophe Gram-positive Stäbchen, die häufig in Paaren oder Ketten angeordnet und durch peritriche Flagellen beweglich sind (Sneath et al., 1986). Taxonomisch gehört B. licheniformis zur Bacillus subtilis Gruppe (Gruppe II), welche sich unter anderem dadurch auszeichnet, dass sie auf einer Vielfalt von Zuckern Säuren produzieren und einige von ihnen auch in der Abwesenheit von Sauerstoff wachsen können (Priest, 1993). Ihr vorrangiger Lebensraum ist der Boden. Durch ihre Fähigkeit zur Sporenbildung kann es aber zur ubiquitären Verbreitung kommen, dabei werden hitzebeständige Sporen vom Wind mit Bodenpartikeln aufgewirbelt und so weit verbreitet. Aufgrund dieser eben beschriebenen Eigenschaften nimmt die B. subtilis Gruppe eine Zwischenstufe zwischen den fakultativ anaeroben Bakterien der Gruppe I (Bacillus polymyxa Gruppe) und den strikt aeroben Stämmen der Gruppe III (Bacillus brevis Gruppe) und IV (Bacillus sphaericus Gruppe) ein (Priest, 1993). 
B. licheniformis ist ein Organismus von biotechnologischer Relevanz. Seine Einsatzgebiete sind neben der Produktion von Proteasen, wie der $\alpha$-Amylase (Yuuki et al., 1985), die fermentative Herstellung des Antibiotikums Bacitracin (Froyshov \& Laland, 1974) und des Lipopeptids Lichenysin (Fiechter, 1992). Die Sequenzierung des Genoms von B. licheniformis DSM13 (Veith et al., 2004) ergab, dass dieses aus einem Chromosom mit einer Größe von 4.222.748 bp besteht und der durchschnittliche $\mathrm{G}+\mathrm{C}$ Gehalt des Genoms bei 46,2\% liegt. Des Weiteren weist DSM13 die vollständige Enzymausstattung für die zentralen Stoffwechselwege der Glykolyse, des Pentosephosphat-Wegs und des Tricarbonsäurezyklus auf. Daneben wurden Gene identifiziert, welche starke Homologien zur Isocitrat-Lyase und Malat-Synthase aufweisen, den essentiellen Enzymen des Glyoxylatzyklus. Vorangegangene Untersuchungen haben bereits gezeigt, dass DSM13 zum reinen fermentativen Wachstum befähigt ist (Schwarzer, 2005) und mit Propionat als einziger Kohlenstoffquelle wachsen kann (Wülfing, 2006). Letzteres wird offensichtlich durch die Enzyme eines putativen Methylcitratzyklus ermöglicht.

\subsection{Ziele der Arbeit}

Basierend auf diesem Fundament wurde zum besseren Verständnis dieses biotechnologisch interessanten Organismus der Aminosäuremetabolismus von B. licheniformis DSM13 in dieser Arbeit untersucht. Es sollte dabei geklärt werden, welche Aminosäuren als Stickstoff- und Kohlenstoffquelle dienen können. Anhand von Transkriptionsanalysen sollten Gene bzw. Gruppen von Genen identifiziert werden, welche charakteristisch für das Wachstum mit einzelnen Aminosäuren sind. Im Anschluss daran galt es die aus diesen Experimenten gewonnen Erkenntnisse auf das Wachstum mit Gemischen von Aminosäuren zu transferieren. Zusätzlich sollten die Kulturüberstände beim Wachstum mit Gemischen von Aminosäuren analysiert werden. Dieses diente zum einen dazu, den Verbrauch bzw. eine etwaige Reihenfolge in der Verwertung von Aminosäuren zu detektieren und zum anderen mögliche Produkte zu identifizieren. Im Zusammenhang mit den physiologischen Untersuchungen zum Aminosäuremetabolismus in DSM13 wurden des Weiteren, unter Verwendung von 
DNA-Microarrays, Transkriptionsanalysen zum fermentativen Wachstum und zur Verwertung von C2-Metaboliten durchgeführt. 


\section{Material und Methoden}

\subsection{Organismen und Plasmide}

Im Rahmen dieser Arbeit wurden verschiedene Stämme und Plasmidvektoren verwendet. Diese sind in den Tabellen 3.1 und 3.2 dargestellt.

Tabelle 3.1: Verwendete Organismen.

\begin{tabular}{|c|c|c|}
\hline Stamm & Geno- / Phänotyp & Herkunft / Referenz \\
\hline Bacillus licheniformis & Wildtyp & DSMZ \\
\hline \multicolumn{3}{|l|}{ DSM13 } \\
\hline B. licheniformis MW3 & $\Delta h s d R 1, \Delta h s d R 2$ & Waschkau et al., 2008 \\
\hline B. licheniformis & $\Delta h s d R 1, \Delta h s d R 2$ & Laborsammlung \\
\hline$\Delta \mathrm{BLi} 04093$ & $\Delta \mathrm{BLi} 04093$ & Göttingen \\
\hline \multirow[t]{2}{*}{ B. licheniformis $\Delta m m g D$} & $\Delta h s d R 1, \Delta h s d R 2, \Delta m m g D$ & Laborsammlung \\
\hline & & Göttingen \\
\hline B. licheniformis $\Delta m m g E$ & $\Delta h s d R 1, \Delta h s d R 2, \Delta m m g E$ & diese Arbeit \\
\hline \multirow[t]{2}{*}{ B. licheniformis $\triangle y q i Q$} & $\Delta h s d R 1, \Delta h s d R 2, \Delta y q i Q$ & Laborsammlung \\
\hline & & Freising \\
\hline \multirow[t]{2}{*}{ B. licheniformis $\Delta$ citA } & $\Delta h s d R 1, \Delta h s d R 2, \Delta c i t A$ & Laborsammlung \\
\hline & & Freising \\
\hline \multirow[t]{4}{*}{ Escherichia coli $\mathrm{DH} 5 \alpha$} & $\mathrm{F}-$, sup $\mathrm{E} 44$, lacZ $\Delta \mathrm{M} 15$, & Hanahan, 1983 \\
\hline & $\Delta l a c \mathrm{U} 169, h s d \mathrm{R} 17, \operatorname{rec} \mathrm{A} 1$, & \\
\hline & endA1, gyrA96, thi-1, & \\
\hline & $\operatorname{relA} 1, \lambda-$ & \\
\hline \multirow[t]{2}{*}{ E. coli S17-1 } & recA, pro, hsdR, & Priefer et al., 1985 \\
\hline & RP4-2-Tc::Mu-Km::Tn7 & \\
\hline
\end{tabular}


Tabelle 3.2: Verwendete Plasmidvektoren.

\begin{tabular}{llll}
\hline Plasmid & Größe $(\mathrm{kb})$ & Geno- / Phänotyp & Herkunft / Referenz \\
\hline pMAD & 9,666 & oripE194 ${ }^{\text {ts }}$, oripBR322, & Arnaud et al., 2004 \\
& & pclpB, bgaB, bla, ermC & \\
pKVM1 & 10,351 & pMAD-Derivat, oriT, traJ & Rachinger, 2010 \\
\hline
\end{tabular}

\subsection{Nährmedien, Puffer und Standardlösungen}

Medien, Puffer und Lösungen wurden mit Milipore $-\mathrm{H}_{2} \mathrm{O}$ angesetzt und $20 \mathrm{~min}$ im Autoklaven bei $121^{\circ} \mathrm{C}$ und 2 bar autoklaviert. Thermolabile Substanzen und Kohlenstoffquellen wurden gelöst und sterilfiltriert (Spritzenvorsatzfilter, 0,22 $\mu \mathrm{m}$, Sartorius, Göttingen). Zur Herstellung von festen Medien wurden 1,5\% (w/v) Agar vor dem Autoklavieren zugegeben. Die Lagerung der Agarplatten erfolgte bei $4^{\circ} \mathrm{C}$.

\subsubsection{Komplexe Medien}

Die beiden folgenden Medien dienten neben der Anzucht von Vorkulturen auch der Sterilitätskontrolle und, unter Zugabe von $50 \mathrm{mM}$ Glucose und entsprechender Antibiotika, dem Ausplattieren von Konjugationsansätzen.

\section{LB (Luria-Bertani)-Medium}

$\begin{array}{lll}\text { Trypton } & 10 & \mathrm{~g} \\ \text { Hefeextrakt } & 5 & \mathrm{~g} \\ \mathrm{NaCl} & 5 & \mathrm{~g} \\ \mathrm{H}_{2} \mathrm{O} & \text { ad } 1000 & \mathrm{ml}\end{array}$

\section{NB (Nutrient broth)-Medium}

$\begin{array}{lll}\text { Nutrient broth } & 8 & \text { g } \\ \mathrm{H}_{2} \mathrm{O} & \text { ad } 1000 & \mathrm{ml}\end{array}$




\subsubsection{Definierte Medien}

Für Transkriptionsanalysen, aber auch zur Analyse von Kulturüberständen ist es von Vorteil ein definiertes Medium zu verwenden. Aus diesem Grund wurde zur Anzucht von B. licheniformis mit definierter C-Quelle das in Tabelle 3.3 beschriebene Minimalmedium verwendet. Anzumerken ist, dass $\mathrm{NH}_{4} \mathrm{Cl}, \mathrm{MgSO}_{4}, \mathrm{CaCl}_{2}$ und $\mathrm{H}_{2} \mathrm{O}$ gemeinsam autoklaviert wurden, sämtliche weiteren Lösungen wurden getrennt sterilisiert und später steril hinzugegeben.

Tabelle 3.3: Zusammensetzung des Minimalmediums zur Kultivierung mit definierter C-Quelle.

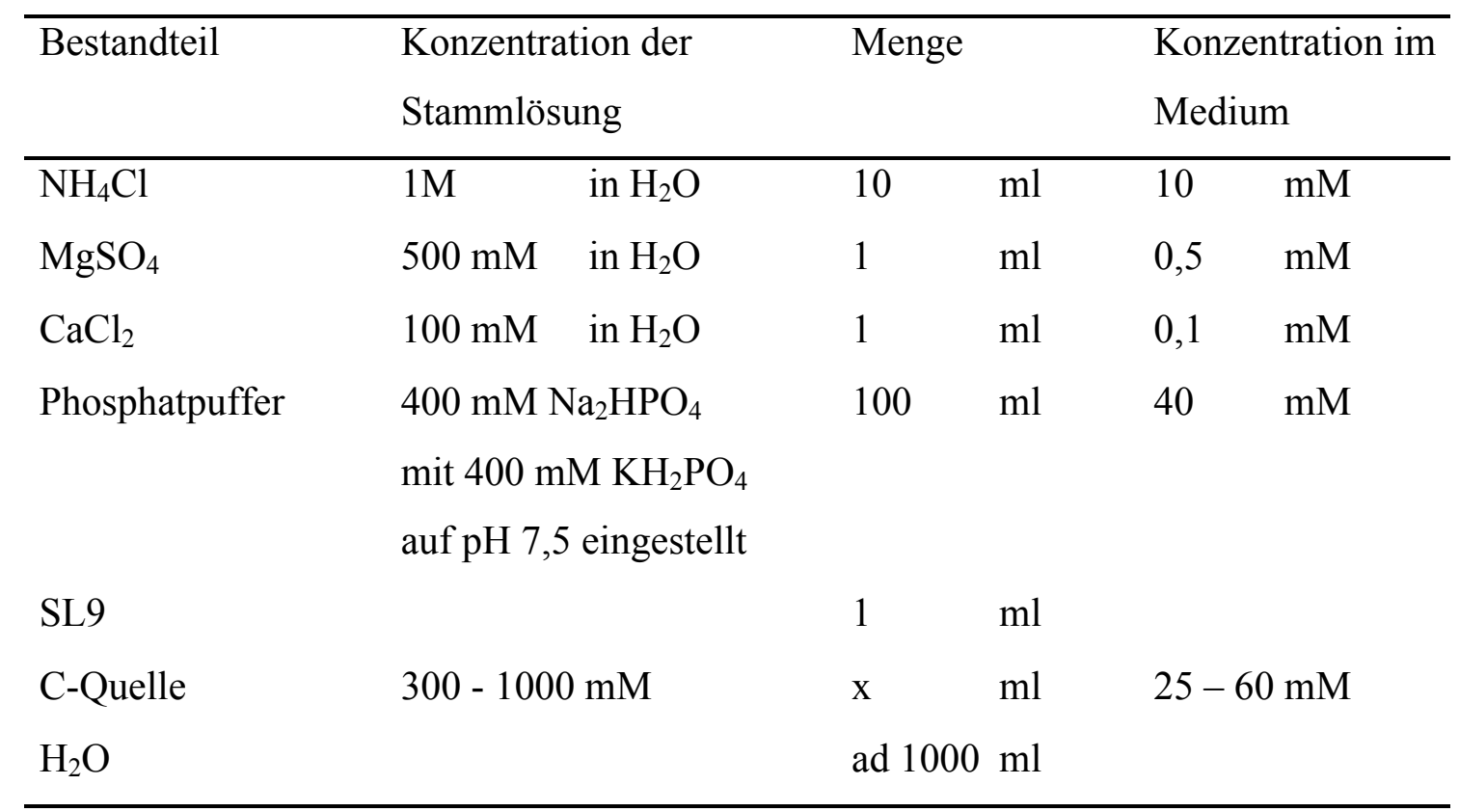

Neben den Untersuchungen mit definierter C-Quelle wurden in dieser Arbeit Experimente durchgeführt in denen die Verwertung von Aminosäuren untersucht wurde. Zunächst wurde die Verwertung von einzelnen Aminosäuren als Kohlenstoffund Stickstoffquelle durch DSM13 untersucht. Die Zusammensetzung des verwendeten Minimalmediums ist in Tabelle 3.4. dargestellt. $\mathrm{MgSO}_{4}, \mathrm{CaCl}_{2}$ und $\mathrm{H}_{2} \mathrm{O}$ wurden gemeinsam autoklaviert, sämtliche weiteren Lösungen wurden getrennt sterilisiert und anschließend der Reihe nach steril hinzugegeben. 
Tabelle 3.4: Zusammensetzung des Minimalmediums zur Kultivierung mit Aminosäuren.

\begin{tabular}{|c|c|c|c|c|c|}
\hline \multirow{2}{*}{$\begin{array}{l}\text { Bestandteil } \\
\mathrm{MgSO}_{4}\end{array}$} & \multirow{2}{*}{$\begin{array}{l}\text { Konzentration der } \\
\text { Stammlösung } \\
500 \mathrm{mM} \text { in } \mathrm{H}_{2} \mathrm{O}\end{array}$} & \multicolumn{2}{|c|}{ Menge } & \multicolumn{2}{|c|}{$\begin{array}{l}\text { Konzentration im } \\
\text { Medium }\end{array}$} \\
\hline & & 1 & $\mathrm{ml}$ & 0,5 & $\mathrm{mM}$ \\
\hline $\mathrm{CaCl}_{2}$ & $100 \mathrm{mM}$ in $\mathrm{H}_{2} \mathrm{O}$ & 1 & $\mathrm{ml}$ & 0,1 & $\mathrm{mM}$ \\
\hline Phosphatpuffer & $\begin{array}{l}400 \mathrm{mM} \mathrm{Na} \mathrm{HPO}_{4} \\
\text { mit } 400 \mathrm{mM} \mathrm{KH} \mathrm{PO}_{4} \\
\text { auf pH 7,5 eingestellt }\end{array}$ & 100 & $\mathrm{ml}$ & 40 & $\mathrm{mM}$ \\
\hline SL9 & & 1 & $\mathrm{ml}$ & & \\
\hline $\begin{array}{l}\mathrm{C}-/ \text { N-Quelle } \\
\mathrm{H}_{2} \mathrm{O}\end{array}$ & $40 \mathrm{mM}-120 \mathrm{mM}$ & $\begin{array}{l}x \\
\text { ad } 10\end{array}$ & $\begin{array}{l}\mathrm{ml} \\
\mathrm{ml}\end{array}$ & 30 & $\mathrm{mM}$ \\
\hline
\end{tabular}

Um das Wachstum auf Gemischen von Aminosäuren zu untersuchen, wurden als C-/ N-Quelle die in den folgenden Tabellen aufgeführten Aminosäuremixe verwendet. Die Aminosäuremixe 1 bis 5 stellen dabei die einzelnen Gruppen eines Gemisches dar, welches der Zusammensetzung des Aminosäuregehaltes der Sojabohne nachempfunden ist.

Tabelle 3.5: Zusammensetzung Aminosäuremix 1.

\begin{tabular}{lcl}
\hline $\begin{array}{l}\text { Bestandteil } \\
\text { SB-Mix 1 }\end{array}$ & $\begin{array}{c}\text { Einwaage der } \\
\text { Stammlösung }\end{array}$ & Menge \\
\hline L-Alanin & $0,3538 \mathrm{~g}$ & \\
L-Arginin & $0,6012 \mathrm{~g}$ & \\
L-Asparagin & $0,4861 \mathrm{~g}$ & $\mathrm{ad} \mathrm{50} \mathrm{ml}$ \\
L-Asparaginsäure & $0,4861 \mathrm{~g}$ & $40^{\circ} \mathrm{C} \mathrm{H}_{2} \mathrm{O}$ \\
\hline
\end{tabular}


Tabelle 3.6: Zusammensetzung Aminosäuremix 2 .

\begin{tabular}{lcl}
\hline $\begin{array}{l}\text { Bestandteil } \\
\text { SB-Mix 2 }\end{array}$ & $\begin{array}{c}\text { Einwaage der } \\
\text { Stammlösung }\end{array}$ & Menge \\
\hline L-Glutamin & $0,7774 \mathrm{~g}$ & \\
L-Glutamninsäure & $0,7774 \mathrm{~g}$ & \\
Glycin & $0,3472 \mathrm{~g}$ & \\
L-Histidin & $0,2102 \mathrm{~g}$ & $\mathrm{ad} 100 \mathrm{ml}$ \\
L-Isoleucin & $0,3778 \mathrm{~g}$ & $40^{\circ} \mathrm{C} \mathrm{H}_{2} \mathrm{O}$ \\
\hline
\end{tabular}

Tabelle 3.7: Zusammensetzung Aminosäuremix 3.

\begin{tabular}{lcl}
\hline $\begin{array}{l}\text { Bestandteil } \\
\text { SB-Mix } 3\end{array}$ & $\begin{array}{c}\text { Einwaage der } \\
\text { Stammlösung }\end{array}$ & Menge \\
\hline L-Leucin & $0,6464 \mathrm{~g}$ & \\
L-Lysin & $0,5306 \mathrm{~g}$ & \\
L-Methionin & $0,1050 \mathrm{~g}$ & \\
L-Phenylalanin & $0,4110 \mathrm{~g}$ & \\
L-Prolin & $0,4562 \mathrm{~g}$ & \\
L-Serin & $0,4256 \mathrm{~g}$ & \\
L-Threonin & $0,3206 \mathrm{~g}$ & $\mathrm{ad} 100 \mathrm{ml}$ \\
L-Valin & $0,3990 \mathrm{~g}$ & $40^{\circ} \mathrm{C} \mathrm{H}_{2} \mathrm{O}$ \\
\hline
\end{tabular}

Tabelle 3.8: Zusammensetzung Aminosäuremix 4.

\begin{tabular}{lcl}
\hline $\begin{array}{l}\text { Bestandteil } \\
\text { SB-Mix } 4\end{array}$ & $\begin{array}{c}\text { Einwaage der } \\
\text { Stammlösung }\end{array}$ & Menge \\
\hline L-Cystein & $0,1104 \mathrm{~g}$ & ad $100 \mathrm{ml}$ \\
L-Tryptophan & $0,1064 \mathrm{~g}$ & $40^{\circ} \mathrm{C} \mathrm{H}_{2} \mathrm{O}$ \\
\hline
\end{tabular}

Tabelle 3.9: Zusammensetzung Aminosäuremix 5.

\begin{tabular}{lcl}
\hline $\begin{array}{l}\text { Bestandteil } \\
\text { SB-Mix 5 }\end{array}$ & $\begin{array}{c}\text { Einwaage der } \\
\text { Stammlösung }\end{array}$ & Menge \\
\hline Tyrosin & $0,2602 \mathrm{~g}$ & ad $150 \mathrm{ml} 40^{\circ} \mathrm{C}$ \\
& & $10 \mathrm{mM} \mathrm{NaOH}$ \\
\hline
\end{tabular}


Spurenelementlösung 9 (SL9) (modifiziert nach Tschech \& Pfennig, 1984)

Titriplex I (Nitrilotriacetat)

$\begin{array}{ll}12,8 & \mathrm{~g} \\ 2 & \mathrm{~g} \\ 0,19 & \mathrm{~g} \\ 0,1 & \mathrm{~g} \\ 0,07 & \mathrm{~g} \\ 0,006 & \mathrm{~g} \\ 0,024 & \mathrm{~g} \\ 0,002 & \mathrm{~g} \\ 0,036 & \mathrm{~g} \\ \mathrm{ad} 1000 \mathrm{ml}\end{array}$

$\mathrm{FeSO}_{4} \times 7 \mathrm{H}_{2} \mathrm{O}$

$\mathrm{CoCl}_{2} \times 6 \mathrm{H}_{2} \mathrm{O}$

g

$\mathrm{MnCl}_{2} \times 2 \mathrm{H}_{2} \mathrm{O}$

$\mathrm{ZnCl}_{2}$

$\mathrm{H}_{3} \mathrm{BO}_{3}$

$\mathrm{NiCl}_{2} \times 6 \mathrm{H}_{2} \mathrm{O}$

$\mathrm{CuCl}_{2} \times 2 \mathrm{H}_{2} \mathrm{O}$

$\mathrm{Na}_{2} \mathrm{MoO}_{4} \times 2 \mathrm{H}_{2} \mathrm{O}$

$\mathrm{H}_{2} \mathrm{O}$

ad $1000 \mathrm{ml}$

Der pH-Wert wurde auf 6,5 eingestellt. Nach dem Sterilfiltrieren erfolgte die Lagerung bei $-20^{\circ} \mathrm{C}$ langfristig oder kurzfristig bei $4^{\circ} \mathrm{C}$.

\subsubsection{Medienzusätze}

Soweit notwendig wurden weitere Zusätze in die Medien pipettiert. Diese Zugabe erfolgte nach dem Abkühlen der autoklavierten Nährlösungen auf mindestens $50^{\circ} \mathrm{C}$.

Tabelle 3.10: Medienzusätze.

\begin{tabular}{llr}
\hline Zusatz & Stammlösung & Endkonzentration \\
\hline Ampicillin & $100 \mathrm{mg} / \mathrm{ml}$ in $\mathrm{H}_{2} \mathrm{O}$ & $100 \mu \mathrm{g} / \mathrm{ml}$ \\
Erythromycin & $5 \mathrm{mg} / \mathrm{ml} \mathrm{in} \mathrm{EtOH}$ & $5 \mu \mathrm{g} / \mathrm{ml}$ \\
Polymyxin B & $40 \mathrm{mg} / \mathrm{ml} \mathrm{in} \mathrm{H}_{2} \mathrm{O}$ & $40 \mu \mathrm{g} / \mathrm{ml}$ \\
Thiamin-HCL & $0,5 \mathrm{mg} / \mathrm{ml} \mathrm{in} \mathrm{H}_{2} \mathrm{O}$ & $1 \mu \mathrm{g} / \mathrm{ml}$ \\
X-GAL & $40 \mathrm{mg} / \mathrm{ml}$ in N,N- & $40 \mu \mathrm{g} / \mathrm{ml}$ \\
& Dimethylformamid & \\
\hline
\end{tabular}

a) vor Gebrauch frisch angesetzt. 


\subsection{Zellanzucht und Stammhaltung}

\subsubsection{Zellanzucht von B. licheniformis aus der Stammkultur}

B. licheniformis wurde aus der Stammkultur in NB-Medium im $250 \mathrm{ml}$ Erlenmeyerkolben angeimpft und bei $37^{\circ} \mathrm{C}$ auf einem Rotationsschüttler inkubiert. Nach 24 Stunden wurden die Zellen passagiert und in einem definierten Medium inokuliert. Am Ende der log-Phase (vgl. 3.3.4., Abb. 3.1) wurden diese Zellen ein zweites Mal in definiertes Medium überführt. Diese Kultur diente zur Bestimmung von Kulturüberständen und zur Zellanzucht für die Transkriptionsanalyse. Für das Wachstum auf Festmedien wurden die beimpften Agarplatten 1-2 Tage bei $37^{\circ} \mathrm{C}$ inkubiert.

\subsubsection{Zellanzucht unter anaeroben Wachstumsbedingungen}

Für die anaerobe Anzucht von B. licheniformis wurde dessen Fähigkeit, sowohl aerob als auch anaerob zu wachsen, genutzt. Die Anzucht von B. licheniformis erfolgte anaerob bei $37^{\circ} \mathrm{C}$ in Minimalmedium in $1000 \mathrm{ml}$ Anaerobenflaschen. Hierzu wurde zum autoklavierten Minimalmedium Phosphatpuffer $(\mathrm{pH} 7,5)$ und die Kohlenstoffquelle bei einer Temperatur von ca. $70^{\circ} \mathrm{C}$ hinzugefügt. Bei etwa $50^{\circ} \mathrm{C}$ erfolgte die Zugabe der SL9-Lösung und des Thiamins, so dass ein Gesamtvolumen von insgesamt $500 \mathrm{ml}$ entstand. Die Flaschen wurden mit einem Butyl-Stopfen verschlossen und im Anschluss daran erfolgte eine Überschichtung des Mediums mit Stickstoff. Um eine gleichmäßige Verteilung der Mediumkomponenten zu gewährleisten, wurden die Flüssigkulturen in den Anaerobenflaschen auf einem Rotationsschüttler mit 100 U/min inkubiert.

\subsubsection{Zellanzucht unter aeroben Wachstumsbedingungen}

Um zum Beispiel Wachstumsparameter wie die maximale Wachstumsrate (siehe 3.3.4.) zu ermitteln, erfolgte die aerobe Zellanzucht von B. licheniformis DSM13 bei $37^{\circ} \mathrm{C}$ oder $42^{\circ} \mathrm{C}$ in statischer Kultur. In einem solchem geschlossenen System werden keine Nährstoffe zu- bzw. Stoffwechselprodukte abgeführt. Um eine ausreichende Sauerstoffversorgung durch Schwenken auf dem Rotationsschüttler $(160 \mathrm{U} / \mathrm{min}) \mathrm{zu}$ 
gewährleisten, sollte die Gefäßgröße dem 10fachen Kulturvolumen entsprechen. Aus diesem Grund wurden für die erste Passage in definierten Medium $250 \mathrm{ml}$ ErlenmeyerSchikanekolben verwendet. Die Zellanzucht der zweiten Passage erfolgte in $1000 \mathrm{ml}$ bzw. $5000 \mathrm{ml}$ Erlenmeyer-Schikanekolben.

\subsection{4. $\quad$ Ermittlung der maximalen Wachstumsrate}

Die maximale Wachstumsrate $\mu_{\max }$ ist ein Maß für die Geschwindigkeit des Zellwachstums und von verschiedenen Wachstumsbedingungen abhängig. Hierzu zählen z.B. die Art der C-, N- oder P-Quelle. Auch Faktoren wie Belüftung, Temperatur oder der pH-Wert der Nährlösung haben einen Einfluss. Um die maximale Wachstumsrate eines Organismus zu ermitteln, ist es erforderlich den Verlauf des Wachstums in einem geschlossenen System, einer statischen Kultur, zu verfolgen. In dieser Arbeit wurden die Wachstumskurven über indirekte Bestimmung der Zelldichte basierend auf der optischen Dichte der Zellkultur bei einer Wellenlänge von $600 \mathrm{~nm}$ in Abhängigkeit von der Zeit ermittelt. Das Wachstum von Bakterien in einer statischen Kultur kann in mehrere Phasen unterteilt und anhand eines typischen Kurvenverlaufes dargestellt werden (Abb. 3.1).

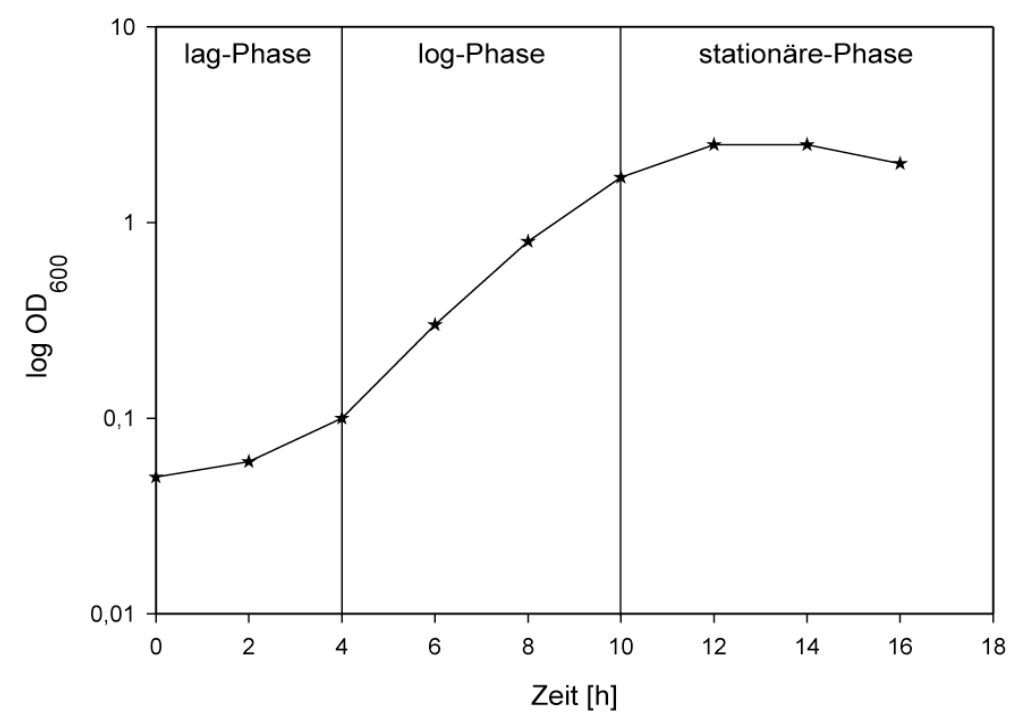

Abbildung 3.1: Wachstumskurve. Logarithmische Auftragung der Zelldichte $\left(\mathrm{OD}_{600}\right)$ über der Zeit und Unterteilung in die Wachstumsphasen. 
In der ersten Phase, der lag-Phase, erfolgt zunächst eine Adaption der Zellen an die Wachstumsbedingungen. Eine Zunahme der Kulturdichte findet in dieser Phase kaum statt. Hieran schließt sich die so genannte log-Phase an, welche durch eine konstante Generationszeit unter optimaler Verwertung der zur Verfügung stehenden Energiequellen gekennzeichnet ist. In einem geschlossenen System erfolgt keine Zufuhr von Nährstoffen. Die Erschöpfung der ersten essentiellen Ressource leitet die stationäre Phase ein. Diese ist anhand eines Plateaus der Kurve zu erkennen. Neben der Begrenzung durch ein Substrat können auch eine hohe Zelldichte und die Ansammlung von Stoffwechselprodukten die stationäre Phase einleiten. In der stationären Phase findet kein Zellwachstum, aber Zellerhaltung durch Verwertung von Speicherstoffen statt. Sind alle Energiequellen verbraucht, beginnen die Bakterien abzusterben und zu lysieren. Dieses ist mit einer Abnahme der Zelldichte in der Suspension verbunden.

Die maximale Wachstumsrate, welche in der log-Phase erreicht wird, kann mit folgender Formel berechnet werden:

$$
\begin{array}{lll}
\mu_{\max }=\left(\ln \mathrm{x}_{2}-\ln \mathrm{x}_{1}\right) /\left(\mathrm{t}_{2}-\mathrm{t}_{1}\right) & \mathrm{x}_{2} & \text { OD } 600 \text { zum Zeitpunkt } 2 \\
& \mathrm{x}_{1} & \text { OD }_{600} \text { zum Zeitpunkt } 1 \\
\mu_{\max } \text { besitzt die Einheit } 1 / \mathrm{h} & \mathrm{t}_{2} & \text { Zeitpunkt } 2[\mathrm{~h}] \\
& \mathrm{t}_{1} & \text { Zeitpunkt } 1[\mathrm{~h}]
\end{array}
$$

\subsubsection{Zellanzucht von B. licheniformis in kontinuierlicher Kultur}

Für Transkriptionsanalysen ist es wünschenswert mit einer höchstmöglichen Reproduzierbarkeit der das Wachstum beeinflussenden Faktoren zu arbeiten. Zu diesem Zweck wurde B. licheniformis in einem definierten Medium mit $50 \mathrm{mM}$ Glucose als Kohlenstoffquelle in kontinuierlicher Kultur angezogen. Die Stabilität dieses kontinuierlichen Systems beruht auf der Begrenzung der Wachstumsrate durch die Limitierung eines für das Wachstum notwendigen Substrates (C-, N- oder P-Quelle). Im Gegensatz zu einer statischen Kultur, in welcher sich die Kulturbedingungen fortwährend ändern, werden der wachsenden Bakterienpopulation einer kontinuierlichen Kultur laufend Nährmedium zugeführt und Bakteriensuspension abgeführt, um möglichst gleichbleibende Milieu- und somit Kulturbedingungen zu schaffen. Eine solche kontinuierliche Kultur stellt somit ein offenes System dar. 


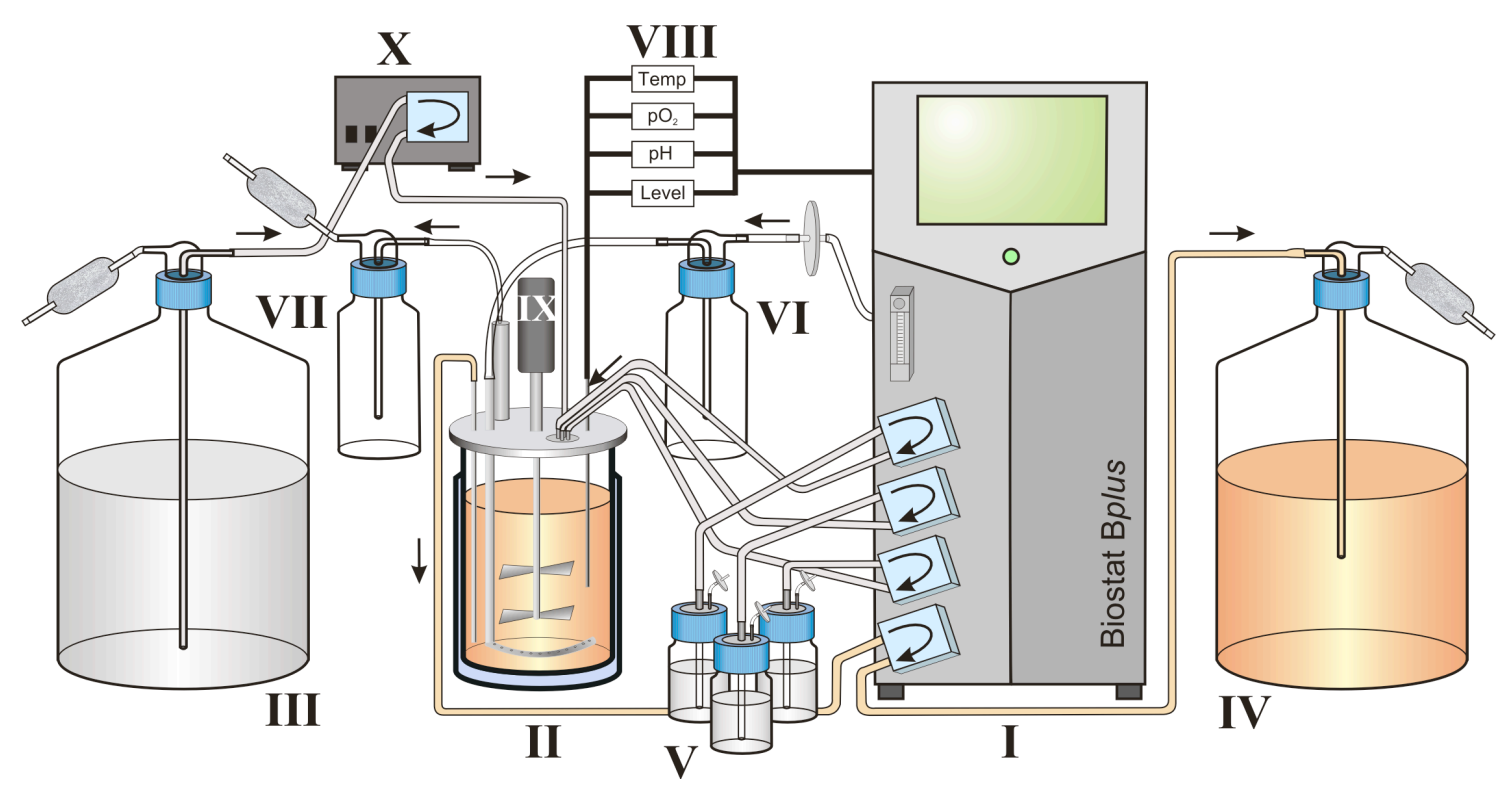

Abbildung 3.2: Aufbau des Chemostaten Biostat ${ }^{\mathbb{R}}$ B ${ }_{\text {plus }}$ der Firma Sartorius (schematische Darstellung nach Schmidt, 2005)

I Basiseinheit des Chemostaten zur Regulation von Temperatur, $\mathrm{pO}_{2}$, und $\mathrm{pH}-\mathrm{Wert}$, sowie Mediumzulauf und Kulturabfluss

II Kulturgefäß mit Doppelmantel, welches zur Einstellung der Wachstumstemperatur der Kultur mit vorgeheiztem Wasser umspült wird (Anschlüsse zur Basiseinheit nicht dargestellt)

III Mediumvorratsflasche (Magnetrührer für gleichmäßige Verteilung der Mediumkomponenten nicht dargestellt)

IV Auffanggefäß für abgeführte Kultur; Probennehmer und Erntevorrichtung, die vom Abpumpschlauch abzweigen sind nicht dargestellt

V Vorratsflaschen für Säure (1 M), Base (1 M) und Antischaum

VI Pressluftversorgung mit $0,22 \mu \mathrm{m}$ Filtereinheit und Waschflasche

VII Abluftvorrichtnug

VIII Elektrodenanschlüsse zur Kontrolle von Temperatur, $\mathrm{pO}_{2}, \mathrm{pH}-$ Wert und des Flüssigkeitsvolumens

IX Motor

X Substratpumpe

Sofern sich die Kultur im sogenannten Fließgleichgewicht befindet bleibt die Zelldichte annähernd konstant und die Zellen befinden sich im dauernden Wachstum (steady state). Beträgt das Volumen der Kultur V (1) und fließt die Nährlösung mit der konstanten Zuflussrate $\mathrm{f}[\mathrm{l} / \mathrm{h}] \mathrm{zu}$, so ergibt sich die Verdünnungsrate $\mathrm{D}=\mathrm{f} / \mathrm{V}[\mathrm{l} / \mathrm{h}]$. Wobei D den Volumenwechsel pro Stunde angibt. Die steady state Zelldichte bleibt nahezu unverändert, solange die maximale exponentielle Wachstumsrate $\mu$ größer ist als die Verdünnungsrate $\mathrm{D}$, und $\mathrm{D}$ größer ist als die $1 / 2$ maximale exponentielle 
Wachstumsrate. Entspricht die Verdünnungsrate D der Wachstumsrate $\mu$, spricht man vom balanced growth, d.h. die relativen Anteile aller Zellbestandteile, wie z.B. Proteine, DNA, RNA und Lipide, bleiben konstant.

In dieser Arbeit wurde zur Anzucht in kontinuierlicher Kultur ein Chemostat der Firma Sartorius BBI Systems GmbH verwendet. Zum Einsatz kam das Modell BIOSTAT ${ }^{\circledR}$ Bplus mit einem Kesselvolumen von einem Liter (Abb. 3.2). Um die gewünschte Verdünnungsrate über eine konstante Zuflussrate des Mediums einzustellen wurde das gepumpte Volumen pro Minute (Schlauch: Masterflex ${ }^{\circledR}$ R96400-14; Pumpe: Watson-Marlow 101U/R) in Abhängigkeit der prozentualen Pumpleistung ermittelt. Im Anschluss daran wurde die pH-Elektrode bei der angegebenen Wachstumstemperatur geeicht.

Die Fermentationseinheit, bestehend aus dem Kulturgefäß mit Doppelmantel, welches mit $500 \mathrm{ml} \mathrm{H} \mathrm{H}_{2} \mathrm{O}$ befüllt war und die $\mathrm{pO}_{2^{-}}, \mathrm{pH}$ - und Temperaturelektrode enthielt, leere Vorratsflaschen für Säure, Base und Antischaum, einer Abluftflasche mit Filter, sowie eine Zuluftapparatur, bestehend aus Filter und Waschflasche, wurden bei $121^{\circ} \mathrm{C}$ für 20 min autoklaviert. Separat wurden eine 201 Vorratsflasche, befüllt mit $\mathrm{H}_{2} \mathrm{O}$ für 101 Minimalmedium, ebenso autoklaviert. Nach dem Abkühlen auf Raumtemperatur wurden der Vorratsflasche sämtliche weitere Zusätze steril zugegeben. Für die abzuführende Bakterienpopulation wurde eine $201 \mathrm{Abfallflasche} \mathrm{auch} \mathrm{bei} 121^{\circ} \mathrm{C}$ für 20 min autoklaviert. Nach dem Autoklavieren wurden die einzelnen Komponenten steril über Luer-Lock-Anschlüsse miteinander verbunden und die Elektroden und Pumpenschläuche an die Basiseinheit angeschlossen. Die drei leeren Vorratsflaschen wurden durch entsprechende Flaschen, welche $1 \mathrm{M} \mathrm{HCl}, 1 \mathrm{M} \mathrm{NaOH}$ bzw. 1\% Antischaum enthielten, steril ausgetauscht.

Nach dem Abpumpen des $\mathrm{H}_{2} \mathrm{O}$ aus dem Kulturgefäß wurde es mit Minimalmedium gespült und schließlich mit $500 \mathrm{ml}$ Medium befüllt. Die Wachstumstemperatur von $37^{\circ} \mathrm{C}$ wurde eingestellt. Um die $\mathrm{pO}_{2}$-Elektrode zu kalibrieren wurde das Medium zuerst mit Stickstoff bis zu einem minimalen Elektrodenstrom (Nullpunkt-Kalibrierung) und anschließend mit Pressluft bis $\mathrm{zu}$ einem maximalen Elektrodenstrom (Steilheitskalibrierung) begast. Die Kultur im Chemostaten wurde mit einer Vorkultur auf eine $\mathrm{OD}_{600}$ von 0,05 angeimpft und unter ständigem Rühren bei $500 \mathrm{U} / \mathrm{min}$, einem $\mathrm{pH}$-Wert von 7,5 und einem Sauerstoffpartialdruck $\left(\mathrm{pO}_{2}\right)$ von $80 \%$ bis in die log-Phase in statischer Kultur angezogen. Beim Erreichen einer $\mathrm{OD}_{600}$ von ca. 1 wurde die 
Substratpumpe auf eine Durchflussrate von 0,4 eingestellt. Die Regulation des Kulturvolumens erfolgte über ein Ablaufrohr, welches an einer Pumpe angeschlossen war. Diese lief mit einer höheren Effizienz als die Zulaufpumpe, so dass nach dem Einstellen der Höhe des Abflussrohres sämtliches Kulturvolumen größer $500 \mathrm{ml}$ abgepumpt wurde. Nach etwa 3 Volumenwechseln sollte sich ein stabiles Fließgleichgewicht der Kultur einstellen. Zeichnete sich dieses durch eine konstante Zelldichte aus, wurden die Zellen geerntet. Zur Überprüfung auf Reinheit wurde die Kultur täglich mikroskopisch und durch Ausstrich auf NB-Platten kontrolliert. Als weiterer Parameter zur Kontrolle wurde die Glucosekonzentration im Kulturüberstand mittels Ionenchromatographie bestimmt.

\subsubsection{Reinheitskontrolle}

Die Reinheitskontrolle von Kulturen erfolgte durch Vereinzelungsausstriche auf Komplexmediumsplatten und wurde ergänzt durch eine mikroskopische Kontrolle der Zellmorphologie.

\subsubsection{Stammhaltung}

Über einen Zeitraum von etwa 4 Wochen können Bakterienkulturen der Gattung Bacillus auf Agarplatten bei $4^{\circ} \mathrm{C}$ gelagert werden. Zur Vermeidung von Austrocknung und Kontaminationen wurden die Petrischalen mit Parafilm verschlossen. Alle 1-2 Wochen sollten die Zellen auf eine frische Agarplatte überimpft werden.

Für die Langzeitkonservierung wurden Stammkulturen mit DMSO (Dimethylsulfoxid) oder 87\%igem Glycerin angelegt. Dazu wurden $800 \mu$ einer Übernachtkultur mit $200 \mu \mathrm{l}$ DMSO bzw. Glycerin versetzt. Die Lagerung erfolgte bei $-70^{\circ} \mathrm{C}$. Mit diesen Kulturen können sowohl Fest- als auch Flüssigmedien direkt angeimpft werden. 


\subsection{Techniken für das Arbeiten mit DNA}

\subsubsection{Lösungen und Puffer für das Arbeiten mit DNA}

Um eine Kontamination durch Nukleasen zu vermeiden, wurden alle thermostabilen Lösungen, Glaswaren und andere Materialien, die für das Arbeiten mit Nukleinsäuren notwendig waren, autoklaviert $\left(121^{\circ} \mathrm{C}, 2 \mathrm{bar}, 20 \mathrm{~min}\right)$ oder ggf. abgeflammt. Thermolabile Medienzusätze wurden sterilfiltriert (Spritzenvorsatzfilter 0,22 $\mu \mathrm{m}$, Sartorius, Göttingen). Des Weiteren wurde der Arbeitsplatz durch regelmäßige Reinigung mit 70\%igen Ethanol (v/v) sauber gehalten.

\section{Calciumchlorid-Lösung}

$\mathrm{CaCl}_{2} \quad 100 \mathrm{mM}$

autoklavieren

E1-Lösung (Lyselösung für Eckhardt-Gele)

Saccharose $25 \%(\mathrm{w} / \mathrm{v})$

Ficoll $400 \quad 10 \%(\mathrm{w} / \mathrm{v})$

vor Gebrauch sterile Zugabe von

$5 \mathrm{mg} / \mathrm{ml}$ Lysozym

$0,5 \mathrm{mg} / \mathrm{ml} \mathrm{RNaseA}$ (Inkubation $15 \mathrm{~min}$ bei $100^{\circ} \mathrm{C}$ )

\section{EDTA-Lösung (pH 8,0)}

Na-EDTA $\quad 500 \quad \mathrm{mM}$

$\mathrm{pH}-\mathrm{Wert}$ mit $\mathrm{NaOH}$ einstellen, autoklavieren

\section{Perchlorat-Lösung}

$\mathrm{NaClO}_{4} \quad 5 \quad \mathrm{M}$

\section{Phosphatpuffer (pH 7,5)}

$\mathrm{Na}_{2} \mathrm{HPO}_{4} \quad 50 \quad \mathrm{mM}$

pH-Wert mit $50 \mathrm{mM} \mathrm{KH}_{2} \mathrm{PO}_{4}$ einstellen, autoklavieren 
SDS-Lösung

Natriumdodecylsulfat $10 \% \quad(\mathrm{w} / \mathrm{v})$

sterilfiltrieren

10x S-Puffer (pH 8,8)

Tris $\quad 100 \mathrm{mM}$

$\mathrm{KCl} \quad 500 \mathrm{mM}$

$\mathrm{MgCl}_{2} \quad 15 \mathrm{mM}$

STE-Puffer (pH 8,0)

$\begin{array}{lll}\text { Saccharose } & 6,7 \% & (\mathrm{w} / \mathrm{v}) \\ \text { Tris } & 50 & \mathrm{mM} \\ \text { EDTA } & 1 & \mathrm{mM}\end{array}$

20x TAE-Puffer (DNA-Gelelektrophorese)

$\begin{array}{lll}\text { Tris } & 96,9 & \mathrm{~g} \\ \text { Essigsäure (100\%) } & 22,8 & \mathrm{ml} \\ \text { EDTA } & 3,8 & \mathrm{~g} \\ \mathrm{H}_{2} \mathrm{O} & \mathrm{ad} 1000 & \mathrm{ml}\end{array}$

TE-Puffer (pH 8,0)

$\begin{array}{lll}\text { Tris } & 10 & \mathrm{mM} \\ \text { EDTA } & 1 & \mathrm{mM}\end{array}$

Tris-Puffer (pH 8,0)

Tris $\quad 1 \quad M$

pH-Wert mit $\mathrm{HCl}$ einstellen 


\subsubsection{Isolierung und Darstellung von DNA}

\subsubsection{Isolierung chromosomaler DNA (modifiziert nach Box, 2006)}

Zur Isolierung chromosomaler DNA wurde das Pellet einer $10 \mathrm{ml}$ Übernachtkultur in $1 \mathrm{ml}$ STE-Puffer aufgenommen und anschließend bei $13000 \mathrm{U} / \mathrm{min},-9^{\circ} \mathrm{C}$ für $2 \mathrm{~min}$ gewaschen. Der Überstand wurde verworfen und das Pellet in $500 \mu$ l STE-Puffer resuspendiert. Zum Aufschluss der Zellen wurde eine Zellmühle verwendet. Hierbei handelt es sich um einen Dismembrator (Mikro-Dismembrator U, Braun Biotech, Melsungen), in welchem eine Chromstahlkugel mit einer hohen Geschwindigkeit in einem mit flüssigem Stickstoff gekühltem PTFE-Zylinder hin und her geschlagen wird ( $3 \mathrm{~min}$ bei $1600 \mathrm{U} / \mathrm{min}$ ). Auf diese Weise werden im Zylinder befindlichen Zellen zu einem feinen Pulver zermahlen. Dieses wurde in 3,8 $\mathrm{ml}$ STE-Puffer aufgenommen und

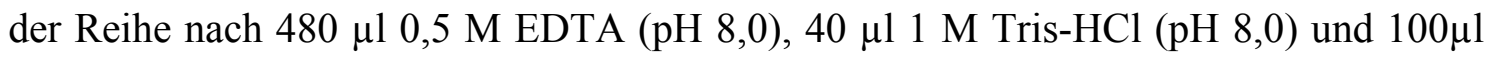
RNAse A (10 mg/ml; zuvor $10 \mathrm{~min}$ bei $100^{\circ} \mathrm{C}$ inkubiert) hinzugegeben. Nach einer 30minütigen Inkubation auf Eis erfolgte die Zugabe von $200 \mu 1$ Proteinase K (2,5 $\mathrm{mg} / \mathrm{ml}$ ). An eine Inkubation von $3 \mathrm{~h}$ bei $37^{\circ} \mathrm{C}$ schloss sich eine Extraktion der DNA mit Perchlorat/Chloroform/Isoamylalkohol an. Im Anschluss daran wurde die DNA mit Isopropanol gefällt (3.4.2.2.).

\subsubsection{Extraktion und Fällung von DNA}

\section{Extraktion von DNA mit Perchlorat/Chloroform/Isoamylalkohol}

Die Extraktion der DNA mit Perchlorat/Chloroform/Isoamylalkohol dient der Entfernung von Proteinen. Nach der Zugabe von 1,2 $\mathrm{ml} 5 \mathrm{M}$ Perchlorat zur DNA-Lösung wurden $3 \mathrm{ml}$ Chloroform/Isoamylalkohol (24:1 v/v) hinzugefügt und der Ansatz gevortext. Es folgte eine Zentrifugation bei $9000 \mathrm{U} / \mathrm{min}$, RT für $10 \mathrm{~min}$. Die DNA-haltige obere Phase wurde vorsichtig in ein neues Reaktionsgefäß überführt. Zur weiteren Reinigung der DNA wurde die Extraktion mit Chloroform/Isoamylalkohol zwei weitere Male wiederholt. Die Fällung der DNA erfolgte im Anschluss mit Isopropanol. 


\section{Fällung von DNA mit Isopropanol}

Die DNA-Lösung wurde mit 1 Vol Isopropanol (100\%) versetzt. Nach 50x Schwenken wurde die gefällte DNA durch Zentrifugation (9000 U/min, RT, $30 \mathrm{~min}$ ) pelletiert. Das Pellet wurde im Anschluss mit $500 \mu 1-20^{\circ} \mathrm{C}$ kaltem 70\%igen Ethanol (v/v) gewaschen. Darauf folgte ein weiterer Zentrifugationsschritt bei $9000 \mathrm{U} / \mathrm{min}$ für $10 \mathrm{~min}$. Nach der Abnahme des Überstandes wurde das verbleibende DNA-Pellet bei $37^{\circ} \mathrm{C}$ im Thermoblock getrocknet. Gelöst wurde die DNA anschließend in sterilem $\mathrm{H}_{2} \mathrm{O}$ und bei $4^{\circ} \mathrm{C}$ kurzfristig oder bei $-20^{\circ} \mathrm{C}$ für einen längeren Zeitraum gelagert.

\subsubsection{Kochlyse}

Ein schnelles Verfahren zur Gewinnung eines DNA-haltigen Überstandes stellt die Kochlyse dar. Hierbei erfolgt die Lyse der Zellen physikalisch durch Aufkochen. Zellmaterial wurde in $40 \mu \mathrm{l}$ sterilem $\mathrm{H}_{2} \mathrm{O}$ resuspendiert und für $15 \mathrm{~min}$ bei $100^{\circ} \mathrm{C}$ im Thermoblock aufgekocht. Anschließend wurde der Ansatz für 3 min bei $10000 \mathrm{U} / \mathrm{min}$ zentrifugiert. Der Überstand konnte direkt als Template in eine PolymeraseKettenreaktion (PCR) eingesetzt werden.

\subsubsection{Verkürzte Isolierung von DNA}

Zur schnellen Isolierung von DNA aus B. licheniformis wurde Zellmaterial einer Kolonie in $450 \mu \mathrm{l}$ STE-Puffer resupendiert und anschließend $75 \mu$ Lysozym $(40$ mg/ml) hinzugegeben. Nach einer Inkubationszeit von $30 \mathrm{~min}$ bei $37^{\circ} \mathrm{C}$ wurden der Reihe nach $70 \mu \mathrm{l} 10 \%$ SDS, $60 \mu \mathrm{l}$ 0,5 M EDTA, $5 \mu \mathrm{l} 1 \mathrm{M}$ Tris und $150 \mu \mathrm{l} 5 \mathrm{M}$ Perchlorat hinzugegeben und für $30 \mathrm{~min}$ bei $10000 \mathrm{U} / \mathrm{min}$ zentrifugiert. $500 \mu \mathrm{l}$ des Überstandes wurden in ein neues $2 \mathrm{ml}$ Reaktionsgefäß überführt und die DNA durch 20 minütige Zentrifugation mit 1 Vol Isopropanol bei 10000 U/min gefällt. Der Überstand wurde verworfen, $500 \mu 170 \%$ Ethanol zugegeben und erneut zentrifugiert. Nach der erneuten Abnahme des Überstandes wurde das verbleibende DNA-Pellet bei $37^{\circ} \mathrm{C}$ im Thermoblock getrocknet, anschließend in $30 \mu$ sterilen $\mathrm{H}_{2} \mathrm{O}$ aufgenommen und konnte direkt als Template in eine PCR eingesetzt werden. 


\subsubsection{Isolierung von Plasmid-DNA}

Zur Isolierung von Plasmid-DNA wurde das QIAprep ${ }^{\circledR}$ Spin Miniprep Kit der Firma Qiagen benutzt und laut mitgelieferter Versuchsvorschrift durchgeführt. Die Methode basiert auf der alkalischen Lyse in Verbindung mit einer Säule, an welche während der Aufreinigung Plasmid-DNA selektiv bindet. Proteine und auch andere zelluläre Verunreinigungen können nicht binden und werden somit abgetrennt. Die gewonnene DNA ist darüber hinaus frei von RNA, da bereits während der Lyse eine RNaseBehandlung erfolgt.

\subsubsection{Aufreinigung von PCR-Produkten}

Zur Sequenzierung von PCR-Produkten ist es erforderlich, noch vorhandene dNTPs, Primer, Puffer und Enzym-Reste aus den PCR-Ansätzen zu entfernen. Dazu wurde das QIAquick $^{\circledR}$ PCR Purification Kit der Firma Qiagen verwendet. Die Aufreinigung erfolgte nach Anleitung des Herstellers mit der Abweichung, dass die Eluation der PCR-Produkte mit $70^{\circ} \mathrm{C}$ warmen sterilen $\mathrm{H}_{2} \mathrm{O}$ erfolgte.

\subsubsection{Agarose-Gelelektrophorese}

Die Auftrennung von DNA Fragmenten nach ihrer Größe erfolgte mit der AgaroseGelelektrophorese. Die Agarose wurde in Abhängigkeit der zu untersuchenden Fragmentgrößen 0,8\%ig (w/v) bzw. 1,5\%ig (w/v) in 1x TAE-Puffer (3.4.1.) angesetzt, welcher auch als Elektrophoresepuffer diente. Die Agaroselösung wurde mit einer Temperatur von etwa $50^{\circ} \mathrm{C}$ in einen abgegrenzten Bereich einer Gellaufkammer gegossen und ein Taschenkamm eingesetzt. Nach dem Erstarren des Agarosegels wurde dieses mit 1x TAE-Puffer bedeckt und der Taschenkamm entfernt. Die mit mindestens 1/5 Vol Loading-Dye versetzten Proben wurden nach vollständiger Durchmischung in die Geltaschen pipettiert. Der Loading-Dye diente einerseits zur Beschwerung der Proben, als auch zur Markierung der Lauffront. Für die Auftrennung der DNA-Proben im Gel wurde die Spannung bei 90 - $110 \mathrm{~V}$ konstant eingestellt und diese für etwa 45 - 60 min beibehalten, bis die Lauffront ca. 1,5 cm vom unteren Rand des Gels entfernt war. Die Auftrennung der DNA-Fragmente erfolgte entsprechend ihrer Größe, 
da deren Laufgeschwindigkeit umgekehrt proportional zu ihrer Molekularmasse ist. Zusätzlich hängt die Wanderungsgeschwindigkeit linearer DNA-Fragmente von weiteren Faktoren wie der Agarosekonzentration, der angelegten Spannung, der Ionenkonzentration des Laufpuffers, sowie der Anwesenheit interkalierender Farbstoffe ab. Nach Beendigung des Laufes wurde die DNA für $10 \mathrm{~min}$ in einem

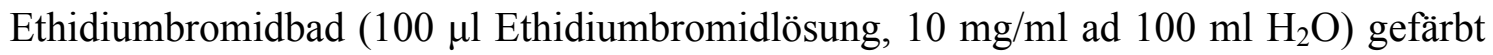
und das Gel anschließend in einem Wasserbad für 10 min entfärbt. In einer GelDokumentationsanlage wurde die DNA bei UV-Licht $(254 \mathrm{~nm})$ durch das eingelagerte Ethidiumbromid sichtbar gemacht und fotografisch dokumentiert. Der Vergleich mit einem Standard erlaubte sowohl eine Größen-, als auch eine Mengenabschätzung der aufgetragenen DNA-Fragmente.

Für Proben mit einer Größe bis zu $10 \mathrm{~kb}$ wurden $3 \mu \mathrm{l}$ der GeneRuler ${ }^{\mathrm{TM}} 1 \mathrm{~kb}$ DNA Ladder (Fermentas, St. Leon-Rot) mit einem Größenstandard von 0,25 - 10 kb benutzt.

Fragmentlängen in bp:

$250,500,750,1000,1500,2000,2500,3000,3500,4000,5000,6000,8000,10000$

3.4.2.8. Eckhardt-Lyse (Eckhardt, 1978, modifiziert nach Buhrmester, 2004)

Die Eckhardt-Lyse ist eine schnelle Methode zur Analyse des Plasmidgehalts eines Bakteriums. Sie lässt Rückschlüsse auf die Anzahl der Plasmide und der Plasmidgröße zu. Bei dieser Methode werden Bakterienzellen durch die Verwendung von Lysozym und SDS innerhalb der Taschen eines Agarosegeles lysiert, so dass Scherkräfte vermieden werden. Anschließend erfolgt die gelelektrophoretische Auftrennung. Die chromosomale DNA der Bakterien ist zu groß um in das Agarosegel einwandern zu können und bleibt aus diesem Grund in den Geltaschen zurück.

Zur Herstellung des Gels wurde 0,8 - 1,0\%ige Agarose (w/v) in 1x TAE-Puffer aufgekocht. Nach dem Abkühlen der Agaroselösung auf ca. $60^{\circ} \mathrm{C}$ erfolgte die Zugabe

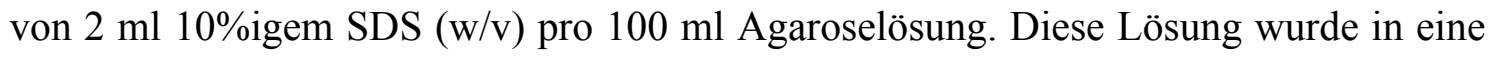
Harnischmacher Kammer zu einem etwa 0,5 cm hohem Gel gegossen und der Kamm eingesetzt. Im Anschluss daran erfolgte die Vorbereitung der Zellen. Hierbei wurden Zellen einer bakteriellen Einzelkolonie mit einem sterilen Zahnstocher in $5 \mu$ TE-Puffer resuspendiert und nach der Zugabe von $20 \mu \mathrm{l}$ E1-Lösung (mit 5 mg/ml Lysozym und 
0,5 mg/ml RNaseA) vorsichtig gemischt. Nach dem Erstarren des Geles wurde dieses mit 1x TAE-Puffer überschichtet. $20 \mu \mathrm{l}$ der Zellsuspension wurde nun auf das Gel aufgetragen und 5 min stehen gelassen. Der Vorlauf wurde ca. 30 - $40 \mathrm{~min}$ bei $20 \mathrm{~V}$, bis zum Aufklaren der Geltaschen, durchgeführt. Die Auftrennung der Plasmide erfolgte für 90 - 120 min bei $100 \mathrm{~V}-120 \mathrm{~V}$. Zur Entfernung des SDS wurde das Gel unter Schwenken 4 x 30 min gewässert. Im Anschluss daran wurde das Gel für 20 min in einem Ethidiumbromidbad gefärbt und $20 \mathrm{~min}$ in einem Wasserbad entfärbt. Die Detektion der angefärbten DNA erfolgte im UV-Licht $(254 \mathrm{~nm})$ mit einer GelDokumentationsanlage.

\subsubsection{Isolierung von DNA-Fragmenten aus Agarosegelen}

Zur Isolierung von DNA aus Agarosegelen wurde das QIAquick ${ }^{\circledR}$ Gel Extraction Kit der Firma QIAGEN nach Angaben des Herstellers verwendet.

\subsubsection{DNA-Konzentrationsbestimmung}

Zur Konzentrationsbestimmung von DNA-Lösungen wurde die Absorption im UV/VIS Spectrophotometer V-530 (JASCO, Groß-Umstadt) bei einer Wellenlänge von $260 \mathrm{~nm}$ gemessen. Dabei kam eine $1 \mathrm{ml}$ Quarzküvette mit $1 \mathrm{~cm}$ Schichtdicke und einem Mindestvolumen von $50 \mu \mathrm{l}$ zum Einsatz. Der Nullabgleich wurde mit $\mathrm{H}_{2} \mathrm{O}$ eingestellt. Für eine $\mathrm{OD}_{260}$ von 1 wurden folgende Konzentrationen angenommen (Sambrook et al., 1989):

$\begin{array}{ll}\text { dsDNA } & 50 \mu \mathrm{g} / \mathrm{ml} \\ \text { ssDNA } & 40 \mu \mathrm{g} / \mathrm{ml}\end{array}$

Außerdem konnte die Reinheit einer DNA-Lösung durch Bestimmung der optischen Dichte bei 280 nm überprüft werden. Für reine DNA gilt (Sambrook et al., 1989):

$$
\mathrm{OD}_{260}: \mathrm{OD}_{280}=1,8
$$

Verunreinigungen durch Proteine sind an einer deutlich stärkeren Absorption bei $280 \mathrm{~nm}$ erkennbar.

Eine weitere Möglichkeit der Konzentrationsbestimmung von DNA-Lösungen stellt das NanoDrop ${ }^{\circledR}$ ND 1000 Spectrophotometer dar. Hierzu wurde $1 \mu$ l Probe in die Lücke 
zwischen zwei Glasfaserkabel pipettiert, so dass diese durch die Flüssigkeit überbrückt wurde. Ein Spectrometer analysierte das Licht, ausgehend von einer Xenon Lampe, nachdem es die Probe passiert hatte. Gesteuert wurde das Gerät über eine spezielle Software mit welcher die Daten auch archiviert werden konnten.

\subsubsection{Restriktion und Modifikation von DNA}

\subsubsection{Restriktion}

Restriktionsendonukleasen sind Enzyme, welche doppelsträngige DNA an spezifischen Basensequenzen schneiden. Hierbei können, je nach Enzym, freie glatte Enden, sogenannte blunt ends oder versetzte Enden, sticky ends, entstehen. Die Spaltung von DNA mit Restriktionsendonukleasen des Typs II wurde unter den vom Hersteller des Enzyms empfohlenen Temperatur- und Pufferbedingungen im Thermoblock für 2 Stunden durchgeführt. Sofern nicht anders angegeben wurden die Ansätze zur Inaktivierung der Restriktionsendonukleasen für $15 \mathrm{~min}$ bei $65^{\circ} \mathrm{C}$ im Thermoblock inkubiert.

\subsubsection{Dephosphorylierung}

Nach der Restriktion (3.4.3.1.) wurde die Vektor-DNA mit alkalischer Phosphatase behandelt. Das Enzym entfernt die 5'-Phosphatgruppe von linearer DNA und verhindert so ein Religieren des Vektors. Die Dephosphorylierung mittels CIAP (Calf Intestine Alkaline Phosphatase) der Firma Fermentas wurde unter den vom Hersteller empfohlenen Temperatur- und Pufferbedingungen im Thermoblock durchgeführt.

\subsubsection{Ligation}

Eine Restriktion von DNA-Fragmenten oder Vektoren mit den gleichen Restriktionsendonukleasen erzeugt komplementäre oder glatte Enden. DNA-Ligasen verknüpfen, unter Ausbildung von Phosphodiesterbrücken, endständige 5'-Phosphatgruppen und 3'-Hydroxylgruppen miteinander. Für eine Ligation von DNAFragmenten wurde ein dreifacher molarer Überschuss an Insert-Fragment gegenüber 
Vektor-Fragment eingesetzt. Der Ligationsansatz wurde nach Angaben des Herstellers mit der T4-DNA-Ligase der Firma Fermentas pipettiert und über Nacht bei $16^{\circ} \mathrm{C}$ in einer PCR-Maschine inkubiert. Die sich anschließende Inaktivierung erfolgte ebenfalls nach Angaben des Herstellers.

\subsubsection{DNA-Transfertechniken}

Für den horizontalen DNA-Transfer bei Prokaryonten gibt es mehrere bekannte Mechanismen:

Transformation: Aufnahme freier DNA aus der Umgebung

Konjugation: Transfer von DNA von einer Donor- zu einer Rezipientenzelle

Transduktion: Übertragung nicht viraler DNA durch temperente Phagen

Alle Formen des DNA-Transfers erfahren im Prinzip den gleichen limitierenden Schritt: Die DNA muss sich gegenüber den Restriktionsenzymen und Nukleasen durchsetzen und sich anschließend stabil im Rezipienten etablieren. Einschränkend wirken zudem eine Inkompatibilität der Plasmidübertragung und -replikation. Um eine homologe Rekombination ablaufen zu lassen muss außerdem eine ausreichende Homologie zwischen chromosomaler und aufgenommener DNA gegeben sein.

Im Rahmen dieser Arbeit erfolgte der DNA-Transfer mittels Transformation (3.4.4.1. und 3.4.4.2.) und Konjugation (3.4.4.3.).

\subsubsection{DNA-Transfer mittels Hitze-Transformation}

Für den Transfer von DNA mittels Hitze-Transformation wurde Escherichia coli S17-1 bzw. E. coli DH5 $\alpha$ verwendet. Die Herstellung der chemisch kompetenten E. coli Zellen erfolgte hierbei modifiziert in Anlehnung an eine Methode, die von Lederberg und Cohen (1974) beschrieben wurde. Die Transformation wurde modifiziert nach Morrison (1977) durchgeführt.

\section{Herstellung chemisch kompetenter $E$. coli S17-1}

$10 \mathrm{ml}$ LB-Medium wurden mit $100 \mu \mathrm{l}$ einer E. coli S17-1 Übernachtkultur angeimpft und bis zu einer $\mathrm{OD}_{600}$ von $0,5-0,6$ bei $37^{\circ} \mathrm{C}$ inkubiert. Zum Ernten der Kultur wurde 
diese bei $6000 \mathrm{U} / \mathrm{min}, 0^{\circ} \mathrm{C}$ für 5 min abzentrifugiert. Das Pellet wurde anschließend in $5 \mathrm{ml} 100 \mathrm{mM} \mathrm{CaCl} 2$-Lösung, ebenfalls $0^{\circ} \mathrm{C}$, resuspendiert. Nach einer zweiten Zentrifugation bei $6000 \mathrm{U} / \mathrm{min}, 0^{\circ} \mathrm{C}$ für $5 \mathrm{~min}$ wurden die Zellen in $1 \mathrm{ml} 100 \mathrm{mM}$ $\mathrm{CaCl}_{2}$-Lösung $\left(0^{\circ} \mathrm{C}\right)$ aufgenommen. Nach der Zugabe $200 \mu \mathrm{l}$ Glycerin (87\%) wurde der Ansatz in $100 \mu \mathrm{l}$ Aliquots portioniert. Bis zur weiteren Verwendung wurden die Zellen bei $-80^{\circ} \mathrm{C}$ gelagert.

\section{Hitze-Transformation $E$. coli S17-1}

Für die Hitztransformation wurden zunächst $10 \quad \mu l$ des $\mathrm{zu}$ transformierenden Ligationsansatzes zu $100 \mu \mathrm{l}$ kompetenten Zellen gegeben und anschließend vorsichtig gemischt. Nach einer Inkubation des Ansatzes auf Eis für $30 \mathrm{~min}$ erfolgte die Transformation bei $43^{\circ} \mathrm{C}$ für $90 \mathrm{sec}$. Zum Kuren der Zellen wurde dem Ansatz $1 \mathrm{ml}$ LB-Medium zugefügt und für $60 \mathrm{~min}$ bei $37^{\circ} \mathrm{C}$ auf einem Rotationsschüttler (160 U/min) inkubiert. Abschließend wurden $100 \mu \mathrm{l}$ und der abzentrifugierte Rest (Überstand verwerfen und Pellet in Rücklauf resuspendieren) auf Selektivplatten (LB/ $100 \mu \mathrm{g} / \mathrm{ml}$ Ampicilin) ausplattiert. Inkubation bei $37^{\circ} \mathrm{C}$ über Nacht.

\subsubsection{DNA-Transfer mittels Protoplasten-Transformation}

Bei der im folgenden vorgestellten Methode nach Chang und Cohen (1979) wurde das Plasmid pMAD in B. licheniformis MW3 transformiert. Bei diesem Stamm sind die beiden Typ I Restriktions-Modifikations-Systeme (Typ I RMS) des Wildtyps B. licheniformis DSM13 durch Deletion jeweils eines Gens des entsprechenden Operons ( $h s d R l$ und $h s d R 2$ ) inaktiviert. RMS modifizieren die zelleigene DNA mit einem für den Organismus spezifischen Methylierungsmuster und bauen fremde DNA mit unterschiedlichem Methylierungsmuster $\mathrm{ab}$, was ein großes Hindernis für die Transformation von $B$. licheniformis DSM13 mit DNA aus anderen Organismen darstellt. B. licheniformis MW3 lässt sich daher wesentlich besser als der Wildtyp transformieren. 
Lösungen und Medien für die Protoplasten-Transformation

\section{4 x PAB-Medium}

Antibiotic broth/ Penassay broth $35 \quad \mathrm{~g}$

$\mathrm{H}_{2} \mathrm{O} \quad$ ad $500 \mathrm{ml}$

autoklavieren

\section{$2 \times \mathrm{SMM}$}

\begin{tabular}{|c|c|}
\hline 2 M Sucrose & 250 \\
\hline $1 \mathrm{M} \mathrm{MgCl}_{2}$ & 10 \\
\hline 0,08 M Maleinsäure pH 6,5 & 240 \\
\hline
\end{tabular}

Alle Komponenten getrennt autoklavieren und anschließend steril vereinigen.

\section{SMMP}

$\mathrm{Zu}$ gleichen Teilen $2 \mathrm{x}$ SMM und $4 \mathrm{x}$ PAB mischen.

\section{SMMP+}

SMMP mit $2 \%$ BSA

BSA in SMMP lösen und anschließend sterilfiltrieren.

\section{DM3-Agar}

$\begin{array}{lll}4 \% \text { Agar } & 100 & \mathrm{ml} \\ 1 \mathrm{M} \mathrm{Na}-\text { Succinat }(\mathrm{pH} 7,3) & 250 & \mathrm{ml} \\ \text { Phosphatpuffer }\left(3,5 \% \mathrm{~K}_{2} \mathrm{HPO}_{4} ; 1,5 \% \mathrm{KH}_{2} \mathrm{PO}_{4}\right) & 50 & \mathrm{ml} \\ 10 \% \text { Hefeextrakt } & 25 & \mathrm{ml} \\ 5 \% \text { Casaminoacids/ Casein Hydrolysat } & 50 & \mathrm{ml} \\ 20 \% \text { Glucose } & 12,5 \mathrm{ml} \\ 1 \mathrm{M} \mathrm{MgCl}_{2} & 10 & \mathrm{ml} \\ 2 \% \mathrm{BSA} & 2,5 \mathrm{ml}\end{array}$

Alle Komponenten getrennt autoklavieren bzw. sterilfiltrieren (Glucose und BSA), anschließend steril vereinigen. 
Um eine Protoplasten-Transformation durchzuführen, wurde zunächst eine Vorkultur von B. licheniformis MW3 in $20 \mathrm{ml} 1$ x PAB-Medium angeimpft. Die Inkubation erfolgte dabei in $250 \mathrm{ml}$ Erlenmeyerkolben über Nacht bei $160 \mathrm{U} / \mathrm{min}$ und $37^{\circ} \mathrm{C}$. Die darauffolgende $50 \mathrm{ml}$ Hauptkultur wurde auf eine $\mathrm{OD}_{600}=0,2$ angeimpft und wiederum bei $160 \mathrm{U} / \mathrm{min}$ und $37^{\circ} \mathrm{C}$ inkubiert. Nach dem Erreichen einer $\mathrm{OD}_{600}$ von $0,8-0,95$ wurde die Hauptkultur durch eine zehnminütige Zentrifugation $(8000 \mathrm{U} / \mathrm{min})$ bei $4^{\circ} \mathrm{C}$ geerntet und das Pellet anschließend in $5 \mathrm{ml}$ SMMP resuspendiert. Die Zellsuspension wurde in einen $100 \mathrm{ml}$ Erlenmeyerkolben überführt und nach der Zugabe von $130 \mu \mathrm{l}$ Lysozym $(20 \mathrm{mg} / \mathrm{ml}$ in $\mathrm{SMM})$ bei $30^{\circ} \mathrm{C}$ und $100 \mathrm{U} / \mathrm{min}$ inkubiert. Die Protoplastierung der Zellen wurde alle 30 min mikroskopisch überprüft. Nach etwa 2 Stunden war der Großteil der Zellen protoplastiert und konnten durch Zentrifugation in zwei Schritten geerntet werden. Die erste Zentrifugation erfolgte bei $4^{\circ} \mathrm{C}, 800 \mathrm{~g}$ für $10 \mathrm{~min}$, der sich anschließende zweite Zentrifugationsschritt bei $4^{\circ} \mathrm{C}, 2000 \mathrm{~g}$, ebenfalls für $10 \mathrm{~min}$. Das daraus resultierende Pellet wurde in $10 \mathrm{ml}$ SMMP resuspendiert und die Zentrifugationsschritte wiederholt. Das Pellet wurde in $2 \mathrm{ml} \mathrm{SMMP} \mathrm{resuspendiert.} \mathrm{Je}$ nach Anzahl der Ansätze wurden parallel hierzu in E-Cup-Reaktionsgefäße jeweils $10 \mu 1 \mathrm{DNA}+10 \mu \mathrm{l} 2 \mathrm{x}$ SMM und in $15 \mathrm{ml}$ Reaktionsgefäße jeweils $1,5 \mathrm{ml} 40 \%$ Polyethylenglykol (PEG) 6000, gelöst in SMM, vorgelegt. Je $500 \mu \mathrm{l}$ der Protoplastensuspension wurden in die E-Cup-Reaktionsgefäße gegeben und vorsichtig gemischt. Anschließend wurde der Ansatz in die $15 \mathrm{ml}$ Reaktionsgefäße, welche das PEG 6000 enthielten, überführt und nach erneutem vorsichtigen mischen für 2 min inkubiert. Nach der Zugabe von je 5 ml SMMP zu den Transformationsansätzen wurden diese bei $8^{\circ} \mathrm{C}$ wie oben beschrieben in zwei Schritten zentrifugiert. Das kaum sichtbare Pellet wurde in je $1 \mathrm{ml} \mathrm{SMMP}+$ resuspendiert und bei $30^{\circ} \mathrm{C}$ inkubiert (100 U/min). Nach 1 Stunde wurden je Ansatz $10 \mu \mathrm{l}$ Erythromycin $(5 \mu \mathrm{g} / \mathrm{ml})$ zugeben und eine weitere Stunde bei $30^{\circ} \mathrm{C}$ und $100 \mathrm{U} / \mathrm{min}$ inkubiert. Abschließend wurden die Ansätze auf DM3-Agar mit Erythromycin $(5 \mu \mathrm{g} / \mathrm{ml})$ ausplattiert und bei $30^{\circ} \mathrm{C}$ inkubiert.

\subsubsection{DNA-Transfer mittels Konjugation}

Neben der Möglichkeit DNA mittels Transformation aufzunehmen stellt die Konjugation mit einem Donorstamm eine Alternative für das Arbeiten mit B. licheniformis dar. 
Als Donorstamm für die Konjugation diente in dieser Arbeit E. coli S17-1 mit dem konjugativen Vektor pKVM1. Die Anzucht des Donorstammes erfolgte in LB-Medium mit entsprechendem Antibiotikum (Ampicilin $100 \mu \mathrm{g} / \mathrm{ml}$ ) bei $37^{\circ} \mathrm{C}$ und $160 \mathrm{U} / \mathrm{min}$ über Nacht. Für die Anzucht des Rezipientenstammes B. licheniformis MW3 wurde ebenfalls LB-Medium, ohne Antibiotikum, verwendet und die Inkubation erfolgte ebenfalls bei $37^{\circ} \mathrm{C}$ und $160 \mathrm{U} / \mathrm{min}$ über Nacht. Der Donor- und Rezipientenstamm wurden jeweils $20 \mathrm{fach}$ in entsprechendem Medium verdünnt und bis zu einer $\mathrm{OD}_{600}$ von 1,2 bei $37^{\circ} \mathrm{C}$ und $160 \mathrm{U} / \mathrm{min}$ inkubiert. Um das Antibiotikum zu entfernen wurden die Zellen des Donorstammes einmal mit $50 \mathrm{mM}$ Phosphatpuffer für $5 \mathrm{~min}$ bei $4^{\circ} \mathrm{C}$ und $10000 \mathrm{U} / \mathrm{min}$ gewaschen. Im Anschluss daran wurde auf das Donorpellet ein 3- bzw. 5-facher Überschuss an Rezipienten-Zellsuspension gegeben. Das Pellet wurde resuspendiert und erneut abzentrifugiert. Nach einem Waschschritt mit LB-Medium wurde das Pellet in $80 \mu 1$ LB-Medium resuspendiert und auf einen Konjugationsfilter (Sartorius, Order No 11306-25-N), welcher sich auf einer LB-Platte ohne Selektionsdruck befand, gegeben. Nach kurzer Antrocknung wurden die Ansätze bei $30^{\circ} \mathrm{C}$ über Nacht inkubiert. Am nächsten Tag wurde die Zellmasse mit vorgewärmten LB-Medium vom Filter geschwemmt und geeignete Verdünnungen auf LB/ Polymyxin B (40 $\mu \mathrm{g} / \mathrm{ml}) /$ Erythromycin $(5 \mu \mathrm{g} / \mathrm{ml})$ ausplattiert. Die Inkubation erfolgte über Nacht bei $30^{\circ} \mathrm{C}$.

\subsubsection{Southern-Blot}

Lösungen und Puffer für den Southern-Blot

\section{Depurinierungslösung}

$\begin{array}{lll}\mathrm{HCl}(37 \%) & 16,66 \mathrm{ml} \\ \mathrm{H}_{2} \mathrm{O} & \text { ad } 800 & \mathrm{ml} \\ \text { autoklavieren } & & \end{array}$

\section{Denaturierungslösung}

$\begin{array}{lll}\mathrm{NaCl} & 70,13 & \mathrm{~g} \\ \mathrm{NaOH} & 16,0 & \mathrm{~g} \\ \mathrm{H}_{2} \mathrm{O} & \mathrm{ad} 800 & \mathrm{ml} \\ \text { autoklavieren } & & \end{array}$


Neutralisierungslösung (pH 7,5)

Tris $48,46 \quad \mathrm{~g}$

$\mathrm{NaCl}$ $140,26 \mathrm{~g}$

$\mathrm{H}_{2} \mathrm{O}$ ad $800 \mathrm{ml}$

pH-Wert mit konz. $\mathrm{HCl}$ einstellen, autoklavieren

Transferlösung $=20 \times \operatorname{SSC}(\mathrm{pH} 7,0)$

$\begin{array}{lll}\mathrm{NaCl} & 140,26 & \mathrm{~g} \\ \mathrm{Na}_{3} \text {-citrat } & 70,58 & \mathrm{~g} \\ \mathrm{H}_{2} \mathrm{O} & \mathrm{ad} 800 & \mathrm{ml}\end{array}$

pH-Wert mit $\mathrm{HCl}$ einstellen, autoklavieren

\section{0\% Blocking Stammlösung}

Blocking Reagent (Roche Cat. No. 1096 176) $5 \quad 5 \quad$ g

Maleinsäurepuffer $\quad$ ad $50 \quad \mathrm{ml}$

In der Mikrowelle kurz erhitzen, bis es beginnt aufzukochen. Anschließend autoklavieren und Lagerung in $10 \mathrm{ml}$ Aliquots bei $-20^{\circ} \mathrm{C}$.

Maleinsäurepuffer (pH 7,5)

$\begin{array}{lll}\text { Maleinsäure } & 9,29 & \mathrm{~g} \\ \mathrm{NaCl} & 7,01 & \mathrm{~g} \\ \mathrm{NaOH} & 5,6 & \mathrm{~g} \\ \mathrm{H}_{2} \mathrm{O} & \mathrm{ad} 800 & \mathrm{ml}\end{array}$

pH-Wert mit konz. $\mathrm{NaOH}$ einstellen, autoklavieren

\section{N-Laurylsarcosin-Lösung}

$\begin{array}{lll}\text { N-Laurylsarcosin } & 10 \% & (\mathrm{w} / \mathrm{v}) \\ \mathrm{H}_{2} \mathrm{O} & \text { ad } 10 & \mathrm{ml} \\ \text { autoklavieren } & & \end{array}$




\section{Prähybridisierungslösung $=$ Hybridisierungslösung}

$\begin{array}{lll}\text { 20x SSC } & 12,5 & \mathrm{ml} \\ 10 \% \text { Blocking Stammlösung } & 5,0 & \mathrm{ml} \\ 10 \% \text { N-Laurylsarcosin } & 0,5 & \mathrm{ml} \\ 10 \% \text { SDS } & 0,1 & \mathrm{ml} \\ \mathrm{H}_{2} \mathrm{O} & \text { ad } 50 & \mathrm{ml}\end{array}$

Lösungen der Reihe nach steril vereinigen und bei $60^{\circ} \mathrm{C}$ lösen, anschließend bei $-20^{\circ} \mathrm{C}$ lagern.

Puffer 1

$\begin{array}{lll}20 \mathrm{xSSC} & 80 & \mathrm{ml} \\ 10 \% \mathrm{SDS} & 8 & \mathrm{ml} \\ \mathrm{H}_{2} \mathrm{O} & \text { ad } 800 & \mathrm{ml}\end{array}$

$\mathrm{H}_{2} \mathrm{O}$ autoklavieren und anschließend steril vereinigen.

Puffer 2

$\begin{array}{lll}20 \mathrm{xSSC} & 4 & \mathrm{ml} \\ 10 \% \text { SDS } & 8 & \mathrm{ml} \\ \mathrm{H}_{2} \mathrm{O} & \text { ad } 800 & \mathrm{ml}\end{array}$

$\mathrm{H}_{2} \mathrm{O}$ autoklavieren und anschließend steril vereinigen.

\section{Puffer 3}

$10 \%$ Blocking Stammlösung $\quad 5 \quad \mathrm{ml}$

Maleinsäurepuffer $\quad 45 \quad \mathrm{ml}$

Puffer frisch ansetzen und nicht autoklavieren.

\section{Waschpuffer}

Tween 20

Maleinsäurepuffer

Puffer frisch ansetzen und nicht autoklavieren.
$150 \mu 1$

ad $50 \mathrm{ml}$ 


\section{Detektionspuffer (pH 9,5)}

$\begin{array}{lcl}\text { Tris } & 9,69 & \mathrm{~g} \\ \mathrm{NaCl} & 4,67 & \mathrm{~g} \\ \mathrm{H}_{2} \mathrm{O} & \text { ad } 800 & \mathrm{ml} \\ \text { pH-Wert mit konz. } \mathrm{HCl} \text { einstellen, autoklavieren }\end{array}$

\section{Detektionslösung}

NBT/BCIP Stock solution (Roche, Cat. No 11681451 001) $\quad 100 \quad \mu l$

Detektionspuffer

ad $5 \mathrm{ml}$

Lösung frisch ansetzen und nicht autoklavieren.

In einem ersten Schritt wurde zunächst die Sonde für den Southern-Blot vorbereitet. Um vergleichend den Einbau des DIG darzustellen, wurde zunächst eine Test-PCR (3.7.1.) angesetzt, in welcher ein $10 \mathrm{mM}$ dNTP-Mix eingesetzt wurde. In einer zweiten PCR, der Sonden-PCR (3.7.1.), wurde ein 5x DIG dNTP-Mix verwendet. Letzterer setzte sich zusammen aus 8,5 $\mu \mathrm{l}$ je $1 \mathrm{mM}$ dNTP-Mix und 1,5 $\mu 1$ DIG DNA Labeling Mix (Roche, Cat. No. 11277065 910). Bei der anschließenden Agarose-Gelelektrophorese $(1,5 \%$ und $80 \mathrm{~V})$ mußte aufgrund des DIG Einbaus in das PCR Produkt eine leicht höher laufende PCR Bande der Sonden PCR zu sehen sein. Die Sonde wurde aufgereinigt (3.4.2.6.), mit $100 \mu \mathrm{l} \mathrm{H}_{2} \mathrm{O}$ eluiert und bis zum Gebrauch bei $-20^{\circ} \mathrm{C}$ gelagert.

Im zweiten Schritt wurden die Proben vorbereitet. Hierzu wurde chromosomale DNA mit geeigneten Restriktionsendonukleasen, welche eine klare Unterscheidung von Wildtyp und Konstrukten zuließen, geschnitten (3.4.3.1.). Die Überprüfung des vollständigen Verdaus erfolgte mittels Agarose-Gelelektrophorese. Im Anschluss daran wurden die Ansätze inaktiviert und bis zum Gebrauch bei $-20^{\circ} \mathrm{C}$ gelagert.

Beim dritten Schritt, dem so genannten Blotten, wurde zunächst 0,8\%ige Agarose in eine Harnischmacher Kammer zu einem etwa $0,5 \mathrm{~cm}$ hohem Gel gegossen. Die Beladung des Geles erfolgte jeweils rechts und links außen mit zwei Leerspuren. Als Marker diente ein DIG-gelabelter $1 \mathrm{~kb}$ Ladder aus GeneRuler $1 \mathrm{~kb}$ Ladder und DIG 1 kb-Ladder (DNA Molecular Weight Marker DIG labeled III, Roche, Cat. No 11218603 910) im Verhältnis 1:9. Die Agarose-Gelelektrophorese wurde bei $80 \mathrm{~V}$ für 90 min durchgeführt. Anschließend wurde das Agarosegel in ein geeignetes Behältnis 
überführt und für 10 min mit Depurinierungslösung überschichtet. Währendessen sollte der Marker gelb werden. Nach zwei kurzen Waschschritten mit $\mathrm{H}_{2} \mathrm{O}$ wurde das Agarosegel zweimal für je 15 min mit Denaturierungslösung überschichtet. Der Marker wurde bei diesem Schritt wieder blau. Es folgten erneut zwei kurze Waschschritte mit $\mathrm{H}_{2} \mathrm{O}$ und im Anschluss daran wurde das Agarosegel zweimal für je 15 min mit Neutralisierungslösung überschichtet. Nach einem abschließenden Waschschritt mit $\mathrm{H}_{2} \mathrm{O}$ wurde das Agarosegel in eine bereits vorbereitete Blot-Apparatur (Bio-Rad Vacuum Blotter Model 785) überführt. Zur Vorbereitung des Aufbaus wurde die Nylonmembran (Roche, Cat. No 11417240 001) und Whatman-Papier $1 \mathrm{~cm}$ breiter und länger als die verwendete Maske zugeschnitten, mit $\mathrm{H}_{2} \mathrm{O}$ angefeuchtet und die BlotApparatur laut Anweisung des Herstellers zusammengesetzt. Der DNA-Transfer erfolgte bei $7 \mathrm{Hg}$ für 45 min. Das Fixieren der DNA auf die noch feuchte Membran wurde in einem Transilluminator für 2 min mit der DNA-Seite nach unten bei $302 \mathrm{~nm}$ durchgeführt.

Für den vierten Schritt, der Hybridisierung, wurde die getrocknete Membran anschließend luftblasenfrei mit der DNA-Seite nach innen in ein Hybridisierungsröhrchen überführt und mit Prähybridisierungslösung $\left(20 \mathrm{ml} / 100 \mathrm{~cm}^{2}\right)$ bei $68^{\circ} \mathrm{C}$ für $90 \mathrm{~min}$ in einem Hybridisierungsofen inkubiert. Parallel hierzu wurde die Sonde für 5 min bei $98^{\circ} \mathrm{C}$ denaturiert und anschließend sofort auf Eis gelagert. Zur eigentlichen Hybridisierung, welche für 16 Stunden bei $68^{\circ} \mathrm{C}$ erfolgte, wurde die Sonde direkt in die Prähybridisierungslösung im Hybridisierungsröhrchen gegeben. Anschließend wurde die Hybridisierungslösung zum Waschen der Membran durch 50 ml Puffer 1 ersetzt und zweimal für je 10 min bei Raumtemperatur inkubiert. Dieser wurde wiederum durch $50 \mathrm{ml}$ auf $68^{\circ} \mathrm{C}$ vorgewärmten Puffer 2 ersetzt und es folgte eine Inkubation für zweimal $20 \mathrm{~min}$ bei $68^{\circ} \mathrm{C}$.

Zur Detektion, dem fünften Schritt, wurde die Membran in ein geeignetes, zu schwenkendes Behältnis überführt, mit $50 \mathrm{ml}$ Puffer 3 überschichtet und für $30 \mathrm{~min}$ bei Raumtemperatur inkubiert. Parallel hierzu wurden Anti Digoxigenin-AP Fab Fragmente (Roche, Cat. No 11093274 910) für 5 min bei $13000 \mathrm{U} / \mathrm{min}$ zentrifugiert und 5 l des Überstandes direkt zum Puffer 3 gegeben. Es folgte eine weitere Inkubation für $30 \mathrm{~min}$ bei Raumtemperatur. Zum Entfernen des ungebundenen Antikörpers wurde die Membran zweimal für je $20 \mathrm{~min}$ mit $50 \mathrm{ml}$ Waschpuffer überschichtet. Nach einer 5 minütigen Inkubation mit $50 \mathrm{ml}$ Detektionspuffer wurde die Membran in Folie 
eingeschweißt und unter Zugabe der Detektionslösung $\left(5 \mathrm{ml} / 100 \mathrm{~cm}^{2}\right)$ lichtgeschützt für $30 \mathrm{~min}$ bzw. bis eine deutliche Farbreaktion zu erkennen war inkubiert. Das Abstoppen der Reaktion erfolgte durch waschen mit $\mathrm{H}_{2} \mathrm{O}$. Die Membran wurde anschließend getrocknet und mit dem Transilluminator (GE Healthcare ImageQuant ${ }^{\mathrm{TM}}$ 400) dokumentiert.

\section{5. $\quad$ Erstellung von clean deletion - Mutanten}

Zur Erstellung dieser Mutanten sollte das Zielgen durch ein stark verkürztes Fragment des gleichen Gens in B. licheniformis mittels homologer Rekombination ausgetauscht und somit inaktiviert werden. Zunächst wurde mittels GeneSOEing (gene splicing by overlap extension, nach Horton et al., 1989) ein Deletionskonstrukt erzeugt. Hierzu wurden mittels getrennten PCR-Reaktionen (3.7.2.) zwei Flanken A und B erzeugt, welche den $\mathrm{zu}$ deletierenden Bereich des Gens umgeben. Die verwendeten Primer waren dabei so konstruiert, dass die jeweils äußeren Primer Restriktionsschnittstellen besaßen und die jeweils inneren Primer Extensions, welche revers komplementär zueinander waren. In einer weiteren PCR fusionierten diese Extensions miteinander und das daraus entstandene Produkt wurde ausgehend von den äußeren Primern amplifiziert (3.7.2.). Nach der Aufreinigung des Deletionskonstruktes (3.4.2.6.) wurde dieses mit Restriktionsendonukleasen geschnitten (3.4.3.1.). Mit dem entsprechend geschnittenen Vektor wurde das Konstrukt im Anschluss ligiert (3.4.3.3.). Sollte der DNA-Transfer mittels Protoplasten-Transformation (3.4.4.2.) erfolgen, wurde der Vektor pMAD für die Ligation gewählt. Für den DNA-Transfer mittels Konjugation (3.4.4.3.) wurde der Vektor pKVM1 verwendet. Obiger Ligationsansatz wurde anschließend in E. coli transformiert (3.4.4.1.). Um zu überprüfen, ob die Transformanten den Vektor mit Deletionskonstrukt aufgenommen hatten, wurden diese entweder mittels Kolonie-PCR (3.7.3.) mit plasmidspezifischen Primern oder durch die Eckhardt-Lyse (3.4.2.8.) überprüft. Aus geeigneten Transformanten wurde im weiteren das Deletionskonstrukt isoliert (3.4.2.5.) und in die Protoplasten-Transformation eingesetzt, oder sie dienten direkt als Donor für die Konjugation mit B. licheniformis MW3.

Sowohl der zur Protoplasten-Transformation verwendete Vektor pMAD, als auch der konjugative Vektor pKVM1 besitzen einen temperatursensitiven Replikationsursprung 
(oriR pE194 ${ }^{\text {ts }}$, Villafane et. al., 1987). Dieser ermöglicht bei einer Temperatur von $30^{\circ} \mathrm{C}$, nicht aber bei einer Temperatur von $37^{\circ} \mathrm{C}$ oder darüber eine stabile Replikation. Um das 1. Rekombinationsereignis über homologe Bereiche des Zielgens einzuleiten wurden Kolonien, welche man aus der Protoplasten-Transformation bzw. Konjugation erhalten hatte, bei nicht-permissiver Temperatur $\left(42^{\circ} \mathrm{C}\right)$ in Erythromycin-haltigem Medium $(5 \mu \mathrm{g} / \mathrm{ml})$ kultiviert. Die Selektion der Integranten erfolgte anschließend mit geeigneten Verdünnungen mittels Blau-Weiß-Screening auf X-Gal-haltigen Selektivplatten (NB/ $50 \mathrm{mM}$ Glucose/ $5 \mu \mathrm{g} / \mathrm{ml}$ Erythromycin). Die verwendeten Vektoren enthalten das Gen bgaB, welches für eine B-Galaktosidase kodiert. Diese wird konstitutiv über den starken Promoter PclpB exprimiert und bewirkt eine Blaufärbung der Integranten-Kolonien durch die Spaltung des chromogenen Substrates X-Gal. Um die chromosomale $\beta$-Galaktosidase von B. licheniformis zu reprimieren wurde dem Medium $50 \mathrm{mM}$ Glucose zugesetzt. Aus geeigneten Kolonien wurde mittels Schnellpräparation (3.4.2.4.) DNA extrahiert, welche als Template für eine PCRReaktion zum Nachweis des integrierten Plasmids diente. Dieser Nachweis erfolgte dabei mit einem plasmidspezifischen Primer und einem Primer, welcher außerhalb des zu deletierenden Genes im Genom bindet. Durch anschließendes Wachstum bei permissiver Temperatur $\left(30^{\circ} \mathrm{C}\right)$ wurde das 2 . Rekombinationsereignis eingeleitet und das Plasmid ging nach mehreren Passagen in Medium ohne Selektionsdruck verloren. Hierbei konnte entweder das chromosomale Wildtypgen oder aber das Deletionskonstrukt mit dem Plasmid herausgeschnitten werden (Arnaud et al., 2004). Durch ausplattieren geeigneter Verdünnungen auf X-Gal-haltigem Medium konnten Kolonien identifiziert werden, bei denen das 2. Rekombinationsereignis stattgefunden hatte. Diese erschienen aufgrund des Verlustes des Plasmids mit der konstitutiv exprimierten $\beta$-Galaktosidase weiß. Wiederum wurde aus geeigneten Kolonien DNA extrahiert (3.4.2.1.), welche als Template für eine PCR-Reaktion zum Nachweis der Deletion diente. Erreicht wurde dieses durch die Verwendung von Primern, welche außerhalb des zu deletierenden Bereichs im Genom binden. Dadurch konnte aufgrund der Größe des erhaltenen PCR-Produktes zwischen potentieller Mutante und Wildtyp unterschieden werden. Mit den gleichen Primern wurde die Deletion durch Sequenzierung überprüft. Mittels Southern-Blot wurde der Verlust des Plasmids überprüft. 


\subsection{Techniken für das Arbeiten mit RNA}

\subsubsection{Lösungen und Puffer zum Arbeiten mit RNA}

Der Umgang mit RNA erfordert äußerst sauberes Arbeiten, um eine Kontamination mit den sehr stabilen RNasen zu vermeiden. Aus diesem Grund wurden alle thermostabilen Lösungen, Glaswaren, Pipettenspitzen und andere Materialien, die für das Arbeiten mit RNA notwendig waren, $2 \mathrm{x}$ bei $121^{\circ} \mathrm{C}$ und 2 bar für 20 min autoklaviert. Die Arbeiten wurden ausschließlich mit Handschuhen durchgeführt. Der Arbeitsplatz und sämtliche notwendigen Gerätschaften wie z.B. Pipetten wurden wiederholt mit 70\%igem Ethanol (v/v) gesäubert.

\section{5x DNase Puffer}

$\begin{array}{lll}\mathrm{MgSO}_{4} & 25 & \mathrm{mM} \\ \text { Na-Acetat, pH 5,0 } & 500 & \mathrm{mM} \\ \text { 2x autoklaviert } & & \end{array}$

\section{0x MOPS-Puffer (pH 7,0)}

$\begin{array}{lll}\text { MOPS } & 200 & \mathrm{mM} \\ \text { Na-Acetat } & 50 & \mathrm{mM} \\ \text { EDTA } & 10 & \mathrm{mM}\end{array}$

pH-Wert mit $\mathrm{NaOH}$ einstellen

\section{RNA-Auftragspuffer}

$\begin{array}{lcc}\text { Formamid } & 6,5 & \mathrm{ml} \\ \text { Formaldehyd } & 1,2 & \mathrm{ml} \\ \text { 10x MOPS } & 2,0 & \mathrm{ml} \\ 50 \% \text { Saccharose } & 0,4 & \mathrm{ml} \\ \text { Bromphenolblau } & 20 & \mathrm{mg} \\ \text { Xylencyanol } & 20 & \mathrm{mg} \\ \text { Ethidiumbromid }(10 \mathrm{mg} / \mathrm{ml}) & 5 & \mu l\end{array}$




\section{TE-Puffer (pH 8,0)}

Tris

$10 \mathrm{mM}$

EDTA

$1 \mathrm{mM}$

2x autoklaviert

\subsubsection{Isolierung von RNA aus B. licheniformis}

Für die Isolierung von RNA aus Zellen von B. licheniformis ist ein enzymatischer Zellaufschluss ungeeignet. Die Inkubationszeiten und -temperaturen hätten einen vorzeitigen Abbau der RNA zur Folge, da RNA eine kurze Halbwertszeit von wenigen Minuten aufweist. Aus diesem Grund wurden die Zellen mit dem Dismembrator im tiefgekühlten Zustand aufgeschlossen (vgl. 3.4.2.1.).

Um RNA aus B. licheniformis-Zellen zu isolieren, wurden Aliquots von $40 \mathrm{ml}$ aus dem Kulturgefäß entnommen, mit jeweils $10 \mathrm{ml}$ vorgekühltem Methanol versetzt und zügig bei $-20^{\circ} \mathrm{C}$ geerntet (9000 U/min, $5 \mathrm{~min}$ ). Der Überstand wurde verworfen und das Pellet in flüssigen Stickstoff gegeben und anschließend bei $-70^{\circ} \mathrm{C}$ gelagert.

Zum Zellaufschluß wurden die Pellets der $40 \mathrm{ml}$ Aliquots in $1 \mathrm{ml}$ sterilem TE-Puffer resuspendiert und bei $-9^{\circ} \mathrm{C}$ gewaschen $(13000 \mathrm{U} / \mathrm{min}, 2 \mathrm{~min})$. Im Anschluss daran wurde das Pellet in $200 \mu \mathrm{l}$ sterilem TE-Puffer resuspendiert. Parallel wurde das Teflongefäß mit der Chromstahlkugel des Dismembrators in flüssigem Stickstoff gekühlt. Die resuspendierten Zellen wurden in den etwas flüssigen Stickstoff und die Chromstahlkugel enthaltenden PTFE-Zylinder pipettiert, das Gefäß verschlossen und in die Zellmühle eingespannt. Während des Aufschlusses bei $1600 \mathrm{U} / \mathrm{min}$ für $3 \mathrm{~min}$ wurden die Zellen zu einem weißen gekühlten Zellpulver zermahlen. Dieses wurde vorsichtig in $4 \mathrm{ml}$ RLT-Puffer des $\mathrm{RNeasy}^{\circledR}$ Midi Kits (Qiagen, Cat no. 75144), welchem zuvor $40 \mu \mathrm{l}$ Mercaptoethanol zugesetzt wurden, resuspendiert. Dieser Puffer wirkt aufgrund einer hohen Guanidiniumhydrochlorid-Konzentration stark proteindenaturierend, so dass die gelösten Zellbestandteile bei $4^{\circ} \mathrm{C}$ über Nacht bis zur weiteren Präparation aufbewahrt werden konnten.

Die weitere Isolierung und Reinigung der RNA erfolgte mit Hilfe des RNeasy® Midi Kits nach Anleitung des Herstellers. Für die Eluation der RNA wurden 2 x $150 \mu 1$ RNase freies und steriles $\mathrm{H}_{2} \mathrm{O}$ verwendet. Die RNA konnte bei $-70^{\circ} \mathrm{C}$ bis zur weiteren Verwendung gelagert werden. 


\subsubsection{DNase-Verdau und Kontrolle der RNA}

Um Verunreinigungen der RNA mit Resten chromosomaler DNA zu vermeiden, erfolgte eine Behandlung der RNA-Lösung mit DNase. Dazu wurden zu den maximal $300 \mu \mathrm{l}$ wässriger RNA-Lösung, hervorgegangen aus der RNA Isolation, $65 \mu \mathrm{l}$

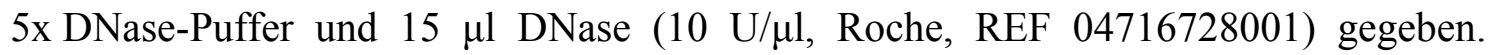
Während einer Inkubation des Ansatzes für 90 min bei $25^{\circ} \mathrm{C}$ wurde verbliebene DNA durch die DNase hydrolysiert. Im folgenden Inkubationsschritt von $10 \mathrm{~min}$ bei $70^{\circ} \mathrm{C} \mathrm{im}$ Thermoblock wurde die DNase inaktiviert. Um sicher zu gehen, dass sämtliche DNA abgebaut wurde, erfolgte eine PCR (3.7.4.) mit spezifischen Primern. Chromosomale DNA wurde als Positivkontrolle mitgeführt. Die PCR-Ansätze wurden anschließend gelelektrophoretisch aufgetrennt, wobei lediglich bei der Positivkontrolle ein Amplifikationsprodukt erscheinen durfte. Im anderen Falle musste die DNaseBehandlung wiederholt werden.

\subsubsection{Extraktion und Fällung von RNA}

\section{Extraktion von RNA mit Phenol/Chloroform/Isoamylalkohol}

Die meisten Nukleinsäurepräparationen enthalten unerwünschte Proteinkontaminationen. Diese können mit einer Form der Phenol/Chloroform-Extraktion entfernt werden. Hierzu wurde der RNA 1 Vol saures Phenol zugegeben. Der Ansatz wurde $10 \mathrm{sec}$ gevortext und $3 \mathrm{~min}$ bei $13000 \mathrm{U} / \mathrm{min}$ zentrifugiert. In diesem Schritt erfolgte eine Phasentrennung. Die obere, wässrige Phase enthielt die gelöste RNA, die denaturierten Proteine hingegen befanden sich in der Interphase. Die obere Phase wurde, unter Vermeidung der Interphase, in ein neues Eppendorf-Reaktionsgefäß überführt. Die abgenommene RNA-haltige Phase wurde anschließend mit 1 Vol Chloroform/Isoamylalkohol (24/1 v/v) versetzt, ebenfalls $10 \mathrm{sec}$ gevortext, $3 \mathrm{~min}$ bei $13000 \mathrm{U} / \mathrm{min}$ zentrifugiert und die entstandene obere Phase erneut in ein neues Eppendorf-Reaktionsgefäß überführt. Um die RNA aufzukonzentrieren erfolgte als nächstes eine Fällung mit Ethanol. 


\section{Fällung der RNA mit Ethanol}

Die in $\mathrm{H}_{2} \mathrm{O}$ gelöste RNA wurde mit $1 / 10$ Vol Na-Acetat $(3,3 \mathrm{M}, \mathrm{pH}$ 5,0) und 2,5 Vol $-20^{\circ} \mathrm{C}$ kaltem, unvergällten Ethanol (96\%) versetzt und gemischt. Die Fällung erfolgte bei $-20^{\circ} \mathrm{C}$ über Nacht oder 2 Stunden bei $-70^{\circ} \mathrm{C}$. Nach einem Zentrifugationsschritt von $30 \mathrm{~min}$ bei $13000 \mathrm{U} / \mathrm{min}$ und $-9^{\circ} \mathrm{C}$ wurde der Ethanol vorsichtig mit der Pipette abgenommen, ohne das transparente RNA-Pellet zu verletzen. Mit $1 \mathrm{ml}-20^{\circ} \mathrm{C}$ kaltem $70 \%$ igen Ethanol (v/v) wurde das Pellet für $15 \mathrm{~min}$ bei $13000 \mathrm{U} / \mathrm{min}$ und $-9^{\circ} \mathrm{C}$ gewaschen und der Ethanol erneut vorsichtig abgenommen. Das EppendorfReaktionsgefäß mit dem RNA-Pellet wurde offen in einem mit Aluminiumfolie verschlossenem, zuvor zweimal autoklaviertem, Becherglas bei $37^{\circ} \mathrm{C}$ für ca. $15 \mathrm{~min}$ getrocknet, bis der Ethanol verdampft war. Gelöst wurde das Pellet in $15 \mu 1$ RNase freiem $\mathrm{H}_{2} \mathrm{O} 2$ Stunden auf Eis. Die Lagerung der RNA erfolgte bei $-70^{\circ} \mathrm{C}$.

\subsubsection{RNA-Konzentrationsbestimmung}

Die Bestimmung der Konzentration von RNA erfolgte analog der Konzentrationsbestimmung von DNA (3.4.2.10.). Eine $\mathrm{OD}_{260}$ von 1 entsprach einer Konzentration von $40 \mu \mathrm{g} / \mathrm{ml}$ RNA (Sambrook et al., 1989).

\subsubsection{Qualitätskontrolle der RNA}

\subsubsection{Elektrophorese von RNA}

Für die elektrophoretische Auftrennung der RNA wurden denaturierende Agarosegele verwendet. Zur Herstellung wurden zunächst $1 \mathrm{~g}$ Agarose in $72 \mathrm{ml} \mathrm{H}_{2} \mathrm{O}$ aufgekocht. Nach Abkühlen auf $60^{\circ} \mathrm{C}$ wurden unter dem Abzug $10 \mathrm{ml}$ 10x MOPS-Puffer sowie $18 \mathrm{ml}$ Formaldehyd zugegeben und gut gemischt. Die Lösung wurde anschließend in einen abgegrenzten Bereich einer Gellaufkammer gegossen und ein Taschenkamm eingesetzt. Nach dem Aushärten wurde das Gel mit 1x MOPS-Puffer überschichtet und der Taschenkamm entfernt. Zur Probenvorbereitung wurde das $1 \mu \mathrm{g}$ RNA entsprechende Volumen mit $\mathrm{H}_{2} \mathrm{O}$ auf $10 \mu \mathrm{l}$ aufgefüllt, anschließend mit 1 Vol RNAAuftragspuffer gemischt und für 15 min bei $65^{\circ} \mathrm{C}$ im Heizblock denaturiert. Nach einer 
Inkubation der Proben für 1 - 2 min auf Eiswasser wurde das Gel zügig beladen. Zur Bestimmung der Transkriptgröße wurde ein identisch behandelter DIG-markierter RNA-Größenstandard (RNA Molecular Weight Marker I, DIG-labeled, Roche 1526529 ) mitgeführt. Die Elektrophorese erfolgte bei $100 \mathrm{~V}$ (Regel: $\sim 5 \mathrm{~V} / \mathrm{cm}$ Elektrodenabstand) für ca. 2 Stunden, bis die vordere Bande $3 / 4$ der Gellänge durchlaufen hatte. Zur Dokumentation wurde das Gel unter UV-Licht fotografiert.

\subsubsection{Bioanalyzer}

Eine weitere Möglichkeit der Auftrennung von RNA stellt der Agilent 2100 Bioanalyzer dar. Die verwendeten RNA Chips des RNA 6000 Nano Kits (Agilent, Cat. No 5067-1511) wurden nach Anweisung des Herstellers präpariert und beladen. Als Matrix diente hierbei ein Gel-Farbstoff-Gemisch. Während der Analyse wandern die Proben aus den beladenen Wells in den Separationskanal des RNA-Chips und werden dort elektrophoretisch aufgetrennt. Anschließend werden die Komponenten über ihre Fluoreszenz detektiert und in ein gelähnliches Bild und ein Elektropherogramm umgewandelt.

\subsubsection{Kontrolle der RNA-Integrität}

Die Qualität der RNA wurde mittels 'Reverser Transkription' (3.7.5.), wie bei der Kontrolle der RNA (3.6.3.), mit spezifischen Primern überprüft. Auch hier erfolgte anschließend eine Auftrennung der Ansätze durch Agarose-Gelelektrophorese, wobei hier für jeden RNA enthaltenden Ansatz ein Amplifikationsprodukt zu sehen sein musste.

\subsection{Polymerase-Kettenreaktion (PCR)}

Die PCR (polymerase chain reaction) dient als in vitro-Methode, welche es ermöglicht spezifische DNA-Fragmente aus einem komplexen DNA-Gemisch enzymatisch zu amplifizieren. Dafür sind Matrizen-DNA (Template), ein Oligonukleotid-Primerpaar, dNTP's, sowie eine thermostabile DNA-Polymerase mit zugehörigem Puffer 
notwendig. Im ersten Schritt der PCR, der Denaturierung, wird die doppelsträngige DNA durch Erhitzen in einzelsträngige DNA überführt. Durch Absenken der Temperatur können sich im zweiten Schritt, dem Annealing, zwei OligonukleotidPrimer an die Matrizen-DNA anlagern. Die Oligonukleotid-Primer wurden so ausgewählt, dass sie die zu amplifizierende Region flankieren. Bei der Elongation, dem dritten Schritt der PCR, werden die beiden Primer mit Hilfe einer thermostabilen Polymerase komplementär zur ursprünglichen doppelsträngigen DNA verlängert. Es wird zur Amplifikation eine bestimmte Anzahl an Zyklen durchgeführt, wodurch die von den Primern flankierte Region exponentiell akkumuliert wird.

In dieser Arbeit wurde die PCR zu unterschiedlichen Zwecken eingesetzt, neben der Herstellung von Sonden für den Southern-Blot, auch zur Herstellung von Deletionskonstrukten und zur Überprüfung einzelner Zwischenschritte der Erstellung von clean deletion - Mutanten. Außerdem erfolgte mittels PCR die Überprüfung auf DNA-Reste, ebenso wie die Überprüfung von RNA mittels vorangegangener 'Reverser Transkription' und sie wurde zur Expressionsanalyse mittels real-time RT-PCR eingesetzt. Als Primer wurden, wenn nicht anders erwähnt, Oligonukleotide zwischen $20 \mathrm{bp}$ und $22 \mathrm{bp}$ und einer Schmelztemperatur zwischen $55^{\circ} \mathrm{C}$ und $60^{\circ} \mathrm{C}$ verwendet. Nach der Amplifikation wurden die PCR-Produkte gelelektrophoretisch überprüft.

\subsubsection{PCRs für den Southern-Blot}

Diese PCRs dienten der Vorbereitung und Generierung der Sonden für den SouthernBlot. Es wurden Fragmente mit einer erwarteten Größe von bis zu 750 bp amplifiziert. Verwendet wurde die Hot Start Phire ${ }^{\mathrm{TM}}$ DNA-Polymerase der Firma Finnzymes.

\section{$\underline{50 \mu 1 \text { Test-PCR-Ansatz: }}$}

$\begin{array}{llll}1 & \mu \mathrm{l} & \text { chromosomale DNA } & (100 \mathrm{ng} / \mu \mathrm{l}) \\ 2,5 & \mu \mathrm{l} & \text { Primer A } & (10 \mu \mathrm{M}) \\ 2,5 & \mu \mathrm{l} & \text { Primer B } & (10 \mu \mathrm{M}) \\ 1 & \mu \mathrm{l} & \text { dNTP-Mix } & (10 \mathrm{mM}) \\ 10 & \mu \mathrm{l} & 5 \mathrm{x} \text { Phire-Puffer } & \\ 1 & \mu \mathrm{l} & \text { Phire DNA-Polymerase } & \\ 32 & \mu \mathrm{l} & \mathrm{H}_{2} \mathrm{O} & \end{array}$


$\underline{50 \mu l \text { Sonden-PCR-Ansatz: }}$

$\begin{array}{llll}1 & \mu \mathrm{l} & \text { chromosomale DNA } & (100 \mathrm{ng} / \mu \mathrm{l}) \\ 2,5 & \mu \mathrm{l} & \text { Primer A } & (10 \mu \mathrm{M}) \\ 2,5 & \mu \mathrm{l} & \text { Primer B } & (10 \mu \mathrm{M}) \\ 10 & \mu \mathrm{l} & 5 \mathrm{x} \text { DIG dNTP-Mix } & \\ 10 & \mu \mathrm{l} & 5 \mathrm{x} \text { Phire-Puffer } & \\ 1 & \mu \mathrm{l} & \text { Phire DNA-Polymerase } & \\ 23 & \mu \mathrm{l} & \mathrm{H}_{2} \mathrm{O}\end{array}$

PCR-Programm:

$$
\begin{array}{lll}
\text { LID }= & 110^{\circ} \mathrm{C} & \\
1 & \mathrm{~T}=98^{\circ} \mathrm{C} & 00: 03: 00 \\
2 & \mathrm{~T}=98^{\circ} \mathrm{C} & 00: 00: 10 \\
3 & \mathrm{~T}=57^{\circ} \mathrm{C} & 00: 00: 10 \\
4 & \mathrm{~T}=72^{\circ} \mathrm{C} & 00: 00: 40 \\
5 & \text { GOTO } 2 \text { REPEAT } 29 \mathrm{x} \\
6 & \mathrm{~T}=72^{\circ} \mathrm{C} & 00: 01: 00 \\
7 & \mathrm{~T}=8^{\circ} \mathrm{C} & \text { FOREVER }
\end{array}
$$

\subsubsection{GeneSOEing-PCRs}

Mit den folgenden PCRs wurden Deletionskonstrukte im Rahmen der Erstellung von clean deletion - Mutanten erzeugt. Es wurden Fragmente mit einer erwarteten Größe zwischen 700 bp und 1700 bp amplifiziert. Eingesetzt wurde die Hot Start Phire ${ }^{\mathrm{TM}}$ DNA-Polymerase der Firma Finnzymes. 


\section{Erstellung der Flanken}

$\underline{50 \mu l \text { Ansatz: }}$

$1 \mu \mathrm{l} \quad$ chromosomale DNA $\quad(250 \mathrm{ng} / \mu \mathrm{l})$

2,5 $\mu \mathrm{l} \quad$ Forward Primer Flanke A bzw. B $(10 \mu \mathrm{M})$

2,5 $\mu \mathrm{l} \quad$ Reverse Primer Flanke A bzw. B $(10 \mu \mathrm{M})$

$1 \mu \mathrm{l}$ dNTP-Mix $\quad(10 \mathrm{mM})$

$10 \mu \mathrm{l} \quad 5 \mathrm{x}$ Phire-Puffer

$1 \quad \mu l \quad$ Phire DNA-Polymerase

$32 \mu \mathrm{l} \quad \mathrm{H}_{2} \mathrm{O}$

\section{Fusion der Flanken}

$50 \mu$ Ansatz:

$\begin{array}{llll}1 & \mu \mathrm{l} & \text { Flanke A } & \\ 1 & \mu \mathrm{l} & \text { Flanke B } & \\ 2,5 & \mu \mathrm{l} & \text { Forward Primer Flanke A } & (10 \mu \mathrm{M}) \\ 2,5 & \mu \mathrm{l} & \text { Reverse Primer Flanke B } & (10 \mu \mathrm{M}) \\ 1 & \mu \mathrm{l} & \text { dNTP-Mix } & (10 \mathrm{mM}) \\ 10 & \mu \mathrm{l} & 5 \mathrm{x} \text { Phire-Puffer } & \\ 1 & \mu \mathrm{l} & \text { Phire DNA-Polymerase } & \\ 31 & \mu \mathrm{l} & \mathrm{H}_{2} \mathrm{O} & \end{array}$

\section{PCR-Programm:}

$$
\begin{array}{lll}
\text { LID }= & 110^{\circ} \mathrm{C} & \\
1 & \mathrm{~T}=98^{\circ} \mathrm{C} & 00: 03: 00 \\
2 & \mathrm{~T}=98^{\circ} \mathrm{C} & 00: 00: 10 \\
3 & \mathrm{~T}=57^{\circ} \mathrm{C} & 00: 00: 10 \\
4 & \mathrm{~T}=72^{\circ} \mathrm{C} & 00: 00: 40 \\
5 & \text { GOTO } 2 \text { REPEAT } 29 \mathrm{x} \\
6 & \mathrm{~T}=72^{\circ} \mathrm{C} & 00: 01: 00 \\
7 & \mathrm{~T}=8^{\circ} \mathrm{C} & \text { FOREVER }
\end{array}
$$




\subsubsection{Kolonie-PCR}

Zur Überprüfung von Transformaten im Rahmen der Erstellung von clean deletion - Mutanten wurden mit dieser PCR Fragmente mit einer erwarteten Größe von maximal 2000 bp amplifiziert. Anstelle der chromosomalen DNA wurde Koloniematerial eingesetzt und in 9,5 $\mu \mathrm{H}_{2} \mathrm{O}$ resuspendiert. Die Lyse der Zellen fand durch eine verlängerte Vorabdenaturierung statt. Als Template für die mitgeführte Positivkontrolle diente Plasmid-DNA. Verwendet wurde die Taq DNA-Polymerase der Firma Qiagen.

$20 \mu$ Ansatz:

$\begin{array}{llll}4 & \mu \mathrm{l} & \text { Primer A } & (5 \mu \mathrm{M}) \\ 4 & \mu \mathrm{l} & \text { Primer B } & (5 \mu \mathrm{M}) \\ 0,4 & \mu \mathrm{l} & \text { dNTP-Mix } & (10 \mathrm{mM}) \\ 2 & \mu \mathrm{l} & \text { 10x S-Puffer } & \\ 0,1 & \mu \mathrm{l} & \text { Taq DNA-Polymerase } & (5 \mathrm{U} / \mu \mathrm{l}) \\ 9,5 & \mu \mathrm{l} & \mathrm{H}_{2} \mathrm{O} & \end{array}$

Programm:

$\mathrm{LID}=110^{\circ} \mathrm{C}$

$1 \quad \mathrm{~T}=98^{\circ} \mathrm{C} \quad 00: 08: 00$

$2 \quad \mathrm{~T}=96^{\circ} \mathrm{C} \quad 00: 00: 30$

$3 \quad \mathrm{~T}=59^{\circ} \mathrm{C} \quad 00: 00: 30$

$4 \quad \mathrm{~T}=72^{\circ} \mathrm{C} \quad 00: 02: 30$

5 GOTO 2 REPEAT $24 \mathrm{x}$

$6 \quad \mathrm{~T}=72^{\circ} \mathrm{C} \quad 00: 10: 00$

$7 \quad \mathrm{~T}=8^{\circ} \mathrm{C} \quad$ FOREVER

\subsubsection{PCR zur Überprüfung auf DNA-Reste}

Diese PCR wurde für die Amplifikation von Fragmenten mit einer erwarteten Größe zwischen 500 bp und maximal 1000 bp verwendet. Eingesetzt wurde die Taq DNAPolymerase der Firma Qiagen. 
$20 \mu$ Ansatz:

$\begin{array}{llll}1 & \mu \mathrm{l} & \text { chromosomale DNA } & (500 \mathrm{ng} / \mu \mathrm{l}) \\ 4 & \mu \mathrm{l} & \text { Primer A } & (5 \mu \mathrm{M}) \\ 4 & \mu \mathrm{l} & \text { Primer B } & (5 \mu \mathrm{M}) \\ 0,4 & \mu \mathrm{l} & \text { dNTP-Mix } & (10 \mathrm{mM}) \\ 2 & \mu \mathrm{l} & 10 x \text { S-Puffer } & \\ 0,1 & \mu \mathrm{l} & \text { Taq DNA-Polymerase } & (5 \mathrm{U} / \mu \mathrm{l}) \\ 8,5 & \mu \mathrm{l} & \mathrm{H}_{2} \mathrm{O} \text { (RNase frei) } & \end{array}$

Programm:

$\mathrm{LID}=110^{\circ} \mathrm{C}$

$1 \quad \mathrm{~T}=96^{\circ} \mathrm{C} \quad$ 00:02:00

$2 \quad \mathrm{~T}=96^{\circ} \mathrm{C} \quad 00: 00: 30$

$3 \quad \mathrm{~T}=59^{\circ} \mathrm{C} \quad 00: 00: 30$

$4 \quad \mathrm{~T}=72^{\circ} \mathrm{C} \quad 00: 01: 30$

5 GOTO 2 REPEAT $24 \mathrm{x}$

$6 \quad \mathrm{~T}=72^{\circ} \mathrm{C} \quad 00: 10: 00$

$7 \quad \mathrm{~T}=8^{\circ} \mathrm{C} \quad$ FOREVER

\subsubsection{Reverse Transkriptions-PCR}

Bei einer Reversen Transkriptions-PCR wird mit Hilfe einer reversen Transkriptase RNA in cDNA (complementary DNA) umgeschrieben, welche anschließend mittels PCR amplifiziert werden kann. Die reverse Transkription und die anschließende PCR konnten mit dem in dieser Arbeit verwendeten QIAGEN $^{\circledR}$ OneStep RT-PCR Kit (Cat no. 210210) in einem Schritt durchgeführt werden. 
$25 \mu$ Ansatz:

\begin{tabular}{lrlc}
500 & ng & Template RNA & \\
4 & $\mu \mathrm{l}$ & Primer A & $(5 \mu \mathrm{M})$ \\
4 & $\mu \mathrm{l}$ & Primer B & $(5 \mu \mathrm{M})$ \\
1 & $\mu \mathrm{l}$ & dNTP-Mix & $(10 \mathrm{mM})$ \\
5 & $\mu \mathrm{l}$ & $5 \mathrm{x}$ 'OneStep RT-PCR Puffer' \\
1 & $\mu \mathrm{l}$ & 'OneStep RT-PCR Enzyme Mix' \\
ad $25 \mu \mathrm{l}$ & \multicolumn{2}{l}{$\mathrm{H}_{2} \mathrm{O}$ (RNase frei) }
\end{tabular}

Programm:

$\mathrm{LID}=110^{\circ} \mathrm{C}$

$1 \mathrm{~T}=50^{\circ} \mathrm{C} \quad 00: 30: 00$

$2 \mathrm{~T}=96^{\circ} \mathrm{C} \quad 00: 15: 00$

$3 \quad \mathrm{~T}=96^{\circ} \mathrm{C} \quad 00: 00: 30$

$4 \quad \mathrm{~T}=59^{\circ} \mathrm{C} \quad 00: 00: 30$

$5 \quad \mathrm{~T}=72{ }^{\circ} \mathrm{C} \quad 00: 02: 00$

6 GOTO 3 REPEAT $24 \mathrm{x}$

$7 \quad \mathrm{~T}=72^{\circ} \mathrm{C} \quad 00: 10: 00$

$8 \quad \mathrm{~T}=8^{\circ} \mathrm{C} \quad$ FOREVER

\subsubsection{Quantitative real-time RT-PCR}

Die quantitative real-time RT-PCR ist eine Methode zur Quantifizierung von Nukleinsäuren und damit zur Expressionsanalyse einzelner Gene geeignet. Sie diente in dieser Arbeit zur Verifizierung der DNA-Microarray Ergebnisse. Ein entscheidendes Werkzeug der real-time RT-PCR sind unterschiedliche Farbstoffe oder Fluorophore, über deren Signal nach Bindung an die DNA die Kinetik der Polynukleotidsynthese per PCR 'in Echtzeit' beobachtet werden kann. Die Markierung der DNA kann auf unterschiedlichen Wegen erfolgen: nach dem TaqMan Prinzip, mit molecular beacons, hybridization probes oder unter Einsatz eines Farbstoffes wie z.B. SYBR ${ }^{\text {TM }}$ Green. Der entscheidende Vorteil von SYBR ${ }^{\text {TM }}$ Green liegt darin, dass dieser Farbstoff unspezifisch in doppelsträngige DNA eingebaut wird, wohingegen für die anderen genannten Markierungsmöglichkeiten die Synthese spezifischer Sonden notwendig ist. Aus diesem 
Grund wurde in dieser Arbeit SYBR ${ }^{\mathrm{TM}}$ Green verwendet.

Bei der quantitativen real-time RT-PCR wird über das Fluoreszenzsignal indirekt die Zunahme des PCR-Produktes gemessen. Zunächst findet in einer PCR-Reaktion eine annähernd exponentielle Vermehrung der DNA-Fragmente statt. Limitierende Faktoren wie z.B. die Abnahme der dNTP-Konzentration, verminderte Enzymaktivität und / oder die Anhäufung von Pyrophosphat verlangsamen jedoch die Produktbildung in der späten Phase der PCR-Reaktion. Die Quantifizierung bei der real-time RT-PCR erfolgt über den so genannten Ct-Wert, hierbei handelt es sich um die Zykluszahl, bei welcher sich das Fluoreszenzsignal einer Probe das erste Mal signifikant vom Hintergrund abhebt. Anhand einer Standardkurve können definierten Templatemengen Ct-Werte zugewiesen werden. Beim Vergleich zweier Versuchsbedingungen hinsichtlich der Expression eines ausgewählten Gens war eine solche Bestimmung der absoluten Templatemenge über eine Eichgerade nicht erforderlich. Nach folgender Formel kann allein über die Ct-Werte eines ausgewählten Gens unter beiden Versuchsbedingungen im Vergleich zu den Ct-Werten eines konstitutiven Gens, ebenfalls unter beiden Versuchsbedingungen, der Regulationsfaktor ermittelt werden:

$$
\begin{aligned}
& \text { Regulationsfaktor }=2^{-\Delta \Delta \mathrm{Ct}} \\
& \text { mit } \Delta \Delta \mathrm{Ct} \text { für Gen } \mathrm{x}=\left(\mathrm{Ct}_{\mathrm{x}}-\mathrm{Ct}_{\text {konstitutiv }}\right)_{\text {Bedingung I }}-\left(\mathrm{Ct}_{\mathrm{x}}-\mathrm{Ct}_{\text {konstitutiv }}\right)_{\text {Bedingung II }}
\end{aligned}
$$

(Talaat et al., 2002)

Die Primer der ausgewählten Gene wurden mit einer Länge von 20-23 bp und einer Schmelztemperatur von etwa $60^{\circ} \mathrm{C}$ generiert und so gewählt, dass die Länge des erwarteten PCR-Produktes bei ca. 150 bp liegt. Sämtliche Arbeiten wurden unter RNase freien Bedingungen durchgeführt. In dieser Arbeit wurden der QuantiTect ${ }^{\circledR} \mathrm{SYBR}^{\circledR}$ Green RT-PCR Master Mix (Qiagen, Hilden) und das 'iCycler $\mathrm{iQ}^{\mathrm{TM}}$ real-time $\mathrm{PCR}$ Detection System' der Firma Bio-Rad verwendet. Für den Ansatz der real-time RT-PCR wurde zuerst ein Mastermix aus dem QuantiTect Mastermix und dem Enzymmix für alle Proben hergestellt, welcher dann auf die zu testenden RNAs aufgeteilt wurde (Premix). Die Primer wurden in 96 well PCR Platten (Bio-Rad, iCycler iQ ${ }^{\mathrm{TM}}$ PCR Plates, Cat. No 2239441, PCR Tube Strips ${ }^{\mathrm{TM}}$ Flat Cap Strips, Cat. No TCS0803) vorgelegt und $20 \mu \mathrm{l}$ Premix zugegeben. Auf diese Weise wurden mit größtmöglicher Wahrscheinlichkeit alle Reaktionskomponenten gleichmäßig auf die 
einzelnen Ansätze verteilt.

$25 \mu$ Ansatz:

400 ng RNA

2,5 $\mu \mathrm{l} \quad$ Primer A $5 \mu \mathrm{M}$

2,5 $\mu \mathrm{l} \quad$ Primer B $5 \mu \mathrm{M}$

12,5 $\mu 1 \quad$ 'QuantiTect Mastermix'

0,5 $\mu \mathrm{l} \quad$ Enzymmix

ad $25 \mu \mathrm{l} \quad \mathrm{H}_{2} \mathrm{O}$ (RNase frei)

I-Cycler Programm:

Cycle 1: (1x)

Step 1: $\quad 50.0^{\circ} \mathrm{C} \quad 30 \mathrm{~min} \quad$ (Reverse Transkription)

Cycle 2: (1x)

Step 1: $\quad 95.0^{\circ} \mathrm{C} \quad 15 \mathrm{~min} \quad$ (Aktivierung der DNA-Polymerase)

Cycle 3: $\quad(45 \mathrm{x})$

Step 1: $\quad 94.0^{\circ} \mathrm{C} \quad 15 \mathrm{sec} \quad$ (PCR)

Step 2: $\quad 57.0^{\circ} \mathrm{C} \quad 30 \mathrm{sec}$

Step 3: $\quad 72.0^{\circ} \mathrm{C} \quad 30 \mathrm{sec}$

Cycle 4: (1x)

Step 1: $\quad 55.0^{\circ} \mathrm{C} \quad 1 \mathrm{~min} \quad$ (Abschließende Elongation)

Cycle 5: $\quad(80 \mathrm{x})$

Step 1: $\quad 55.0^{\circ} \mathrm{C} \quad 10 \mathrm{sec} \quad$ (Ermittlung des Schmelzpunktes

$+0.5^{\circ} \mathrm{C} \quad$ der PCR-Produkte)

Cycle 6: (1x)

Step 1: $\quad 4.0^{\circ} \mathrm{C} \quad$ HOLD

\subsection{Hybridisierung und Auswertung von Microarrays}

Die Genexpressionsanalyse dient der Untersuchung der qualitativen und quantitativen Zusammensetzung zellulärer mRNA, wofür typischerweise die relativen Expressionsstärken zweier Proben miteinander verglichen werden. Bei diesen Proben 
handelt es sich um RNA, welche aus Zellen gewonnen wird, die zum einen unter Standard- oder Referenzbedingungen und zum anderen unter den experimentell zu untersuchenden Bedingungen gewachsen sind.

Die für die Hybridisierung verwendete RNA (targets) wird mit den fluoreszierenden Cyanin-Farbstoffen $\mathrm{Cy}^{\mathrm{TM}} 3$ und $\mathrm{Cy}^{\mathrm{TM}} 5$ (GE Healthcare, Cy ${ }^{\mathrm{TM}} 3-$ detp, Cat no. PA53021, Cy ${ }^{\mathrm{TM}} 5$-detp, Cat no. PA55021) markiert. Die jeweils korrespondierenden Fluoreszenzsignale der beiden Farbstoffe können nach der Hybridisierung der probes mit den targets unabhängig voneinander mit dem GenePix 4000B (AXON Instruments, Union City, USA) Scanner detektiert werden. Als probes werden in diesem Zusammenhang die immobilisierten Nukleinsäuresequenzen auf der Oberfläche des DNA-Microarrays bezeichnet. Die Verwendung von Fluoreszenz ermöglicht, im Vergleich zu einer radioaktiven Markierung, neben höherer Sensitivität und Auflösung, das Auswerten von zwei oder mehreren verschiedenen Signalen in einem Experiment. Im Anschluss an eine Normalisierung der Daten kann die Intensität der Hybridisierungssignale miteinander verglichen werden. DNA-Microarrays geben keine Information über die absoluten Expressionsstärken in den untersuchten Proben, da die Fluoreszenzsignale auch von der Anzahl eingebauter Farbstoffmoleküle abhängt, der Markierungsdichte. Letztere wird in erster Linie durch die variable Nukleotidsequenz der Gene bestimmt.

Für die Transkriptionsanalysen standen verschiedene DNA-Microarrays zur Verfügung. Als probes dienten zum einen PCR amplifizierte Fragmente, zum anderen Oligonukleotide. Einher gingen damit unterschiedliche Protokolle im Zusammenhang mit der Markierung von RNA und der Hybridisierung von cDNA.

\subsubsection{Markierung von RNA mit $\mathrm{Cy}^{\mathrm{TM}} 3 / \mathrm{Cy}^{\mathrm{TM}} 5$ Fluoreszenzfarbstoff}

\section{Markierung von RNA mit $\mathrm{Cy}^{\mathrm{TM}} 3 / \mathrm{Cy}^{\mathrm{TM}} 5$ Fluoreszenzfarbstoff für PCR-basierende DNA-Microarrays}

Die Markierung der isolierten RNA (3.6.2.) erfolgte über eine reverse Transkription mit random nonamers als Primer. Für die Hybridisierung der als Kontrolle verwendeten ScoreCard ${ }^{\mathrm{TM}}$ wurde in Form eines spike mix spezifische RNA (Lucedia ${ }^{\mathrm{TM}}$ Universal ScoreCard ${ }^{\mathrm{TM}}$, Amersham Biosciences) für beide Farbreaktionen mitgeführt. Während 
des Umschreibens der RNA werden CyDye markierte dCTPs in die cDNA eingebaut. Die restlichen dNTPs werden ohne eine Markierung als dCTP Nukleotid Mix zugegeben. Es kam hierbei der Cyscribe First Strand cDNA Labeling Kit (Amersham Biosciences) zum Einsatz.

Als erster Schritt des Markierens erfolgte das Annealing der random nonamers an die RNA, wofür $25 \mu \mathrm{g}$ RNA benötigt wurden. Aufgrund unterschiedlicher Markierungseffizienz der Farbstoffe wurden für eine Hybridisierungsreaktion ein Ansatz Cy ${ }^{\mathrm{TM}} 3$ und zwei Ansätze CyTM5 markiert. Es ist zu bemerken, dass die Cyanin-Farbstoffe stark lichtempfindlich sind und daher die Reaktionsansätze der Markierung, sowie die markierten Proben möglichst lichtgeschützt behandelt wurden. Das Annealing fand im Thermocycler (Eppendorf Mastercycler Gradient, Hamburg) statt:

Annealing-Ansatz:

$25 \mu \mathrm{g}$ isolierte RNA

$1 \quad \mu$ spike mix für $\mathrm{Cy}^{\mathrm{TM}} 3$ oder $\mathrm{Cy}^{\mathrm{TM}} 5$ Reaktion

$1 \mu \mathrm{l}$ random nonamers

ad $11 \mu \mathrm{l} \quad \mathrm{H}_{2} \mathrm{O}$

Annealing-Programm:

$\mathrm{LIDHT}=110^{\circ} \mathrm{C}$

1 HOLD

$5 \min \quad 70^{\circ} \mathrm{C}$

2 TEMP GRADIENT

$3,0^{\circ} \mathrm{C} / \mathrm{min}$ to $50^{\circ} \mathrm{C}$

3 TEMP GRADIENT

$1,0^{\circ} \mathrm{C} / \mathrm{min}$ to $40^{\circ} \mathrm{C}$

4 TEMP GRADIENT

$0,3^{\circ} \mathrm{C} / \mathrm{min}$ to $35^{\circ} \mathrm{C}$

5 TEMP GRADIENT

$0,2^{\circ} \mathrm{C} / \mathrm{min}$ to $30^{\circ} \mathrm{C}$

6 TEMP GRADIENT

$0,1^{\circ} \mathrm{C} / \mathrm{min}$ to $25^{\circ} \mathrm{C}$

7 TEMP GRADIENT

$0,1^{\circ} \mathrm{C} / \mathrm{min}$ to $22^{\circ} \mathrm{C}$

8 HOLD

$20 \mathrm{~min} \quad 22^{\circ} \mathrm{C}$

9 TEMP

FOREVER $\quad 4^{\circ} \mathrm{C}$

Im Anschluss wurden dem Annealing-Ansatz folgende Komponenten für die reverse Transkription hinzugefügt: 
Ansatz für die reverse Transkription:

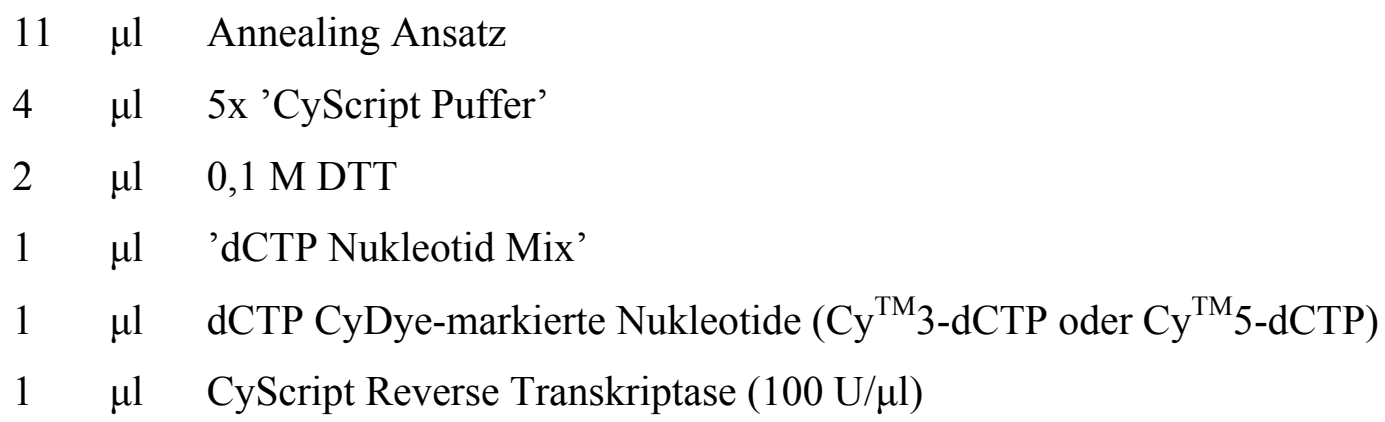

Die $20 \mu \mathrm{l}$ Reaktionsansätze wurden kurz gemischt, abzentrifugiert und $1,5 \mathrm{~h}$ bei $42^{\circ} \mathrm{C}$ im Mastercycler Gradient der Firma Eppendorf inkubiert. Um die Template RNA und nicht eingebaute CyDye Nukleotide zu entfernen, erfolgte anschließend eine zügige Aufreinigung der markierten cDNA. Zunächst wurde die RNA durch Zugabe von $2 \mu 1$ 2,5 $\mathrm{M} \mathrm{NaOH}$ in kurze Oligomere hydrolysiert. Die Ansätze wurden $10 \mathrm{sec}$ gevortext, kurz abzentrifugiert und 15 min bei $37^{\circ} \mathrm{C}$ für die Hydrolyse im Mastercycler Gradient inkubiert. Um die Lösung zu neutralisieren wurden im Anschluss $10 \mu 12$ M HEPES hinzugegeben, $10 \mathrm{sec}$ gevortext und wiederholt zentrifugiert. Im Anschluss daran folgte eine Aufreinigung der markierten cDNA (3.8.2.) über eine Säule des illustra ${ }^{\mathrm{TM}}$ CyScribe $^{\mathrm{TM}}$ GFX ${ }^{\mathrm{TM}}$ Purification Kits (GE Healthcare, Cat no. 27-9606-02).

\section{Markierung von RNA mit Cy ${ }^{\mathrm{TM}} / \mathrm{Cy}^{\mathrm{TM}} 5$ Fluoreszenzfarbstoff für Oligo-basierende DNA-Microarrays}

Anders als bei den PCR-basierenden DNA-Microarrays erfolgte die Markierung der isolierten RNA (3.6.2.) über eine reverse Transkription mit random hexamers (Primer random $\mathrm{p}(\mathrm{dN})_{6}$ Roche, REF 11034731001) als Primer. Des weiteren wurde für den Ansatz der reversen Transkription ein 4/10 dNTP Nukleotid-Mix verwendet, welcher 4 mM dCTP und jeweils 10 mM dATP, dTTP, dGTP enthielt. Außer den verwendeten Cyanin-Farbstoffen lagen die weiteren Komponenten des Ansatzes der reversen Transkription der verwendeten SuperScript ${ }^{\circledR}$ III Reverse Transcriptase (Invitrogen, Cat no. 18080-044) bei.

Zunächst erfolgte als erster Schritt des Markierens das Annealing der random hexamers an die RNA, von welcher $50 \mu$ g eingesetzt wurde. Wie bei den PCR-basierenden DNAMicroarrays wurden für eine Hybridisierungsreaktion ein Ansatz $\mathrm{Cy}^{\mathrm{TM}} 3$ und zwei 
Ansätze Cy ${ }^{\mathrm{TM}} 5$ markiert. Das Annealing hingegen fand für $10 \mathrm{~min}$ bei $70^{\circ} \mathrm{C}$ im Thermocycler (Eppendorf Mastercycler Gradient, Hamburg) statt:

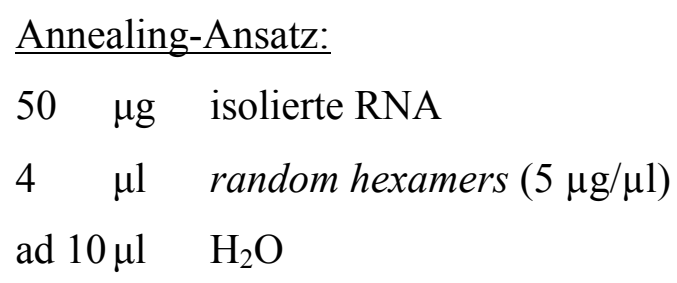

Anschließend wurden dem Annealing-Ansatz für die reverse Transkription die folgenden Komponenten der Reihe nach zugeben:

Ansatz für die reverse Transkription:

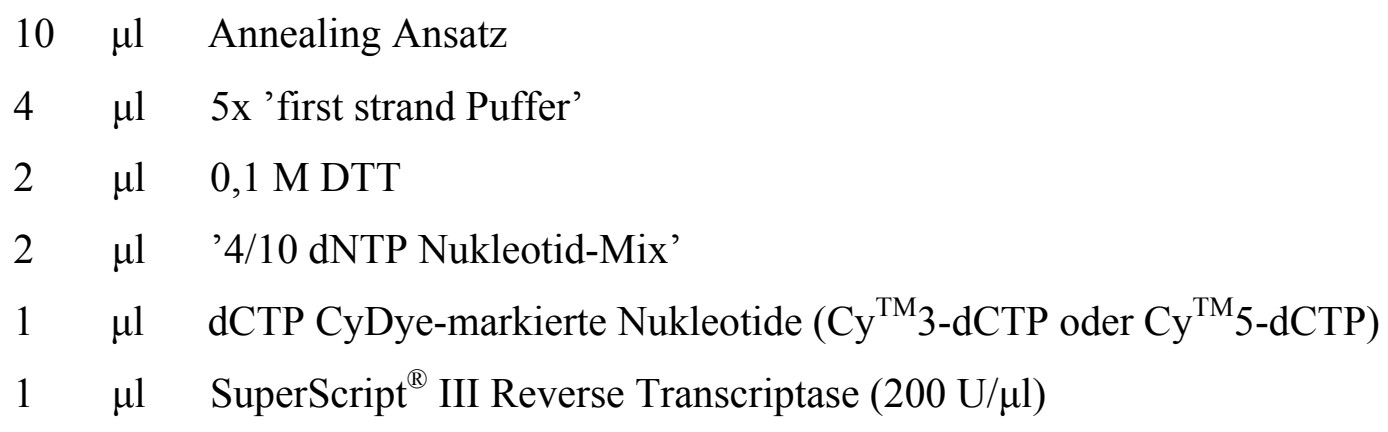

Die Reaktionsansätze wurden nach kurzem Mischen abzentrifugiert und 3 Stunden bei $42^{\circ} \mathrm{C}$ im Mastercycler Gradient der Firma Eppendorf inkubiert. Die weitere Durchführung entsprach der zur Markierung von RNA für PCR-basierende DNAMicroarrays, mit dem Unterschied, dass für Aufreinigung der markierten cDNA (3.8.2.) mit dem illustra ${ }^{\mathrm{TM}}$ CyScribe ${ }^{\mathrm{TM}}$ GFX $^{\mathrm{TM}}$ Purification Kit je Cyanin-Farbstoff eine Säule verwendet wurde. Aus diesem Grund erfolgte die Eluation der cDNA mit $30 \mu 170^{\circ} \mathrm{C}$ warmen Eluationspuffer.

\subsubsection{Aufreinigung der markierten cDNA}

Die Aufreinigung der markierten cDNA erfolgte mit dem illustra ${ }^{\mathrm{TM}} \mathrm{CyScribe}^{\mathrm{TM}} \mathrm{GFX}^{\mathrm{TM}}$ Purification Kit. Zunächst wurden hierzu $500 \mu$ l Capture Buffer auf die Säule pipettiert, die Markierungsansätze hinzugegeben und vorsichtig mit der Pipette gemischt. Aufgrund der Lichtempfindlichkeit der Cyanin-Farbstoffe wurden die folgenden 
Schritte möglichst lichtgeschützt durchgeführt. Es folgte ein Zentrifugationsschritt für $30 \mathrm{sec}$ bei 13000 U/min, wobei die cDNA an die Säulenmatrix bindet. Der Durchfluss wurde anschließend verworfen und nach der Zugabe von $600 \mu 1$ Waschpuffer wieder für $30 \mathrm{sec}$ bei $13000 \mathrm{U} / \mathrm{min}$ zentrifugiert. Der Durchfluss wurde erneut verworfen und der Waschschritt weitere zweimal wiederholt. Danach erfolgte die Eluation der markierten target cDNA in ein neues Reaktionsgefäß, indem $70 \mu 170^{\circ} \mathrm{C}$ warmer Eluationspuffer auf die Säule gegeben, für $5 \mathrm{~min}$ bei RT inkubiert und für $1 \mathrm{~min}$ bei $13000 \mathrm{U} / \mathrm{min}$ zentrifugiert wurde. Das markierte cDNA enthaltende Eluat konnte bis zur Hybridisierung lichtgeschützt auf Eis gelagert werden.

\subsection{3. Überprüfung der Markierungsreaktion}

Um die Effizienz der Markierungsreaktion bewerten zu können, wurde ein Wavelength scan mit der markierten cDNA durchgeführt. Die Absorbtionsmaxima von eingebautem $\mathrm{Cy}^{\mathrm{TM}} 3 / \mathrm{Cy}^{\mathrm{TM}} 5$ liegen bei 550/650 nm, von freiem $\mathrm{Cy}^{\mathrm{TM}} 3 / \mathrm{Cy}^{\mathrm{TM}} 5$ bei ca. 520/600 nm.

Für die Messung wurden $10 \mu \mathrm{l}$ der aufgereinigten Markierungsreaktion 1:6 mit RNase freiem $\mathrm{H}_{2} \mathrm{O}$ verdünnt und das Absorbtionsspektrum in einer Quarzküvette $(\mathrm{d}=1 \mathrm{~cm})$ gemessen. Das Spektrum wurde über einen Bereich von 700-500 nm gefahren und die Extinktion bei 550 und $650 \mathrm{~nm}$ ermittelt. Die eingebauten pmol der beiden Farbstoffe konnten nun nach folgender Formel berechnet werden:

pmol Cy3 bzw. Cy5 in der Probe $=(\mathrm{A} / \mathrm{E}) \times(\mathrm{z} \mu \mathrm{l}) \times \mathrm{F} \times 10^{12}$
$\mathrm{A}=$ Absorbtion von Cy3 bei $550 \mathrm{~nm}$ bzw. Cy5 bei $650 \mathrm{~nm}$
$\mathrm{E}=$ Extinktionskoeffizient von Cy3 (150000 $1 \mathrm{~mol}-1 \mathrm{~cm}-1)$ bzw. Cy5 (250000 1 mol-1 cm-1)
$\mathrm{z}(\mu \mathrm{l})=\quad$ Volumen der cDNA-Lösung; $\mu \mathrm{l}$ entspricht $10^{-6} 1$
$\mathrm{F}=$ Verdünnungsfaktor 


\subsubsection{Hybridisierung der cDNA}

\section{Hybridisierung der probes mit markierter target-cDNA für PCR-basierende DNA-Microarrays}

Die Hybridisierung der probes mit der markierten target-cDNA erfolgte vollautomatisch mit dem Automated Slide Processor (ASP Lucidea, Amersham Pharmacia Biotech). Vorbereitend wurde die target-cDNA denaturiert und die benötigten Hybridisierungskammern des ASP gespült. Die Denaturierung der target-cDNA erfolgte durch 5 minütiges Inkubieren bei $95^{\circ} \mathrm{C}$, anschließender Abkühlung auf Eis und der Zugabe von $50 \mu$ Microarray Hybridization Buffer des Cyscribe First Strand cDNA Labeling Kits (Amersham Biosciences), sowie $110 \mu 1$ $100 \%$ (v/v) Formamid. Der Ansatz wurde gemischt, bei 13000 U/min kurz abzentrifugiert und lichtgeschützt auf Eis gelagert. Anschließend wurden $200 \mu \mathrm{l}$ des Hybridisierungsansatzes mit einer Hamiltonspritze in die Hybridisierungskammer des ASP, in welche bereits ein gespotteter DNA-Microarray eingespannt war, injiziert. Die Hybridisierung erfolgte mit dem folgenden Programm:

\section{ASP-Hybridisierungsprogramm:}

$\begin{array}{lll}00 & \text { Wait } & \begin{array}{l}\text { Check dummy slides } \\ \text { (Überprüfen, ob in jeder Kammer ein dummy Slide ist) }\end{array} \\ 01 & \text { Flush } & \begin{array}{l}\text { Leeren der Schläuche und Kammern von alten Lösungen } \\ \text { Kammern auf } 38^{\circ} \mathrm{C} \text { aufheizen }\end{array} \\ 02 & \text { Heat } & \text { Kammern mit Isopropanol spülen und leeren } \\ 03 & \text { Flush } & \text { Kammern mit Wasser spülen und leeren } \\ 04 & \text { Flush } & \text { Kammern für } 60 \text { sec mit Luft spülen } \\ 05 & \text { Air Pump } & \text { Heizung ausschalten } \\ 06 & \text { Heat Switch Off } & \text { Schläuche mit Wash 1 (Lösung 3) füllen } \\ 07 & \text { Prime } & \text { INSERT TEST SLIDES - Test slides einlegen } \\ 08 & \text { Wait } & \text { Kammern auf 42 }{ }^{\circ} \mathrm{C} \text { aufheizen } \\ 09 & \text { Heat } & \text { Inject probe solution }- \text { Proben-Lösung injizieren } \\ 10 & \text { Wait } & \text { Mischen der Lösungen in den Kammern für 12 Stunden } \\ 11 & \text { Mix } & \text { Mit Wash 1 spülen }\end{array}$




$\begin{array}{lll}13 & \text { Heat } & \text { Kammern auf } 45^{\circ} \mathrm{C} \text { aufheizen } \\ 14 & \text { Mix } & \text { Mischen mit Wash 1 für } 10 \text { min } \\ 15 & \text { Prime } & \text { Schläuche mit Wash 2 (Lösung 4) füllen } \\ 16 & \text { Flush } & \text { Mit Wash 2 spülen } \\ 17 & \text { Mix } & \text { Mischen mit Wash 2 für } 10 \text { min } \\ 18 & \text { Flush } & \text { Mit Wash 2 spülen } \\ 19 & \text { Mix } & \text { Mischen mit Wash 2 für 4 min } \\ 20 & \text { Prime } & \text { Schläuche mit Wash 3 (Lösung 2) füllen } \\ 21 & \text { Flush } & \text { Mit Wash 3 spülen } \\ 22 & \text { Prime } & \text { Schläuche mit Isopropanol füllen } \\ 23 & \text { Flush } & \text { Mit Isopropanol spülen } \\ 24 & \text { Flush } & \text { Kammern mit Luft spülen } \\ 25 & \text { AirPump } & \text { Kammern mit Luft trocknen } \\ 26 & \text { Heat } & \text { Heizung ausschalten } \\ 27 & \text { Wait } & \text { REMOVE TEST SLIDES }\end{array}$

Test slides entfernen und mit dummy slides ersetzen

28 Heat Heizen auf $48^{\circ} \mathrm{C}$

29 Flush Mit Wash 2 spülen

30 Mix Mischen mit Wash 2 für 5 min

31 Prime Schläuche mit Wasser füllen

32 Flush Mit $6 \mathrm{ml}$ Wasser spülen

33 Mix Mischen mit Wasser für 5 min

34 Flush Mit $6 \mathrm{ml}$ Wasser spülen

35 Flush Mit Luft spülen

36 Prime Schläuche mit Isopropanol füllen

37 Flush Mit Isopropanol spülen

38 Flush Mit Luft spülen

39 Air Pump Kammern mit Luft trocknen

[Ende] 
Erläuterung der Programmbefehle:

Air Pump: Trocknen der Kammer durch Luft

Flush: $\quad$ Spülen der Hybridisierungskammern und Schläuche

Heat: Heizen der Kammer auf eine bestimmte Temperatur

Mix: $\quad$ Mixen der Lösung innerhalb der Kammer durch Vor- und Zurückpumpen

Prime: Füllen der Schläuche bis zur Hybridisierungskammer

Wait: Warten bis zu einer Bestätigung vom User

Lösungen:

Lösung 1: $\mathrm{H}_{2} \mathrm{O}$

Lösung 2: Wash $3(0,1 \times \mathrm{SSC})$

Lösung 3: Wash 1 (1x SSC / 0,2\% SDS)

Lösung 4: Wash 2 (0,1x SSC / 0,2\% SDS)

Lösung 5: Isopropanol

Hybridisierung der probes mit markierter target-cDNA für Oligo-basierende DNA-Microarrays

Lösungen für die Hybridisierung Oligo-basierender DNA-Microarrays

Tom-Freeman-Hybridisierungspuffer (Fitzpatrick et al., 2005)

$\begin{array}{lll}\text { Formamid (deionisiert) } & 20 & \mathrm{ml} \\ \text { 50x Denhart's solution } & 5,0 & \mathrm{ml} \\ \text { 20x SSC } & 12,5 & \mathrm{ml} \\ 100 \mathrm{mM} \text { Na-Pyrophosphat } & 0,5 & \mathrm{ml} \\ 1 \mathrm{M} \text { Tris (pH 7,4) } & 2,5 & \mathrm{ml} \\ 10 \% \text { SDS } & 0,5 & \mathrm{ml} \\ \text { HLPC- } \mathrm{H}_{2} \mathrm{O} & 9,0 & \mathrm{ml} \\ \text { sterilfiltrieren } & & \end{array}$

Wie bei den PCR-basierenden DNA-Microarrays erfolgte die Hybridisierung vollautomatisch mit dem Automated Slide Processor. Für die Hybridiserung wurden etwa 80 pmol pro Farbstoff der Markierungsreaktion eingesetzt und in einem 
Reaktionsgefäß vereinigt. Während die benötigten Hybridisierungskammern des ASP gespült wurden, erfolgte die Denaturierung der target-cDNA durch 5 minütiges Inkubieren bei $95^{\circ} \mathrm{C}$. Der Hybridisierungsansatz wurde unverzüglich auf Eis gestellt und mit Tom-Freeman-Hybridisierungspuffer bis $\mathrm{zu}$ einem Volumen von $210 \mu \mathrm{l}$ aufgefüllt. Im Anschluss daran wurde dieser gemischt und nach kurzer Zentrifugation bei $13000 \mathrm{U} / \mathrm{min}$ lichtgeschützt auf Eis gelagert. Nach dem Einspannen des gespotteten Microarrays in die Hybridisierungskammer des ASP wurden $200 \mu$ les Hybridisierungsansatzes mit einer Hamiltonspritze in letztere injiziert. Die Hybridisierung erfolgte mit dem folgenden Programm:

\section{ASP-Hybridisierungsprogramm:}

\begin{tabular}{|c|c|c|}
\hline 00 & Wait & $\begin{array}{l}\text { Check dummy slides } \\
\text { (Überprüfen, ob in jeder Kammer ein dummy Slide ist) }\end{array}$ \\
\hline 01 & Flush & Leeren der Schläuche und Kammern von alten Lösungen \\
\hline 02 & Heat & Kammern auf $48^{\circ} \mathrm{C}$ aufheizen \\
\hline 03 & Flush & Kammern mit Isopropanol spülen \\
\hline 04 & Flush & mit Luft spülen \\
\hline 05 & Air Pump & Kammern mit Luft trocknen \\
\hline 06 & Heat Switch Off & Heizung ausschalten \\
\hline 07 & Prime & Schläuche mit Wash 1 (Lösung 3) füllen \\
\hline 08 & Wait & INSERT TEST SLIDES - Test slides einlegen \\
\hline 09 & Heat & Kammern auf $55^{\circ} \mathrm{C}$ aufheizen \\
\hline 10 & Wait & Inject probe solution - Proben-Lösung injizieren \\
\hline 11 & Mix & mischen der Lösungen in den Kammern für 15 Stunden \\
\hline 12 & Heat Switch Off & Heizung ausschalten \\
\hline 13 & Flush & mit Wash 1 spülen \\
\hline 14 & Mix & Mischen mit Wash 1 für 2 min \\
\hline 15 & Flush & mit Wash 1 spülen \\
\hline 16 & Prime & Schläuche mit Wash 3 (Lösung 2) füllen \\
\hline 17 & Flush & Mit Wash 3 spülen \\
\hline 18 & Flush & Kammern mit Luft spülen \\
\hline 19 & Heat & Kammern auf $37^{\circ} \mathrm{C}$ aufheizen \\
\hline 20 & Prime & Schläuche mit Isopropanol füllen \\
\hline
\end{tabular}




$\begin{array}{lll}21 & \text { Flush } & \text { mit Isopropanol spülen } \\ 22 & \text { Flush } & \text { Kammern mit Luft spülen } \\ 23 & \text { Flush } & \text { Kammern mit Luft spülen } \\ 24 & \text { AirPump } & \text { Kammern mit Luft trocknen } \\ 25 & \text { Heat Switch Off } & \text { Heizung ausschalten } \\ 26 & \text { Wait } & \text { REMOVE TEST SLIDES } \\ & & \text { Test slides entfernen und mit dummy slides ersetzen } \\ 27 & \text { Heat } & \text { Heizen auf 48 }{ }^{\circ} \text { C } \\ 28 & \text { Flush } & \text { mit Wash 2 spülen } \\ 29 & \text { Mix } & \text { Mischen mit Wash 2 für } 5 \text { min } \\ 30 & \text { Prime } & \text { Schläuche mit Wasser füllen } \\ 31 & \text { Flush } & \text { mit 6 ml Wasser spülen } \\ 32 & \text { Mix } & \text { Mischen mit Wasser für } 5 \text { min } \\ 33 & \text { Flush } & \text { mit 6 ml Wasser spülen } \\ 34 & \text { Flush } & \text { mit Luft spülen } \\ 35 & \text { Prime } & \text { Schläuche mit Isopropanol füllen } \\ 36 & \text { Flush } & \text { mit Isopropanol spülen } \\ 37 & \text { Flush } & \text { mit Luft spülen } \\ 38 & \text { Air Pump } & \text { Kammern mit Luft trocknen } \\ {[\text { Ende] }} & \end{array}$

Erläuterungen der Programmbefehle und Lösungen sind dem Abschnitt zur Hybridisierung PCR-basierender DNA-Microarrays zu entnehmen.

\subsubsection{Quantifizierung der Microarraydaten mit GenePix Pro 6.0}

Zur Verarbeitung der Hybridisierungsdaten wurden diese mit dem Scanner GenePix 4000B (AXON Instruments, Union City) und dem Programm GenePix Pro 6.0 visualisiert. Bereits während des Scannens erfolgte bei Verwendung der PCRbasierenden DNA-Microarrays eine erste Normalisierung der Arraydaten über KontrollProben der sog. Scorecard. Hierbei handelt es sich um spezifische DNA, welche mit den probes gespottet wurde. Diese DNA wurde mit spezifischer RNA, die als spike mix dem Markierungsansatz hinzugefügt wurde, hybridisiert. Da die beiden den 
Markierungsansätzen hinzugefügten Kontrollen eine Fluoreszenzintensitätsverhältnis von 1:1 ergeben sollten, wurde bei dem Prescan die Scanstärke (PMT $635 \mathrm{~nm}$ - Cy5, PMT $532 \mathrm{~nm}$ - Cy3) für die beiden Farbstoffe anhand der Fluoreszenz der Kontrollen ermittelt. Bei den Oligo-basierenden DNA-Microarrays wurde die Scanstärke des Prescans anhand des Hintergrundes ermittelt. Anschließend erfolgte der Hauptscan mit folgenden Einstellungen:

Pixel size: $\quad 10 \mu \mathrm{m}$

Lines to average: 1

Focus position: $\quad 0 \quad \mu \mathrm{m}$

Scan area: $\quad$ ca.1000 $\quad 7000$ Pixel

Für die Quantifizierung der Fluoreszenzwerte jedes einzelnen Spots in 'GenePix' wurde zunächst mit der Software eine Art Schablone auf den Chip gelegt, womit jedem Spot die entsprechende Annotation zugewiesen und der auszuwertende Bereich festgelegt wurde. Mit Hilfe eines eigens dafür entwickelten Computerprogramms (Ehrenreich, unveröffentlicht) wurde die Schablone, basierend auf einer Excel-Belegungsliste (Microsoft, Redmond, USA), in Form eines gal files generiert. Die Ausrichtung dieser Schablone wurde für jeden einzelnen Spot manuell überprüft. Die Berechnung der Fluoreszenzwerte, des Hintergrunds und der Standardabweichung des Hintergrunds für beide Farbstoffe, sowie des Ratio of Medians, Ratio of Means und dem Regression Ratio erfolgte für jeden Spot automatisch durch das Programm GenePix Pro. Bei den Ratio of Medians, Ratio of Means und dem Regression Ratio handelt es sich um jeweils unterschiedliche mathematische Ansätze zu Ermittlung des mittleren Expressionswertes eines Spots. Jeder Spot besteht aus einer Vielzahl von einzelnen Bildelementen (Pixel), für welche jeweils ein Wert der Pixel-Intensität für die Wellenlänge $1(I P, \lambda I)$ und der Pixel-Intensität für die Wellenlänge $2(I P, \lambda 2)$ vorliegt. Die Intensitäten der zwei Wellenlängen der den definierten Spot umgebenden Hintergrund-Pixel werden ebenfalls mit einbezogen $(I B, \lambda 1$ und $I B, \lambda 2)$. Das mittlere Fluoreszenzverhältnis eines Spots wird aus den einzelnen Pixel-Intensitäten berechnet. Der Ratio of Medians, der dem geometrischen Mittel entspricht, wird häufig zur Berechnung von Mittelwerten herangezogen, da starke Abweichungen einzelner Werte aus mathematischen Gründen das Endergebnis weniger beeinflussen. 
Ratio of Medians:

$$
\frac{\left\{\left(I_{P}, \lambda 2\right) h\right\}_{\text {med }}-\left\{\left(I_{B}, \lambda 2\right) h\right\}_{\text {med }}}{\left\{\left(I_{P}, \lambda 1\right) \eta\right\}_{\text {med }}-\left\{\left(I_{B}, \lambda 1\right) h\right\}_{\text {med }}}
$$

Der Ratio of Means hingegen kann mehr von starken Abweichungen einzelner Werte beeinflusst werden.

Ration of Means:

$$
\frac{\sum_{i=1}^{n}\left\langle I_{P, \lambda 2}-\left\{\left(I_{B, \lambda 2}\right)_{n}\right\}_{\text {med }}\right\rangle_{i}}{\sum_{i=1}^{n}\left\langle I_{P}, \lambda 1-\left\{\left(I_{B}, \lambda 1\right)_{n}\right\}_{\text {med }}\right\rangle_{i}}
$$

Für die Berechnung des Regression Ratios ist eine Definition von Pixel, die zu dem eigentlichen Spot gehören, und Hintergrund-Pixel durch die 'Schablone' nicht nötig. Jeder Pixel innerhalb des zweifachen Spotdurchmessers, unabhängig von seiner Position, wird einbezogen. Das Verhältnis der beiden Wellenlängen zueinander wird mittels linearer Regression zwischen den zwei sich ergebenden Pixelwolken ermittelt (Abbildung 3.3).

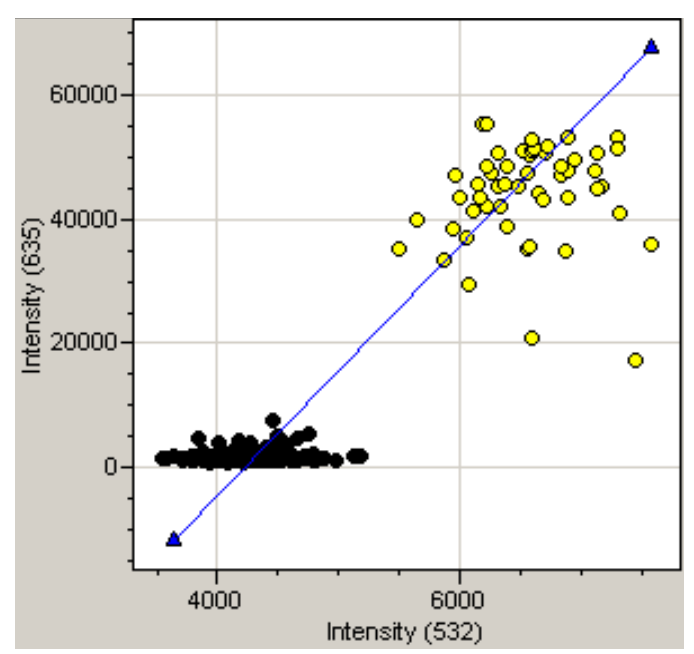

Abbildung 3.3: Regression Ratio eines einzelnen Spots. Aufgetragen sind die Intensitäten der einzelnen Pixel bei $532 \mathrm{~nm}$ gegen die Intensitäten bei $635 \mathrm{~nm}$. Die schwarzen Punkte liegen im Hintergrund, die gelben heben sich vom Hintergrund ab. Die blaue Linie stellt die mathematisch ermittelte Regressionsgerade dar, ihre Steigung gibt das durchschnittliche Verhältnis der Pixelintensitäten und damit der Regression Ratio an. 
Die Ergebnisse konnten in Form einer Datentabelle und eines Scatterplots eingesehen werden. An dieser Stelle erfolgte eine weitere Normalisierung der Daten. Unter der Voraussetzung, dass sich unter den zu vergleichenden Bedingungen nur die Expression einzelner Gene verändert und die Expression eines Großteils der Gene unverändert bleibt, wurde im Scatterplot die Hauptwolke der Gene auf die Winkelhalbierende gelegt, also in den Bereich eines Regulationsfaktors von 1. Eine logarithmische Auftragung der Expressionswerte vereinfacht dieses Verfahren zusätzlich, da Spots mit einem Expressionsfaktor von annähernd 1 gestaucht werden und sich die Dichte der Hauptwolke der Daten erhöht (Abb. 3.4).

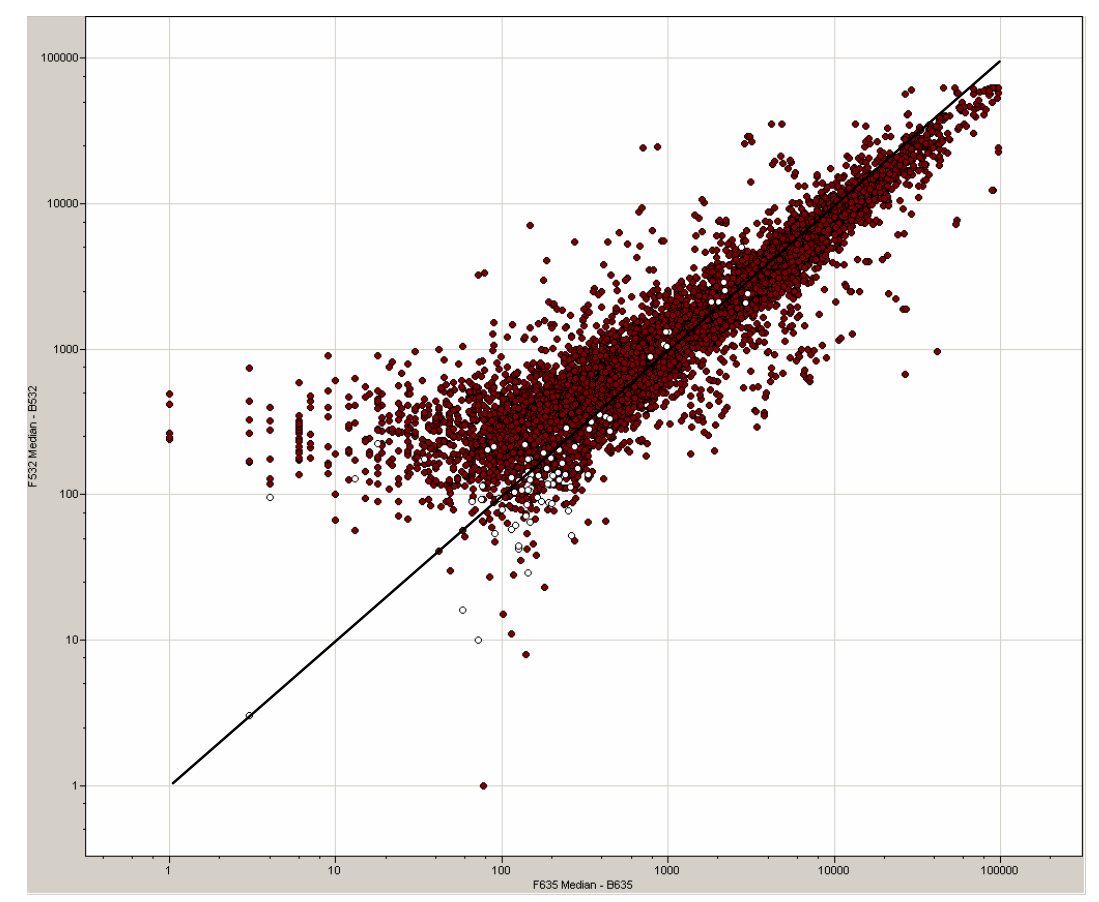

Abbildung 3.4: Logarithmische Auftragung der Expressionswerte eines Microarrays als Scatterplot im Programm GenePix Pro. Die Hauptwolke der Gene liegt nach der Normalisierung im Bereich der Winkelhalbierenden.

\subsubsection{Analyse der Transkriptionsdaten}

Für die weitere Bearbeitung und Analyse der normalisierten Transkriptionsdaten wurden diese aus GenePix Pro in das Programm Excel (Microsoft, Redmond, USA) exportiert. Hier wurden sämtliche Daten auf Qualität und somit Aussagekraft überprüft. Alle Daten wurden daraufhin gefiltert, dass die Fluoreszenzsignale für Rot und Grün 
selbst, und nach Abzug der Standardabweichung des Hintergrundes einen Wert größer Null besaßen. Ein weiteres Merkmal für die Qualität eines Spots war, dass die nach unterschiedlichen mathematischen Verfahren berechneten Expressionsverhältnisse, Ratio of Medians, Ratio of Means und der Regression Ratio, für einen Spot nicht mehr als 30\% voneinander abweichen. Bei starken Diskrepanzen dieser Werte, kann man methodische Artefakte nicht ausschließen. Im Anschluss an die Evaluation der Daten wurden alle ORFs, deren Expression sich unter den jeweiligen Bedingungen mindestens um einen Faktor 3 änderte, herausgefiltert, mit anderen Chipdaten verglichen und ihre Funktion im Stoffwechsel beurteilt.

\subsection{Analyse von Kulturüberständen}

\subsubsection{Dünnschichtchromatographie (DC)}

Zur Detektion von Aminosäuren gibt es verschiedene Methoden. Im Rahmen dieser Arbeit erfolgte die Detektion der Aminosäuren im Kulturüberstand zunächst mittels Dünnschichtchromatographie. Aufgrund der schnelleren Durchführung und der leichteren Quantifizierung wurde dazu übergegangen die Aminosäuren mit der Ionenchromatographie (3.9.2.) zu bestimmen.

Vorbereitend wurde zunächst das Laufmittel ca. $1 \mathrm{~cm}$ hoch in die Entwicklungskammer eingefüllt und diese abgedeckt. Hierbei ist darauf zu achten, das ausreichend Laufmittel in der Kammer vorhanden ist, aber auf der anderen Seite darf das Laufmittel nicht in Kontakt mit der Auftragszone der Kieselgelplatte kommen. Zunächst diente ein Gemisch aus Butanol/Eisessig/ $\mathrm{H}_{2} \mathrm{O} \quad(\mathrm{v} / \mathrm{v}, 4: 1: 1)$ als Laufmittel. Eine bessere Auftrennung der Komponenten konnte aber mit einem Gemisch aus Ethanol/ $\mathrm{H}_{2} \mathrm{O}(\mathrm{v} / \mathrm{v}$, 70:30) erzielt werden. Während sich die Atmosphäre in der Entwicklungskammer mit dem Dampf des Laufmittels anreicherte, wurden auf einer Kieselgelplatte (DC-Plastikfolien 20x20 cm Kieselgel 60, Merck 5748) etwa $2 \mathrm{~cm}$ vom unteren Rand vorsichtig die Startlinie und die Auftragspunkte mit einem weichen Bleistift markiert. Damit die Proben nicht ineinander laufen, sollte zwischen den Auftragsbanden ein Abstand von 0,5 bis $1 \mathrm{~cm}$ eingehalten werden. Mit einer $10 \mu$ l Pipette wurden jeweils $10 \mu \mathrm{l}$ der in $\mathrm{H}_{2} \mathrm{O}$ gelösten Aminosäure $(5 \mu \mathrm{g} / \mu \mathrm{l})$ bzw. des verdünnten Kulturüberstandes 
aufgetragen und getrocknet. Die Lösungen sollten möglichst kleine Flecken ergeben. Die Dünnschichtplatte wurde anschließend in die Kammer gestellt und das Laufmittel begann infolge der Kapillarkräfte nach oben zu wandern. Dabei werden die einzelnen Komponenten unterschiedlich stark mitgenommen. Nach etwa 2,5 bis 3 Stunden, bis die Lauffront $10 \mathrm{~cm}$ vorangeschritten war, wurde die Kieselgelplatte aus der Kammer entnommen und getrocknet. Anschließend wurde diese mit dem NinhydrinSprühreagenz (0,2 g in $95 \mathrm{ml} \mathrm{n-Butanol} \mathrm{und} 5 \mathrm{ml}$ Essigsäure) besprüht und für $10 \mathrm{~min}$ bei $110^{\circ} \mathrm{C}$ inkubiert. Ninhydrin bewirkt hierbei über die Bildung einer Schiffschen Base eine oxidative Decarboxylierung der Aminosäure. Die Hydrolyse der Schiffschen Base des decarboxylierten Produkts führt zu einem Aldehyd und einem Ninhydrinderivat, welches den Aminstickstoff trägt. Letzteres bildet mit dem mittleren Carbonyl-C-Atom eines zweiten Ninhydrinmoleküls eine Schiffsche Base, welche durch Deprotonierung einen blauvioletten Farbstoff ergibt (Ruhemanns Violett). Die Ringstruktur von Prolin führt zu einer abweichenden Reaktionsfolge unter Bildung eines gelblichen Farbstoffes. Abschließend wurde die DC-Platte eingeschweißt und zur Dokumentation eingescannt (Abb.3.5).

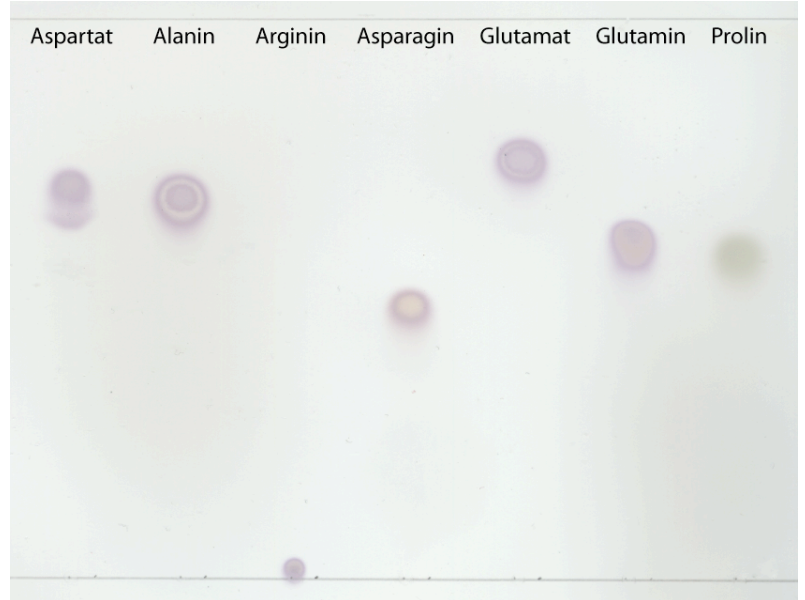

Abbildung 3.5: Repräsentative Dünnschichtchromatographie zur Darstellung von L-Aminosäuren. Als Laufmittel diente ein Gemisch aus 96\% EtOH, reinst und $\mathrm{H}_{2} \mathrm{O}$ im Verhältnis 70:30 (v/v). 


\subsubsection{Ionenchromatographie (IC)}

Zur Analyse von Kulturüberständen standen zwei Flüssigkeitschromatographiesysteme der Firma Dionex zur Verfügung. Zum einen war dies ein DX-500 System bestehend aus einer GP40 Gradientenpumpe, einem ED40 elektrochemischen Detektor und einem LC10 Chromatographie Organizer. Des Weiteren ein ICS-3000 Ionenchromatographiesystem mit eingebauten Leitfähigkeits- und elektrochemischen Detektor. Zusätzlich war ein VWD-3100 (Variable Wavelength Detector) der Ultimate 3000 Serie angeschlossen. Die Injektion der Proben erfolgte bei diesem System mit einem AS40 Autosampler. Gesteuert wurden beide Chromatographiesysteme mit dem Chromatographie Management System Chromeleon ${ }^{\circledR}$. Mithilfe dieser Software erfolgte auch die Auswertung der Chromatogramme. Die im Weiteren beschriebenen analytischen Säulen mit zugehörigen Guard-Säulen wurden ebenfalls von der Firma Dionex bezogen. Zur Herstellung der Eluenten wurde Milipore $-\mathrm{H}_{2} \mathrm{O}(18 \mathrm{M} \Omega-\mathrm{cm})$ verwendet. Sofern nicht anders angegeben wurde dieses steril filtriert (0,22 $\mu \mathrm{m}$ Nylon-Filter, Nalgene), vorsichtig in geeignete Behältnisse überführt und im Anschluss daran mit Helium 5.0 für 10 min durchströmt. Um eine Kontamination mit Carbonat zu minimieren, welche im Verlust der Chromatographieauflösung und -effizienz resultiert, wurden für Natriumhydroxid-Eluenten eine 50\%ige Natriumhydroxid-Lösung (Fluka, Product No 72064) verwendet. Die Eluenten waren permanent mit einem Druck von 5-8 psi beaufschlagt. Zur Probenvorbereitung wurden zunächst $500 \mu$ l Aliquots aus Wachstumsexperimenten für 10 min gekühlt zentrifugiert. Der Kulturüberstand wurde vorsichtig in ein neues Reaktionsgefäß überführt und bis zum Gebrauch bei $-20^{\circ} \mathrm{C}$ gelagert. Nach geeigneter Verdünnung konnten die Proben mittels Ionenchromatographie analysiert werden. Standards wurden in Milipore $-\mathrm{H}_{2} \mathrm{O}$ gelöst, steril filtriert (Spritzenvorsatzfilter $0,22 \mu \mathrm{m}$ ) und nach geeigneter Verdünnung bis zur weiteren Verwendung bei $-20^{\circ} \mathrm{C}$ gelagert.

\subsubsection{Quantitative Bestimmung von Alkoholen und Zuckern}

Sowohl mit der CarboPac ${ }^{\mathrm{TM}}$ MA1, als auch die CarboPac ${ }^{\mathrm{TM}}$ PA1 konnte isokratisch eine Separation von Glucose, Glycerol und 2,3 Butandiol erzielt werden. Die Detektion erfolgte dabei elektrochemisch. Im Vergleich zur CarboPac ${ }^{\mathrm{TM}}$ PA1 konnte mit der 
CarboPac ${ }^{\mathrm{TM}}$ MA1 eine bessere Trennung der Alkohole erreicht werden, welches aber mit längeren Laufzeiten einherging. Des Weiteren konnte mit beiden analytischen Säulen die proteinogenen Aminosäuren L-Alanin, L-Arginin, L-Asparagin, L-Glutamin und L-Prolin getrennt werden. Zusätzlich konnte mit der CarboPac ${ }^{\mathrm{TM}}$ MA1 die nichtproteinogene Aminosäure L-Ornithin und Harnstoff separiert werden.

Generelle Parameter zur Durchführung mit der CarboPac ${ }^{\mathrm{TM}}$ MA1-Säule:

System: DX-500

Säulen: $\quad$ CarboPac $\quad$ MA1 $\quad(4 \times 250 \mathrm{~mm}, \mathrm{P} / \mathrm{N} 044066)$

CarboPac ${ }^{\mathrm{TM}}$ MA1 Guard (4 x 50 mm, P/N 044067)

Flußrate: $\quad 0,4 \mathrm{ml} / \mathrm{min}$

Injektionsvolumen: $\quad 10 \mu 1$

Temperatur: $\quad$ RT

Detektion: integrierte gepulste Amperometrie, Goldelektrode

Eluenten: $\quad$ A: Wasser

B: $1 \mathrm{M} \mathrm{NaOH}$

Methode:

\begin{tabular}{ccc}
\hline Zeit (min) & A (\%) & B (\%) \\
\hline 0.0 & 52 & 48 \\
70.0 & 52 & 48 \\
\hline
\end{tabular}

Waveform elekrochemischer Detektor:

\begin{tabular}{ccc}
\hline Zeit (sec) & $\begin{array}{c}\text { Potential (V) } \\
\text { vs. Ag/AgCl }\end{array}$ & Integration \\
\hline 0.00 & 0,10 & \\
0.20 & 0,10 & Start \\
0.40 & 0,10 & Ende \\
0.41 & $-2,00$ & \\
0.42 & $-2,00$ & \\
0.43 & 0,60 & \\
0.44 & $-0,10$ & \\
0.50 & $-0,10$ & \\
\hline
\end{tabular}


Generelle Parameter zur Durchführung mit der CarboPac ${ }^{\mathrm{TM}}$ PA1-Säule:

System: DX-500

Säulen: $\quad$ CarboPac $\quad$ PA1 $\quad(4 \times 250 \mathrm{~mm}, \mathrm{P} / \mathrm{N}$ 035391)

CarboPac ${ }^{\mathrm{TM}}$ PA1 Guard (4 x 50 mm, P/N 043096)

Flußrate: $\quad 1,0 \mathrm{ml} / \mathrm{min}$

Injektionsvolumen: $\quad 10 \mu 1$

Temperatur: $\quad$ RT

Detektion: $\quad$ integrierte gepulste Amperometrie, Goldelektrode

Eluenten: $\quad$ A: Wasser

B: $1 \mathrm{M} \mathrm{NaOH}$

Methode:

\begin{tabular}{ccc}
\hline Zeit (min) & A (\%) & B (\%) \\
\hline 0.0 & 75 & 25 \\
70.0 & 75 & 25 \\
\hline
\end{tabular}

Waveform elekrochemischer Detektor: siehe Durchführung CarboPac ${ }^{\text {TM }}$ MA1-Säule

\subsubsection{Quantitative Bestimmung von Anionen}

Zur Bestimmung von Anionen im Kulturüberstand standen zwei Möglichkeiten der Detektion zur Verfügung. Zum einen konnten Lactat, Acetat, Formiat und andere organische Säuren mittels supprimierter Leitfähigket mit dem Dionex ICS-3000 System unter Verwendung der analytischen Säule IonPac ${ }^{\circledR}$ AS11-HC in Kombination mit einer vorgeschalteten IonPac ${ }^{\circledR}$ AG11-HC Guard-Säule gemessen werden. Als Suppressor diente der ASRS $^{\circledR}$ Ultra II. Die Separation erfolgte mit einem Natriumhydroxidgradienten bei einer Flußrate von $0,38 \mathrm{ml} / \mathrm{min}$. 
Generelle Parameter zur Durchführung mit der IonPac ${ }^{\circledR}$ AS11-HC-Säule:

System:

ICS-3000

Säulen:

$\mathrm{IonPac}^{\circledR} \mathrm{AS} 11-\mathrm{HC}(2 \times 250 \mathrm{~mm}, \mathrm{P} / \mathrm{N}$ 052961)

IonPac ${ }^{\circledR}$ AG11-HC Guard ( 2 x $50 \mathrm{~mm}, \mathrm{P} / \mathrm{N}$ 052963)

Flußrate: $\quad 0,38 \mathrm{ml} / \mathrm{min}$

Injektionsvolumen: $\quad 2,5 \mu 1$

Temperatur: $\quad 30^{\circ} \mathrm{C}$

Detektion: $\quad$ supprimierte Leitfähigkeit, ASRS $^{\circledR}$ Ultra II (2 mm, P/N 061562)

AutoSuppression recycle mode

Eluenten: $\quad$ A: Wasser

B: $5 \mathrm{mM} \mathrm{NaOH}$

C: $100 \mathrm{mM} \mathrm{NaOH}$

Methode:

\begin{tabular}{cccc}
\hline Zeit (min) & A (\%) & B (\%) & C (\%) \\
\hline 0.0 & 80 & 20 & 0 \\
8.0 & 80 & 20 & 0 \\
18.0 & 85 & 0 & 15 \\
28.0 & 70 & 0 & 30 \\
38.0 & 40 & 0 & 60 \\
40.0 & 40 & 0 & 60 \\
40.1 & 80 & 20 & 0 \\
50.0 & 80 & 20 & 0 \\
\hline
\end{tabular}


Die analytische Säule Acclaim ${ }^{\circledR}$ OA stellte eine weitere Möglichkeit zur Trennung von organischen Säuren dar. Die Separation erfolgte isokratisch mit einer Flußrate von $0,6 \mathrm{ml} / \mathrm{min}$ und die Substanzen wurden im Anschluss daran bei einer Wellenlänge von $210 \mathrm{~nm}$ detektiert.

Generelle Parameter zur Durchführung mit der Acclaim ${ }^{\circledR}$ OA-Säule:

System: $\quad$ ICS-3000

Säulen: $\quad$ Acclaim $^{\circledR} \mathrm{OA}(4 \times 250 \mathrm{~mm}, \mathrm{P} / \mathrm{N}$ 062902)

Acclaim $^{\circledR}$ OA Guard $(4,3 \times 10 \mathrm{~mm}, \mathrm{P} / \mathrm{N} 062925)$

Flußrate: $\quad 0,6 \mathrm{ml} / \mathrm{min}$

Injektionsvolumen: $\quad 10 \mu 1$

Temperatur: $\quad 30^{\circ} \mathrm{C}$

Detektion: $\quad$ UV, $210 \mathrm{~nm}$

Eluenten: $\quad$ A: Wasser

B: $200 \mathrm{mM} \mathrm{Na}_{2} \mathrm{SO}_{4}, \mathrm{pH} 2,68$

(mit Methansulfonsäure eingestellt)

Methode:

\begin{tabular}{ccc}
\hline Zeit (min) & A (\%) & B (\%) \\
\hline 0.0 & 50 & 50 \\
30.0 & 50 & 50 \\
\hline
\end{tabular}




\subsubsection{Quantitative Bestimmung von Kationen}

Die Detektion von Ammonium erfolgte mittels supprimierter Leitfähigkeit unter Verwendung der analytischen Säule $\operatorname{IonPac}^{\circledR}$ CS18 und zugehöriger IonPac ${ }^{\circledR}$ CG18 Guard-Säule. Als Suppressor diente der CSRS ${ }^{\circledR}$ Ultra II.

Generelle Parameter zur Durchführung:

System: $\quad$ ICS-3000

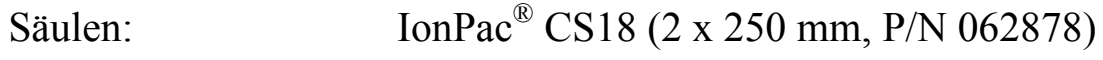
IonPac ${ }^{\circledR}$ CG18 Guard ( 2 x $50 \mathrm{~mm}, \mathrm{P} / \mathrm{N}$ 062880)

Flußrate: $\quad 0,25 \mathrm{ml} / \mathrm{min}$

Injektionsvolumen: $5 \mu 1$

Temperatur: $\quad 40^{\circ} \mathrm{C}$

Detektion: $\quad$ supprimierter Leitfähigkeit, $\operatorname{CSRS}^{\circledR}$ Ultra II (2 mm, P/N 061564) AutoSuppression recycle mode

Eluenten: $\quad$ A: Wasser

B: $50 \mathrm{mM}$ Methansulfonsäure

Methode:

\begin{tabular}{ccc}
\hline Zeit (min) & A (\%) & B (\%) \\
\hline 0.0 & 94 & 6 \\
5.0 & 94 & 6 \\
20.0 & 64 & 36 \\
25.0 & 10 & 90 \\
35.0 & 10 & 90 \\
35.1 & 94 & 6 \\
50.0 & 94 & 6 \\
\hline
\end{tabular}

\subsubsection{Quantitative Bestimmung von Aminosäuren}

Mithilfe eines Gradienten konnten Aminosäuren unter Verwendung der analytischen Säule AminoPac ${ }^{\mathrm{TM}}$ PA10 getrennt werden. L-Cystein wurde unter diesen alkalischen Bedingungen zu Cystin umgewandelt. Die Detektion erfolgte elektrochemisch. 
Anders als eingangs beschrieben wurde zur Herstellung des Acetat-Eluenten zunächst das Na-Acetat (wasserfrei, Dionex, $\mathrm{P} / \mathrm{N}$ 059326) in Milipore $-\mathrm{H}_{2} \mathrm{O}$ gelöst und im Anschluss daran steril filtriert (0,22 $\mu \mathrm{m}$ Nylon-Filter, Nalgene). Nach der Begasung mit Helium 5.0 für 10 min erfolgte die Zugabe des Natriumhydroxid.

Generelle Parameter zur Durchführung:

System: $\quad$ ICS-3000

Säulen: $\quad$ AminoPac $\quad$ TM PA10 (2 x $250 \mathrm{~mm}, \mathrm{P} / \mathrm{N} 55406)$

AminoPac ${ }^{\mathrm{TM}}$ PA10 Guard (2 x $\left.50 \mathrm{~mm}, \mathrm{P} / \mathrm{N} 55407\right)$

Flußrate: $\quad 0,25 \mathrm{ml} / \mathrm{min}$

Injektionsvolumen: $25 \mu 1$

Temperatur: $\quad 30^{\circ} \mathrm{C}$

Detektion: integrierte gepulste Amperometrie, Goldelektrode

Eluenten: $\quad$ A: $10 \mathrm{mM} \mathrm{NaOH}$

B: $250 \mathrm{mM} \mathrm{NaOH}$

C: $25 \mathrm{mM} \mathrm{NaOH}+1 \mathrm{M} \mathrm{Na}$-Acetat

Waveform elekrochemischer Detektor:

\begin{tabular}{ccc}
\hline Zeit (sec) & $\begin{array}{c}\text { Potential (V) } \\
\text { vs. Ag/AgCl }\end{array}$ & Integration \\
\hline 0.00 & $-0,20$ & \\
0.04 & $-0,20$ & \\
0.05 & 0,00 & \\
0.21 & 0,00 & Start \\
0.22 & $+0,22$ & \\
0.46 & $+0,22$ & \\
0.47 & 0,00 & \\
0.56 & 0,00 & Ende \\
0.57 & $-2,00$ & \\
0.58 & $-2,00$ & \\
0.59 & $+0,60$ & \\
0.60 & $-0,20$ & \\
\hline
\end{tabular}


Gradientenmethode:

\begin{tabular}{ccccc}
\hline Zeit (min) & Curve Type & A (\%) & B (\%) & C (\%) \\
\hline 0.0 & 5 & 79.2 & 20.8 & 0.0 \\
2.0 & 5 & 79.2 & 20.8 & 0.0 \\
8.0 & 8 & 66.7 & 33.3 & 0.0 \\
11.0 & 8 & 66.7 & 33.3 & 0.0 \\
18.0 & 8 & 45.8 & 14.2 & 40.0 \\
21.0 & 5 & 50.0 & 10.0 & 40.0 \\
23.0 & 8 & 21.9 & 8.1 & 70.0 \\
42.0 & 5 & 21.9 & 8.1 & 70.0 \\
42.1 & 5 & 20.8 & 79.2 & 0.0 \\
44.1 & 5 & 20.8 & 79.2 & 0.0 \\
44.2 & 5 & 79.2 & 20.8 & 0.0 \\
75.0 & 5 & 79.2 & 20.8 & 0.0 \\
\hline
\end{tabular}

\subsubsection{Gas-Chromatographie (GC)}

Die qualitative Detektion von Ethanol erfolgte in Zusammenarbeit mit Frau S. Dummert (AG Schwarz, TU München). Zum Einsatz kam das Gerät GC-2010 der Firma Shimadzu mit einer Stabilwax-DA-Säule. Als Trägergas diente Stickstoff.

Methode:

\begin{tabular}{cc}
\hline Zeit (min) & Temperatur $\left({ }^{\circ} \mathrm{C}\right)$ \\
\hline 0.0 & 70 \\
5.0 & 98 \\
20.0 & 250 \\
\hline
\end{tabular}

\subsubsection{Quantitative Bestimmung von Acetat}

Zur Bestimmung von Acetat in Kulturüberständen wurde ein UV-Test der Firma R-BIOPHARM (Best. Nr. 10148261 035) verwendet. Nach geeigneter Verdünnung des Kulturüberstandes erfolgten die Messungen bei einer Temperatur von $25^{\circ} \mathrm{C}$ und einer Wellenlänge von $340 \mathrm{~nm}$ mit dem Varian cary 100 scan UV-Visible 
Spectrophotometer. Die Ansätze wurden nach Anleitung des Hersteller pipetiert, mit dem Unterschied, dass das Testvolumen $1 \mathrm{ml}$ betrug.

\subsubsection{Quantitative Bestimmung von Acetoin}

Acetoin wurde colorimetrisch im Kulturüberstand bei einer Wellenlänge von $546 \mathrm{~nm}$, wie bei Westerfeld (1945) beschrieben, bestimmt. Als Reagenzien dienten eine 0,5\%ige Creatin-Lösung (0,1 g in $20 \mathrm{ml} \mathrm{H}$ O) und eine 5\%ige 1-Naphthol-Lösung (1g in $20 \mathrm{ml}$ 2,5 N NaOH). Die Lösungen wurden frisch angesetzt. Der Kulturüberstand wurde geeignet verdünnt, die 0,5\%ige Creatin-Lösung zugegeben und im Anschluss daran die $5 \%$ ige Naphthol-Lösung. Die Inkubation erfolgte für 1 Stunde bei $30^{\circ} \mathrm{C}$.

\subsubsection{Quantitative Bestimmung von Ammoniak und Harnstoff}

Die Bestimmung von Ammoniak und Harnstoff im Kulturüberstand erfolgte mit einem UV-Test der Firma R-BIOPHARM (Best. Nr. 10542946 035). Wie bereits bei der quantitativen Bestimmung von Acetat beschrieben, erfolgten die Messungen nach geeigneter Verdünnung des Kulturüberstandes bei einer Temperatur von $25^{\circ} \mathrm{C}$ und einer Wellenlänge von $340 \mathrm{~nm}$ mit dem Varian cary 100 scan UV-Visible Spectrophotometer. Die Ansätze wurden nach Anleitung des Hersteller pipetiert, wiederum mit dem Unterschied, dass das Testvolumen $1 \mathrm{ml}$ betrug. 


\subsection{Oligonukleotide}

Tabelle 3.11: Primer real-time RT-PCR. Die Oligonukleotide wurden von der Firma Eurofins MWG Operon (Eurofins MWG Operon Sequencing Department, Ebersberg, Deutschland) synthetisiert.

\begin{tabular}{|c|c|}
\hline Primer & Sequenz $\left(5^{\prime} \rightarrow 3^{\prime}\right)$ \\
\hline blanRNRfor & CGAGAGTTCCAGACATTATGCG \\
\hline blanRNRrev & GACCAATGGTATCTGACAGCAAG \\
\hline blcydBfor & GTACTCACTGTCCTGACATGC \\
\hline blcydBrev & GACAAGGGTAACAGCATGTCG \\
\hline blglcKfor & GGAGGCAACAACAGTAAAACTCGC \\
\hline blglcKrev & ATGTGCTTCGGTTTGCCGAG \\
\hline blaslDfor & GTCTATCAGGTCTCAACGATGG \\
\hline blalsDrev & CGGAACGGAGACGGTAAAAC \\
\hline blldhfor & CATGGCAACTCCGTAGTATGTC \\
\hline blldhrev & GTCTGGAGCCATGCGAATATC \\
\hline blsdhBfor & CACTCGTCAGGATACATCGG \\
\hline blsdhBrev & GTTCATATCCCAAGCAATCGGC \\
\hline blrpoEfor & GGGAAAGAAGAGCTGGAAGAC \\
\hline blrpoErev & GTCGGCTGGGTTTCTTCATC \\
\hline bldeaDfor & GGGATGTTGTGGTGAAATCGC \\
\hline bldeaDrev & GTCAAATCCTCCTTAACCTGAGC \\
\hline ackA_fwd_rt & CGGTTTCCATGGTACATCTC \\
\hline ackA_rev_rt & AAGCGGTGTGAAGCCATTG \\
\hline BLi02132_fwd_rt & GCGCCTGAACCGAATTTAAC \\
\hline BLi02132_rev_rt & GGCGATTCCGTAGTCATCAC \\
\hline glpD_fwd_rt & CAACAGACACCGTCTACAAC \\
\hline glpD_rev_rt & TCATGAATCAGCGGTCTGAG \\
\hline mmgE_fwd_rt & TCCGCTGGCTCGATTATAAC \\
\hline mmgE_rev_rt & CCTTAACAATTGCCGTCAGG \\
\hline BLi04049 rt fwd & GGGCATGATGGAGACGTTTG \\
\hline BLi04049 rt rev & CTTCTGCTGCGCTTCTTGAG \\
\hline
\end{tabular}


Tabelle 3.11: Primer real-time RT-PCR. Fortführung.

\begin{tabular}{ll}
\hline Primer & Sequenz $\left(5^{\prime} \rightarrow 3^{\prime}\right)$ \\
\hline acoR rt fwd & TTTCCGACTGGAGGAGAATG \\
acoR rt rev & GAAACGGGATACGAGTGATG \\
mmsA rt fwd & AACCCGGCTTCATAGAACAG \\
mmsA rt rev & GATTTGGCGCTATCCTTTGG \\
BLi04275 rt fwd & CCAATCCGCTCAACATTGC \\
BLi04275 rt rev & CAATCGCCACGTCTACAAC \\
pdhD rt fwd & TCGAAGTGAAAGGCGAAGAG \\
pdhD rt rev & GATGATGTCACCGATCGCATAG \\
blrecOfor & CGAAAGCATGAGGAATATCCGC \\
blrecOrev & TACCGTCATTCAGCCTCCTC \\
\hline
\end{tabular}

Tabelle 3.12: Primer clean Deletion - Mutation. Die Oligonukleotide wurden von der Firma Eurofins MWG Operon (Eurofins MWG Operon Sequencing Department, Ebersberg, Deutschland) synthetisiert.

\begin{tabular}{llc}
\hline Primer & Sequenz $\left(5^{\prime} \rightarrow 3^{\prime}\right)$ & Schnittstelle \\
\hline mmgE_FA_fwd & TGCTGGATCCGCTTTACAGCGAGCA & BamHI \\
& CGAAATG & \\
mmgE_FA_rev_MS & GACCAATCGGGTATTCGACGTAACG & \\
mmgE_FB_fwd_MS & GATTGAAACCGCCCGTTACGTCGAA & \\
mmgE_FB_rev & TACCCGATTGGTC & NGCTCCATGGAGGAGCGGCGCTTTA \\
mmgE_check_fwd & ACAGCCGTCTTTGATCAG & \\
mmgE_check_rev & GGTAATGGCAGCCATTCC & \\
\hline
\end{tabular}




\subsection{Enzyme}

DNase (10000 U)

Proteinase K (15 mg/ml)

Taq DNA-Polymerase (5 U/ $\mu 1)$

Phire DNA-Polymerase

BamHI

EcoRI

NcoI

PstI
Roche Diagnostics, Mannheim, Deutschland

Sigma-Aldrich Chemie GmbH, München,

Deutschland

Qiagen GmbH, Hilden, Deutschland

Finnzymes, Espoo, Finnland

Fermentas GmbH, St. Leon-Rot, Deutschland

Fermentas GmbH, St. Leon-Rot, Deutschland

Fermentas GmbH, St. Leon-Rot, Deutschland

Fermentas GmbH, St. Leon-Rot, Deutschland

\subsection{Chemikalien und sonstige Geräte}

Sofern nicht anders angegeben wurden alle sonstigen verwendeten allgemeinen Chemikalien von Merck, Serva, Fluka, Sigma oder Roth in p.a. Qualität bezogen.

Autoklav

Biofuge fresco (Sorvall \# 3328)

Biofuge primo R (Sorvall \# 7588)

Eppendorf Centrifuge 5417R

Eppendorf Mastercycler gradient

Primus HT

Magnet-Heizrührer

Mikroskop Carl Zeiss

Spannungsgerät

Vortex Genie $2^{\mathrm{TM}}$

Waage Sartorius B1 3100

Typ 2462

Typ 2254

Wasservollentsalzungsanlage
Zirbus, Bad Grund, Deutschland

Heraeus Christ, Osterode, Deutschland

Heraeus Christ, Osterode, Deutschland

Eppendorf, Hamburg, Deutschland

Eppendorf, Hamburg, Deutschland

MWG AG Biotech

JAK Werk, Staufen

Zeiss, Göttingen, Deutschland

Bio-Rad Laboratories California USA

Bender \& Hobein AG, Zürich, Schweiz

Sartorius, Göttingen, Deutschland

Millipore, Schwalbach, Deutschland 


\section{Ergebnisse}

\subsection{Untersuchungen zum anaeroben Wachstum}

Im Rahmen dieser Arbeit wurde die Thematik des fermentativen Wachstums von B. licheniformis DSM13 erneut aufgegriffen (vgl. Schwarzer, 2005). Hintergrund hierfür war zum einen, dass nun die Möglichkeit bestand Transkriptionsanalysen mit Oligo-basierenden DNA-Microarrays durchführen zu können. Im Gegensatz zu DNA-Microarrays, welche auf PCR-Produkten basieren, zeichnen sich diese durch die Ausbildung eines geringeren Hintergrundes während der Hybridisierung aus. Zum anderen konnten nun potentielle Fermentationsendprodukte mittels Ionenchromatographie detektiert werden.

\subsubsection{Anaerobe Verwertung von Zuckern durch B. licheniformis}

Um die anaerobe Verwertung von Zuckern durch B. licheniformis zu untersuchen, wurde der Organismus in einem definierten Medium angezogen (vgl. 3.2.2. \& 3.3.2.). Als C-Quellen dienten neben den Pentosen Arabinose, Ribose, Xylose und den Hexosen Fructose, Galaktose und Glucose, auch die Disaccharide Maltose und Saccharose (Tab. 4.1).

Tabelle 4.1: Potenzielle Kohlenstoffquellen. Verwendet wurde ein Medium wie es unter 3.2.2. beschrieben ist, mit den angeführten Zuckern als Kohlenstoffquelle in einer Konzentration von 50 mM. Betrachtet wurde das Wachstum über einen Zeitraum von 50 Stunden. + Wachstum, - kein Wachstum

\begin{tabular}{lcc}
\hline Kohlenstoffquelle & Wachstum anaerob & Wachstum aerob \\
\hline L-Arabinose & - & + \\
D-Ribose & - & + \\
D-Xylose & - & + \\
D-Fructose & + & + \\
D-Galaktose & - & + \\
D-Glucose & + & + \\
Maltose & $(+)$ & + \\
Saccharose & + & + \\
\hline
\end{tabular}


Betrachtet man vergleichend die Verwertung verschiedener Kohlenstoffquellen durch DSM13, so ist $\mathrm{zu}$ beobachten, dass DSM13 unter anaeroben Wachstumsbedingungen keine der getesteten Pentosen verwerten konnte. Von den Hexosen konnten nur Glucose und Fructose, nicht aber Galaktose als Kohlenstoffquelle genutzt werden. Die Disaccharide Maltose und Saccharose konnten ebenfalls unter anaeroben Kultivierungsbedingungen verwertet werden, wobei einschränkend erwähnt werden muss, dass DSM13 ein schwaches Wachstum mit Maltose zeigte. Wurden diese Versuche hingegen unter aeroben Kultivierungsbedingungen durchgeführt, so war bei allen getesteten Kohlenstoffquellen, Pentosen, Hexosen, wie auch Disacchariden, ein Wachstum zu beobachten.

\subsubsection{Transkriptionsanalysen zum fermentativen Wachstum}

Wie bereits eingangs erwähnt, wurden im Rahmen dieser Arbeit Transkriptionsanalysen mit Oligo-basierenden DNA-Microarrys durchgeführt. Untersucht wurde die Genexpression bei Wachstum unter aeroben Bedingungen im Vergleich zum Wachstum unter anaeroben Bedingungen. Zur Anzucht für diese vergleichenden Expressionsanalysen wurde ein definiertes Medium mit 50 mM Glucose als Kohlenstoffquelle verwendet. Unter aeroben Bedingungen erfolgte die Kultivierung der Zellen in $100 \mathrm{ml}$ Batch-Kulturen, die bei einer $\mathrm{OD}_{600}$ von 0,5 bis 0,6 geerntet wurden. Auch die Kultivierung unter anaeroben Bedingungen erfolgte in Batch-Kulturen, das Volumen betrug jedoch hier $500 \mathrm{ml}$ und die Zellen wurden bei einer $\mathrm{OD}_{600}$ von 0,2 geerntet (vgl. Schwarzer, 2005). Des Weiteren wurde das Medium für die anaerobe Anzucht mit Thiamin supplementiert (Broman et al., 1978). Ausgewertet wurden die vergleichenden Genexpressionsanalysen anhand von 4 Hybridisierungen. Die verwendete RNA stammte aus mindestens jeweils zwei biologisch unabhängigen Experimenten. Es sei in diesem Zusammenhang darauf hingewiesen, dass es sich bei den Angaben der Expressionsdaten um keine absoluten Werte handelt. Als signifikant wird eine Änderung des Expressionverhältnisses um mindestens den Faktor 3 eingestuft (vgl. 3.8.6.). Die im weiteren gezeigten Expressionsdaten sind logarithmisch zur Basis 2 dargestellt und eine Änderung um den Faktor 3 dieser Daten entspricht Werten von 1,5849 bzw. $-1,5849$. 


\subsubsection{Vergleichende Genexpressionsanalyse des Wachstums unter aeroben bzw. anaeroben Bedingungen}

\section{Expression der Gene des Zentralstoffwechsels}

Zunächst lag der Focus des Interesses auf den Genen des Zentralstoffwechsels von DSM13. Für die Gene der Glykolyse konnte im Rahmen dieser Untersuchungen keine signifikante Genregulation ermittelt werden. Eine Übersicht der beteiligten Gene und deren Expressionswerte ist im Anhang in der Tabelle 7.1 aufgeführt.

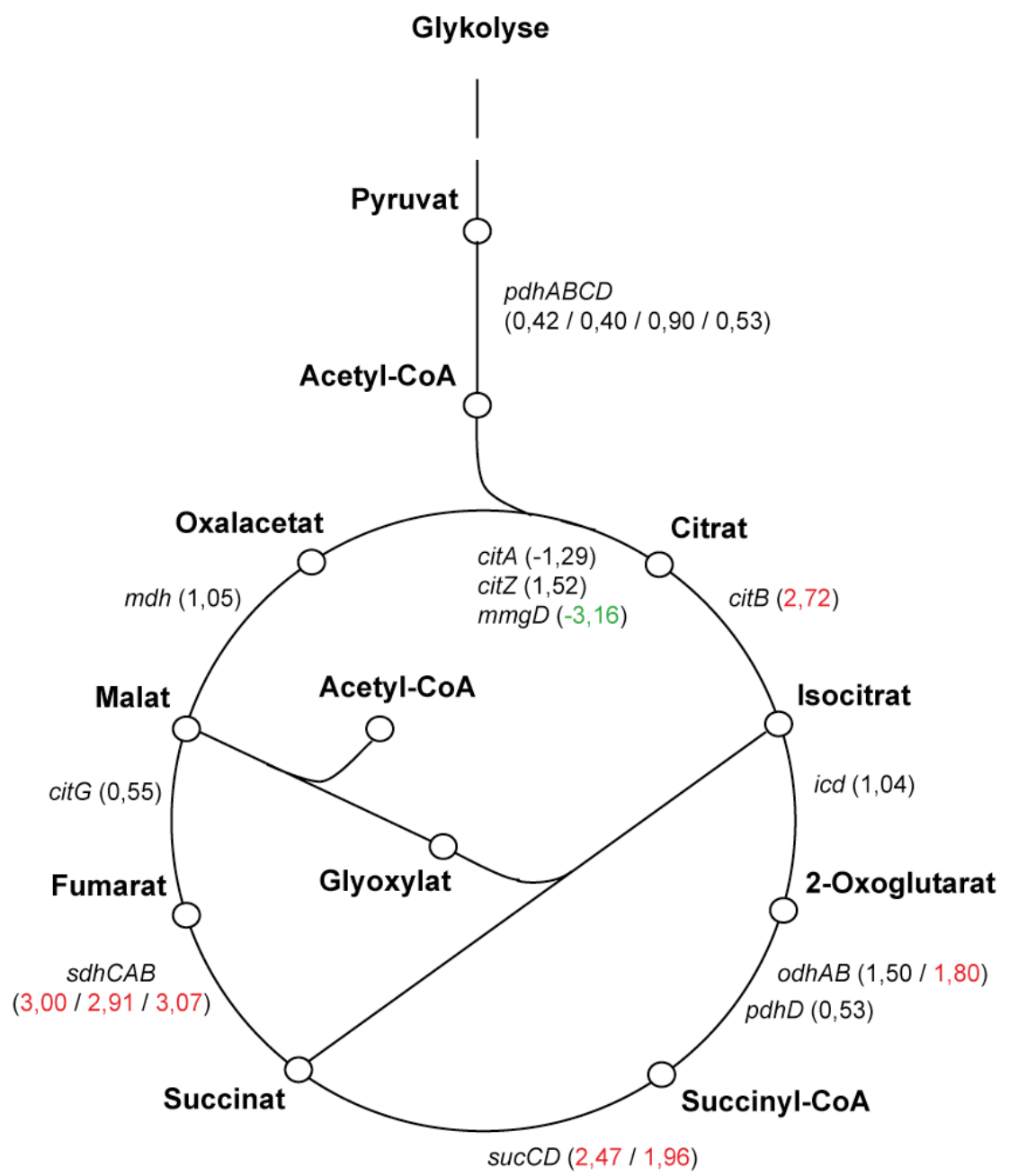

Abbildung 4.1: Schematische Darstellung des Tricarbonsäurezyklus. Angegeben sind die Expressionsverhältnisse der beteiligten Gene bei Wachstum unter aeroben Bedingungen im Vergleich zum Wachstum unter anaeroben Bedingungen. Werte größer 1 bedeuten eine verstärkte Expression unter aeroben Bedingungen, Werte kleiner -1 eine verstärkte Expression unter anaeroben Bedingungen. Die angegebenen Werte sind logarithmisch dargestellt und repräsentative Einzelmessungen. 
Die Ergebnisse der Transkriptionsanalyse für den Tricarbonsäurezyklus sind in Abbildung 4.1 dargestellt. Die in der eben genannten Abbildung verwendeten Gene und deren Funktion sind in der Tabelle 4.2 zu finden. Anders als im Zusammenhang mit der Glykolyse konnte für einige Gene des Tricarbonsäurezyklus eine signifikante Änderung der Expressionsverhältnisse beobachtet werden. Im Rahmen der Genomanalyse konnten für DSM13 drei Gene identifiziert werden, welche für Citrat-Synthasen kodieren. Eines dieser Gene, $m m g D$, zeigte unter anaeroben Wachstumsbedingungen eine erhöhte Expression. Auf der anderen Seite zeigten die Gene, welche an der Umsetzung zum Fumarat, ausgehend vom 2-Oxoglutarat, beteiligt sind, eine Induktion unter aeroben Kultivierungsbedingungen. Im Detail sind dieses Gene, die für die Untereinheiten der 2-Oxoglutarat-Dehydrogenase (odhAB), Succinyl-CoA-Synthase $(s u c C D)$ und Succinat-Dehydrogenase $(s d h C A B)$ kodieren. Gene, welche für die Untereinheiten der Pyruvat-Dehydrogenase kodieren, $p d h A B C D$, sowie die Gene der Fumarat Hydratase $(\mathrm{cit} G)$ und der Malat-Dehydrogenase $(m d h)$ zeigten keine Änderung des Expressionsverhältnisses.

Tabelle 4.2: Genkürzel und Funktionen der in Abbildung 4.1 dargestellten Gene des Tricarbonsäurezyklus.

\begin{tabular}{ll}
\hline Gen & Funktion \\
\hline$c i t A$ & Citratsynthase I \\
$c i t B$ & Aconitat-Hydratase \\
$c i t G$ & Fumarat-Hydratase \\
$c i t Z$ & Citratsynthase II \\
$i c d$ & Isocitrat-Dehydrogenase \\
$m d h$ & Malat-Dehydrogenase \\
$m m g D$ & Citratsynthase III \\
odhAB & Untereinheiten der 2-Oxoglutarat-Dehydrogenase \\
$p d h A B C$ & Untereinheiten der Pyruvat-Dehydrogenase \\
$p d h D$ & Untereinheit der Pyruvat-Dehydrogenase / \\
& Untereinheit der 2-Oxoglutarat-Dehydrogenase \\
$s d h C A B$ & Untereinheiten der Succinat-Dehydrogenase \\
sucCD & Untereinheiten der Succinyl-CoA-Synthetase \\
\hline
\end{tabular}




\title{
Expressionsdaten anderer Enzyme
}

Ribonukleotidreduktasen katalysieren die Reduktion von RibonukleosidTriphosphaten zu den entsprechenden Desoxyribonukleotiden. Für die katalytische Aktivität der anaeroben Ribonukleotidreduktase ist ein Sauerstoff-sensitives Glycyl-Radikal entscheidend. Zuständig für dessen Generierung und somit für die Aktivierung der Ribonukleotidreduktase ist ein spezifisches Aktivierungesenzym (Sun et al., 1995). Durch die Genomanalyse von DSM13 konnten die Gene einer putativen anaeroben Ribonukleotidreduktase und zwei potentiell zugehöriger Aktivierungsenzyme identifiziert werden. Die ORFs der anaeroben Ribonukleotidreduktase (BLi03824) und eines der putativen Aktivierungesenzyme (BLi03823) sind direkt nebeneinander lokalisiert (Abb. 4.2). Flankiert werden diese downstream von dem Gen der Mannose-6Phosphat-Isomerase (pmi) und upstream von einem Gencluster der Pectinverwertung $(k d g T A K R)$. Das Gen des zweiten putativen Aktivierungsenzyms ist etwa $344 \mathrm{~kb}$ upstream lokalisiert.

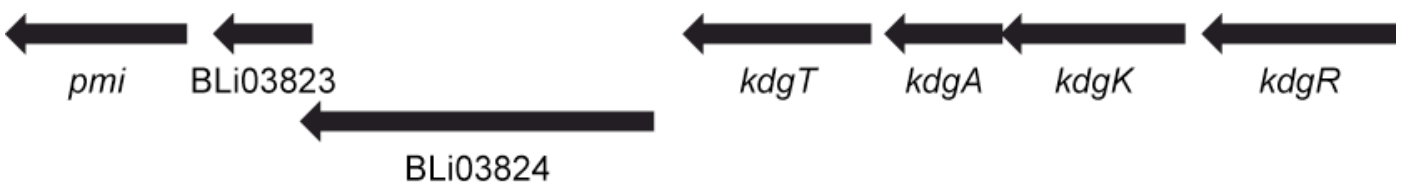

\begin{abstract}
Abbildung 4.2: Schematische Anordnung des ORFs der putativen anaeroben Ribonukleotidreduktase und der angrenzenden Gene im Genom von B. licheniformis DSM13. Erläuterung im Text.
\end{abstract}

Unter anaeroben Kultivierungsbedingungen konnte für den ORF der anaeroben Ribonukleotidreduktase (EC 1.17.4.2, BLi03824) eine signifikant erhöhte Expression ermittelt werden (Tab. 4.3). Für ein zugehöriges Aktivierungsenzym würde man ein ähnliches Verhalten erwarten. Tatsächlich konnte für eines der putativen Aktivierungsenzyme (BLi03823) mit einem Wert von -4,63 ebenfalls eine stärkere Expression unter diesen Wachstumsbedingungen beobachtet werden. Das Gen des zweiten putativen Aktivierungsenzym (BLi04172) hingegen zeigte mit einem Wert von 0,53 keine signifikante Änderung der Expression. Die Gene der aeroben Ribonukleotidreduktasen $n r d E$ und $n r d F$ waren während des fermentativen Wachstums reprimiert. 
Tabelle 4.3: Expressionsverhältnisse der ORFs der Ribonukleotidreduktasen. Werte größer 1 bedeuten eine verstärkte Expression unter aeroben Bedingungen, Werte kleiner -1 eine verstärkte Expression unter anaeroben Bedingungen. Die Tabelle enthält repräsentative Einzelmessungen.

\begin{tabular}{|c|c|c|c|}
\hline ID & Gen & Annotation & $\begin{array}{c}\text { log Expressionsverhältnisse } \\
\text { aerob / anaerob }\end{array}$ \\
\hline BLi03824 & & $\begin{array}{l}\text { putative anaerobe } \\
\text { Ribonukleotidreduktase }\end{array}$ & $-4,61$ \\
\hline BLi03823 & & $\begin{array}{l}\text { Aktivierungsenzym putative } \\
\text { anaerobe Ribonukleotidreduktase }\end{array}$ & $-4,63$ \\
\hline BLi04172 & & $\begin{array}{l}\text { Aktivierungsenzym putative } \\
\text { anaerobe Ribonukleotidreduktase }\end{array}$ & 0,53 \\
\hline BLi01966 & $n r d E$ & $\begin{array}{l}\text { Ribonukleosid-diphosphat } \\
\text { Reduktase (gr. Untereinheit) }\end{array}$ & 1,74 \\
\hline BLi01967 & $n r d F$ & $\begin{array}{l}\text { Ribonukleosid-diphosphat } \\
\text { Reduktase (kl. Untereinheit) }\end{array}$ & 1,93 \\
\hline
\end{tabular}

Im Genus Bacillus konnten verschiedene Typen von terminalen Oxidasen identifiziert werden (von Wachenfeldt und Hederstedt, 2002). Zum einen sind dieses Häm-Kupfer Oxidasen und zum anderen Oxidasen des Typs Cytochrom bd. Ersteren Typs können Cytochrom $\mathrm{aa}_{3}$, sowie Cytochrom $\mathrm{caa}_{3}$ zugeordnet werden und dienen, im Gegensatz zu Oxidasen des Cytochrom bd Typs, als Protonenpumpen. Die vier Untereinheiten des Cytochroms $a a_{3}$, einer Quinol-Oxidase, werden von den Genen qox $A B C D$ kodiert. Unter anaeroben Wachstumsbedingungen werden diese reprimiert (Tab. 4.4). Die Gene, welche die vier Untereinheiten des Cytochroms $\mathrm{caa}_{3}$ kodieren, $c t a C D E F$, zeigten hingegen keine signifikante Expressionsänderung. Zur Expression des Cytochroms $b d$ werden in $B$. subtilis alle durch die $c y d A B C D$ kodierten Proteine benötigt (Winstedt et al., 1998). Hierbei stellen CydA und CydB die strukturellen Proteine der Oxidase dar. Eine Induktion unter anaeroben Kultivierungsbedingungen konnte sowohl für die kodierenden Gene dieser strukturellen Proteine, als auch für die am Transport beteiligten Gene $c y d C$ und $c y d D$ beobachtet werden. Anders hingegen die Expressionsverhältnisse der Gene $q c r A B C$, die für die Untereinheiten des Cytochrom $b c$ Komplexes kodieren. Hier konnte nur für die Gene $q c r B$ und $q c r C$, nicht aber für das 
Gen $q c r A$ eine erhöhte Expression unter anaeroben Wachstumsbedingungen beobachtet werden.

Tabelle 4.4: Komponenten der Elektronentransportkette. Werte größer 1 bedeuten eine verstärkte Expression unter aeroben Bedingungen, Werte kleiner -1 eine verstärkte Expression unter anaeroben Bedingungen. Die Tabelle enthält repräsentative Einzelmessungen.

\begin{tabular}{|c|c|c|c|c|}
\hline ID & Gen & Häm-Protein & Funktion & $\begin{array}{c}\log \\
\text { Expressionsverhältnisse } \\
\text { aerob / anaerob }\end{array}$ \\
\hline BLi01704 & $\operatorname{ctaA}$ & & $\begin{array}{l}\text { Biosynthese von } \\
\text { Cytochrom } \mathrm{caa}_{3}\end{array}$ & $-1,55$ \\
\hline BLi01705 & $c t a B$ & & $\begin{array}{l}\text { Assembly Faktor } \\
\text { Cytochrom } \mathrm{caa}_{3}\end{array}$ & 0,42 \\
\hline BLi01706 & $\operatorname{ctaC}$ & Cytochrom $\mathrm{caa}_{3}$ & Cytochrom $\mathrm{caa}_{3}$ & 0,48 \\
\hline BLi01707 & $c t a D$ & & Oxidase & 0,43 \\
\hline BLi01708 & $\operatorname{ctaE}$ & & & 0,53 \\
\hline BLi01709 & $c t a F$ & & & $-0,09$ \\
\hline BLi02391 & $q c r A$ & Cytochrom $b c$ & Menaquinol- & $-0,39$ \\
\hline BLi02390 & $q c r B$ & & Cytochrom $c$ & $-1,37$ \\
\hline BLi02389 & $q c r C$ & & Oxidoreduktase & $-1,52$ \\
\hline BLi04040 & $\operatorname{qox} A$ & Cytochrom $a a_{3}$ & Cytochrome $a a_{3}$ & 2,68 \\
\hline BLi04039 & $q o x B$ & & Quinol-Oxidase & 3,38 \\
\hline BLi04038 & $q o x C$ & & & 2,88 \\
\hline BLi04037 & qoxD & & & 2,87 \\
\hline BLi04134 & $c y d A$ & Cytochrom $b d$ & Cytochrome $b d$ & $-4,94$ \\
\hline BLi04133 & $c y d B$ & & Ubiquinol-Oxidase & $-5,47$ \\
\hline BLi04132 & $\operatorname{cyd} d C$ & & ABC-Transporter & $-5,57$ \\
\hline BLi04131 & $c y d D$ & & ABC-Transporter & $-5,50$ \\
\hline
\end{tabular}

Im folgendem wurden nun die Expressionsverhältnisse von Genen, welche mit der Nitrat/Nitrit-Atmung im Zusammenhang stehen, untersucht. Neben den Genen res $D$ und resE, welche für Zwei-Komponenten Regulatorproteine in B. subtilis kodieren (Sun et al., 1996), zeigten auch weitere Komponenten der Nitrat/Nitrit-Atmung eine 
Tabelle 4.5: Expressionsverhältnisse von Komponenten der Nitrat/Nitrit-Atmung. Werte größer 1 bedeuten eine verstärkte Expression unter aeroben Bedingungen, Werte kleiner -1 eine verstärkte Expression unter anaeroben Bedingungen. Werte, die mit einem Stern versehen sind, erfüllen nicht vollständig die Kriterien zur Ermittlung der Expressionsverhältnisse wie unter 3.8.6. beschrieben. Die Tabelle enthält repräsentative Einzelmessungen. n.b. - nicht bestimmt

\begin{tabular}{|c|c|c|c|}
\hline ID & Gen & Annotation & $\begin{array}{c}\text { log Expressionsverhältnisse } \\
\text { aerob / anaerob }\end{array}$ \\
\hline BLi02456 & $r e s D$ & $\begin{array}{l}\text { Zwei-Komponenten Response- } \\
\text { Regulator }\end{array}$ & $-2,23$ \\
\hline BLi02458 & $\operatorname{res} E$ & $\begin{array}{l}\text { Zwei-Komponenten Histindin- } \\
\text { Sensor Kinase }\end{array}$ & $-1,87$ \\
\hline BLi02080 & fnr & $\begin{array}{l}\text { transkriptionaler Regulator } \\
\text { anaerober Gene }\end{array}$ & $-4,37$ \\
\hline BLi02081 & $\operatorname{narK}$ & Nitrit Export Protein & $-8,38$ \\
\hline BLi02078 & $\operatorname{arf} M$ & Regulator anaerober Gene & $-8,97$ \\
\hline BLi02074 & $\operatorname{nar} G$ & Nitrat-Reduktase (Untereinheit) & $-8,97$ \\
\hline BLi02073 & narH & Nitrat-Reduktase (Untereinheit) & $-8,97$ \\
\hline BLi02072 & narJ & Nitrat-Reduktase (Protein J) & $-8,16$ \\
\hline BLi02071 & narI & Nitrat-Reduktase (Untereinheit) & $-7,97$ \\
\hline BLi03915 & $\operatorname{moaA}$ & Molybdopterin Vorläufer & $-2,64$ \\
\hline BLi00482 & $n a s B$ & $\begin{array}{l}\text { assimilatorische Nitrat-Reduktase } \\
\text { (Untereinheit) }\end{array}$ & $-0,62$ \\
\hline BLi00483 & nas $C$ & $\begin{array}{l}\text { assimilatorische Nitrat-Reduktase } \\
\text { (Untereinheit) }\end{array}$ & n.b. \\
\hline BLi00484 & nas $D$ & $\begin{array}{l}\text { assimilatorische Nitrit-Reduktase } \\
\text { (Untereinheit) }\end{array}$ & $-1,69$ \\
\hline BLi00485 & nasE & $\begin{array}{l}\text { assimilatorische Nitrit-Reduktase } \\
\text { (Untereinheit) }\end{array}$ & $-1,39$ \\
\hline BLi00486 & nas $F$ & $\begin{array}{l}\text { Uroporphyrin-III- } \\
\text { Methyltransferase }\end{array}$ & $-1,25$ \\
\hline BLi01006 & $h m p$ & Flavohämoglobin & $-0,02 *$ \\
\hline
\end{tabular}


erhöhte Expression unter anaeroben Wachstumsbedingungen (Tab. 4.5). Darunter befinden sich Gene der Nitrat-Reduktase (narGHJI), wie auch narK, involviert in den Nitrit Export. Ebenso Gene, welche für die Untereinheiten der assimilatorischen NitritReduktase (nasD und nasE) kodieren. Organisiert sind diese im Genom zusammen mit den Genen der assimilatorischen Nitrat-Reduktase (nasB und nasC) und dem Gen nas $F$, welches für ein Enzym kodiert, dass in der Synthese von Sirohäm involviert ist (Abb. 4.3).

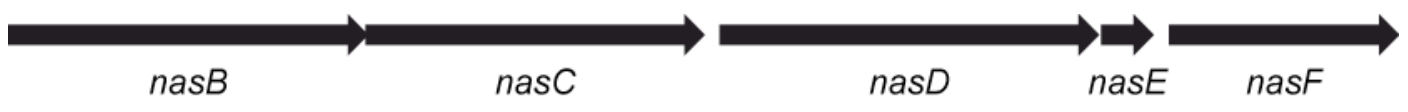

Abbildung 4.3: Schematische Anordnung der Gene der assimilatorischen Nitrat- und NitritReduktasen im Genom von B. licheniformis DSM13. Erläuterung im Text.

Daneben sind in der Tabelle 4.5 Expressionsverhältnisse von Genen angeben, die für Enzyme mit regulatorischer Funktion im Zusammenhang mit anaeroben Wachstum kodieren. Zu nennen wären hier die ORFs BLi02078 und BLi02080. Letzterer konnte bereits in B. licheniformis als Gen identifiziert werden, welches für den Sauerstoff sensitiven transkriptionalen Regulator Fnr kodiert (Klinger et al., 1998). Sowohl für fnr (BLi02080), als auch für arfM (BLi02078) konnten eine Induktion unter anaeroben Kultivierungsbedingungen beobachtet werden.

In diesem Zusammenhang ist die Lokalisation einiger der eben beschriebenen ORFs im Genom interessant (Abb. 4.4). So befinden sich die Gene fnr, arf $M$ und Gene, welche für die Untereinheiten der Nitrat Reduktase (narGHJ) kodieren in Nachbarschaft zueinander. Ebenfalls dort lokalisiert ist das Gen narK. Ausgenommen fnr handelt es sich hierbei um Gene, welche mit Werten von etwa -8 eine sehr erhöhte Expression aufweisen (Tab. 4.5). Des Weiteren konnten mittels virtual footprint, einer Software die zur Vorhersage möglicher binding sites von Transkriptionsfaktoren in Prokaryoten dient (Münch et al., 2005), potentielle Fnr bindig sites in B. licheniformis DSM13 identifiziert werden (Tab. 4.6). 


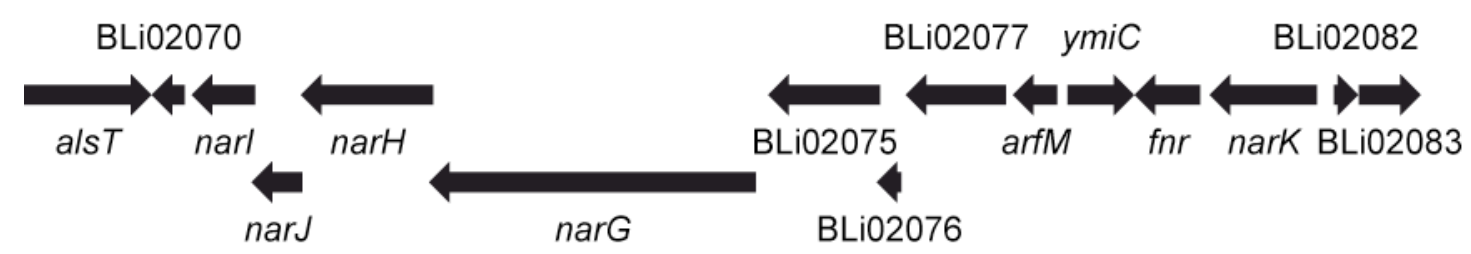

Abbildung 4.4: Übersicht der genetische Anordnung von ORFs in B. licheniformis DSM13, welche im Zusammenhang mit Komponenten der Nitrat/Nitrit Atmung stehen.

Für die Suche der potenziellen Fnr binding sites wurde die Sequenz (TGTGAN 6 TCACA) aus B. subtilis verwendet (Cruz Ramos et al., 1995). Unter anderem konnten jeweils upstream der Gene narG, arfM und narK mögliche Fnr binding sites identifiziert werden. In Tabelle 4.6 sind diese Bindemotive mit der Distanz zum Startcodon des jeweiligen ORFs angegeben.

Tabelle 4.6: Auswahl putativer Fnr binding sites in DSM13. Erläuterung im Text.

\begin{tabular}{lllc}
\hline ID & Gen & Sequenz $^{\mathrm{a}}$ & 5'UTR $^{\mathrm{b}}$ \\
\hline BLi02081 & narK & TGACCGTGTGACGTAATTCACAATGTTTTA & 80 \\
BLi02078 & arfM & CAGTCGTGTGAATTAAATCACTGCGCCCTG & 58 \\
BLi02074 & narG & AAACCATGTGACAAATTTAACAAGGTGCAG & 65 \\
BLi02132 & & AAAATATGTGATGTTTATCACATTCAAACC & 81 \\
B. subtilis & & & \\
Consensus & $-\ldots \ldots$-TGTGA - $\ldots$ - TCACA - $\ldots \ldots \ldots \ldots$ & \\
\hline
\end{tabular}

${ }^{a}$ Die Basen der Consensussequenz sind fett hervorgehoben.

${ }^{\mathrm{b}}$ Die angegebene Zahl steht für die Anzahl der Basenpaare von der ersten Base hinter dem Consensus bis zur ersten Base des Startcodons.

Die Pyruvat-Formiat-Lyase ( $p f l$ ) katalysiert die Umwandlung von Pyruvat zu Acetyl-CoA und Formiat. Es konnte in E. coli gezeigt werden, dass es sich hierbei um ein Radikalenzym handelt, dessen Bildung durch ein Aktivierungsenzym katalysiert wird (Knappe et al., 1984; Wagner et al., 1992). Im Genom von DSM13 konnte ein ORF für eine mögliche Pyruvat-Formiat-Lyase (EC 2.3.1.54) identifiziert werden. Beschrieben wurde dessen Produkt als putative Formiat-Acetyltransferase (BLi02132). Direkt daneben ist der ORF eines putativen Aktivierungsenzyms der Pyruvat-FormiatLyase (BLi02131) lokalisiert (Abb. 4.5). 


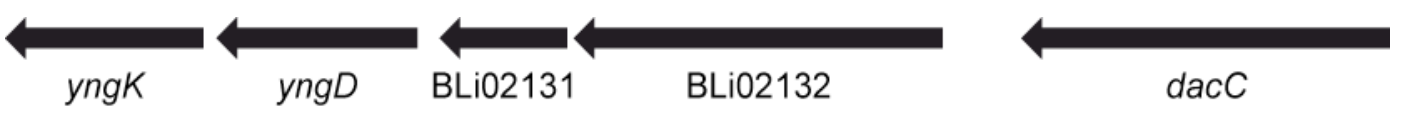

Abbildung 4.5: Schematische Anordnung des ORFs der putativen Pyruvat-Formiat-Lyase und der angrenzenden Gene im Genom von B. licheniformis DSM13. Erläuterung im Text.

Begrenzt werden dieses Gene upstream von $d a c C$, ein Gen welches für ein Penicillinbindendes Protein kodiert und downstream von den Genen yngKD, dessen Funktionen bisher nicht bekannt sind. Interessanterweise konnte auch vor dem ORF der putativen Pyruvat-Formiat-Lyase eine potenzielle Fnr bindig site identifiziert werden (Tab. 4.6). Sie befindet sich 81 bp upstream des ORFs und liegt hoch konserviert vor.

Tabelle 4.7: Expressionsverhältnisse der Gene der putativen Pyruvat-Formiat-Lyase und des Multienzymkomplexes Pyruvat-Dehydrogenase. Werte größer 1 bedeuten eine verstärkte Expression unter aeroben Bedingungen, Werte kleiner -1 eine verstärkte Expression unter anaeroben Bedingungen. Die Tabelle enthält repräsentative Einzelmessungen.

\begin{tabular}{|c|c|c|c|}
\hline ID & Gen & Annotation & $\begin{array}{c}\text { log Expressionsverhältnisse } \\
\text { aerob / anaerob }\end{array}$ \\
\hline BLi02131 & & $\begin{array}{l}\text { putatives Aktivierungsenzym der } \\
\text { Pyruvat-Formiat-Lyase }\end{array}$ & $-8,97$ \\
\hline BLi02132 & & $\begin{array}{l}\text { putative Formiat- } \\
\text { Acetyltransferase }\end{array}$ & $-8,16$ \\
\hline BLi01674 & $p d h A$ & $\begin{array}{l}\text { Pyruvat-Dehydrogenase } \\
\text { (Untereinheit) }\end{array}$ & 0,42 \\
\hline BLi01675 & $p d h B$ & $\begin{array}{l}\text { Pyruvat-Dehydrogenase } \\
\text { (Untereinheit) }\end{array}$ & 0,40 \\
\hline BLi01676 & $p d h C$ & $\begin{array}{l}\text { Pyruvat-Dehydrogenase } \\
\text { (Untereinheit) }\end{array}$ & 0,90 \\
\hline BLi01677 & $p d h D$ & $\begin{array}{l}\text { Pyruvat-Dehydrogenase / } \\
\text { 2-Oxoglutarat-Dehydrogenase } \\
\text { (Untereinheit) }\end{array}$ & 0,53 \\
\hline
\end{tabular}


Im Gegensatz hierzu fehlt $B$. subtilis dieses Gen und verwendet an dessen Stelle den Multienzymkomplex der Pyruvat-Dehydrogenase für ein sehr schwach ausgeprägtes fermentatives Wachstum (Nakano et al., 1997). Die durchgeführten Transkriptionsanalysen ergaben für DSM13, dass sowohl der ORF der putativen Pyruvat-Formiat-Lyase (BLi02132), als auch der angrenzende ORF des putativen Aktivierungsenzyms (BLi02131) unter anaeroben Wachstumsbedingungen eine signifikant erhöhte Expression zeigten. Für die Untereinheiten der PyruvatDehydrogenase kodierenden Gene (BLi01674 - BLi01677) konnte hingegen keine starke Änderung des Expressionverhältnisses beobachtet werden (Tab. 4.7).

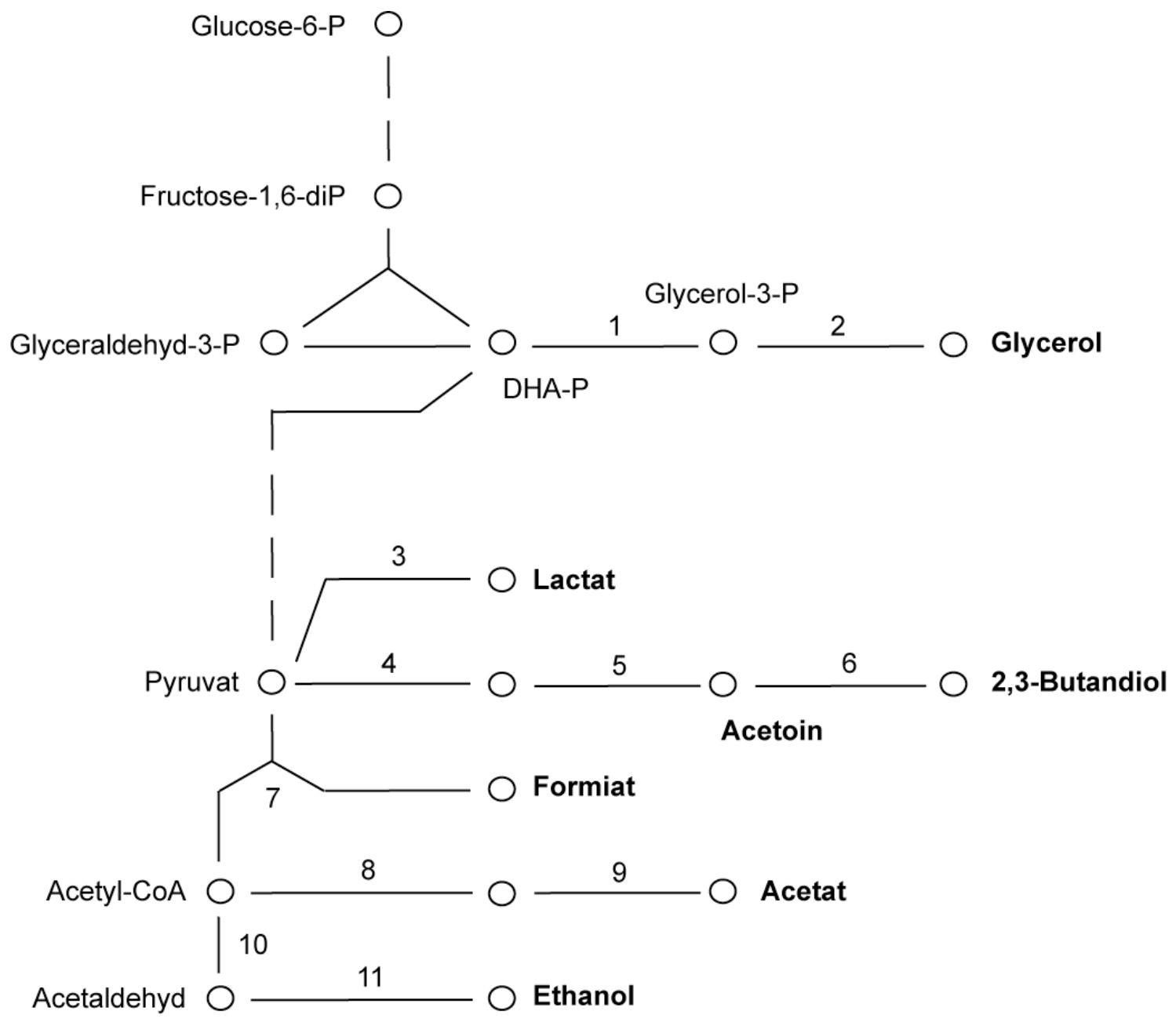

Abbildung 4.6: Schematische Übersicht möglicher Fermentationsprodukte von B. licheniformis DSM13. 1, Glycerol-Dehydrogenase; 2, Glycerophosphatase; 3, Lactat-Dehydrogenase; 4, $\alpha$-AcetolactatSynthase; 5, $\alpha$-Acetolactat-Decarboxylase; 6, Acetoin-Reduktase; 7, Pyruvat-Formiat Lyase; 8, Phosphotransacetylase; 9, Acetat-Kinase; 10, Acetaldehyd-Dehydrogenase; 11; AlkoholDehydrogenase; DHA-P - Dihydroxyaceton-Phosphat 
Tabelle 4.8: Expressionsverhältnisse von Genen, welche im Zusammenhang mit der Bildung von Fermentationsendprodukten stehen. Werte größer 1 bedeuten eine verstärkte Expression unter aeroben Bedingungen, Werte kleiner -1 eine verstärkte Expression unter anaeroben Bedingungen. Werte, die mit einem Stern versehen sind, erfüllen nicht vollständig die Kriterien zur Ermittlung der Expressionsverhältnisse wie unter 3.8.6. beschrieben. Die Tabelle enthält repräsentative Einzelmessungen.

\begin{tabular}{|c|c|c|c|}
\hline ID & Gen & Annotation & $\begin{array}{c}\text { log Expressionsverhältnisse } \\
\text { aerob / anaerob }\end{array}$ \\
\hline BLi00366 & $l d h$ & Lactat-Dehydrogenase & $-3,94 *$ \\
\hline BLi00367 & $l c t P$ & Lactat-Permease & $-4,12^{*}$ \\
\hline BLi02066 & & putative Acetoin-Reduktase & $-4,08$ \\
\hline BLi02132 & & putative Formiat-Acetyltransferase & $-8,16$ \\
\hline BLi03086 & ack $A$ & Acetat-Kinase & 1,82 \\
\hline BLi03847 & als $D$ & $\alpha$-Acetolactat-Decarboxylase & $-2,73$ \\
\hline BLi03848 & als $S$ & $\alpha$-Acetolactat-Synthase & $-4,08$ \\
\hline \multirow[t]{2}{*}{ BLi03849 } & alsR & transkriptionaler Regulator des & $-0,60$ \\
\hline & & $\alpha$-Acetolactat-Operons & \\
\hline BLi03997 & pta & Phosphotransacetylase & 1,86 \\
\hline
\end{tabular}

Wie bereits eben erläutert, ist die Pyruvat-Formiat-Lyase an der Bildung von Formiat beteiligt. Dieses ist eines der Produkte, welches mittels NMR-Spektroskopie im Zusammenhang mit der Fermentation von B. licheniformis identifiziert wurde (Shariati et al., 1995). Weitere in dieser Publikation beschriebene Produkte sind unter anderem Acetat, 2,3-Butandiol, Ethanol, Glycerol und Lactat. Anhand der in Tabelle 4.8 dargestellten Expressionsverhältnisse kann man erkennen, dass Gene, welche an der Bildung von Fermentationsendprodukten beteiligt sind, eine Induktion unter anaeroben Bedingungen im Vergleich zu aeroben Wachstumsbedingungen zeigten. Dazu gehören das Gen der Lactat-Dehydrogenase $(l d h)$, welche die Umsetzung von Pyruvat zu Lactat katalysiert (Abb. 4.6). Im Genom von DSM13 direkt daneben lokalisiert ist das Gen der Lactat-Permease $(l c t P)$. Dieses war ebenfalls unter anaeroben Wachstumsbedingungen induziert. Des Weiteren sind die Gene alsS und $a l s D$ zu nennen. Diese kodieren für die $\alpha$-Acetolactat-Synthase $($ als $S)$ und $\alpha$-Acetolactat-Decarboxylase $(\operatorname{als} D)$, welche an der Bildung von Acetoin beteiligt sind. Für das Gen des zugehörigen transkriptionalen Repressors, alsR, konnte hingegen keine erhöhte Änderung des Expressions- 
verhältnisses ermittelt werden. Der ORF BLi02066 kodiert für eine putative AcetoinReduktase (EC 1.1.1.5), welche die Reduktion von Acetoin zu 2,3-Butandiol katalysiert. Wie schon die Gene, die an der Bildung von Acetoin beteiligt sind (alsSD), so konnte auch für diesen ORF eine erhöhte Expression beim Wachstum unter anaeroben Bedingungen beobachtet werden. Gene, welche an der Bildung von Acetat involviert sind, namentlich pta und ackA, waren hingegen unter anaeroben Wachstumsbedingungen reprimiert.

Tabelle 4.9: Expressionsverhältnisse von Genen, welche im Zusammenhang mit dem Fermentationsendprodukt Glycerol stehen. Werte größer 1 bedeuten eine verstärkte Expression unter aeroben Bedingungen, Werte kleiner -1 eine verstärkte Expression unter anaeroben Bedingungen. Die Tabelle enthält repräsentative Einzelmessungen.

\begin{tabular}{|c|c|c|c|}
\hline ID & Gen & Funktion & $\begin{array}{c}\text { log Expressionsverhältnisse } \\
\text { aerob / anaerob }\end{array}$ \\
\hline BLi00828 & gldA & putative Glycerol-Dehydrogenase & 1,11 \\
\hline BLi00993 & $g l p P$ & $\begin{array}{l}\text { transkriptionaler Antiterminator } \\
\text { und Kontrolle der mRNA Stabilität } \\
\text { von } g l p D\end{array}$ & 1,11 \\
\hline BLi00994 & $g l p F$ & $\begin{array}{l}\text { Unterstützung der Glycerol- } \\
\text { Aufnahme }\end{array}$ & 0,49 \\
\hline BLi00995 & $g l p K$ & Glycerol-Kinase & 0,32 \\
\hline BLi00996 & $g l p D$ & $\begin{array}{l}\text { Glycerol-3-Phosphat- } \\
\text { Dehydrogenase }\end{array}$ & $-2,78$ \\
\hline BLi02420 & $g p s A$ & $\begin{array}{l}\text { NAD }(\mathrm{P}) \mathrm{H} \text { abhängige Glycerol-3- } \\
\text { Phosphat-Dehydrogenase }\end{array}$ & $-0,27$ \\
\hline BLi04259 & & $\begin{array}{l}\text { putative Glycerol-1-Phosphat- } \\
\text { Dehydrogenase }\end{array}$ & $-4,88$ \\
\hline BLi04260 & $y k r X$ & $\begin{array}{l}\text { YkrX / } \\
\text { putative D- } \alpha \text {-Glycerophosphatase }\end{array}$ & $-4,28$ \\
\hline
\end{tabular}

Ein einleitender Schritt zur Bildung von Glycerol als Fermentationsendprodukt kann durch eine Dehydrogenasereaktion ausgehend vom Dihydroxyaceton-Phopsphat katalysiert werden (Abb. 4.6). Im Genom von DSM13 konnten vier Gene identifiziert 
werden, dessen Produkt in Verbindung mit Glycerol-Dehydrogenasen annotiert wurde (Tab. 4.9). Beim Wachstum unter anaeroben Kultivierungsbedingungen konnten nur für die ORFs BLi00996 und BLi04259 eine erhöhte Expression im Vergleich zum aeroben Wachstum beobachtet werden. Im Genom von DSM13 ist der ORF BLi00996 ( $g l p D)$ mit Genen ( $g l p P F K)$ assoziiert, welche mit der Verwertung von Glycerol in Verbindung stehen. Für diese Gene konnte unter den gegebenen Versuchsbedingungen keine signifikante Änderung des Expressionsverhältnisses beobachtet werden (Tab. 4.9). Anders hingegen das in direkter Nachbarschaft zum ORF BLi04259 lokalisierte Gen $y k r X$ (BLi04260). Dieses zeigte eine erhöhte Expression unter anaeroben Wachstumsbedingungen. Über UniProtKB/TrEMBL (Q65CZ1_BACLD) konnte dessen Produkt als putative D- $\alpha$-Glycerophosphatase ermittelt werden.

Tabelle 4.10: Expressionsverhältnisse von Genen, welche im Zusammenhang mit AlkoholDehydrogenasen stehen. Werte größer 1 bedeuten eine verstärkte Expression unter aeroben Bedingungen, Werte kleiner -1 eine verstärkte Expression unter anaeroben Bedingungen. Die Tabelle enthält repräsentative Einzelmessungen. n.b. - nicht bestimmt, put. - putativ

\begin{tabular}{lllc}
\hline ID & Gen & Annotation & $\begin{array}{c}\text { log Expressionsverhältnisse } \\
\text { aerob / anaerob }\end{array}$ \\
\hline BLi00509 & $y d a D$ & ähnl. zur Alkohol-Dehydrogenase & n.b. \\
BLi00992 & $y$ ogA & ähnl. zur Alkohol-Dehydrogenase & $-0,04$ \\
BLi01117 & $y h x C$ & ähnl. zur Alkohol-Dehydrogenase & $-3,97$ \\
BLi01355 & $y j m D$ & ähnl. zur Alkohol-Dehydrogenase & 0,51 \\
BLi02097 & $a d h A$ & NADP abhängige Alkohol- & $-0,71$ \\
& & Dehydrogenase & $-0,21$ \\
BLi03269 & gbsB & Alkohol-Dehydrogenase & n.b. \\
BLi03502 & & putative Alkohol-Dehydrogenase & $-1,04$ \\
BLi03831 & $a d h B$ & Alkohol-Dehydrogenase & $-7,97$ \\
BLi04290 & & put. Alkohol-Dehydrogenase / & \\
& & Acetaldehyd-Dehydrogenase &
\end{tabular}

Wie in der Abbildung 4.6 beschrieben kann die Umsetzung zu Ethanol, beginnend vom Acetyl-CoA, durch die Enzyme Acetaldehyd-Dehydrogenase und Alkohol-Dehydrogenase erfolgen. Untersuchungen in E. coli haben gezeigt, dass diese 
beiden Reaktionen auch durch eine Alkohol-Dehydrogenase (EC 1.1.1.1) katalysiert werden kann (Goodlove et al., 1989). Im Zusammenhang mit der AcetaldehydDehydrogenase bzw. Alkohol-Dehydrogenase konnten in DSM13 neun ORFs identifiziert werden (Tab. 4.10). Nur für zwei von ihnen wurde eine erhöhte Expression beim anaeroben Wachstum beobachtet. Im einzelnen sind dieses der ORF BLi01117, dessen Produkt Ähnlichkeit mit einer Alkohol-Dehydrogenase aufweist und der ORF BLi04290, welcher wiederum für eine putative Alkohol- bzw. AcetaldehydDehydrogenase kodiert. Ein für den letztgenannten ORF durchgeführter Sequenzvergleich durch BLAST auf Aminosäureebene ergab eine mehr als 50\%ige Übereinstimmung mit dem Alkohol-Dehydrogenase-Enzym AdhE aus E. coli K12 (Daten nicht gezeigt).

\subsubsection{Verifizierung ausgewählter Daten der DNA-Microarray-Experimente durch real-time RT-PCR}

Für einige ausgewählte Gene sollten die mit dem DNA-Microarray beobachteten Expressionsdaten durch eine zweite Methode verifiziert werden. Zur Validierung der Daten wurde die real-time RT-PCR herangezogen. Wie für die DNA-MicroarrayAnalysen wurde auch für die Analyse mittels real-time RT-PCR die RNA aus B. licheniformis Zellen in je zwei unabhängigen Kultivierungen unter anaeroben bzw. aeroben Wachstumsbedingungen gewonnen. Die sich anschließenden Experimente bestätigten die bereits ermittelten Daten. So konnten für Gene, welche in Verbindung mit der Bildung von Fermentationsendprodukten, wie $l d h$, als $D$ oder aber auch BLi02132 eine gesteigerte Expression unter anaeroben Wachstumsbedingungen beobachtet werden (Tab. 4.11). Gleiches konnte für den ORF der anaeroben Ribonukleotidreduktase beobachtet werden. Auch für das Gen der zweiten Untereinheit der Cytochrom bd Ubiquinol Oxidase $(c y d B)$ bzw. der putativen MethylaconitatHydratase $(m m g E)$ konnte die Induktion unter anaeroben Kultivierungsbedingungen bestätigt werden. Letzteres Enzym steht im Zusammenhang mit dem Methylcitratzyklus. Hierauf wird zu einem späteren Zeitpunkt in Kapitel 4.6 näher eingegangen. Auf der anderen Seite konnte auch mittels real-time RT-PCR, wie auch schon bei den vergleichenden Genexpressionsanalysen der DNA-Microarrays eine Repremierung für das Gen der Acetat-Kinase, $a c k A$, wie auch für das Gen $\operatorname{sdh} B$, 
welches für eine Untereinheit der Succinat-Dehydrogenase kodiert, unter anaeroben Wachstumsbedingungen gezeigt werden.

Tabelle 4.11: Vergleich der durch DNA-Microarrays und real-time RT-PCR ermittelten Expressionsverhältnisse für ausgewählte Gene. Werte größer 1 bedeuten eine verstärkte Expression unter aeroben Bedingungen, Werte kleiner -1 eine verstärkte Expression unter anaeroben Bedingungen. Werte, die mit einem Stern versehen sind, erfüllen nicht vollständig die Kriterien zur Ermittlung der Expressionsverhältnisse wie unter 3.8.6. beschrieben. Die Tabelle enthält repräsentative Einzelmessungen. put. - putativ

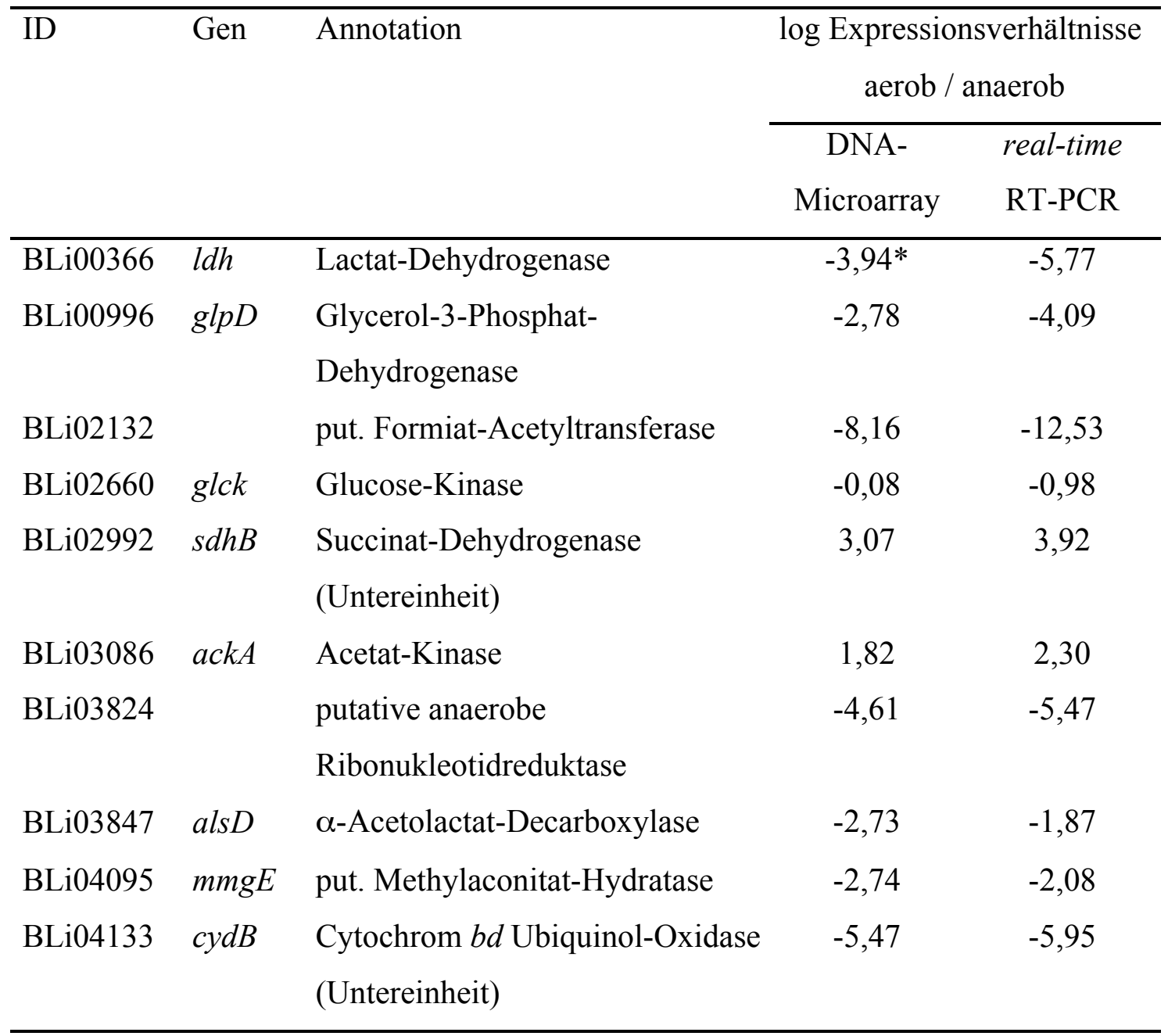

\subsubsection{Bestimmung von Fermentationsendprodukten}

Die durchgeführten Transkriptionsanalysen zeigten eine Induktion von Genen unter anaeroben Wachstumsbedingungen, welche im Zusammenhang mit der Bildung von Fermentationsendprodukten stehen. Anders als bei Shariati et al. (1995) beschrieben erfolgte im Rahmen dieser Arbeit die Analyse von Kulturüberständen 
mittels Ionenchromatographie (3.9.2.). Hierzu wurden während des Wachstumsverlaufs $\mathrm{zu}$ verschiedenen Zeitpunkten Aliquots von $0,5 \mathrm{ml}$ der Kultur entnommen, gekühlt abzentrifugiert und der Kulturüberstand bis zur weiteren Verwendung bei $-20^{\circ} \mathrm{C}$ gelagert. Als Hauptfermentationsprodukte von DSM13 beim anaeroben Wachstum in einem definierten Medium mit Glucose als Kohlenstoffquelle konnten 2,3-Butandiol und Formiat identifiziert werden (Abb. 4.7). Anders als bei Formiat war erst nach einem Verbrauch von etwa $10 \mathrm{mM}$ Glucose eine Zunahme der Konzentration von 2,3-Butandiol im Kulturüberstand $\mathrm{zu}$ beobachten. Dieses ging einher mit der qualitativen Bestimmung von Acetoin, welche nach der unter 3.9.5. beschriebenen Methode erfolgte. Daneben konnte noch Glycerol und Lactat im Kulturüberstand bestimmt werden. Eine erhöhte Zunahme von Glycerol konnte jedoch erst mit dem Einschwenken in die stationäre Phase beobachtet werden. Der Nachweis von Acetat im Kulturüberstand erfolgte zunächst ebenfalls mittels Ionenchromatographie und konnte anschließend durch UV-Tests (3.9.4.) verifiziert werden. Ethanol hingegen wurde qualitativ mittels Gas-Chromatographie (3.9.3.) ermittelt.

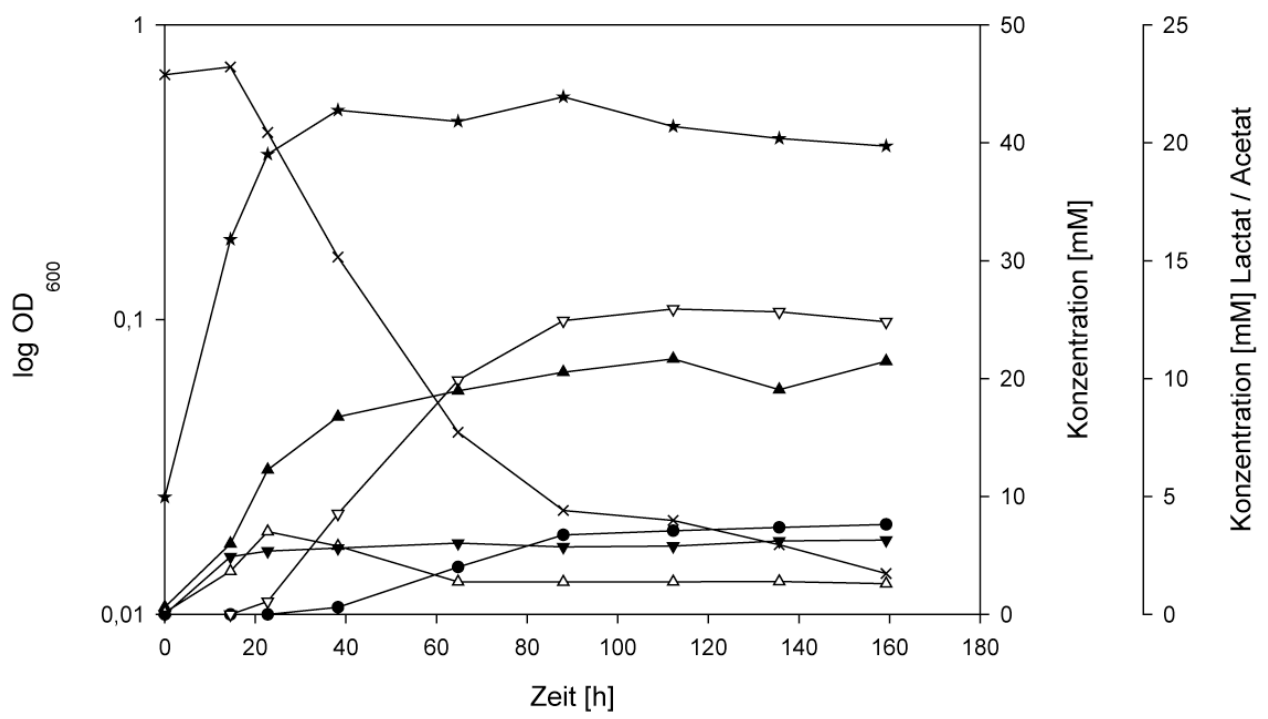

Abbildung 4.7: Wachstumskurve von DSM13 in einem definierten Medium unter anaeroben Kultivierungsbedingungen. Dargestellt ist neben dem Wachstum von DSM13 ( $\star$ ) und den Verbrauch

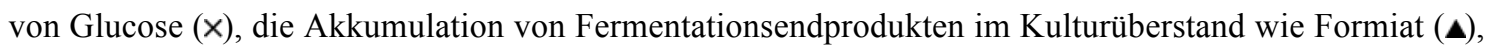
2,3-Butandiol $(\nabla)$, Glycerol $(\bullet)$, Lactat $(\nabla)$ und Acetat $(\Delta)$. Die Abbildung zeigt repräsentative Einzelmessungen. 


\subsection{Untersuchungen zur Verwertung von C2-Metaboliten}

Die Thematik der Assimilation von C2-Einheiten durch DSM13 wurde im Rahmen dieser Arbeit ebenfalls erneut aufgegriffen. In vorangegangenen Arbeiten konnte bereits anhand von Wachstumsversuchen und Transkriptionsanalysen gezeigt werden, dass B. licheniformis DSM13 vermutlich durch den Glyoxylatzyklus zum Wachstum auf Acetat und 2,3-Butandiol befähigt ist (vgl. Schmidt, 2005 und Veith, 2004). Es konnten im Rahmen der Genomanalyse von DSM13 zwei Gene identifiziert werden, welche starke Homologie zur Isocitrat-Lyase (BLi04207, Sandeman et al., 1991) und der Malat-Synthase (BLi04208, Sharma et al., 2000) aufweisen. Gemeinsam mit weiteren Enzymen des Tricarbonsäurezyklus bilden sie den Glyoxylatzyklus. Wie bereits im Kapitel zum fermentativen Wachstum von DSM13 angesprochen, sollte auch bei dieser Thematik eine Reproduktion der Transkriptionanalysen mit Oligobasierenden DNA-Microarrays erfolgen. Die vergleichenden Genexpressionsanalysen hierzu wurden anhand von jeweils 2 Hybridisierungen ausgewertet. Eine als signifikant eingestufte Änderung des Expressionverhältnisses um mindestens den Faktor 3 entspricht Werten von 1,5849 bzw. -1,5849, da die gezeigten Expressionsdaten logarithmisch zur Basis 2 dargestellt sind. Bei den im Weiteren dargestellten Transkriptionsanalysen zur Verwertung von C2-Metaboliten entsprechen Werte größer 1 einer erhöhten Expression beim Wachstum mit Acetat bzw. 2,3-Butandiol, Werte kleiner -1 hingegen unter Referenzbedingungen.

\subsubsection{Wachstum mit Acetat als Kohlenstoffquelle}

Im Zusammenhang mit den Transkriptionsanalysen wurde DSM13 in einem definierten Medium mit $60 \mathrm{mM}$ Acetat in einem Schüttelkolben bei $42^{\circ} \mathrm{C}$ angezogen. Unter vergleichbaren Kultivierungsbedingungen wurde $\mathrm{zu}$ verschiedenen Zeitpunkten Aliquots des Kulturüberstandes entnommen und wie bereits unter 4.1.3. beschrieben behandelt. Mittels Ionenchromatographie konnte im Anschluss der Verbrauch des Acetats detektiert werden (Abb. 4.8). 


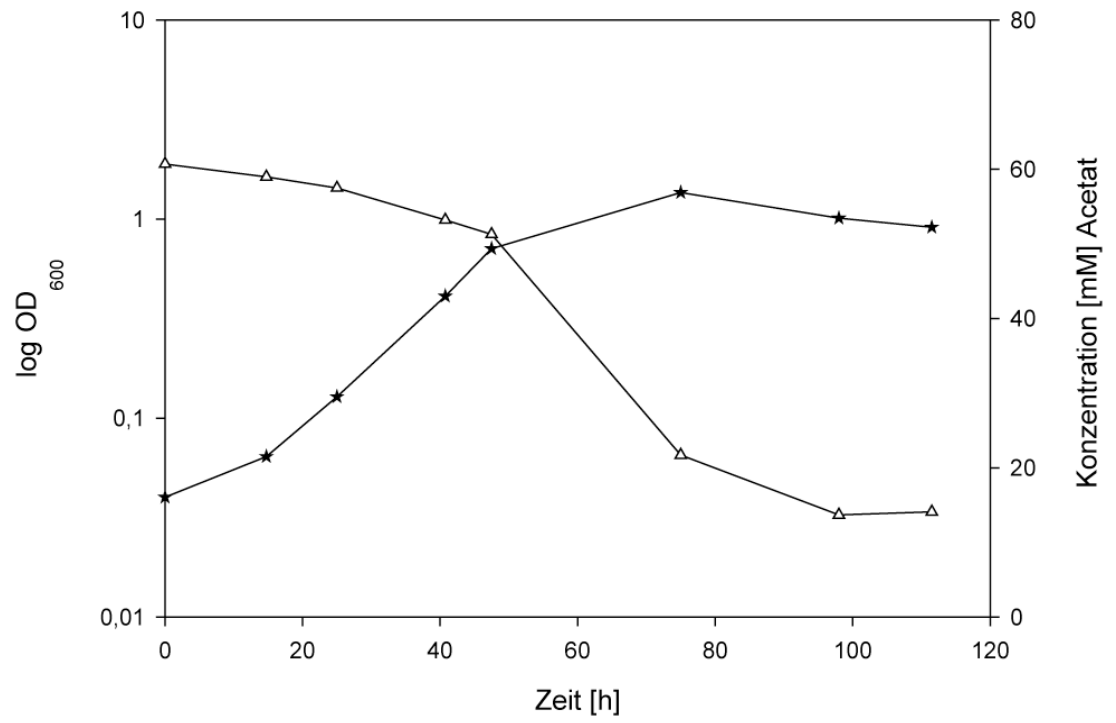

Abbildung 4.8: Wachstumsverlauf von DSM13 in einem definierten Medium mit $60 \mathrm{mM}$ Acetat als Kohlenstoffquelle. Dargestellt ist das Wachstum von DSM13 ( $\star$ ) und der Verbrauch von Acetat $(\Delta)$ über die Zeit. Die Abbildung zeigt repräsentative Einzelmessungen.

\subsubsection{Transkriptionsanalysen zum Wachstum mit Acetat}

Zur Isolation von RNA aus $B$. licheniformis Zellen für die Transkriptionsanalysen wurden $100 \mathrm{ml}$ Batch-Kulturen der auf Acetat gewachsenen Zellen in jeweils zwei biologisch unabhängigen Experimenten in der mittleren logarithmischen Phase bei einer $\mathrm{OD}_{600}$ von 0,5 bis 0,6 geerntet. Die Anzucht für die Referenzbedingung der Transkriptionsanalysen erfolgte im Chemostaten mit $50 \mathrm{mM}$ Glucose als Kohlenstoffquelle wie unter 3.3.5. beschrieben.

\section{Expression der Gene des Zentralstoffwechsels}

Zunächst lag das Augenmerk der Transkriptionsanalysen auf den Tricarbonsäurebzw. Glyoxylatzyklus. Die Ergebnisse der Transkriptionsanalyse für den Tricarbonsäurezyklus sind in Abbildung 4.9, eine Übersicht der beteiligten Gene und deren Erläuterung in der Tabelle 4.12 dargestellt. 


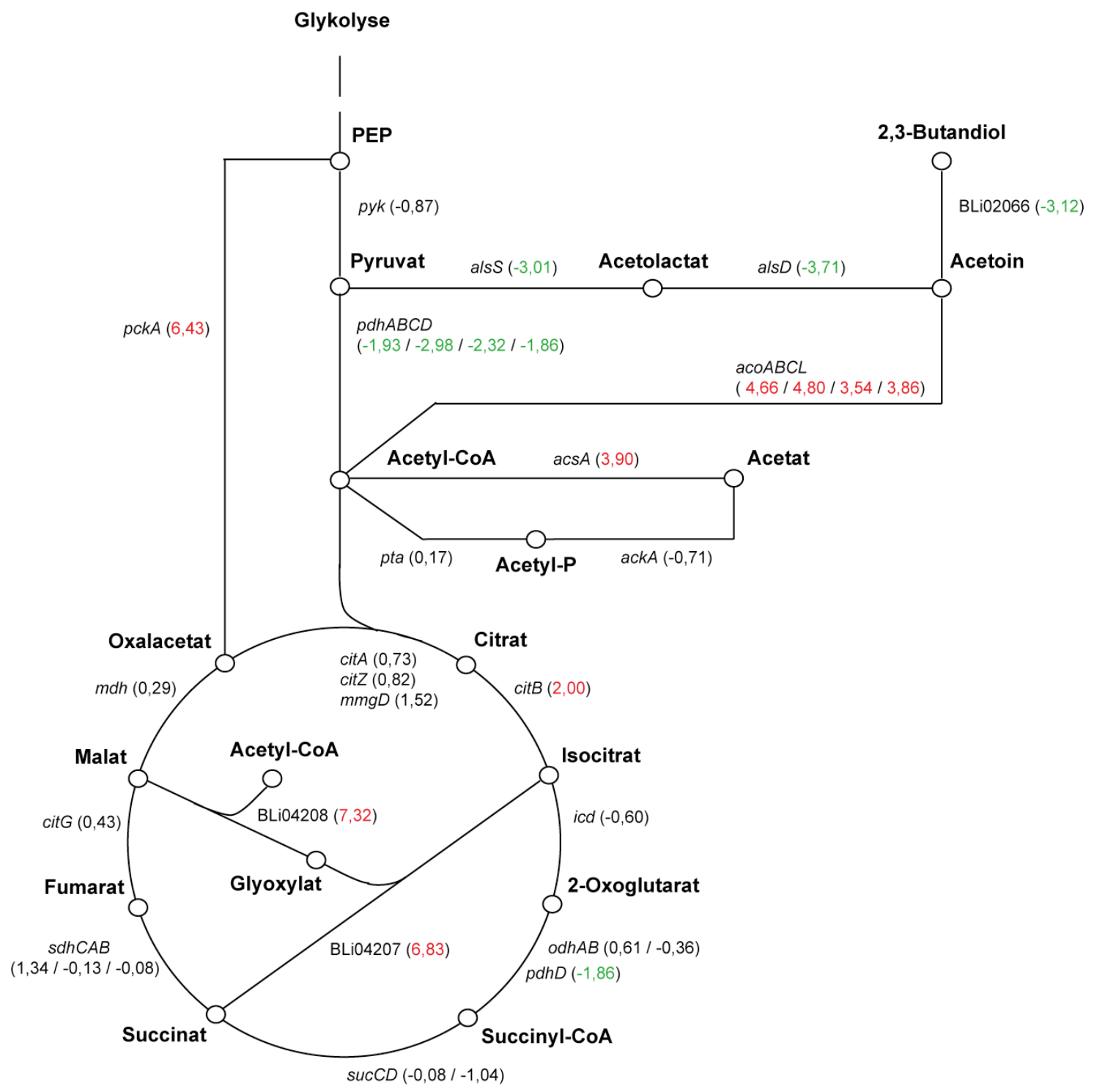

Abbildung 4.9: Schematische Darstellung des Tricarbonsäure- und Glyoxylatzyklus.

Angegeben sind die Expressionsverhältnisse der beteiligten Gene bei Wachstum mit Acetat im Vergleich zum Wachstum mit Glucose. Werte größer als 1 stellen eine erhöhte Expression beim Wachstum mit Acetat dar, kleiner -1 hingegen unter der Referenzbedingung. Die gezeigten Daten sind logarithmisch dargestellt und repräsentative Einzelmessungen. 
Tabelle 4.12: Gen- bzw. ORF-Bezeichnungen und Funktionen der in den Abbildungen 4.9 und 4.12 dargestellten Gene des Tricarbonsäurezyklus.

\begin{tabular}{ll}
\hline Gen / ORF & Funktion \\
\hline$a c k A$ & Acetat-Kinase \\
$a c o A B C L$ & Untereinheiten der Acetoin-Dehydrogenase \\
$a c s A$ & Acetyl-CoA-Synthetase \\
$a l s D$ & $\alpha-A c e t o l a c t a t-D e c a r b o x y l a s e$ \\
$a l s S$ & $\alpha$-Acetolactat-Synthase \\
BLi02066 & putative Acetoin-Reduktase \\
BLi04207 & Isocitrat-Lyase \\
BLi04208 & Malat-Synthase \\
$c i t A$ & Citrat-Synthase I \\
$c i t B$ & Aconitat-Hydratase \\
$c i t G$ & Fumarat-Hydratase \\
$c i t Z$ & Citrat-Synthase II \\
$i c d$ & Isocitrat-Dehydrogenase \\
$m d h$ & Malat-Dehydrogenase \\
$m m g D$ & Citrat-Synthase III \\
odh $A B$ & Untereinheiten der 2-Oxoglutarat-Dehydrogenase \\
$p c k A$ & Phosphoenolpyruvat-Carboxykinase \\
$p d h A B C$ & Untereinheiten der Pyruvat-Dehydrogenase \\
$p d h D$ & Untereinheit der Pyruvat-Dehydrogenase / \\
Untereinheit der 2-Oxoglutarat-Dehydrogenase & Phosphotransacetylase \\
sucCD &
\end{tabular}

Im Vergleich zum Wachstum mit Glucose zeigten B. licheniformis Zellen beim Wachstum mit Acetat als alleiniger Kohlenstoffquelle unter anderem eine Erhöhung der Expression für das Gen acsA. Dieses kodiert für die Acetyl-CoA-Synthetase, welche essentiell für die Verwertung von Acetat ist. Daneben konnte noch eine erhöhte Expression für das Gen der Aconitat Hydratase ( $c i t B)$ beobachtet werden, welche die 
Umsetzung von Citrat zu Isocitrat katalysiert. Letzteres kann zum einen über 2-Oxoglutarat zu Succinat oder direkt zu Succinat umgewandelt werden. Katalysiert wird die Umsetzung von Isocitrat zu Succinat unter Bildung von Glyoxylat durch die Isocitrat-Lyase (BLi04207), einem der Enzyme des Glyoxylatzyklus. Das zweite Enzym, die Malat-Synthase (BLi04208) katalysiert die Kondensation des Glyoxylats mit einem weitern Molekül Acetyl-CoA zu Malat. Für beide ORFs, sowohl BLi04207, als auch BLi04208, konnte eine signifikant erhöhte Expression beim Wachstum mit Acetat im Vergleich zum Wachstum mit Glucose beobachtet werden. Ebenfalls eine starke Erhöhung konnte in diesem Kontext für das Gen der PhosphoenolpyruvatCarboxykinase $(p c k A)$ beobachtet werden, welches durch die Umsetzung von Oxalacetat zu Phosphoenolpyruvat (PEP) letzteres für die Gluconeogenese bereitstellt. Eine Repression von Genen beim Wachstum mit Acetat im Vergleich zum Wachstum mit Glucose konnte hingegen für die die Untereinheiten der Pyruvat-Dehydrogenase kodierenden Gene ( $p d h A B C D$ ) beobachtet werden. Gleiches zeigte sich für die Gene der $\alpha$-Acetolactat-Synthase $(a l s S)$ und $\alpha$-Acetolactat-Decarboxylase $(a l s D)$, welche an der Synthese von Acetoin beteiligt sind. Der ORF der putativen Acetoin-Reduktase (BLi02066) war ebenfalls beim Wachstum mit Acetat reprimiert.

Im Gegensatz dazu waren die Gene, welche im Zusammenhang mit der Verwertung von Acetoin stehen beim Wachstum mit Acetat als Kohlenstoffquelle induziert. Dieses sind die für die Untereinheiten der Acetoin-Dehydrogenase kodierenden Gene acoABCL. Direkt angrenzend im Genom liegt das Gen des zugehörigen transkriptionalen Aktivators $a c o R$ (Abb. 4.10). Auch für dieses konnte eine erhöhte Expression ermittelt werden (Tab. 7. 2 im Anhang). Begrenzt werden diese Gene von dem ORF BLi00848, welcher für eine putative Protease kodiert und dem Gen $y f j F$. Die Funktion des Produktes von letzterem ist bisher unbekannt.

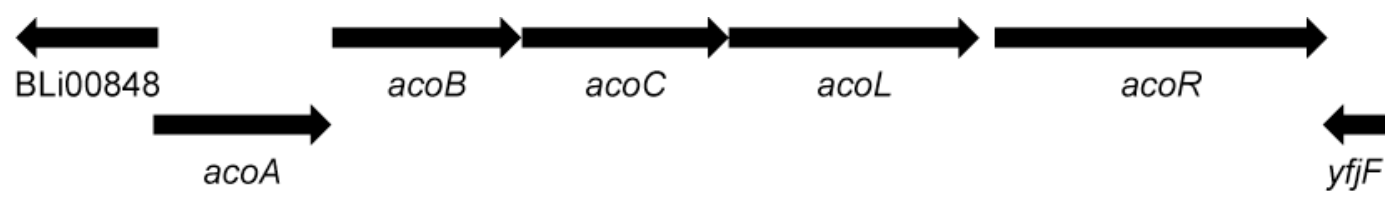

Abbildung 4.10: Genregion des aco-Operons von B. licheniformis DSM13. Erläuterung im Text. 


\section{Expressionsdaten anderer Enzyme}

Anhand der durchgeführten DNA-Microarray-Analysen konnte für insgesamt 146 Gene eine signifikante Änderung des Expressionsverhältnisses beim Wachstum mit Acetat als Kohlenstoffquelle ermittelt werden. Darunter befinden sich 44 putative bzw. hypothetische Gene und 43 Y-ORFs. Den verbleibenden 59 Genen konnte während der Annotation eine Funktion zugewiesen werden. Neben Genen, welche in die PurinBiosynthese involviert sind ( $p u r B$, purE, purK und $x p t$ ) konnten Gene identifiziert werden, deren Produkte an den gegenläufigen Prozessen der Differenzierung einer Endospore bzw. ihrer Auskeimung beteiligt sind. Beispielhaft können in diesem Zusammenhang neben $\operatorname{cotVX}$ (Proteine der Sporenhülle), $\operatorname{coxA}$ (Cortexprotein der Spore), die Gene gerPF, gerPE, gerPB und gerPA (Keimung der Spore), aber auch cwlC (N-Acetylmuramoyl-L-Alanin-Amidase $c w l L$ Vorläufer) genannt werden. Ebenfalls eine erhöhte Transkription der Gene beim Wachstum mit Acetat konnte für die Proteine AprX (intrazellulare alkalische Serin-Protease), AsnO (AsparaginSynthetase), CstA (bei Kohlenstoffmangel induziertes Protein), DhaS (AldehydDehydrogenase), IspA (intrazellulare Serine-Protease) und PyrB (AspartatCarbamoyltransferase) beobachtet werden.

\subsubsection{Wachstum mit 2,3-Butandiol als Kohlenstoffquelle}

Wie auch schon bei den Untersuchungen zum Wachstum mit Acetat, erfolgten die Kultivierungen mit $30 \mathrm{mM}$ 2,3 Butandiol als Kohlenstoffquelle in einem definierten Medium im Schüttelkolben bei $42^{\circ} \mathrm{C}$. Analysen der Kulturüberstände, von denen Aliquots im Verlauf des Wachstums über die Zeit entnommen wurden, ergaben eine zwischenzeitliche Anhäufung und Verbrauch von Acetoin. Die Experimente lassen vermuten, dass DSM13 2,3-Butandiol zunächst zu Acetoin umsetzt, letzteres wieder zur Bildung von Zellmasse verstoffwechselt und erst im Anschluss daran 2,3 Butandiol weiter verwertet (Abb. 4.11). 


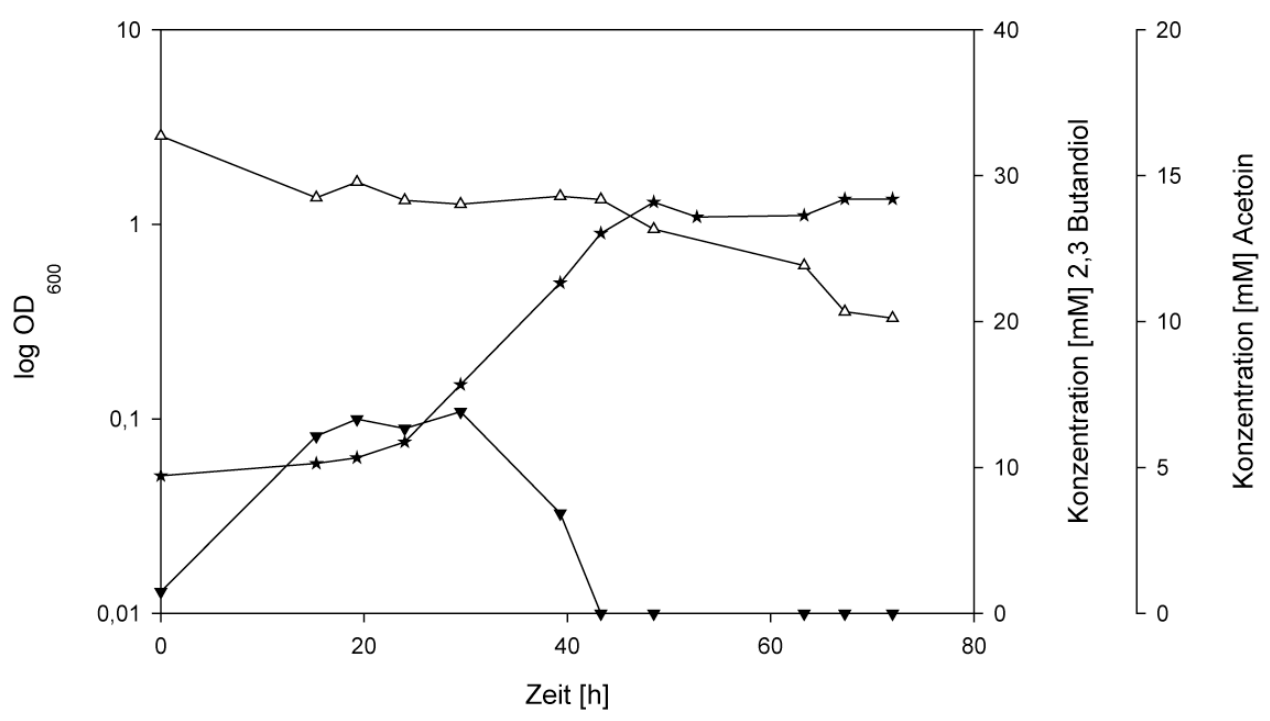

Abbildung 4.11: Wachstumsverlauf von DSM13 in einem definierten Medium mit $30 \mathrm{mM}$ 2,3-Butandiol. Dargestellt ist das Wachstum von DSM13 ( $\star$ ) und der Verbrauch von 2,3-Butandiol $(\Delta)$ mit zwischenzeitlicher Anhäufung und Verbrauch von Acetoin ( $\boldsymbol{\nabla}$ ) über die Zeit. Die Abbildung zeigt repräsentative Einzelmessungen.

\subsubsection{Transkriptionsanalysen zum Wachstum mit 2,3-Butandiol}

Die Transkriptionsanalyse von B. licheniformis für den Vergleich des Wachstums mit 2,3-Butandiol und Glucose wurde analog der Untersuchungen mit Acetat und Glucose vorgenommen. Die aus zwei biologisch unabhängigen Experimenten stammende RNA wurde ebenfalls in der mittleren logarithmischen Phase von $100 \mathrm{ml}$ Batch-Kulturen gewonnen. Auch bezüglich der Datenauswertung wurde wie bei der vergleichenden Expressionsanalyse des Wachstums mit Acetat und Glucose verfahren.

\section{Expression der Gene des Zentralstoffwechsels}

Wie schon bei den Transkriptionsanalysen zum Wachstum mit Acetat, so lag auch hier zunächst das Augenmerk auf den Tricarbonsäure- bzw. Glyoxylatzyklus. Interessanterweise konnte beim Wachstum mit 2,3-Butandiol ein Expressionsmuster, ähnlich zum Wachstum mit Acetat beobachtet werden (Abb. 4.12). 


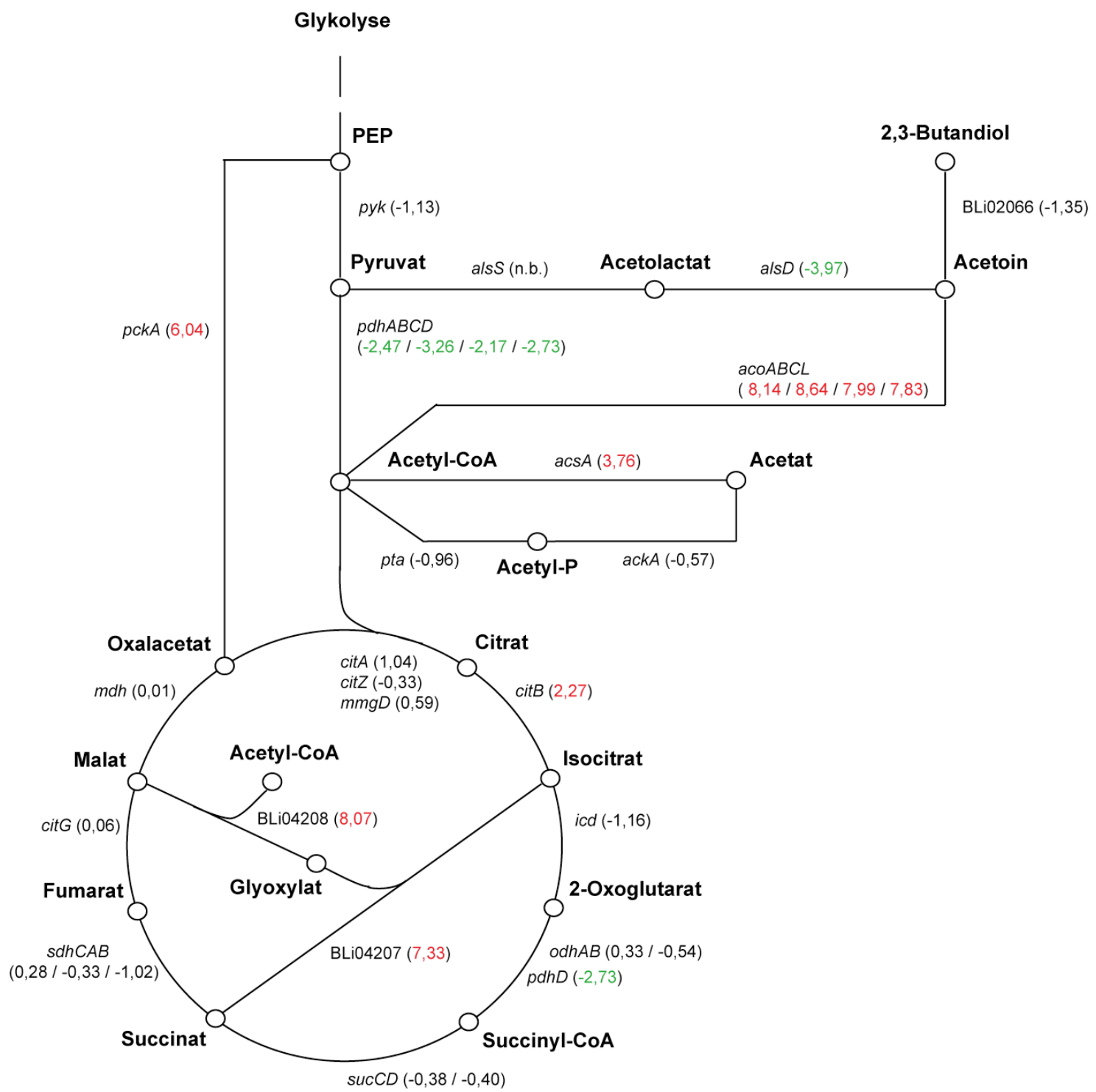

Abbildung 4.12: Schematische Darstellung des Tricarbonsäure- und Glyoxylatzyklus.

Angegeben sind die Expressionsverhältnisse der beteiligten Gene bei Wachstum mit 2,3-Butandiol im Vergleich zum Wachstum mit Glucose. Werte größer als 1 stellen eine erhöhte Expression beim Wachstum mit 2,3-Butandiol dar, kleiner -1 hingegen unter der Referenzbedingung. Die gezeigten Daten sind logarithmisch dargestellt und repräsentative Einzelmessungen. n.b. - nicht bestimmt

Die kodierenden Gene des Multienzymkomplexes der Pyruvat-Dehydrogenase ( $p d h A B C D$ ) waren beim Wachstum mit 2,3-Butandiol im Vergleich zum Wachstum mit Glucose reprimiert. Gleiches konnte für das Gen der $\alpha$-Acetolactat-Decarboxylase $(a l s D)$, welche die abschließende Reaktion zur Synthese von Acetoin katalysiert, beobachtet werden. Die Acetoin-Reduktase setzt im Weiteren Acetoin zu 2,3-Butandiol 
um. Für den zugehörigen ORF BLi02066 konnte ebenfalls eine gesenkte Expression ermittelt werden. Eine erhöhte Expression im Zusammenhang mit dem Wachstum auf 2,3-Butandiol konnte wiederum für das Gen der Aconitat-Hydratase (citB), der Phosphoenolpyruvat-Carboxykinase $(p c k A)$, wie auch für die Gene des Glyoxylatzyklus, der Isocitrat-Lyase (BLi04207) und der Malat-Synthase (BLi04208) bestimmt werden. Ebensolches gilt für die Gene acoABCL, welche für die Untereinheiten der Acetoin-Dehydrogenase kodieren, aber auch für das Gen $a c o R$ des zugehörigen transkriptionalen Aktivators (Tab. 7.2 im Anhang).

\section{Expressionsdaten anderer Enzyme}

Steht B. licheniformis Zellen nur 2,3-Butandiol als alleinige Kohlenstoffquelle zur Verfügung, so konnte für 77 ORFs eine signifikante Erhöhung der Expression im Vergleich zu Glucose gewachsenen Zellen ermittelt werden. Hierunter befinden sich 28 hypothetische bzw. putative Gene und 17 Y-ORFs. Den verbleibenden 32 Genen konnte eine Funktion zugewiesen werden. Wie bereits beim Wachstum mit Acetat zu beobachten war, so sind auch beim Wachstum mit 2,3-Butandiol Gene zu finden, deren Produkte an der Differenzierung bzw. Auskeimung der Endospore beteiligt sind. Neben den Genen $\cot V X Y$ (Proteine der Sporenhülle) können unter anderem die Gene gerPC, gerPB und gerPA (Keimung der Spore) und $c w l C$ ( $N$-Acetylmuramoyl-L-AlaninAmidase $c w l L$ Vorläufer) angeführt werden. Eine gesteigerte Expression konnte ebenfalls für aprX (intrazellulare alkalische Serin-Protease), cstA (bei Kohlenstoffmangel induziertes Protein), dhaS (Aldehyd-Dehydrogenase) und isp $A$ (intrazellulare Serin-Protease) beobachtet werden. Daneben wurden noch die kodierenden Gene der Proteine FhuD (Ferrichrom ABC-Transporter), LcfA (beteiligt am Fettsäurestoffwechsel) GlpF und GlpK (involviert in die Verwertung von Glycerol) erhöht transkribiert. 


\subsection{Untersuchungen zur Verwertung von Aminosäuren}

Die Verwertung von Zuckern durch Mikroorganismen ist in der Literatur gut beschrieben. Wenig hingegen ist über die Verwertung von Aminosäuren als Stickstoffund Kohlenstoffquelle bekannt. Diese Thematik aufgreifend sollen nun im folgenden Wachstumsdaten, Transkriptionsanalysen und Ergebnisse der Ionenchromatographie zur Verwertung von Aminosäuren dargestellt werden. Zunächst soll hierbei auf die Verwertung einzelner Aminosäuren eingegangen werden. Im Anschluss daran werden Untersuchungen zur Verwertung von Gemischen von Aminosäuren erläutert.

\subsubsection{Wachstum mit einzelnen Aminosäuren}

\subsubsection{Verwertung einzelner Aminosäuren als Wachstumskomponenten}

Um die Verwertung von Aminosäuren als Wachstumskomponenten durch DSM13 zu untersuchen, wurde dieser in einem definierten Medium mit einzelnen Aminosäuren angezogen (vgl. 3.2.2.). Diese Wachstumsexperimente zeigten, dass sieben von 18 proteinogenen Aminosäuren sowohl als Stickstoff-, als auch als Kohlenstoffquelle dienen können. Im Einzelnen sind dieses L-Alanin, L-Arginin, L-Asparagin, L-Aspartat, L-Glutamin, L-Glutamat und L-Prolin (Tab. 4.13). Wachstumsversuche mit L-Cystein als Stickstoff- und Kohlenstoffquelle konnten nicht durchgeführt werden, da Komponenten des Mediums bei der benötigten Wachstumstemperatur ausfielen. L-Tyrosin lässt sich nicht in ausreichender Konzentration in Wasser lösen, so dass auch bei dieser Aminosäure kein Wachstum bestimmt werden konnte. Im Rahmen der Wachstumsexperimente proteinogener Aminosäuren wurde ebenfalls die nichtproteinogene Aminosäure L-Ornithin als Wachstumskomponente untersucht. Diese Experimente ergaben, dass DSM13 auch diese Aminosäure als Stickstoff- und Kohlenstoffquelle nutzen kann (Daten nicht gezeigt). 
Tabelle 4.13: Überprüfung von proteinogenen Aminosäuren als Stickstoff- und Kohlenstoffquelle. Die Kultivierungsexperimente erfolgten in einem definierten Medium wie unter 3.2.2. beschrieben. Das Wachstum wurde über einen Zeitraum von 50 Stunden beobachtet. + Wachstum, - kein Wachstum, n.b. - nicht bestimmt

\begin{tabular}{lcc}
\hline Aminosäure & Konzentration & Wachstum \\
\hline L-Alanin & $30 \mathrm{mM}$ & + \\
L-Arginin & $30 \mathrm{mM}$ & + \\
L-Asparagin & $30 \mathrm{mM}$ & + \\
L-Aspartat & $30 \mathrm{mM}$ & n.b. \\
L-Cystein & $30 \mathrm{mM}$ & + \\
L-Glutamin & $30 \mathrm{mM}$ & + \\
L-Glutamat & $30 \mathrm{mM}$ & - \\
Glycin & $30 \mathrm{mM}$ & - \\
L-Histidin & $30 \mathrm{mM}$ & - \\
L-Isoleucin & $30 \mathrm{mM}$ & - \\
L-Leucin & $30 \mathrm{mM}$ & - \\
L-Lysin & $30 \mathrm{mM}$ & - \\
L-Methionin & $30 \mathrm{mM}$ & - \\
L-Phenylalanin & $30 \mathrm{mM}$ & + \\
L-Prolin & $30 \mathrm{mM}$ & - \\
L-Serin & $30 \mathrm{mM}$ & - \\
L-Threonin & $30 \mathrm{mM}$ & - \\
L-Tryptophan & $30 \mathrm{mM}$ & - \\
L-Tyrosin & $30 \mathrm{mM}$ & - \\
L-Valin & $30 \mathrm{mM}$ & + \\
\hline & & - \\
\hline
\end{tabular}

\subsubsection{Transkriptionsanalysen zur Verwertung einzelner Aminosäuren}

Nach der Beobachtung, welche Aminosäuren als Stickstoff- und Kohlenstoffquelle dienen können, wurden Transkriptionsanalysen $\mathrm{zu}$ diesen Kultivierungsbedingungen durchgeführt. Für das Design des Experiments wurde hierbei die Methode der common reference gewählt (Ehrenreich, 2006). Bei Genexpressionsanalysen werden in der Regel die relativen Expressionsstärken zweier Proben miteinander verglichen. Bei diesen Proben handelt es sich um RNA, welche aus Zellen 
gewonnen wird, die zum einen unter Referenzbedingungen und zum anderen unter den experimentell zu untersuchenden Bedingungen gewachsen sind. Als Referenzbedingung sollte eine Bedingung gewählt werden, welche schnell reproduzierbar ist und bei der Zellen zur RNA-Präparation in großen Mengen verfügbar sind. In dieser Arbeit wurde DSM13 deshalb, sofern nicht anders angegeben, im Chemostaten in einem definierten Medium mit $50 \mathrm{mM}$ Glucose als Kohlenstoffquelle kultiviert (vgl. 3.3.5.). Ein Vorteil dieser Methode der common reference ist zum einen, dass die experimentell zu untersuchenden Bedingungen direkt miteinander vergleichbar sind und zum anderen, dass ein so genannter dye-flip, eine Umkehrung der Markierungsreaktion, nicht mehr notwendig ist. Analog der bereits in vorangegangenen Kapiteln beschriebenen Durchführung wurden die vergleichenden Genexpressionsanalysen anhand von jeweils 2 Hybridisierungen ausgewertet. Aufgrund der logarithmisch zur Basis 2 dargestellten Expressionsdaten entspricht eine als signifikant eingestufte Änderung des Expressionverhältnisses um mindestens den Faktor 3 Werten von 1,5849 bzw. -1,5849.

\subsection{Einmünden der Aminosäuren in den Zentralmetabolismus}

Zunächst lag der Focus der Untersuchungen auf den zentralen Stoffwechselwegen. Die Abbildung 4.13 zeigt das Einmünden verschiedener Aminosäuren in den Zentralmetabolismus. In Tabelle 4.14 sind die Expressionswerte von Genen dargestellt, welche im Zusammenhang mit dem Abbau der Aminosäuren stehen, die DSM13 als Stickstoff- und Kohlenstoffquelle nutzen kann.

\section{L-Alanin}

L-Alanin wird durch die L-Alanin-Dehydrogenase (EC 1.4.1.1) zu Ammoniak und Pyruvat, mit NAD ${ }^{+}$als Cofaktor, nach folgender Reaktion umgesetzt:

L-Alanin $+\mathrm{H}_{2} \mathrm{O}+\mathrm{NAD}^{+}<=>$Pyruvat $+\mathrm{NH}_{3}+\mathrm{NADH}+\mathrm{H}^{+}$

In DSM13 kodiert das Gen ald (BLi03382) für die L-Alanin-Dehydrogenase. Im Genom konnte auch ein homologes Gen (BLi04275) annotiert werden. Beide Gene zeigten beim Wachstum mit L-Alanin als Stickstoff- und Kohlenstoffquelle eine erhöhte 


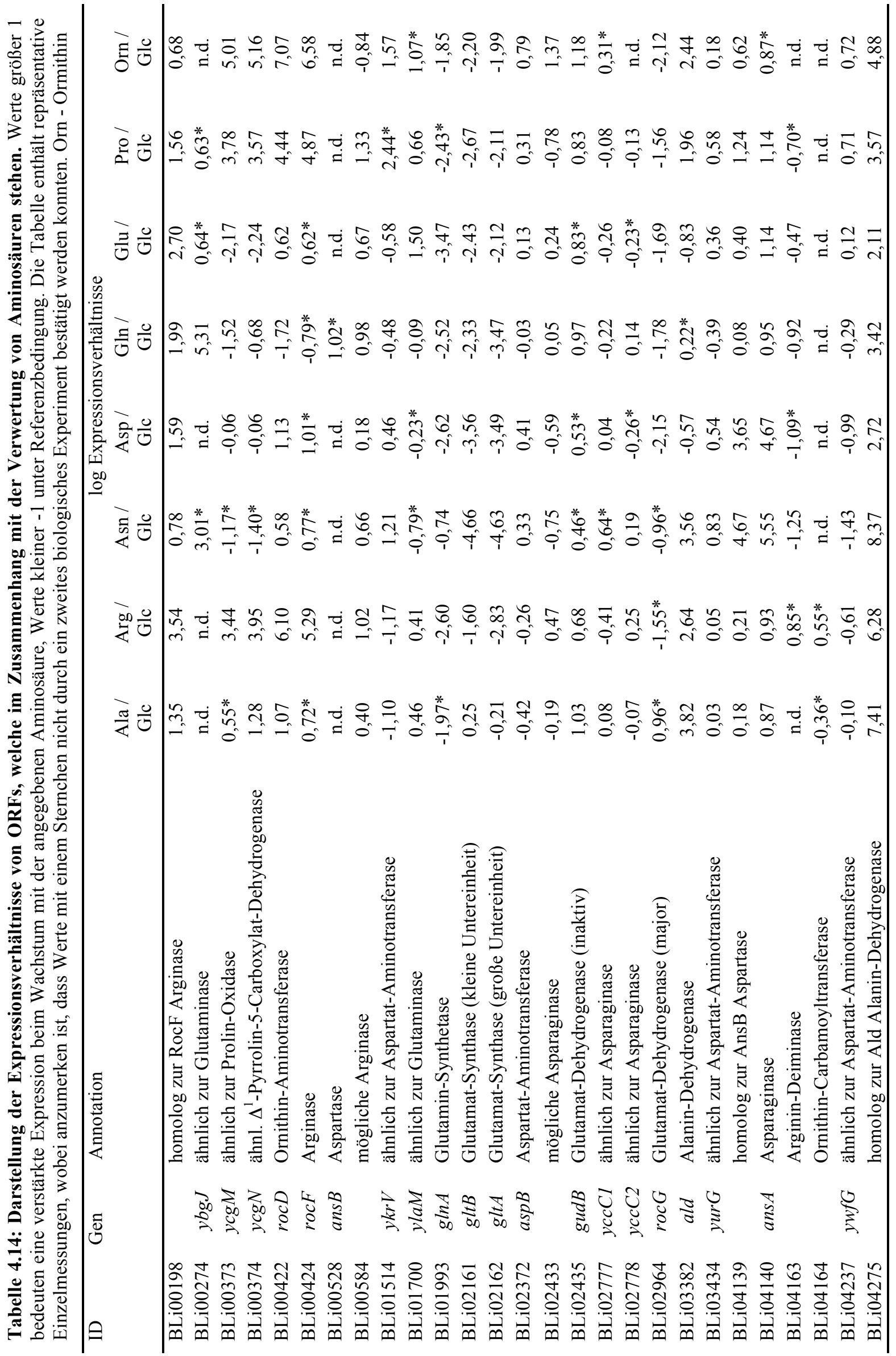




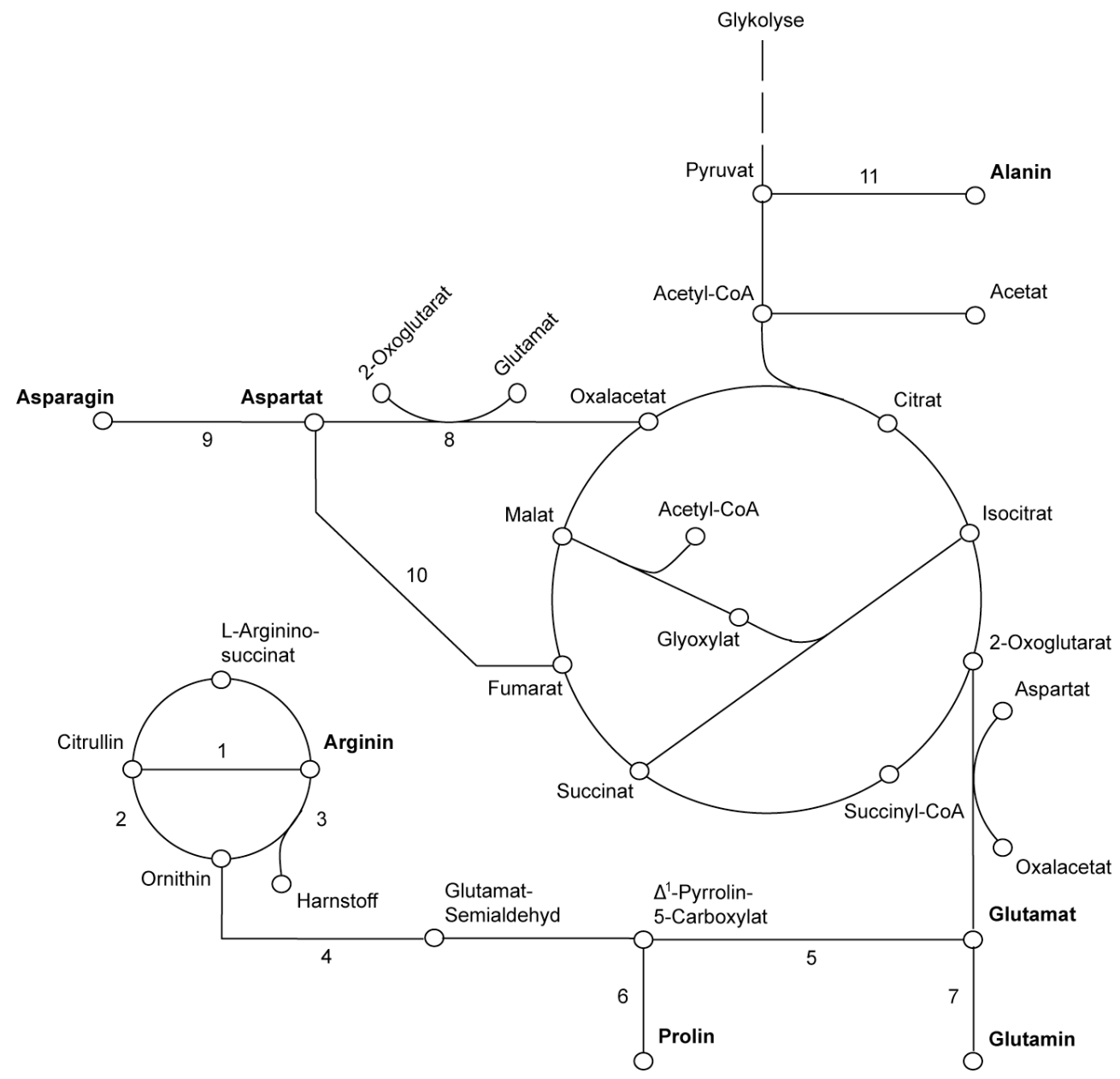

\section{Abbildung 4.13: Einmünden der Aminosäuren in den Zentralmetabolismus.}

Dargestellt ist der Tricarbonsäurezyklus und der Harnstoffzyklus. Die proteinogenen Aminosäuren sind fett hervorgehoben. 1, Arginin-Deiminase; 2, Ornithin-Carbamoyltransferase; 3, Arginase; 4, OrnithinAminotransferase; 5, Pyrrolin-5-Carboxylat-Dehydrogenase; 6, Prolin-Oxidase; 7, Glutaminase; 8, Aspartat-Aminotransferase; 9, L-Asparaginase; 10, L-Aspartase; 11, L-Alanin-Dehydrogenase

Expression im Vergleich zum Wachstum mit Glucose (Tab. 4.14). Daneben war der ORF BLi03382 ebenfalls beim Wachstum mit L-Asparagin, L-Arginin, L-Prolin und L-Ornithin induziert. Neben der erhöhten Expression beim Wachstum mit L-Alanin konnte auch beim Wachstum mit allen weiteren getesteten Aminosäuren eine erhöhte Expression für den ORF BLi04275 ermittelt werden.

\section{L-Arginin}

In B. licheniformis sind zwei Wege zum Abbau von L-Arginin bekannt (Cunin et al., 1986). Diese sind nach dem jeweiligen ersten Enzym benannt. Bei dem Arginase 
degradativen Pfad wird in einem ersten Schritt L-Arginin zu Harnstoff und L-Ornithin umgesetzt [4.2]. Katalysiert wird diese Reaktion durch das Enzym Arginase (EC 3.5.3.1). L-Ornithin wiederum wird durch die Ornithin-Transaminase (EC 2.6.1.13, BLi00422) zu L-Glutamat und L-Glutamat-Semialdehyd umgewandelt [4.3]. Letzteres wird spontan zu $\Delta^{1}$-Pyrrolin-5-Carboxylat, der stabileren zyklischen Form des L-Glutamat-Semialdehyds, umgewandelt. Die anschließende Umwandlung zum L-Glutamat wird durch das Enzym $\Delta^{1}$-Pyrrolin-5-Carboxylat-Dehydrogenase (EC 1.5.1.12, BLi00374) katalysiert [4.4].

L-Arginin $+\mathrm{H}_{2} \mathrm{O}<=>$ L-Ornithin + Harnstoff

L-Ornithin + 2-Oxoglutarat $<=>$ L-Glutamat-Semialdehyd + L-Glutamat

L-Glutamat-Semialdehyd $<=>\Delta^{1}$-Pyrrolin-5-Carboxylat

$\Delta^{1}$-Pyrrolin-5-Carboxylat $+2 \mathrm{H}_{2} \mathrm{O}+\mathrm{NAD}^{+}<=>$L-Glutamat $+\mathrm{NADH}+\mathrm{H}^{+}$

Im Genom von DSM13 sind drei Gene (BLi00198, BLi00424 und BLi00584) im Zusammenhang mit der Arginase annotiert. Beim Wachstum mit L-Arginin als Stickstoff- und Kohlenstoffquelle zeigten sowohl der ORF BLi00198, als auch BLi00424 eine erhöhte Expression im Vergleich zum Wachstum mit Glucose, nicht aber BLi00584 (Tab. 4.14). Bei den weiteren an der Verwertung von L-Arginin beteiligten Genen, BLi00422 und BLi00374, konnte ebenfalls eine erhöhte Expression beobachtet werden. Zusätzlich ist noch anzumerken, dass eines der für die Arginase kodierenden Gene, BLi00424, im Genom von DSM13 mit dem die OrnithinAminotransferase kodierenden Gen rocD (BLi00422) assoziiert ist. Zwischen diesen ORFs ist das für eine Aminosäurepermease kodierende Gen rocE (BLi00423) lokalisiert (Abb. 4.14) Beim Wachstum mit L-Arginin war auch dieses Gen induziert (Tab. 7.3 im Anhang). Upstream der Gene rocDEF ist das Gen rocR (BLi00421) lokalisiert, welches für den zugehörigen transkriptionalen Aktivator kodiert (Abb. 4.14). Des Weiteren konnte für das Gen rocF (BLi00424) ebenfalls eine erhöhte Expression beim Wachstum mit L-Prolin und L-Ornithin ermittelt werden. Sowohl für die am weiteren Abbau zum L-Glutamat beteiligten Gene $\operatorname{rocD}$ (BLi00422) und ycgN (BLi00374), als auch für das die Aminosäurepermease kodierenden Gen rocE (Tab. 7.3 im Anhang) konnte dieses ebenfalls beobachtet werden (Tab. 4.14). 


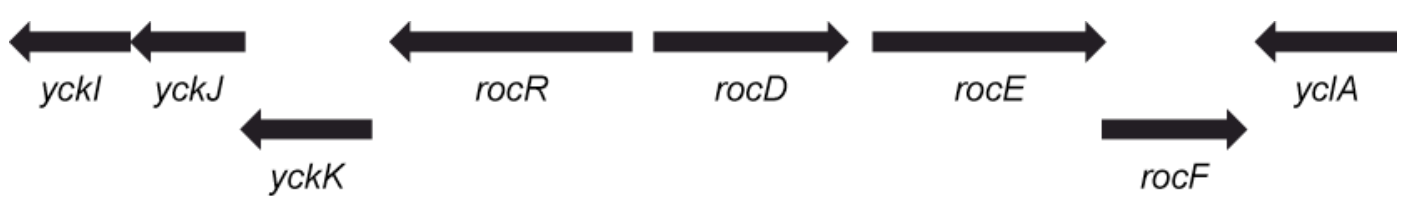

Abbildung 4.14: Genregion, welche im Zusammenhang mit der Verwertung von L-Arginin steht. Erläuterung im Text.

Beim zweiten beschriebenen Weg zum Abbau von L-Arginin wird die einleitende Reaktion von der Arginin Deiminase (EC 3.5.3.6) katalysiert. Dieses Enzym setzt L-Arginin unter Abspaltung von Ammoniak zu L-Citrullin um [4.5]. Letzteres wird durch die Ornithin Carbamoyltransferase (EC 2.1.3.3) zu L-Ornithin und Carbamoylphosphat umgewandelt [4.6]. Die weiteren Schritte bis zum L-Glutamat entsprechen denen des Abbaus über die Arginase.

L-Arginin $+\mathrm{H}_{2} \mathrm{O}<=>$ L-Citrullin $+\mathrm{NH}_{3}$

L-Citrullin + Phosphat $<=>$ L-Ornithin + Carbamoylphosphat

Beim Wachstum mit L-Arginin als alleiniger Stickstoff- und Kohlenstoffquelle konnte weder bei dem die Arginin-Deiminase (BLi04163) kodierenden, noch bei dem für die Ornithin-Carbamoyltransferase (BLi04164) kodierenden Gen, eine erhöhte Expression im Vergleich zum Wachstum mit Glucose beobachtet werden (Tab. 4.14). Anzumerken ist hierbei, dass BLi04164 in direkter Nachbarschaft zu dem Gen der Arginin-Deiminase liegt. Ebenfalls dort lokalisiert ist neben dem ORF BLi04162, dessen Produkt homolog zum AhrC Transkriptionsregulator ist, der ORF BLi04166 (Abb. 4.15). Dieser kodiert für eine Carbamat-Kinase, welche unter Bildung von ATP Carbamoylphosphat zu Ammoniak und Kohlendioxid umsetzt.

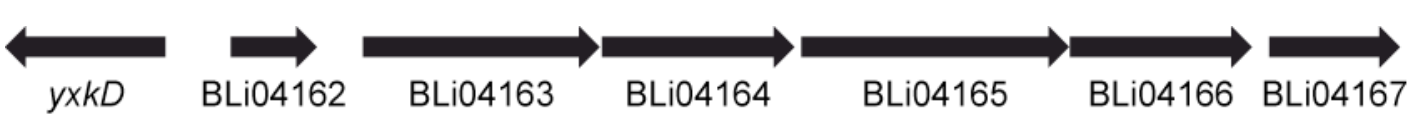

Abbildung 4.15: Genregion um den ORF der Arginin-Deiminase in DSM13. Erläuterung im Text. 


\section{L-Asparagin und L-Aspartat}

Bei der Verwertung von L-Asparagin wird dieses zunächst in einer HydrolaseReaktion, katalysiert durch das Enzym Asparaginase (EC 3.5.1.1), zu L-Asparat und Ammoniak umgesetzt [4.7]. Anschließend kann L-Aspartat in einem zweiten Schritt durch die Aspartase (EC 4.3.1.1) zu Fumarat und Ammoiak umgewandelt werden [4.8].

L-Asparagin $+\mathrm{H}_{2} \mathrm{O}<=>$ L-Aspartat $+\mathrm{NH}_{3}$

L-Aspartat $<=>$ Fumarat $+\mathrm{NH}_{3}$

Im Zusammenhang mit der Asparaginase sind vier Gene (BLi02433, BLi02777, BLi02778 und BLi04140) in DSM13 annotiert. Bei der Kultivierung von DSM13 mit L-Asparagin als Stickstoff- und Kohlenstoffquelle zeigt nur das Gen BLi04140 eine erhöhte Expression im Vergleich zum Wachstum mit Glucose (Tab. 4.14). Von den zwei Genen (BLi00528 und BLi04139), welche im Zusammenhang mit der Aspartase in DSM13 annotiert sind, konnte nur für den ORF BLi04139 eine erhöhte Expression beim Wachstum mit L-Aspartat ermittelt werden. Ergänzend kann noch hinzugefügt werden, dass für beide eben angesprochenen ORFs, BLi04139 (AnsB) und BLi04140 (AnsA), sowohl beim Wachstum mit L-Asparagin, als auch mit L-Aspartat eine Erhöhung des Expressionsverhältnisses ermittelt werden konnte. Im Genom von B. licheniformis DSM13 sind diese Gene in einem Operon mit dem Gen des zugehörigen transkriptionalen Repressors, ansR, lokalisiert (Abb. 4.16). In direkter Nachbarschaft hiervon sind ORFs lokalisiert, welche im Zusammenhang mit der Verwertung von Malat stehen. Hierbei kodiert das Gen mleN für einen Malat- $\mathrm{H}^{+} / \mathrm{Na}^{+}$-Lactat Antiporter und mleA für ein mögliches Malo-Lactat-Enzym. Begrenzt werden sie von dem Gen $y \mathrm{kgB}$, welches für ein Protein kodiert, dessen Funktion unbekannt ist und dem ORF BLi04136, welcher wiederum für ein hypothetisches Protein kodiert.

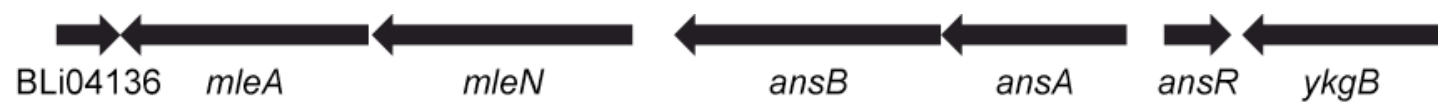

Abbildung 4.16: Genregion des ans $\boldsymbol{A B}$ Operon. Erläuterungen im Text. 


\section{L-Glutamin und L-Glutamat}

Die Umwandlung von L-Glutamin zu L-Glutamat kann über verschiedene Enzyme erfolgen. Das Enzym Glutaminase (EC 3.5.1.2) katalysiert eine HydrolaseReaktion, in welcher L-Glutamin zu L-Glutamat und Ammoniak umgesetzt wird [4.9]. Laut der Annotation sind in DSM13 zwei Gene (BLi00274 und BLi01700) vorhanden, dessen Produkt Ähnlichkeit zu einer Glutaminase aufweisen. Beim Wachstum mit L-Glutamin zeigte nur eines der Gene, ybgJ (BLi00274), eine erhöhte Expression im Vergleich zum Wachstum mit Glucose (Tab. 4.14).

L-Glutamin $+\mathrm{H}_{2} \mathrm{O}<=>$ L-Glutamat $+\mathrm{NH}_{3}$

Lokalisiert ist dieser ORF BLi00274 im Genom von DSM13 in direkter Nachbarschaft zu Genen, welche im Zusammenhang mit einem möglichen ZweiKomponenten-System stehen (Abb. 4.17). Das Gen $y c b A$ kodiert hierbei für ein Enzym, welches Ähnlichkeit zu einer Histidin-Kinase aufweist und das Produkt des Gens $y c b B$ Ähnlichkeit zu einem dazugehörigen Response-Regulator. Interessanterweise ist downstream des ORFs BLi00274 ein Bereich von etwa 1,6 kb vorhanden, in dem kein Gen annotiert wurde.

$y j g A$

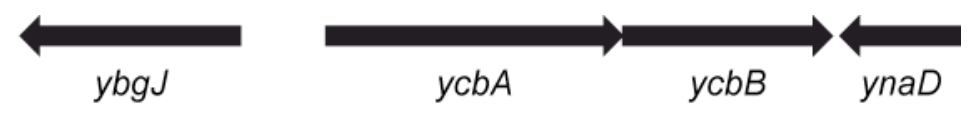

Abbildung 4.17: Genregion des die Glutaminase kodierenden Gens des Göttinger Genomlabors. Erläuterungen im Text.

Neben dem Göttinger Genomlabor wurde B. licheniformis DSM13 parallel von der Firma Novozymes Biotech Inc sequenziert (Rey et al., 2004). Im Gegensatz zu Ersteren verwendete Novozymes für diese Genregion keine so genannten Y-ORFs, sondern wählten Genbezeichnungen, wie sie für B. subtilis beschrieben sind (vgl. Satomura et al., 2005). Hierbei kodiert $g \ln L$ für den Response-Regulator, $g \ln K$ für die Histidin-Kinase und $g l s A$ für die Glutaminase. Des Weiteren wurde für den downstream der Glutaminase liegenden Bereich das Gen $g \ln T$ annotiert, welches für einen NatriumAlanin Symporter kodiert (Abb. 4.18). Ein Sequenzvergleich von $g \ln T$ mit diesem 
Abschnitt der Genregion des Göttinger Genomlabors mittels BLAST ergab eine 100\%ige Übereinstimmung auf Nukleotidebene (Abb. 7.1 im Anhang).

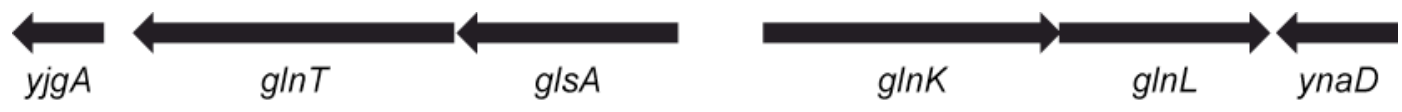

Abbildung 4.18: Genregion des die Glutaminase kodierenden Gens der Firma Novozymes. Erläuterungen im Text.

Ein weiteres Enzym mit welchem die Verwertung von L-Glutamin als Stickstoffund Kohlenstoffquelle eingeleitet werden kann ist die Glutamat-Synthase (EC 1.4.1.13). Durch die Arbeiten von Schreier und Bernlohr (1984) konnte für B. licheniformis gezeigt werden, dass diese aus zwei Untereinheiten besteht. Annotiert wurden die zugehörigen Gene als gltA (BLi02162) und gltB (BLi02161). Beim Wachstum mit L-Glutamin waren diese Gene, im Vergleich zum Wachstum mit Glucose, reprimiert (Tab. 4.14).

Die Verwertung von L-Glutamat in Enterobakterien kann über drei Wege erfolgen (McFall \& Newman, 1996). Neben der Möglichkeit die Glutamat-Dehydrogenase oder die Glutamat-Decarboxylase zum Abbau von L-Glutamat zu verwenden, konnte in E. coli gezeigt werden, dass die Transaminierung der bevorzugte Weg ist (Marcus \& Halpern, 1969). Hierbei werden zunächst L-Glutamat und Oxalacetat durch die Aspartat-Aminotransferase (EC 2.6.1.1) zu L-Aspartat und 2-Oxoglutarat umgesetzt [4.10]. L-Aspartat kann im Weiteren durch die Aspartase zu Fumarat umgewandelt werden [4.8].

L-Glutamat + Oxalacetat $<=>$ L-Aspartat +2 -Oxoglutarat

Im Vergleich zum Wachstum mit Glucose konnte für das die AspartatAminotransferase kodierende Gen aspB (BLi02372) keine erhöhte Expression beim Wachstum mit L-Glutamat beobachtet werden (Tab. 4.14). Auch für die drei ORFs dessen Produkt Ähnlichkeit zu Aspartat-Aminotransferasen aufweisen, BLi01514, BLi03434 und BLi04237, konnte ebenfalls keine erhöhte Expression beim Wachstum mit L-Glutamat ermittelt werden. 


\section{L-Prolin}

An dem Abbau von L-Prolin zu L-Glutamat sind zwei Enzyme beteiligt. Zunächst wird L-Prolin, katalysiert durch die Prolin Oxidase (EC 1.5.99.8, BLi00373), zu $\Delta^{1}$-Pyrrolin-5-Carboxylat umgesetzt [4.11]. Letzteres wird im Anschluss daran zu L-Glutamat umgewandelt [4.4]. Diese Reaktion wird durch das Enzym $\Delta^{1}$-Pyrrolin-5-Carboxylat-Dehydrogenase (EC 1.5.1.12, BLi00374) katalysiert.

L-Prolin + FAD $<=>\Delta^{1}$-Pyrrolin-5-Carboxylat $+\mathrm{FADH}_{2}$

Sowohl BLi00373 (ycgM), als auch BLi00374 (ycgN) zeigten beim Wachstum mit L-Prolin als alleinige Stickstoff- und Kohlenstoffquelle eine erhöhte Expression im Vergleich zum Wachstum mit Glucose (Tab. 4.14). Hinzuzufügen ist in diesem Kontext, dass beide Gene in direkter Nachbarschaft im Genom von DSM13 liegen (Abb. 4.19). Des Weiteren ist dort auch das Gen ycgO lokalisiert, dessen Produkt Ähnlichkeit zu einer Prolin-Permease aufweist. Auch dieses Gen zeigte beim Wachstum mit L-Prolin eine erhöhte Expression (Tab. 7.4 im Anhang).

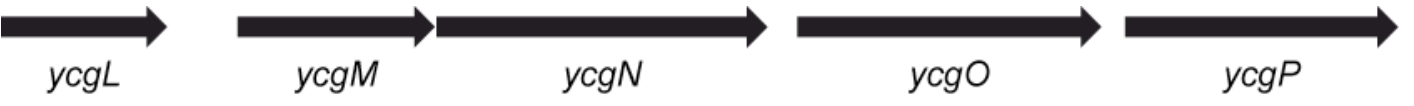

Abbildung 4.19: Genregion der am Abbau von L-Prolin beteiligten ORFs. Erläuterung im Text.

\section{L-Ornithin}

Die nicht-proteinogene Aminosäure L-Ornithin ist ein Zwischenprodukt des Abbaus von L-Arginin zu L-Glutamat über den Arginase degradativen Weg. Wie bereits zuvor erläutert wird L-Ornithin durch die Ornithin-Aminotransferase (EC 2.6.1.13, BLi00422) zu L-Glutamat und L-Glutamat-Semialdehyd umgesetzt. Letzters wird zunächst spontan zu $\Delta^{1}$-Pyrrolin-5-Carboxylat und anschließend durch das Enzym $\Delta^{1}$-Pyrrolin-5-Carboxylat-Dehydrogenase (EC 1.5.1.12, BLi00374) zu L-Glutamat umgewandelt. 
Wie schon bei der Verwertung von L-Arginin zu beobachten war, so zeigten auch mit L-Ornithin gewachsene Zellen von DSM13 eine erhöhte Expression dieser beiden Gene im Vergleich zum Wachstum mit Glucose (Tab. 4.14).

\subsection{Gene mit gleicher Genexpression}

Bei den Untersuchungen zum Einmünden der Aminosäuren in den Zentralmetabolismus konnte beobachtet werden, dass Zellen, welche auf unterschiedlichen Aminosäuren gewachsen waren, die gleiche Expression bestimmter Gene zeigten. Um zu untersuchen, ob es Gene gibt, die bei allen auf proteinogenen Aminosäuren gewachsenen Zellen eine signifikant erhöhte Expression im Vergleich zum Wachstum mit Glucose zeigten, wurde zunächst die Anzahl der Gene festgestellt, welche eine signifikante Änderung der Expression zeigten (Tab. 4.15). Wie bereits im Vorfeld erläutert, wurde als signifikant eine mindestens dreifache Änderung des ratio of medians erachtet, dieser entspricht logarithmiert zur Basis 2 1,5849 bzw. -1,5849.

Tabelle 4.15: Anzahl von Genen, welche eine signifikante Änderung der Expression beim Wachstum mit den einzelnen Aminosäuren zeigten.

\begin{tabular}{lcc} 
& Gesamtzahl der ORFs & 4286 \\
\hline Aminosäure & \multicolumn{1}{c}{ log Expressionsverhältnisse } \\
& $>1,5849$ & $<-1,5849$ \\
\hline L-Alanin & 112 & 35 \\
L-Arginin & 382 & 164 \\
L-Asparagin & 151 & 60 \\
L-Aspartat & 86 & 46 \\
L-Glutamin & 365 & 105 \\
L-Glutamat & 245 & 67 \\
L-Prolin & 140 & 120 \\
\hline
\end{tabular}

Mittels eines Informatikprogramms (A. Wollherr, unveröffentlicht), welches in der Programmiersprache Perl geschrieben wurde, konnten nach vergleichender Darstellung Gene identifiziert werden, welche reproduzierbar bei allen auf Aminosäuren gewachsenen Zellen eine signifikante Erhöhung der Expression zeigten. Um den Effekt 
auszuschließen, dass eine Katabolitrepression auf Glucose gewachsenen Zellen als erhöhte Expression bei Aminosäure gewachsenen Zellen interpretiert wird, wurden zusätzlich Daten von Transkriptionsanalysen Gluconat gewachsener Zellen vergleichend mit einbezogen. Diese zeigten keine signifikante Änderung des Expressionsverhältnisses (Tab. 7.6 im Anhang).

Tabelle 4.16: Gene mit gleicher Genexpression. Dargestellt ist die Schnittmenge an Genen, welche beim Wachstum mit einzelnen Aminosäuren eine signifikante Erhöhung der Expression zeigten.

\begin{tabular}{lll}
\hline ID & Gen & Annotation \\
\hline BLi00853 & acoR & transkriptionaler Aktivator des Acetoin-Dehydrogenase Operon \\
BLi01143 & melA & $\alpha$-D-Galaktosid-Galaktohydrolase \\
BLi02102 & & putative Enoyl(3-hydroxyisobutyryl)-Coenzyme A Hydratase- \\
& & Protein \\
BLi02103 & & putative Enoyl-CoA-Hydratase \\
BLi02104 & mmsA & Methylmalonat-Semialdehyd-Dehydrogenase \\
BLi02105 & & putative 2-Hydroxy-3-Oxopropionat-Reductase \\
BLi02106 & & putative Butyryl-CoA-Dehydrogenase \\
BLi03498 & & putative Pectin-Methylesterase \\
BLi04275 & & homolog zu Ald: L-Alanin-Dehydrogenase \\
\hline
\end{tabular}

Unter den noch verbleibenden in der Tabelle 4.16 dargestellten ORFs ist das Gen des transkriptionalen Aktivators der aco-Gene, acoR (BLi0853), zu finden. Ebenso wie der ORF BLi02104, welcher für eine Methylmalonat-Semialdehyd Dehydrogenase kodiert. Gleiches gilt für die im Genom jeweils zwei angrenzenden Gene upstream (BLi02105, BLi02106) und downstream (BLi02103, BLi02102) (Abb. 4.20). Ebenfalls eine signifikante Erhöhung der Expression bei Aminosäure gewachsenen Zellen konnte für BLi04275, welches für ein Homolog der L-Alanin-Dehydrogenase kodiert, beobachtet werden.

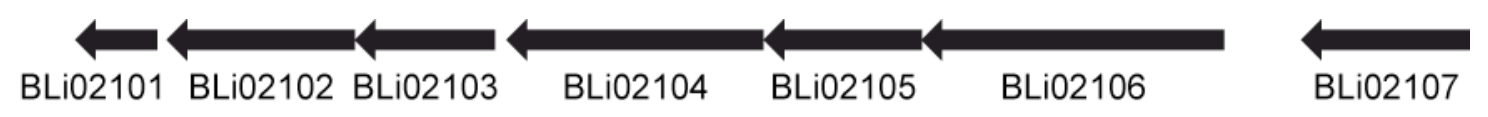

Abbildung 4.20: Genregion BLi02106 - BLi02102. Erläuterung der Proteinfunktion ist der Tabelle 4.16 zu entnehmnen. 


\subsection{Gene mit unterschiedlicher Genexpression}

In einem nächsten Schritt wurde nun untersucht, ob einzelne Gene oder Gruppen von Genen identifiziert werden können, welche charakteristisch für die Verwertung einzelner Aminosäuren sind. Wie schon bei Genen mit gleicher Genexpression wurden zunächst die Gene vergleichend dargestellt. Als signifikant wurde auch hier eine Änderung des ratio of medians um mindestens einen Faktor 3 erachtet. Anschließend konnten mit einem weiteren in Perl geschriebenen Informatikprogramm (H. Kurka, unveröffentlicht) Gene identifiziert werden, welche reproduzierbar charakteristisch für das Wachstum mit einer Aminosäure sind (Tab. 4.17). In diesem Kontext konnten 45 Gene ermittelt werden, welche reproduzierbar eine signifikante Erhöhung des Expressionsverhältnisses zeigten, wenn die Zellen mit L-Asparagin gewachsen waren. Darunter befinden sich die die Untereinheiten der Pyruvat-Dehydrogenase kodierenden Gene $p d h A B C D$.

Tabelle 4.17: Anzahl charakteristischer Gene für das Wachstum auf einzelnen Aminosäuren.

\begin{tabular}{lc}
\hline Aminosäure & $\begin{array}{c}\log \text { Expressionsverhältnis } \\
>\end{array}$ \\
\hline L-Alanin & 6849 \\
L-Arginin & 86 \\
L-Asparagin & 45 \\
L-Aspartat & 2 \\
L-Glutamin & 80 \\
L-Glutamat & 19 \\
L-Prolin & 22 \\
\hline
\end{tabular}

Am Beispiel der Pyruvat-Dehydrogenase sollen nun vergleichend die logarithmierten Expressionswerte Aminosäure gewachsener Zellen dargestellt werden. Wie der Abbildung $4.21 \mathrm{zu}$ entnehmen ist, konnte nur eine signifikante Erhöhung der Expression beobachtet werden, wenn Zellen von DSM13 mit L-Asparagin als alleiniger Stickstoff- und Kohlenstoffquelle angezogen wurden. Für die verbleibenden sechs Aminosäuren konnte für einige Untereinheiten eine entgegengesetzte Expression 
ermittelt werden. Beispielhaft können hierfür die kodierenden Gene der Untereinheiten PdhA und PdhB beim Wachstum mit L-Prolin angeführt werden.

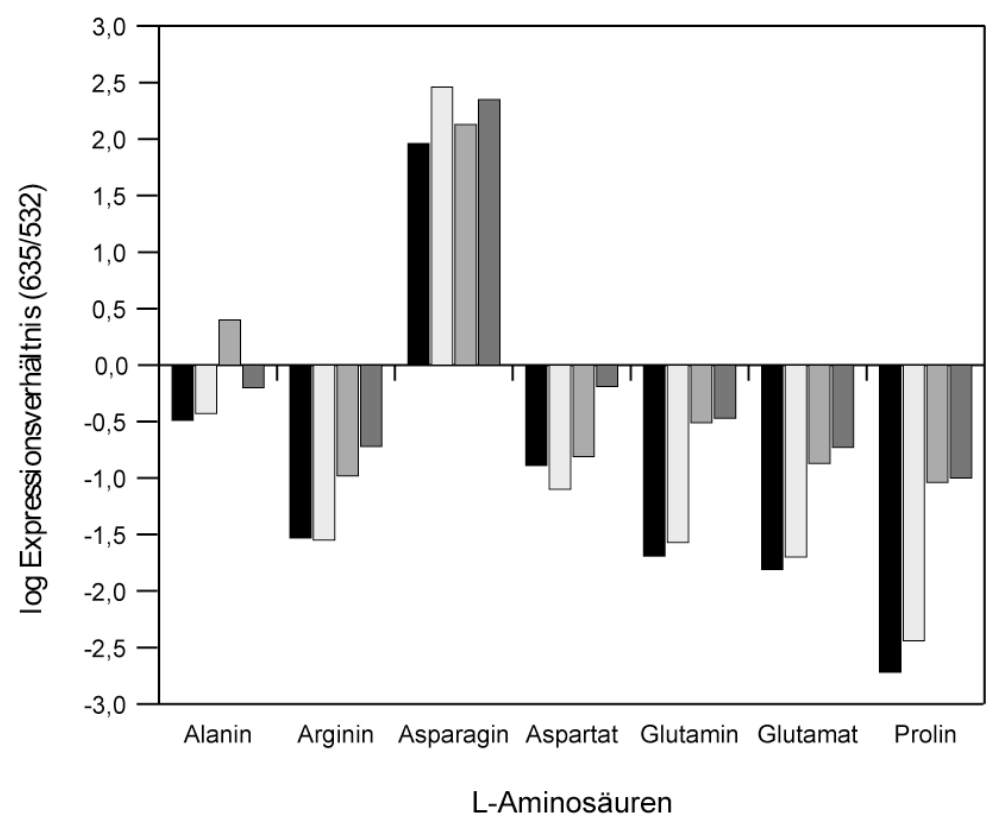

Abbildung 4.21: Vergleichende Darstellung von Expressionverhältnissen. Übersicht der die PyruvatDehydrogenase kodierenden Gene $p d h A(\square), p d h B(\square), p d h C(\square)$ und $p d h D(\square)$ beim Wachstum mit einzelnen Aminosäuren. Die Abbildung zeigt repräsentative Einzelmessungen.

\subsection{Genexpressionsdaten weiterer Enzyme}

Wie bereits im Abschnitt 4.3.1.2.1. beschrieben, zeigten eine Anzahl von Genen eine ähnlich erhöhte Expression bei der Kultivierung auf verschiedenen Aminosäuren. Diese Aminosäuren wiederum können aufgrund ihres Einmündens in den Zentralmetabolismus in Gruppen eingeteilt werden. Gruppe 1 stellt L-Alanin dar, welches über Pyruvat in den Tricarbonsäurezyklus eingeschleust wird. Die zweite Gruppe besteht aus L-Asparagin und L-Aspartat. Aminosäuren, welche über L-Glutamat in den Zentralmetabolismus einmünden, können in einer dritten Gruppe zusammengefasst werden. Betrachtet man nur die proteinogenen Aminosäuren, sind dieses L-Glutamin, L-Glutamat, L-Arginin und L-Prolin. Letztere beiden nehmen aufgrund ihres gemeinsamen Zwischenproduktes, $\Delta^{1}$-Pyrrolin-5-Carboxylat, eine Sonderstellung ein. In den folgenden Ausführungen soll nun näher auf Genexpressionsdaten weiterer Enzyme der zweiten Gruppe eingegangen werden. 
Um gemeinsame Genxpressionsdaten der Gruppe II, L-Asparagin und L-Aspartat, $\mathrm{zu}$ erhalten, wurden, wie in den vorangegangenen Abschnitten bereits beschrieben, Gene mit signifikant erhöhter Expression vergleichend dargestellt. Im Anschluss daran wurde daraus die Ausschlußmenge bestimmt. In dieser Ausschlußmenge (Tab. 7.5 im Anhang) sind neben dem ans $A B$ Operon, dem Gen des zugehörigen Repressor, ans $R$, auch Gene enthalten, welche im Zusammenhang mit der möglichen Verwertung von Malat stehen (Tab. 4.18). Hierbei handelt es sich um die bereits im Zusammenhang mit dem Einmünden der Aminosäuren in den Zentralmetabolimus erläuterten Gene mleA und mleN.

Tabelle 4.18: Auswahl an Genen, welche aufgrund ihrer Expressionsdaten im Zusammenhang mit L-Asparagin und L-Aspartat stehen. Werte größer 1 bedeuten eine verstärkte Expression beim Wachstum mit der angegeben Aminosäure im Vergleich zur Referenzbedingung. Die Tabelle enthält repräsentative Einzelmessungen.

\begin{tabular}{lllcc}
\hline ID & Gen & Annotation & \multicolumn{2}{c}{$\log$ Expressionsverhältnisse } \\
& & & Asn / Glc & Asp / Glc \\
\hline BLi04137 & mleA & mögl. Malo-Lactat-Enzym & 4,72 & 3,94 \\
BLi04138 & mleN & Malat-H ${ }^{+} \mathrm{Na}^{+}$-Lactat Antiporter & 4,32 & 3,47 \\
BLi04139 & & homolog zur AnsB L-Aspartase & 4,67 & 3,65 \\
BLi04140 & ans A & L-Asparaginase & 5,55 & 4,67 \\
BLi04141 & ansR & transkriptionaler Repressor des & 3,00 & 3,23 \\
& & ansAB Operons & & \\
\hline
\end{tabular}

Ein weiteres Beispiel für Genexpressionsdaten weiterer Enzyme mit L-Asparagin bzw. L-Aspartat als Stickstoff- und Kohlenstoffquelle stellen die Citratsynthasen dar. B. licheniformis DSM13 besitzt drei Citratsynthasen: CitA (Citratsynthase I, BLi01010), CitZ (Citratsynthase II, BLi03062) und MmgD (Citratsynthase III, BLi04094). Eine vergleichende Darstellung der logarithmierten Expressionverhältnisse der ORFs der Citratsynthasen zeigte, dass beim Wachstum mit L-Asparagin bzw. L-Aspartat nur bei dem die Citratsynthase I kodierenden Gen citA eine signifikant erhöhte Expression beobachtet werden konnte. Beim Wachstum mit den anderen proteinogenen Aminosäuren, welche als Stickstoff- und Kohlenstoffquelle dienen können, zeigte hingegen das Gen $m m g D$, welches für die Citratsynthase III kodiert, eine 
signifikant erhöhte Expression (Abb. 4.22). Hierbei ist anzumerken, dass das für die Citratsynthase III kodierende Gen im Genom an $m m g E$ und $y q i Q$ angrenzt. Gene, welche im Zusammenhang mit dem Methylcitratzyklus stehen. Hierauf wird unter 4.6 in dieser Arbeit eingegangen.

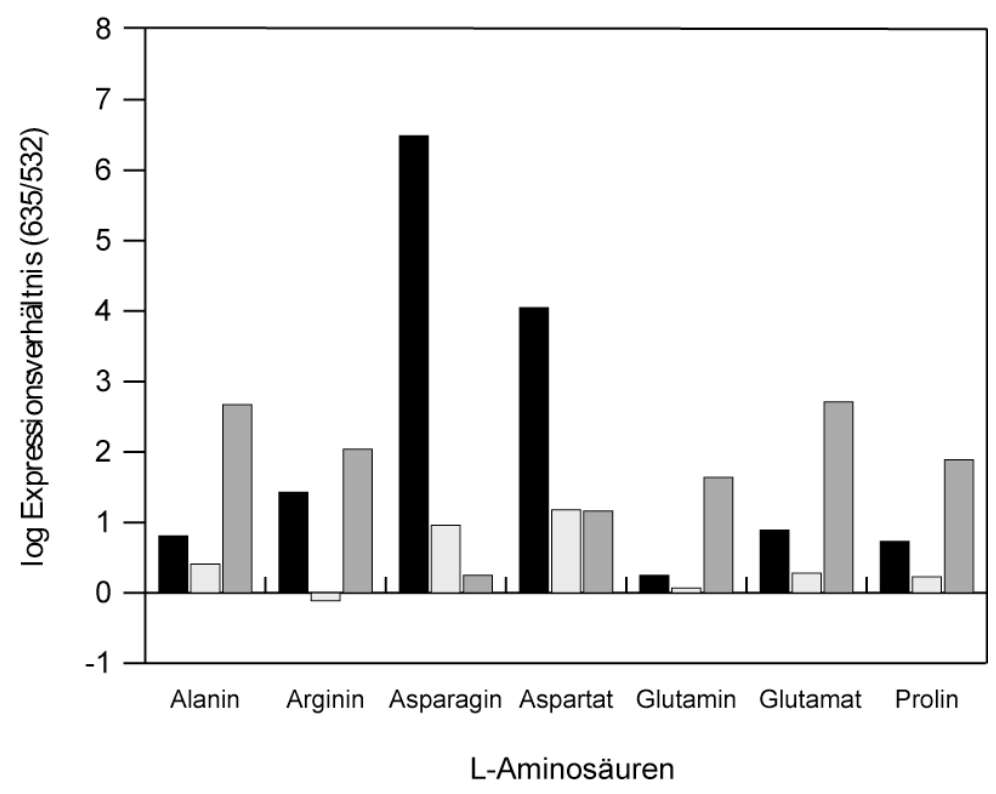

Abbildung 4.22: Vergleichende Darstellung von Expressionverhältnissen. Übersicht der die drei Citratsynthasen kodierenden Gene citA $(\square)$, citZ $(\square)$ und $m m g D(\square)$ beim Wachstum mit einzelnen Aminosäuren. Die Abbildung zeigt repräsentative Einzelmessungen.

\subsubsection{Verifizierung ausgewählter Daten aus DNA-Microarray-Experimenten durch real-time RT-PCR}

In den vorangegangenen Abschnitten wurden ausgewählte Gene dargestellt, welche zum einen bei allen auf Aminosäuren gewachsenen Zellen (4.3.1.2.2.) eine signifikante Erhöhung der Expression zeigten oder zum anderen aufgrund ihres Expressionsverhältnisses als charakteristisch für das Wachstum auf einzelnen Aminosäuren eingestuft werden konnten (4.3.1.2.3.). Diese aus DNA-MicroarrayAnalysen gewonnenen Expressionsdaten sollten für eine Auswahl an Genen über eine zweite unabhängige Methode verifiziert werden. Für die Analyse mittels real-time RT-PCR wurde, wie für die DNA-Microarray-Analysen, RNA aus B. licheniformis Zellen gewonnen, welche in je zwei unabhängigen Experimenten auf einzelnen Aminosäuren bzw. im Chemostaten kultiviert wurden. 


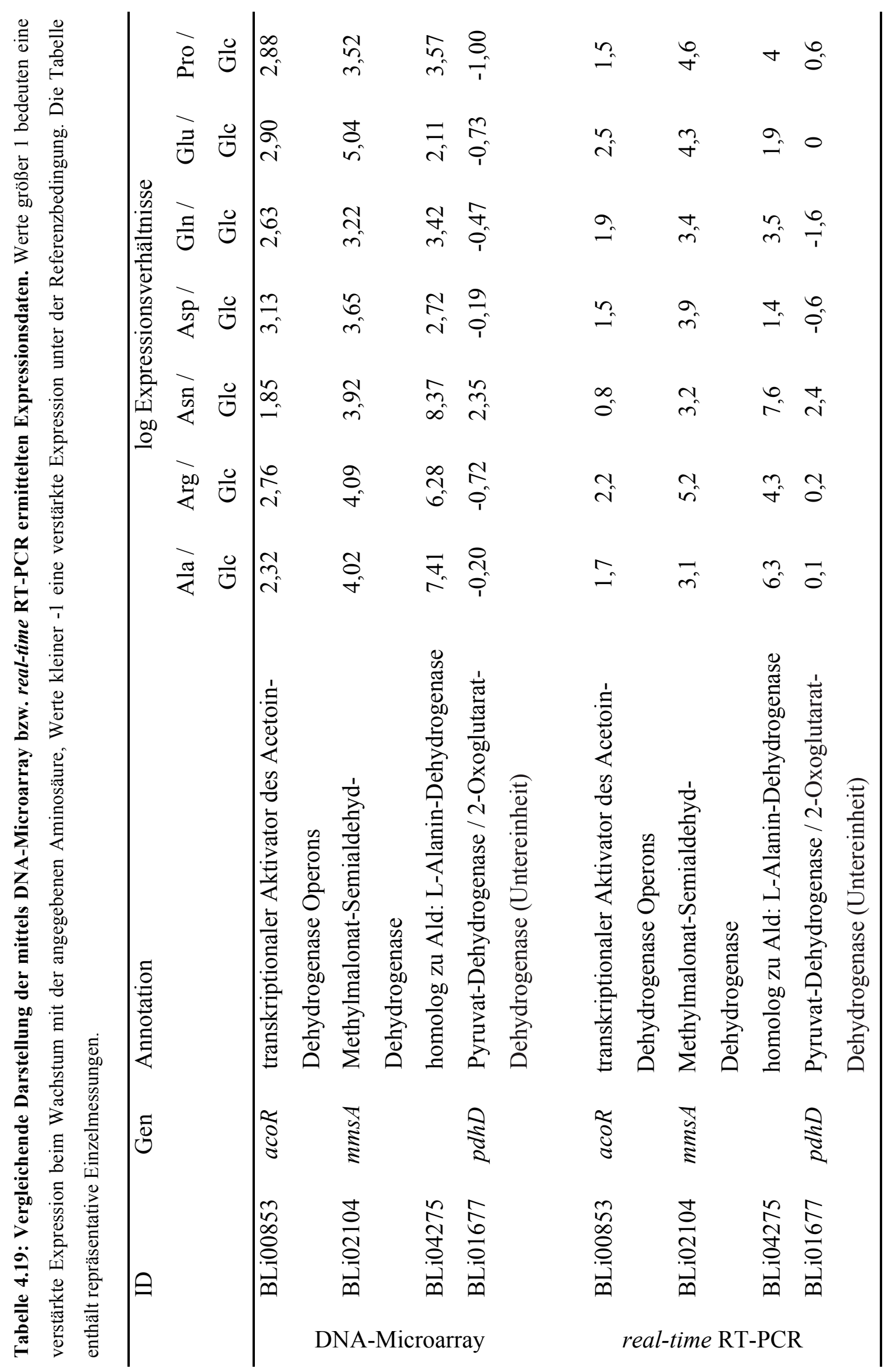


Es wurden für jede RNA zwei konstitutive Gene mitgeführt, wobei für die Normalisierung eines der Gene benutzt wurde (Daten nicht angegeben). Die Berechnung der Expressionswerte erfolgte nach der Ermittlung der Ct-Werte, wie unter 3.7.6. beschrieben.

In der Tabelle 4.19 sind vergleichend die Resultate der mittels DNA-Microarray bzw. real-time RT-PCR durchgeführten Genexpressionsanalysen für verschiedene ORFs dargestellt. Mit einer Ausnahme konnte für alle betrachteten Aminosäuren die erhöhte Expression für das Gen des transkriptionalen Aktivators des AcetoinDehydrogenase Operons, acoR, bestätigt werden. Lediglich für das Wachstum mit L-Asparagin konnte reproduzierbar keine erhöhte Expression ermittelt werden. Des Weiteren konnte nicht nur für den eine Methylmalonat-Semialdehyd-Dehydrogenase kodierenden ORF BLi02104, sondern auch für den ORF BLi04275, welcher wiederum für ein Homolog der L-Alanin-Dehydrogenase kodiert, die erhöhte Expression beim Wachstum mit einzelnen Aminosäuren bestätigt werden. Die Daten für das Gen einer Untereinheit der Pyruvat Dehydrogenase (BLi01677) konnten ebenfalls via real-time RT-PCR verifiziert werden. Nur Zellen, welche mit L-Asparagin als Stickstoff- und Kohlenstoffquelle angezogen wurden, zeigten eine signifikant erhöhte Expression.

\subsubsection{Wachstum mit Gemischen von Aminosäuren}

Vorangegangene Experimente zeigten, welche der untersuchten Aminosäuren einzeln als Stickstoff-, Kohlenstoff- und Energiequelle dienen können. In der Natur liegen Aminosäuren aber nicht einzeln, sondern in der Regel als Gemische vor. In der Abbildung 4.23 ist der prozentuale Anteil einzelner Aminosäuren am Gesamtprotein vergleichend dargestellt. Für weitere Untersuchungen wurde die Aminosäurezusammensetzung der Sojabohne ausgewählt. Hierzu wurde einem definierten Medium, welches keine Stickstoff- oder Kohlenstoffquellen enthielt, die Menge an Aminosäuren zugegeben, die 20 g Sojabohne pro Liter Medium entsprechen (vgl. 3.2.2.). Da aufgrund des Versuchaufbaus zur Ermittlung des Aminosäuregehaltes nach FAO keine Angaben zum Gehalt an Asparagin und Glutamin ermittelt werden konnten, wurde der Gehalt an Aspartat bzw. Glutamat halbiert, so dass ein Mix aus 20 proteinogen Aminosäuren hergestellt werden konnte. 


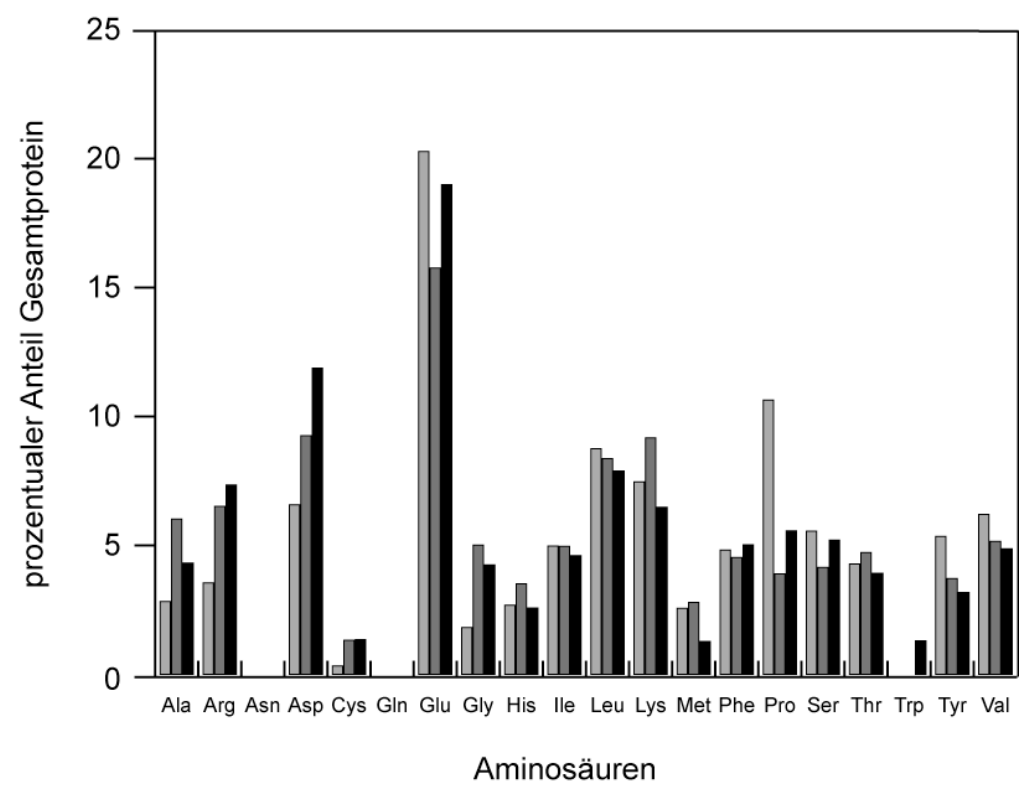

Abbildung 4.23: Zusammensetzung des Aminosäuregehalts von Nahrungsmitteln. Nach FAO (Food And Agriculture Organization Of The United Nations), Stand 1981. Kuh-Casein ( $\square$ ), Rind- und

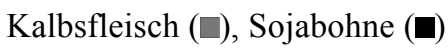

\subsubsection{Verwertung eines Gemisches aus sieben Aminosäuren}

Wie bereits gezeigt wurde, kann DSM13 sieben proteinogene Aminosäuren als Stickstoff- und Kohlenstoffquelle nutzen (vgl. 4.3.1.1., Tab. 4.13). Um das Wachstum von B. licheniformis auf Gemischen von Aminosäuren zu untersuchen, wurde zunächst ein Gemisch aus diesen sieben Aminosäuren zusammengestellt, welches der Sojabohne nachempfunden war (vgl. 3.2.2.). Während des Wachstums von DSM13 in einem definierten Medium mit dem Gemisch dieser sieben Aminosäuren als Stickstoff- und Kohlenstoffquelle wurden $\mathrm{zu}$ verschiedenen Zeitpunkten Proben entnommen, um mittels Ionenchromatographie den Verbrauch der Aminosäuren im Kulturüberstand zu detektieren (Abb. 4.24A). Diese Untersuchungen zeigten, dass $\mathrm{zu}$ Beginn des Wachstums alle Aminosäuren genutzt werden, sich aber die Rate des Verbrauchs unterscheidet. Die erste Aminosäure, die nicht mehr im Kulturüberstand detektiert werden konnte, war L-Asparagin. Erst im Anschluss daran wurde ein signifikanter Verbrauch der verbleibenden Aminosäuren beobachtet. Noch vor dem Einschwenken in die stationäre Phase waren nur noch L- Aspartat und L-Glutamat als proteinogene Aminosäuren im Kulturüberstand zu detektieren. 

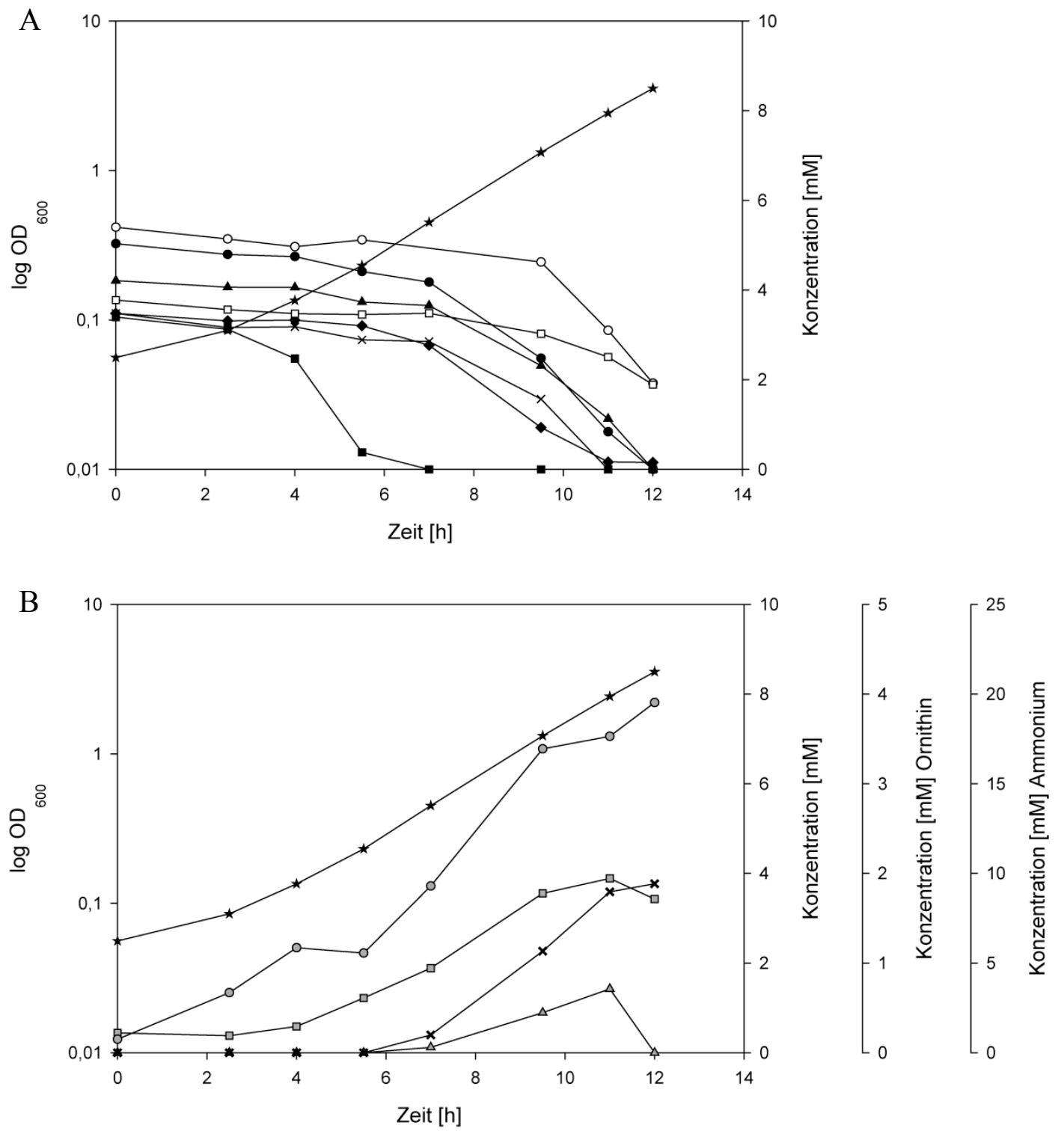

Abbildung 4.24: Wachstumsverlauf von DSM13 auf einem definierten Medium mit einem Gemisch aus sieben Aminosäuren. Neben der jeweiligen Darstellung des Wachstums von DSM13 ( $\star$ ) ist in A der

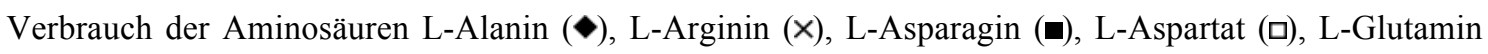
$(\bullet)$, L-Glutamat (O) und L-Prolin (A) abgebildet. B zeigt die einhergehende Akkumulation von Acetat (ם), Ammoinum (o) und Harnstoff (x). Außerdem konnte die Bildung und der Verbrauch von L-Ornithin $(\Delta)$ beobachet werden. Die Abbildung zeigt repräsentative Einzelmessungen.

Neben dem Verbrauch der proteinogenen Aminosäuren wurden noch weitere Substanzen im Kulturüberstand detektiert (Abb. 4.24B). Während des Wachstums von DSM13 konnte eine Anhäufung von Acetat mittels Ionenchromatographie ermittelt werden (3.9.2.2). Um zu Überprüfen, ob es sich nicht um Acetoin handelt, welches die 
gleiche Retentionszeit wie Acetat bei den in dieser Arbeit verwendeten analytischen Säulen hatte, wurde zunächst eine Bestimmung von Acetoin durchgeführt (3.9.5.). Es konnte jedoch kein Acetoin im Kulturüberstand detektiert werden (Daten nicht gezeigt). Durch UV-Tests zur Bestimmung von Acetat konnten die zuvor ermittelten Daten der Ionenchromatographie verifiziert werden (3.9.4.). Während des Wachstums von DSM13 in dem definierten Medium mit sieben Aminosäuren als Stickstoff- und Kohlenstoffquelle konnte außerdem die Anhäufung von Ammonium im Kulturüberstand mittels Ionenchromatographie detektiert werden. Diese Daten konnten anschließend durch UV-Tests verifiziert werden (3.9.6.).

Ein einleitender Schritt zum Abbau von L-Arginin wird durch die Arginase katalysiert, wobei L-Arginin zu Harnstoff und L-Ornithin umgesetzt wird. Im Rahmen der Analyse der Kulturüberstände konnte eine Akkumulation von Harnstoff detektiert werden. Im Genom von B. licheniformis DSM13 wurden keine Gene annotiert, die im Zusammenhang mit der Verwertung von Harnstoff stehen. Zur experimentellen Überprüfung wurde DSM13 in einem definierten Medium mit $30 \mathrm{mM}$ Harnstoff als Stickstoff- und Kohlenstoffquelle kultiviert. Zusätzlich wurde noch überprüft, ob DSM13 Harnstoff als Stickstoffquelle nutzen kann. Hierzu wurde er in einem definierten Medium mit $50 \mathrm{mM}$ Glucose, als reprimierenden Zucker, bzw. $50 \mathrm{mM}$ Xylose, als nicht-reprimierenden Zucker, und $10 \mathrm{mM}$ Harnstoff als Stickstoffquelle kultiviert. Wie schon zu erwarten, zeigten diese Wachstumsexperimente, dass DSM13 Harnstoff weder als Stickstoff-, noch als Kohlenstoffquelle nutzen kann (Daten nicht gezeigt). Etwas zeitversetzt mit der beginnenden Akkumulation von Harnstoff war eine Anhäufung von L-Ornithin im Kulturüberstand zu beobachten. Dieses wurde jedoch wieder verbraucht, nachdem kein L-Arginin mehr im Kulturüberstand zu detektieren war (Abb. 4.24B).

\subsubsection{Transkriptionsanalysen zur Verwertung eines Gemisches aus sieben Aminosäuren}

Wie schon beim Wachstum mit einzelnen Aminosäuren wurden auch zur Verwertung eines Gemisches aus sieben Aminosäuren Transkriptionsanalysen durchgeführt. Von besonderem Interesse war hierbei, ob Gene, welche sich als charakteristisch für das Wachstum auf einzelnen Aminosäuren erwiesen, auch beim 
Wachstum mit einem Gemisch dieser Aminosäuren zu identifizieren waren. Aus diesem Grund wurden für die Transkriptionsanalysen zwei verschiedene Zeitpunkte so gewählt, dass beim ersten Zeitpunkt L-Asparagin noch im Kulturüberstand zu detektieren war, zum zweiten Zeitpunkt nicht mehr (Abb. 4.25).

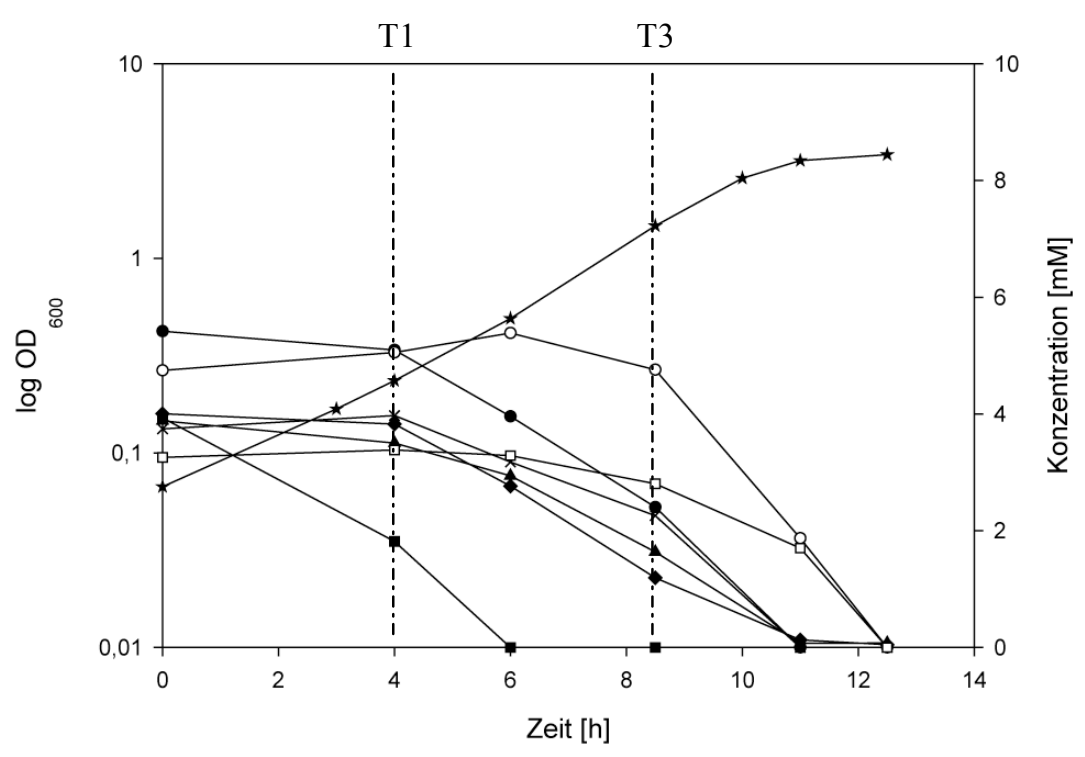

Abbildung 4.25: Zeitpunkte der durchgeführten Transkriptionsanalysen. Dargestellt ist das Wachstum von DSM13 ( $\star$ ) mit den Zeitpunkten, zu welchen Kulturanteile zur RNA-Präparation geerntet wurden. Des Weiteren ist der Verbrauch der Aminosäuren L-Alanin (४), L-Arginin (×), L-Asparagin (ם),

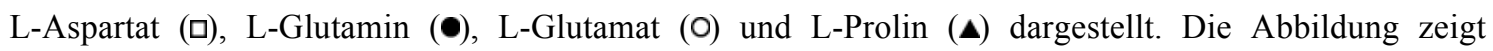
repräsentative Einzelmessungen.

Anhand von Transkriptionsanalysen konnte im Abschnitt 4.3.1.2.3. gezeigt werden, dass die Gene der Untereinheiten der Pyruvat-Dehydrogenase lediglich beim Wachstum mit L-Asparagin als Stickstoff- und Kohlenstoffquelle induziert waren. Auch bei der Kultivierung in einem Gemisch aus sieben Aminosäuren konnte eine solche erhöhte Expression mit der Verwertung von L-Asparagin in Zusammenhang gebracht werden. Die Gene der Untereinheiten der Pyruvat Dehydrogenase zeigten zum Zeitpunkt T1 (L-Asparagin ist im Kulturüberstand nachzuweisen, Abb. 4.25), eine signifikant erhöhte Expression. Zum Zeitpunkt T3 (es ist kein L-Asparagin im Kulturüberstand zu detektieren) kann dieses nicht mehr beobachtet werden. (Tab. 4.20). 
Tabelle 4.20: Vergleichende Darstellung von Expressionsverhältnissen. Angegeben sind die Expressionsdaten für die Gene der Pyruvat-Dehydrogenase zu den Zeitpunkten der durchgeführten Transkriptionsanalysen. Werte größer 1 bedeuten eine verstärkte Expression beim Wachstum mit einem Gemisch von Aminosäuren, Werte kleiner -1 eine verstärkte Expression unter der Referenzbedingung. Die Tabelle enthält repräsentative Einzelmessungen.

\begin{tabular}{lllcc}
\hline ID & Gen & Annotation & \multicolumn{2}{c}{ log Expressionsverhältnisse } \\
& & & T1 / Glc & T3 / Glc \\
\hline BLi01674 & $p d h A$ & Pyruvat-Dehydrogenase & 2,95 & $-1,66$ \\
BLi01675 & $p d h B$ & Pyruvat-Dehydrogenase & 2,94 & $-1,46$ \\
BLi01676 & $p d h C$ & Pyruvat-Dehydrogenase & 2,08 & $-0,21$ \\
BLi01677 & $p d h D$ & Pyruvat-Dehydrogenase / & 3,11 & 0,02 \\
& & 2-Oxoglutarat-Dehydrogenase & \\
\hline
\end{tabular}

Auch für Gene, welche als charakteristisch für das Wachstum mit L-Asparagin bzw. L-Aspartat identifiziert wurden, konnte eine Expressionsänderung beobachtet werden. Sowohl für die Gene des ans $A B$ Operons, als auch für die benachbarten Gene mleA und mleN konnte eine erhöhte Expression ermittelt werden, wenn L-Asparagin im Kulturüberstand zu detektieren war ( Zeitpunkt T1). Auf der anderen Seite konnte keine signifikante Änderung der Expression mehr für diese Gene beobachtet werden, wenn kein L-Asparagin, jedoch noch L-Aspartat zu detektieren war (Zeitpunkt T3, Tab. 4.21).

Tabelle 4.21: Auswahl an Genen, welche aufgrund ihrer Expressionsdaten im Zusammenhang mit L-Asparagin und L-Aspartat stehen. Werte größer 1 bedeuten eine verstärkte Expression beim Wachstum mit einem Gemisch von Aminosäuren, Werte kleiner -1 eine verstärkte Expression unter der Referenzbedingung. Die Tabelle enthält repräsentative Einzelmessungen.

\begin{tabular}{lllcc}
\hline ID & Gen & Annotation & \multicolumn{2}{c}{$\log$ Expressionsverhältnisse } \\
& & & T1 / Glc & T3 / Glc \\
\hline BLi04137 & mleA & mögl. Malo-Lactat Enzym & 5,29 & $-0,34$ \\
BLi04138 & mleN & Malat- ${ }^{+} / \mathrm{Na}^{+}$-Lactat Antiporter & 4,38 & $-1,27$ \\
BLi04139 & & homolog zur AnsB L-Aspartase & 4,45 & $-0,19$ \\
BLi04140 & \multirow{2}{*}{ ans $A$} & L-Asparaginase & 5,58 & $-0,41$ \\
BLi04141 & \multirow{2}{*}{ ans $R$} & transkriptionaler Repressor des & 3,21 & $-1,10$ \\
& & ansAB Operons & & \\
& &
\end{tabular}


Ein weiteres Beispiel für die Gruppe II (L-Asparagin / L-Aspartat) sind die Citratsynthasen. Wie bei den eben beschriebenen Genen, so konnte auch für die Citratsynthase I eine Änderung der Expression im Zusammenhang mit L-Asparagin ermittelt werden (Abb. 4.26). Zum Zeitpunkt T1 war das Gen der Citratsynthase I im Vergleich zum Wachstum mit Glucose induziert. Keine signifikante Änderung der Expression war hingegen zum Zeitpunkt T3 zu beobachten.

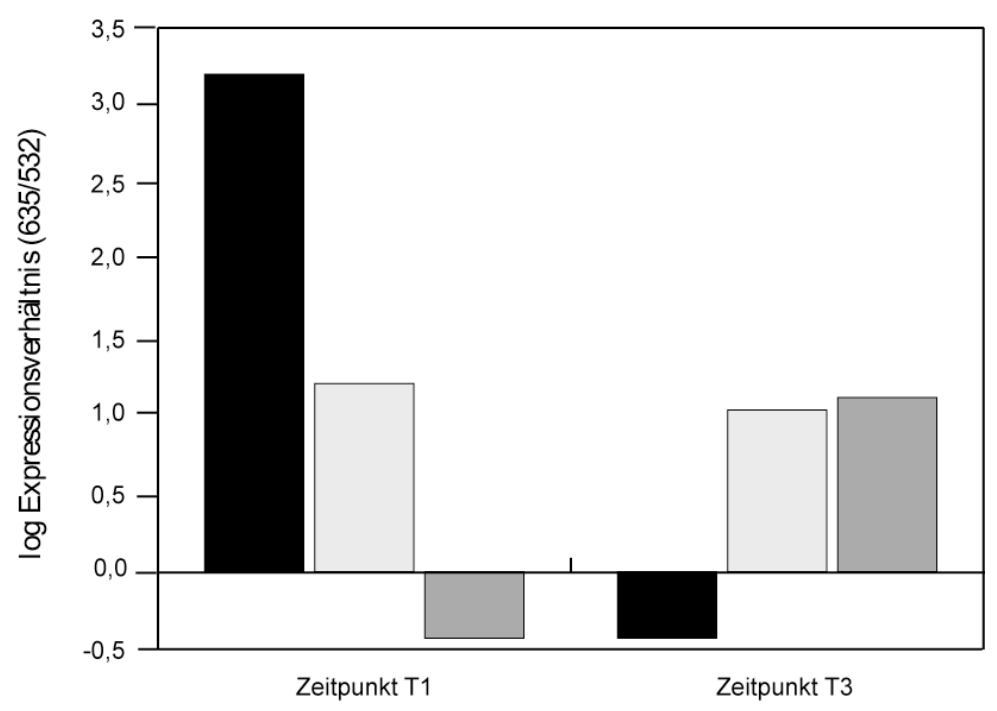

Abbildung 4.26: Vergleichende Darstellung von Expressionsverhältnissen. Übersicht der die drei Citratsynthasen kodierenden Gene Gene citA $(\square)$, citZ $(\square)$ und $m m g D(\square)$ zu den Zeitpunkten T1 und T3. Die Abbildung zeigt repräsentative Einzelmessungen.

Im Rahmen der unter 4.3.1.2.2. vorgestellten Transkriptionsanalysen konnte eine Schnittmenge von ORFs ermittelt werden, die beim Wachstum mit einzelnen Aminosäuren eine signifikante Erhöhung der Expression zeigten. Ebensolches konnte auch beim Wachstum mit einem Gemisch aus sieben Aminosäuren als Stickstoff- und Kohlenstoffquelle beobachtet werden (Tab. 4.22). Neben dem ORF BLi02104, der für eine Methylmalonat-Semialdehyd-Dehydrogenase kodiert, konnte auch für die im Genom von DSM13 jeweils zwei angrenzenden ORFs upstream (BLi02105, BLi02106) und downstream (BLi02103, BLi02102) eine Änderung des Expressionsverhältnisses beobachtet werden. Dieses ist unabhängig von der Anwesenheit von L-Asparagin im Kulturüberstand. $\mathrm{Zu}$ beiden Zeitpunkten konnte eine signifikant erhöhte Expression beim Wachstum mit einem Gemisch von Aminosäuren ermittelt werden. Dieses konnte ebenfalls für die ORFs BLi03498 und BLi04275 verzeichnet werden. 
Tabelle 4.22: Vergleichende Darstellung von Expressionsverhältnissen. Übersicht der unter 4.3.1.2.2. bestimmten Schnittmenge von Genen zu den Zeitpunkten T1 und T3. Werte größer 1 bedeuten eine verstärkte Expression beim Wachstum mit einem Gemisch von Aminosäuren im Vergleich zur Referenzbedingung. Die Tabelle enthält repräsentative Einzelmessungen. put. - putativ

\begin{tabular}{|c|c|c|c|c|}
\hline \multirow[t]{2}{*}{ ID } & \multirow[t]{2}{*}{ Gen } & \multirow[t]{2}{*}{ Annotation } & \multicolumn{2}{|c|}{ log Expressionsverhältnisse } \\
\hline & & & T1 / Glc & T3 / Glc \\
\hline \multirow[t]{2}{*}{ BLi00853 } & acoR & transkriptionaler Aktivator des & 1,91 & 2,36 \\
\hline & & Acetoin-Dehydrogenase Operons & & \\
\hline BLi01143 & melA & $\alpha$-D-Galaktosid-Galaktohydrolase & 1,09 & 1,81 \\
\hline \multirow[t]{2}{*}{ BLi02102 } & & put. Enoyl(3-hydroxyisobutyryl)- & 2,49 & 3,49 \\
\hline & & Coenzyme A Hydratase-Protein & & \\
\hline BLi02103 & & putative Enoyl-CoA-Hydratase & 2,70 & 3,82 \\
\hline \multirow[t]{2}{*}{ BLi02104 } & $m m s A$ & Methylmalonat-Semialdehyd- & 3,00 & 4,19 \\
\hline & & Dehydrogenase & & \\
\hline \multirow[t]{2}{*}{ BLi02105 } & & putative 2-Hydroxy-3- & 3,00 & 3,64 \\
\hline & & Oxopropionat-Reductase & & \\
\hline BLi02106 & & put. Butyryl-CoA-Dehydrogenase & 2,29 & 3,05 \\
\hline BLi03498 & & putative Pectin-Methylesterase & 2,35 & 3,98 \\
\hline \multirow[t]{2}{*}{ BLi04275 } & & homolog zu Ald: L-Alanin- & 7,38 & 7,19 \\
\hline & & Dehydrogenase & & \\
\hline
\end{tabular}

\subsubsection{Verwertung eines Gemisches aus 20 Aminosäuren}

In einem weiteren Schritt wurde, um das Wachstum auf Gemischen von Aminosäuren zu untersuchen, ein Gemisch aus 20 Aminosäuren zusammengestellt, welches der Sojabohne nachempfunden war (vgl. 3.2.2.). In den folgenden Ausführungen wird zunächst auf die proteinogenen Aminosäuren, welche als alleinige Stickstoff- und Kohlenstoffquelle dienen können, eingegangen (Abb 4.27A). Wie schon bei den Untersuchungen zum Wachstum auf einem Gemisch aus sieben Aminosäuren, konnte auch hier während des Wachstums eine Aufnahme dieser Aminosäuren beobachtet werden, wobei sich aber die Rate des Verbrauchs unterschied. Als erste Aminosäure wurde wieder L-Asparagin komplett verstoffwechselt. Im Anschluss daran konnte ein erhöhter Verbrauch der verbliebenen Aminosäuren beobachtet werden. Zu 
Beginn der stationären Phase war nur noch L-Glutamat in erhöhter Konzentration im Kulturübestand zu detektieren. Auch die in diesem Kontext beschriebene Akkumulation von Harnstoff und L-Ornithin im Kulturüberstand war mit zunehmendem Verbrauch von L-Arginin zu beobachten (Abb. 4.27B). Ebenso wie ein anschließender Verbrauch des L-Ornithins, nachdem L-Arginin nicht mehr detektiert wurde.
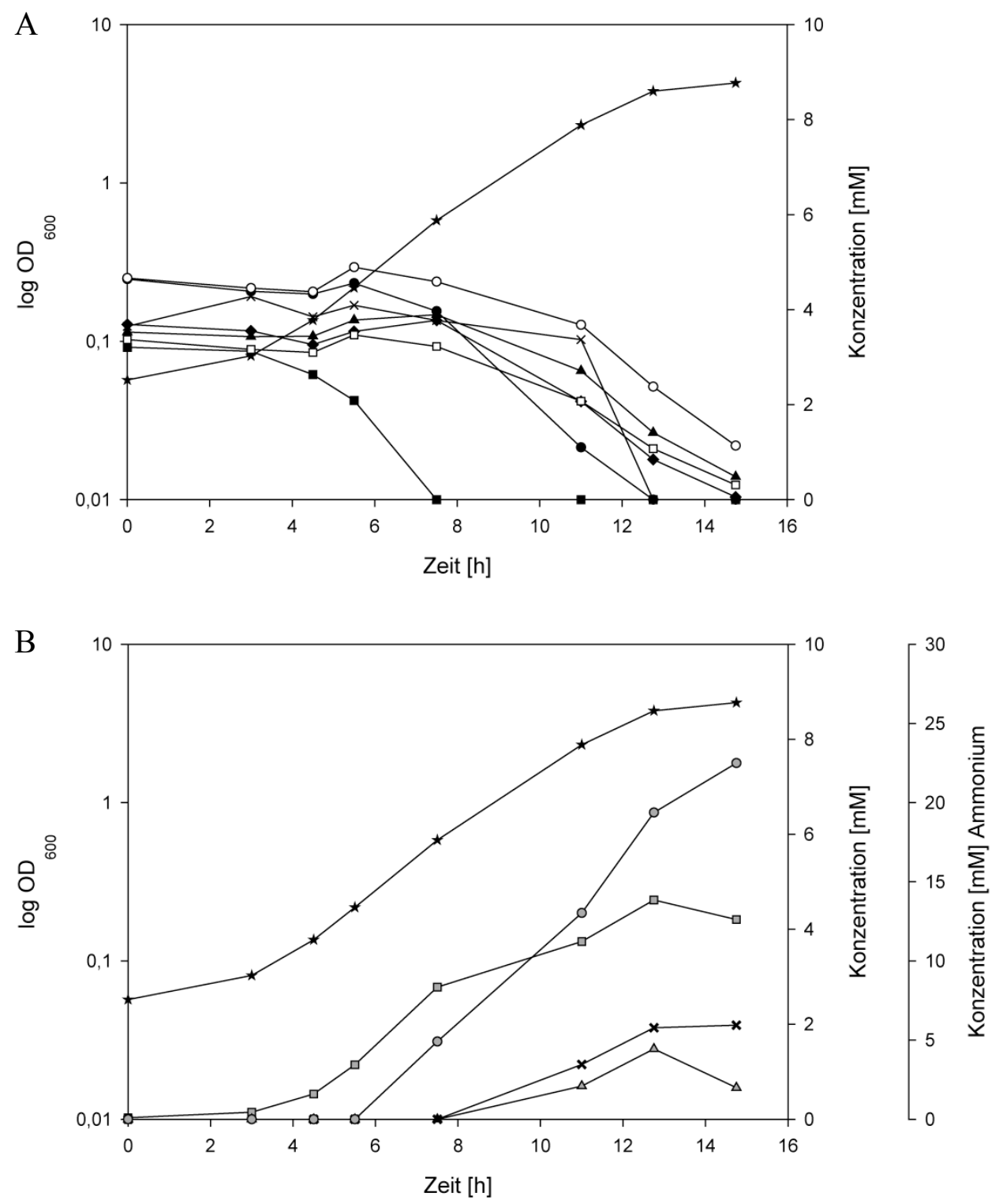

Abbildung 4.27: Wachstumskurve von DSM13 auf einem definierten Medium mit einem Gemisch aus 20 Aminosäuren. Neben der jeweiligen Darstellung des Wachstums von DSM13 ( $\star$ ) ist in A der

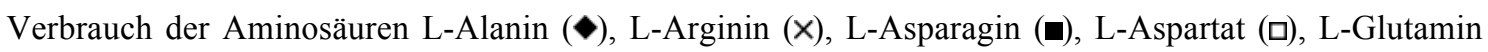
$(\bullet)$, L-Glutamat (O) und L-Prolin (A) abgebildet. B zeigt die über die Zeit gesteigerte Akkumulation von Acetat ( $\square$ ), Ammoinum (o) und Harnstoff (x). Des Weiteren konnte die Bildung und der Verbrauch von L-Ornithin $(\Delta)$ beobachet werden. Die Abbildung zeigt repräsentative Einzelmessungen. 
Des Weiteren konnte eine mit dem Wachstum einhergehende Akkumulation von Acetat und Ammonium beobachtet werden. Aus der Abbildung 4.27A ist zu ersehen, dass DSM13 beim Wachstum mit einem Gemisch aus 20 Aminosäuren in die stationäre Phase einschwenkt, wenn die Aminosäuren, welche als alleinige Stickstoff- und Kohlenstoffquelle dienen können, limitierend werden.
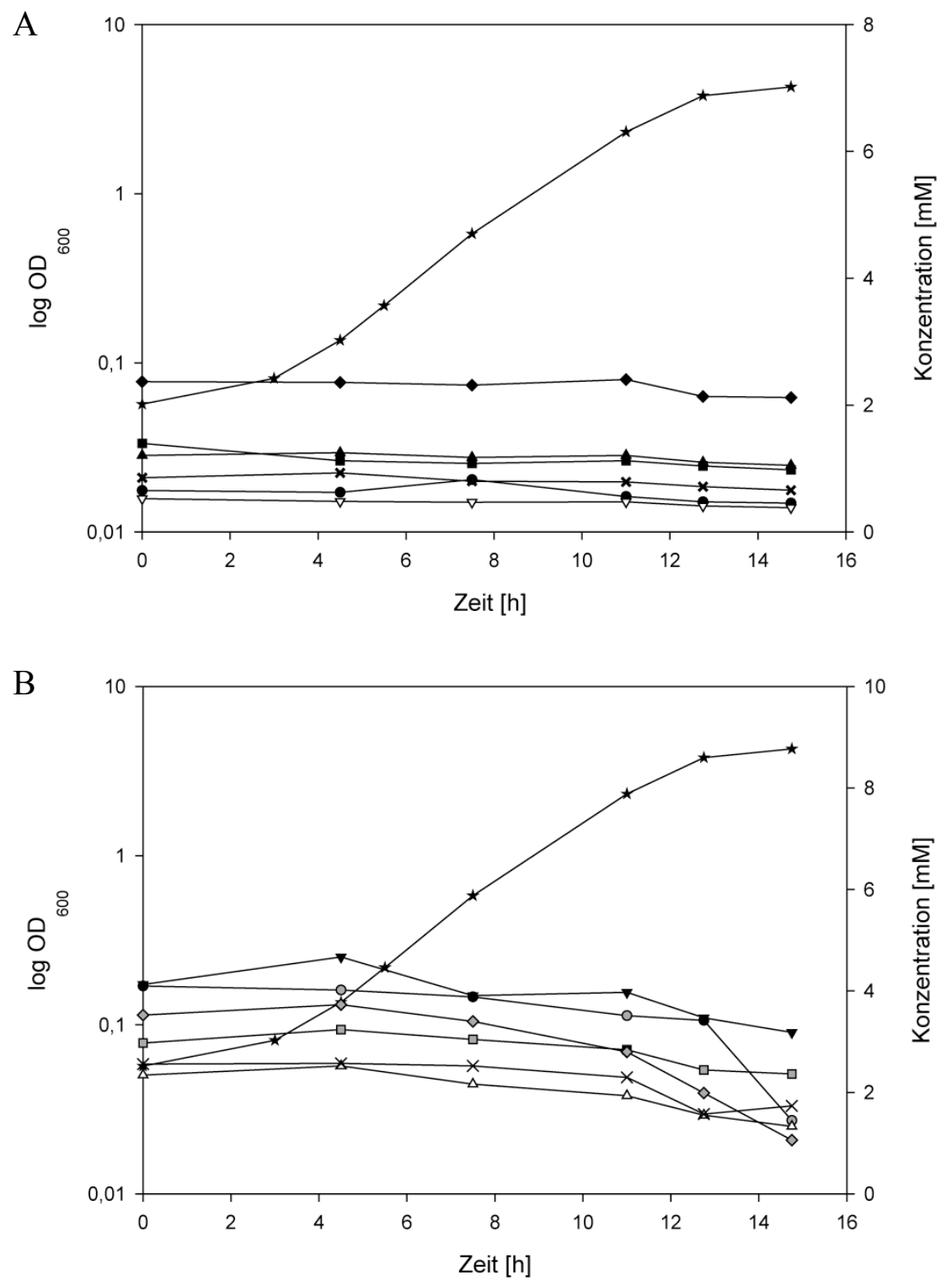

Abbildung 4.28: Wachstumskurve von DSM13 auf einem definierten Medium mit einem Gemisch aus 20 Aminosäuren. Neben der jeweiligen Darstellung des Wachstums von DSM13 ( $\star$ ) sind in A die Messungen der Konzentrationen der Aminosäuren L-Phenylalanin (•), L-Tyrosin (৯), L-Histidin ( Cystin (x), L-Methionin (•), L-Tryptophan ( $\nabla)$ angegeben und in $\mathbf{B}$ der Verbrauch der Aminosäuren

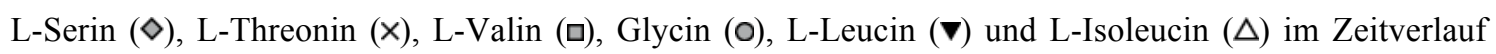
dargestellt. Die Abbildung zeigt repräsentative Einzelmessungen. 
Betrachtet man daneben die verbleibenden Aminosäuren im Zeitverlauf, so können Aminosäuren identifiziert werden, für die im Rahmen der durchgeführten Experimente keine Verwertung verzeichnet werden konnte (Abb. 4.28A). Darunter ist neben den aromatischen Aminosäuren L-Phenylalanin, L-Tyrosin und L-Tryptophan auch L-Histidin zu finden. Des Weiteren konnte kein signifikanter Verbrauch von L-Methionin und L-Cystein emittelt werden. Hier gilt es anzumerken, dass L-Cystein, bedingt durch den Versuchsaufbau, während der Analyse zu der dimeren Form Cystin oxidiert. Auf der anderen Seite wurde mit dem Einschwenken in die stationäre Phase ein gesteigerter Verbrauch für Glycin und L-Serin ermittelt (Abb. 4.28B). Für L-Threonin und die verzweigtkettigen Aminosäuren L-Valin, L-Leucin und L-Isoleucin konnte hingegen ein leichter Verbrauch detektiert werden. Im Rahmen dieser Untersuchungen erfolgte jedoch keine quantitative Analyse von L-Lysin, da es im Zeitverlauf zur Koeluation mit anderen Produkten unter den gegebenen Versuchbedingungen kam. Erste Experimente zur besseren Trennung dieser Substanzen lassen den Schluss zu, dass auch L-Lysin im untersuchten Zeitraum nicht verwertet wird (Daten nicht gezeigt).

\subsubsection{Transkriptionsanalysen zur Verwertung eines Gemisches aus 20 Aminosäuren}

Im Focus des Interesses lag zunächst auch bei diesen Transkriptionanalysen, ob Gene, welche sich als charakteristisch für das Wachstum auf einzelnen Aminosäuren erwiesen, auch beim Wachstum mit einem Gemisch dieser Aminosäuren zu identifizieren waren. Hierzu wurden während des Wachstums von DSM13 mit einem Gemisch von 20 Aminosäuren zu fünf Zeitpunkten Zellen geerntet, um daraus RNA für Transkriptionsanalysen zu präparieren. Diese Zeitpunkte waren so gewählt, dass zum Zeitpunkt T1 noch L-Asparagin im Kulturüberstand $\mathrm{zu}$ detektieren war, sich die Zeitpunkte T2 und T3 während des logarithmischen Wachstums, der Zeitpunkt T4 im Übergang zur stationären Phase und der Zeitpunkt T5 zu Beginn der stationären Phase befand (Abb. 4.29). 


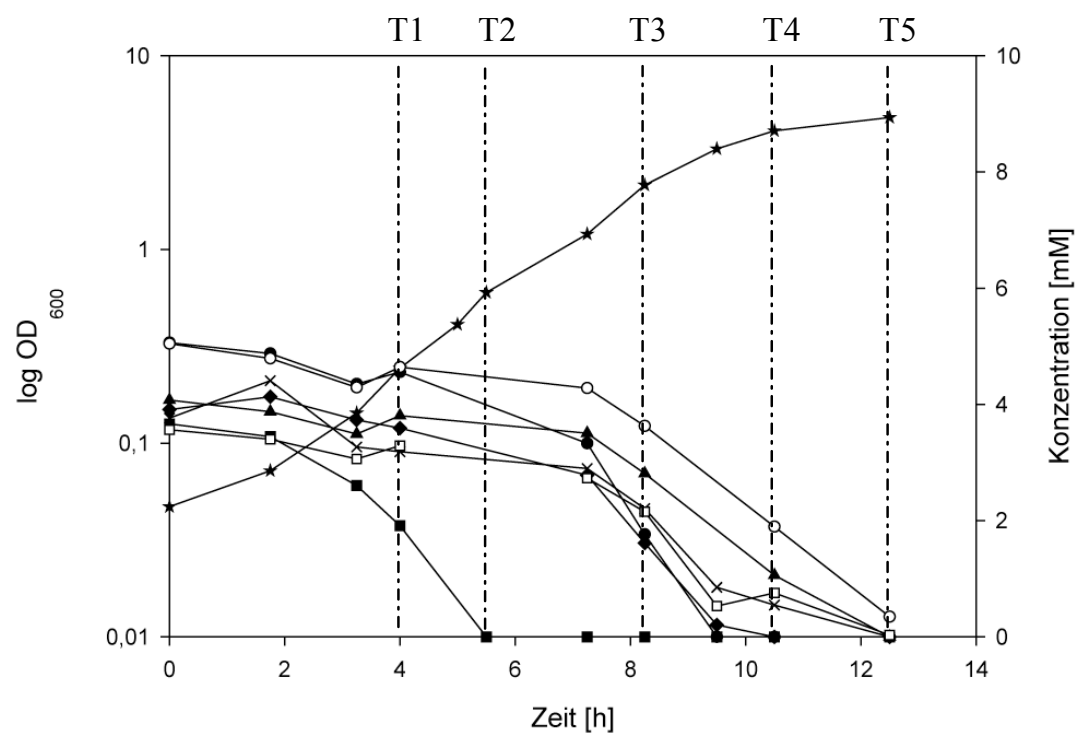

Abbildung 4.29: Zeitpunkte der durchgeführten Transkriptionsanalysen. Dargestellt ist das Wachstum von DSM13 ( $\star$ ) mit den Zeitpunkten, zu welchen Kulturanteile zur RNA-Präparation geerntet wurden. Die Anzucht erfolgte in einem definierten Medium mit einem Gemisch aus 20 Aminosäuren. Des Weiteren ist der Verbrauch der Aminosäuren L-Alanin ( $\bullet)$, L-Arginin ( $\times$ ), L-Asparagin (घ),

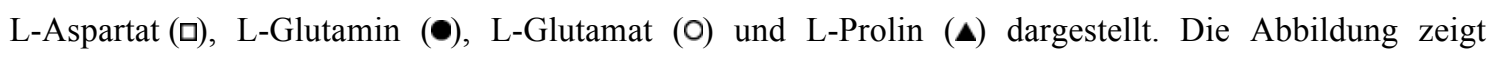
repräsentative Einzelmessungen.

Im Rahmen der Untersuchungen zum Einmünden der Aminosäuren in den Zentralmetabolismus konnten Gene anhand ihrer Expressionsverhältnisse in Verbindung mit dem Abbau von Aminosäuren gebracht werden. Im Weiteren konnten diese anschließend in Gruppen eingeteilt werden (vgl. 4.3.1.2.1. \& 4.3.1.2.4.).

Richtet man zunächst sein Augenmerk auf die Gruppe I (Tab. 4.23), so kann man erkennen, dass erst ab dem Zeitpunkt T2 und im Anschluss daran für die weiteren Zeitpunkte, also wenn keine L-Asparagin mehr im Kulturüberstand zu detektieren war, eine erhöhte Expression des Gens der Alanin-Dehydrogenase (ald) ermittelt werden konnte. Für den ORF BLi04275 hingegen konnte eine erhöhte Expression bei allen fünf Zeitpunkten im Vergleich zum Wachstum mit Glucose beobachtet werden. 
Tabelle 4.23: Vergleichende Darstellung der Expressionsverhältnisse von Genen der Gruppe I. Werte größer 1 bedeuten eine verstärkte Expression beim Wachstum mit einem Gemisch von 20 Aminosäuren zu den angegebenen Zeitpunkten, Werte kleiner -1 eine verstärkte Expression unter der Referenzbedingung. Die Tabelle enthält repräsentative Einzelmessungen.

\begin{tabular}{llllllll}
\hline ID & Gen & Annotation & \multicolumn{5}{c}{ log Expressionsverhältnisse } \\
& & T1 / & T2 / & T3 / & T4 / & T5 / \\
& & Glc & Glc & Glc & Glc & Glc \\
\hline BLi03382 & ald & Alanin-Dehydrogenase & $-0,60$ & 1,91 & 2,00 & 2,56 & 3,52 \\
BLi04275 & & homolog zur Ald: & 4,74 & 6,78 & 5,97 & 4,83 & 4,66 \\
& & Alanin-Dehydrogenase & & & & & \\
\hline
\end{tabular}

Anders als beim Wachstum mit L-Asparagin als alleiniger Stickstoff- und Kohlenstoffquelle, oder dem Wachstum auf einem Gemisch von sieben Aminosäuren, konnte bei den Transkriptionsanalysen zur Verwertung von 20 Aminosäuren keine reproduziert signifikant erhöhte Expression für die Gene des Multienzymkomplexes der Pyruvat-Dehydrogenase beobachtet werden (Daten nicht gezeigt).

Tabelle 4.24: Vergleichende Darstellung der Expressionsverhältnisse einer Auswahl an Genen der Gruppe II. Werte größer 1 bedeuten eine verstärkte Expression beim Wachstum mit einem Gemisch von 20 Aminosäuren zu den angegebenen Zeitpunkten, Werte kleiner -1 eine verstärkte Expression unter der Referenzbedingung. Die Tabelle enthält repräsentative Einzelmessungen. n.b. - nicht bestimmt

\begin{tabular}{|c|c|c|c|c|c|c|c|}
\hline \multirow[t]{3}{*}{ ID } & \multirow[t]{3}{*}{ Gen } & \multirow[t]{3}{*}{ Annotation } & \multicolumn{5}{|c|}{ log Expressionsverhältnisse } \\
\hline & & & $\mathrm{T} 1 /$ & $\mathrm{T} 2 /$ & $\mathrm{T} 3 /$ & $\mathrm{T} 4$ / & T5 / \\
\hline & & & Glc & Glc & Glc & Glc & Glc \\
\hline \multirow[t]{2}{*}{ BLi04137 } & mleA & mögl. Malo-Lactat & 4,40 & $-0,50$ & $-1,34$ & $-1,21$ & $-1,78$ \\
\hline & & Enzym & & & & & \\
\hline \multirow[t]{2}{*}{ BLi04138 } & mleN & Malat- $\mathrm{H}^{+} / \mathrm{Na}^{+}-$Lactat & 3,78 & $-1,85$ & $-2,37$ & n.b. & $-3,40$ \\
\hline & & Antiporter & & & & & \\
\hline \multirow[t]{2}{*}{ BLi04139 } & & homolog zur AnsB & 3,82 & $-0,29$ & $-0,47$ & $-0,58$ & $-0,35$ \\
\hline & & L-Aspartase & & & & & \\
\hline BLi04140 & ans $A$ & L-Asparaginase & 5,15 & $-0,14$ & $-1,11$ & $-0,68$ & $-0,78$ \\
\hline \multirow[t]{2}{*}{ BLi04141 } & ansR & transkript. Repressor des & 3,81 & $-0,58$ & $-0,82$ & 0,43 & 0,05 \\
\hline & & ans $A B$ Operons & & & & & \\
\hline
\end{tabular}


Für die Gene, welche sich zunächst als charakteristisch für das Wachstum auf L-Asparagin und L-Aspartat (Gruppe II) erwiesen, zeigten auch diese Transkriptionsanalysen eine Änderung der Expression im Zusammenhang mit dem Abbau von L-Asparagin (Tab. 4.24). Zum Zeitpunkt T1, L-Asparagin ist noch im Kulturüberstand zu detektieren, zeigten sowohl die Gene mleA und $m l e N$, als auch die Gene des ans $A B$ Operons bzw. des zugehörigen transkriptionalen Repressors eine signifikante Erhöhung der Expression. Für die weiteren Zeitpunkte T2 bis T5 konnte für diese Gene keine erhöhte Expression, teilweise sogar eine Repression wie am Beispiel des Gens mleN zu sehen, ermittelt werden.

Ähnliches konnte auch im Zusammenhang mit den Citratsynthasen beobachtet werden (Abb. 4.30). Solange L-Asparagin im Kulturüberstand zu detektieren war (Zeitpunkt T1), zeigte nur das für die Citratsynthase I kodierende Gen citA eine signifikant erhöhte Expression. War zu den Zeitpunkten T2 bis T5 kein L-Asparagin mehr nachzuweisen, konnte eine erhöhte Expression für das Gen der Citratsynthase III, $m m g D$, ermittelt werden.

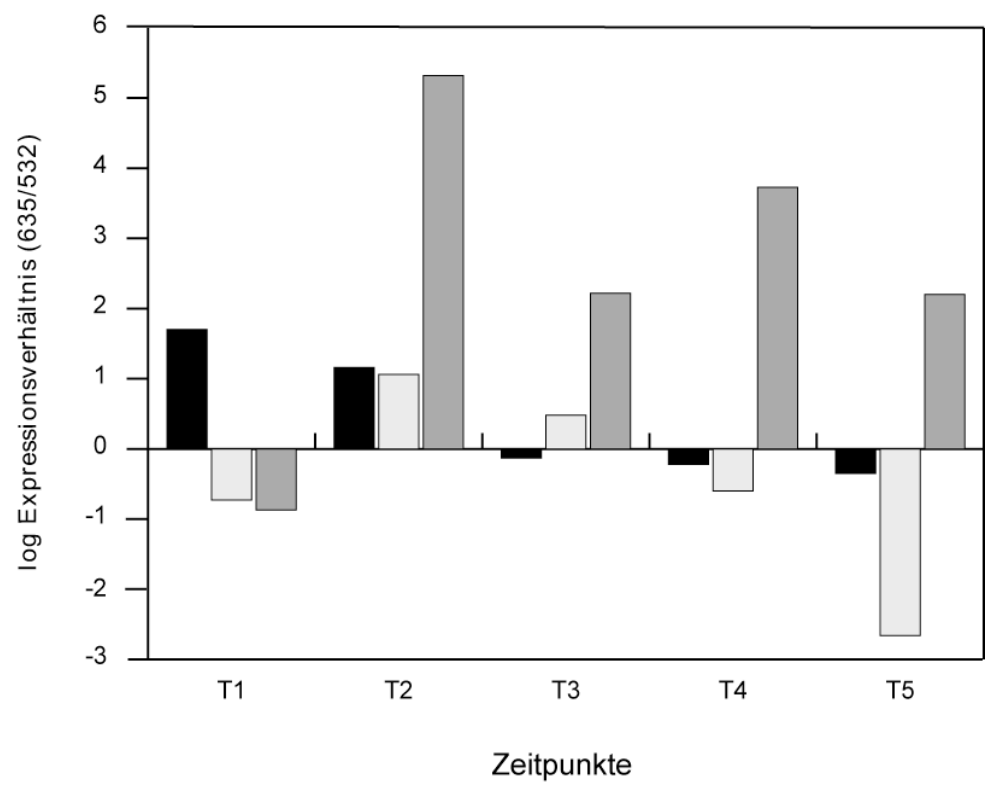

Abbildung 4.30: Vergleichende Darstellung von Expressionsverhältnissen. Übersicht der die drei Citratsynthasen kodierenden Gene citA $(\square)$, citZ $(\square)$ und $m m g D(\square)$ zu den Zeitpunkten T1 bis T5. Die Abbildung zeigt repräsentative Einzelmessungen. 
Wie bereits unter 4.3.1.2.1. beschrieben zeigte eine Gruppe von Genen sowohl beim Wachstum mit L-Arginin als auch mit L-Prolin eine erhöhte Expression. Dieses konnte auch beim Wachstum mit einem Gemisch aus 20 Aminosäuren bestätigt werden (Tab. 4.25).

Tabelle 4.25: Vergleichende Genexpressionsverhältnisse von Genen, welche im Zusammenhang mit der Verwertung von L-Arginin und L-Prolin stehen. Werte größer 1 bedeuten eine verstärkte Expression beim Wachstum mit einem Gemisch von 20 Aminosäuren zu den angegebenen Zeitpunkten, Werte kleiner -1 eine verstärkte Expression unter der Referenzbedingung.Die Tabelle zeigt repräsentative Einzelmessungen. n.b. - nicht bestimmt

\begin{tabular}{|c|c|c|c|c|c|c|c|}
\hline \multirow[t]{3}{*}{ ID } & \multirow[t]{3}{*}{ Gen } & \multirow[t]{3}{*}{ Annotation } & \multicolumn{5}{|c|}{ log Expressionsverhältnisse } \\
\hline & & & $\mathrm{T} 1 /$ & $\mathrm{T} 2 /$ & $\mathrm{T} 3 /$ & $\mathrm{T} 4 /$ & $\mathrm{T} 5 /$ \\
\hline & & & Glc & Glc & Glc & Glc & Glc \\
\hline BLi00373 & $y c g M$ & ähnl. zur Prolin-Oxidase & 4,04 & 5,07 & 5,59 & 3,70 & 2,69 \\
\hline \multirow[t]{2}{*}{ BLi00374 } & $y \operatorname{cgN}$ & ähnl. zur $\Delta^{1}$-Pyrrolin-5- & 4,75 & 5,04 & 6,21 & 4,76 & 3,51 \\
\hline & & Carboxylat-DH & & & & & \\
\hline BLi00375 & $y c g O$ & ähnl. zur Prolin-Permease & 1,95 & 3,76 & 3,53 & 1,36 & 0,54 \\
\hline \multirow[t]{2}{*}{ BLi00421 } & rock & transkript. Aktivator des & $-0,45$ & $-1,26$ & 0,06 & $-0,83$ & $-0,40$ \\
\hline & & Arginin Operons & & & & & \\
\hline \multirow[t]{2}{*}{ BLi00422 } & $\operatorname{roc} D$ & Ornithin- & 1,43 & 6,23 & 5,91 & 5,70 & 4,26 \\
\hline & & Aminotransferase & & & & & \\
\hline BLi00423 & $\operatorname{roc} E$ & Aminosäure-Permease & n.b. & 4,25 & 2,24 & 1,14 & 0,10 \\
\hline BLi00424 & $r o c F$ & Arginase & 0,61 & 4,44 & 3,96 & 1,99 & 1,11 \\
\hline \multirow[t]{2}{*}{ BLi04162 } & & Homolog zum AhrC & 0,40 & 1,77 & 1,29 & 2,65 & 2,28 \\
\hline & & transkript. Regulator & & & & & \\
\hline BLi04163 & & Arginin-Deiminase & 6,41 & 8,18 & 8,91 & 8,70 & 2,51 \\
\hline \multirow[t]{2}{*}{ BLi04164 } & & Ornithin- & n.b. & 8,03 & 8,17 & n.b. & 1,79 \\
\hline & & Carbamoyltransferase & & & & & \\
\hline BLi04165 & & putative Zucker-Permease & n.b. & 4,17 & 5,55 & n.b. & 1,03 \\
\hline BLi04166 & & Carbamat-Kinase & n.b. & 6,73 & 6,33 & n.b. & 0,48 \\
\hline
\end{tabular}

Betrachtet man zunächst die Gene, welche im Zusammenhang mit der Verwertung von L-Prolin stehen, konnte sowohl für das Gen ycgM, welches für die Prolin-Oxidase kodiert, als auch für das die $\Delta^{1}$-Pyrrolin-5-Carboxylat-Dehydrogenase kodierende Gen 
$y c g N$, für alle Zeitpunkte eine signifikant erhöhte Expression beobachtet werden. Für das benachbarte Gen $y c g O$, dessen Produkt Ähnlichkeit mit einer Prolin-Permease aufweist, konnte eine Änderung der Expression über die Zeitreihe beobachtet werden. Diese ging mit der Verwertung von L-Prolin konform. Für die Zeitpunkte T1 bis T4 konnte eine erhöhte Expression beobachtet werden. Zum Zeitpunkt T5, bei welchem nur noch eine geringe Menge L-Prolin im Kulturüberstand zu detektieren war (vgl. Abb. 4.29), konnte keine Induktion dieses Gens beim Wachstum mit Aminosäuren beobachtet werden. Für Gene, welche an der Verwertung von L-Arginin über den Arginase Weg involviert sind, wurde ein anderes Expressionsmuster ermittelt. Das Gen der OrnithinAminotransferase, $r o c D$, zeigte nur für die Zeitpunkte T2 bis T5 eine signifikant erhöhte Expression. Daneben konnte für das die Arginase kodierende Gen rocF lediglich für die Zeitpunkte T2 bis T4 eine Induktion ermittelt werden. Diese Expressionsdaten gehen insoweit mit den Analysen der Kulturüberstände konform, als zum Zeitpunkt T5 noch L-Ornithin im Gegensatz zu L-Arginin zu detektieren war (vgl. Abb. 4.27). Interessanterweise konnten, anders als bei der Verwertung einzelner Aminosäuren, beim Wachstum mit einem Gemisch aus 20 Aminosäuren Änderungen der Expressionsverhältnisse für Gene, die im Zusammenhang mit dem Arginin-Deiminase Weg stehen, beobacht werden (Tab. 4.25). Der für die Arginin-Deiminase kodierende ORF BLi04163 zeigte zu allen fünf Zeitpunkten eine signifikant erhöhte Expression. Gleiches konnte für die benachbarten ORFs BLi04164, BLi04165 und BLi04166 ebenso für die Zeitpunkte T2 und T3 beobachtet werden. Anzumerken gilt es hierbei, dass für die Zeitpunkte T1 und T4 keine Expressionsdaten ermittelt werden konnten.

Ebenfalls von Interesse im Rahmen der Transkriptionsanalysen zur Verwertung eines Gemisches aus 20 Aminosäuren waren die Expressionsdaten der unter 4.3.1.2.2. vorgestellten Schnittmenge von ORFs, welche beim Wachstum mit einzelnen Aminosäuren eine signifikante Erhöhung der Expression zeigten (Tab. 4.26). Neben dem ORF des transkriptionalen Aktivators des Acetoin-Dehydrogenase Operons (BLi00853) konnte auch für die ORFs der Genregion BLi02106 bis BLi02102 eine erhöhte Expression beim Wachstum mit einem Gemisch von Aminosäuren zu allen fünf untersuchten Zeitpunkten ermittelt werden. Ebenfalls beobachtet werden konnte dieses für den ORF BLi04275, welcher für ein Homolog der L-Alanin-Dehydrogenase kodiert. 
Tabelle 4.26: Vergleichende Darstellung von Expressionsverhältnissen. Übersicht der unter 4.3.1.2.2. bestimmten Schnittmenge von Genen zu den Zeitpunkten T1 bis T5. Werte größer 1 bedeuten eine verstärkte Expression beim Wachstum mit einem Gemisch von 20 Aminosäuren zu den angegebenen Zeitpunkten im Vergleich zur Referenzbedingung. Die Tabelle enthält repräsentative Einzelmessungen. n.b. - nicht bestimmt, put - putativ

\begin{tabular}{|c|c|c|c|c|c|c|}
\hline \multirow[t]{3}{*}{ ID } & \multirow[t]{3}{*}{ Annotation } & \multicolumn{5}{|c|}{ log Expressionsverhältnisse } \\
\hline & & $\mathrm{T} 1 /$ & $\mathrm{T} 2 /$ & $\mathrm{T} 3 /$ & $\mathrm{T} 4 /$ & $\mathrm{T} 5 /$ \\
\hline & & Glc & Glc & Glc & Glc & Glc \\
\hline \multirow[t]{2}{*}{ BLi00853 } & transkriptionaler Aktivator des & 1,45 & 3,79 & 2,20 & 2,26 & 2,40 \\
\hline & Acetoin-Dehydrogenase Operons & & & & & \\
\hline BLi01143 & $\alpha$-D-Galaktosid-Galaktohydrolase & n.b. & 2,94 & 1,93 & 1,72 & n.b. \\
\hline \multirow[t]{2}{*}{ BLi02102 } & put. Enoyl(3-hydroxyisobutyryl)- & 2,24 & 5,00 & 3,89 & 3,96 & 3,70 \\
\hline & Coenzyme A Hydratase-Protein & & & & & \\
\hline BLi02103 & putative Enoyl-CoA-Hydratase & 2,25 & 4,79 & 3,95 & 3,90 & 3,38 \\
\hline \multirow[t]{2}{*}{ BLi02104 } & Methylmalonat-Semialdehyd- & 1,30 & 4,22 & 3,27 & 3,32 & 2,90 \\
\hline & Dehydrogenase & & & & & \\
\hline \multirow[t]{2}{*}{ BLi02105 } & putative 2-Hydroxy-3- & 2,27 & 5,77 & 4,01 & 4,40 & 4,06 \\
\hline & Oxopropionat-Reductase & & & & & \\
\hline BLi02106 & put. Butyryl-CoA-Dehydrogenase & 2,06 & 5,31 & 3,97 & 4,46 & 4,24 \\
\hline BLi03498 & putative Pectin-Methylesterase & 1,89 & 4,11 & 2,87 & 2,99 & n.b. \\
\hline \multirow[t]{2}{*}{ BLi04275 } & homolog zu Ald: L-Alanin- & 4,74 & 6,78 & 5,97 & 4,83 & 4,66 \\
\hline & Dehydrogenase & & & & & \\
\hline
\end{tabular}

Während der Wachstumsuntersuchungen in definierten Medien konnte mit zunehmender Kulturdichte eine rotbraune Färbung des Mediums beobachtet werden. Bereits in einer vorangegangenen Arbeit (Veith, 2004) wurden die ORFs BLi01185 bis BLi01188 in diesem Zusammenhang erwähnt, da diese Homologien zu den Genen iucABCD aufweisen. Auf dem enterobakteriellen Virulenzplasmid pColV-K30 kodieren letztere für das Siderophor Aerobactin (Martinez et al., 1994). Im Rahmen der Transkriptionsanalysen der vorliegenden Arbeit konnten keine eindeutigen Genexpressionsdaten zu diesen ORFs ermittelt werden. Die Daten lassen jedoch vermuten, dass diese Gene zu den Zeitpunkten T2 und T5 beim Wachstum mit Aminosäuren induziert sind (Daten nicht gezeigt). Daneben konnte noch eine weitere 
Gruppe von Genen, $d h b A C E B F$, mit der Siderophorbiosynthese in Verbindung gebracht werden (Rey et al., 2004).

Tabelle 4.27: Expressionsdaten von ORFs, welche im Zusammenhang mit der Biosynthese von Siderophoren stehen. Werte größer 1 bedeuten eine verstärkte Expression beim Wachstum mit einem Gemisch von 20 Aminosäuren zu den angegebenen Zeitpunkten im Vergleich zur Referenzbedingung. Die Tabelle enthält repräsentative Einzelmessungen. n.b. - nicht bestimmt

\begin{tabular}{|c|c|c|c|c|c|c|c|}
\hline \multirow[t]{3}{*}{ ID } & \multirow[t]{3}{*}{ Gen } & \multirow[t]{3}{*}{ Annotation } & \multicolumn{5}{|c|}{ log Expressionsverhältnisse } \\
\hline & & & $\mathrm{T} 1 /$ & $\mathrm{T} 2 /$ & $\mathrm{T} 3 /$ & $\mathrm{T} 4 /$ & $\mathrm{T} 5 /$ \\
\hline & & & Glc & Glc & Glc & Glc & Glc \\
\hline \multirow[t]{2}{*}{ BLi02503 } & fur & transkript. Repressor der & 0,06 & 1,27 & 0,32 & 1,12 & 0,13 \\
\hline & & Eisen-Aufnahme & & & & & \\
\hline \multirow[t]{2}{*}{ BLi03472 } & $y u s V$ & ähnl. zur Eisen-(III)- & 1,81 & 4,14 & $-1,04$ & 2,06 & 1,64 \\
\hline & & Dicitrat Permease & & & & & \\
\hline \multirow[t]{3}{*}{ BLi03898 } & $d h b F$ & involviert in die $2,3-$ & $-0,37$ & 4,39 & n.b. & 3,76 & 2,42 \\
\hline & & Dihydroxybenzoat & & & & & \\
\hline & & Biosynthese & & & & & \\
\hline BLi03899 & $d h b B$ & Isochorismatase & 0,96 & 6,97 & n.b. & 4,97 & 3,85 \\
\hline \multirow[t]{2}{*}{ BLi03900 } & $d h b E$ & 2,3-Dihydroxybenzoat- & 0,77 & 6,22 & 0,74 & 4,51 & 4,10 \\
\hline & & AMP-Ligase & & & & & \\
\hline BLi03901 & $d h b C$ & Isochorismat-Synthase & $-0,01$ & 4,18 & 0,19 & 4,24 & 4,08 \\
\hline \multirow[t]{2}{*}{ BLi03902 } & $d h b A$ & 2,3-Dihydroxybenzoat- & 1,11 & 6,09 & 0,81 & 4,31 & 5,11 \\
\hline & & 2,3-Dehydrogenase & & & & & \\
\hline BLi03903 & yuiI & YuiI & 3,22 & 5,96 & 1,97 & 5,10 & 5,02 \\
\hline \multirow[t]{2}{*}{ BLi03904 } & feuC & Eisenaufnahmesystem & 2,84 & 5,59 & 1,87 & 4,18 & 4,86 \\
\hline & & (Membran-Protein) & & & & & \\
\hline \multirow[t]{2}{*}{ BLi03905 } & $\mathrm{feu} B$ & Eisenaufnahmesystem & 2,92 & 6,27 & 2,00 & 5,19 & 5,38 \\
\hline & & (Membran-Protein) & & & & & \\
\hline \multirow[t]{2}{*}{ BLi03906 } & feu $A$ & Eisenaufnahmesystem & 3,57 & 7,27 & 2,43 & 4,30 & 4,44 \\
\hline & & (bindendes Protein) & & & & & \\
\hline \multirow[t]{2}{*}{ BLi03907 } & $y b b B$ & ähnl. zum transkript. & 0,27 & 1,48 & 0,55 & 1,69 & 1,00 \\
\hline & & Regulator & & & & & \\
\hline
\end{tabular}


Zusammen mit einer weiteren Anzahl von Genen sind diese in B. subtilis an der Biosynthese und Aufnahme des Siderophors Bacillibactin beteiligt (Miethke et al., 2006). Anhand der in Tabelle 4.27 dargestellten Transkriptionsanalysen von DSM13 ist zu erkennen, dass diese Gruppe von Genen (dhbACEBF) zu den Zeitpunkten T2, T4 und T5 beim Wachstum mit Aminosäuren induziert waren. Für die Gene yuiI und feuABC konnte hingegen $\mathrm{zu}$ allen fünf Zeitpunkten unter diesen Kultivierungsbedingungen eine erhöhte Expression ermittelt werden. Letztere Gene kodieren für die Untereinheiten eines Eisen-Aufnahme-Systems. Einschränkend muß aber hinzugefügt werden, dass es sich bei einigen der dargestellten Expressionsdaten um Einzelmessungen handelt, welche bisher noch nicht durch ein zweites biologisches Experiment nicht bestätigt werden konnten.

Im Rahmen der Genomanalyse von B. licheniformis DSM13 konnten vier Prophagen identifiziert werden, von denen drei in Bereichen des Genoms lokalisiert sind, in welchen nur geringe bis keine Homologien zu ORFs seines nahen Verwandten B. subtilis ersichtlich sind. Die Gene des vierten Prophagen weisen hingegen eine hohe Homologie zu dem PBSX Prophagen von B. subtilis auf (Veith, 2004). Aufgrund der teilweise nur geringen Homologien der ORFs wurden für die Transkriptionsanalysen Bereiche definiert, in welcher eine erhöhte Anzahl von ORFs im Zusammenhang mit Phagen annotiert werden konnten. Interessanterweise konnte eine Änderung der Expressionsverhältnisse für einzelne Phagenbereiche während des Wachstums mit einem Gemisch von 20 Aminosäuren ermittelt werden (Tab. 7.8 im Anhang). So konnten für einen Großteil der ORFs, welche ausgehend vom Replikationsursprung des Genoms von DSM13 im Uhrzeigersinn dem ersten Phagenbereich zugeordnet wurden, reproduzierbar zum Zeitpunkt T3 eine erhöhte Expression beim Wachstum mit Aminosäuren ermittelt werden. Hierbei handelt es sich ORFs, die mit dem Phagen PBSX assoziiert sind. Daneben konnte für eine Anzahl der ORFs des zweiten Phagenbereiches zwischen den Zeitpunkten T1 und T4 eine erhöhte Expression verzeichnet werden. Für phagenassoziierte ORFs, welche im dritten bzw. vierten Bereichen lokalisiert sind, konnten im Gegensatz dazu keine gesteigerten Änderungen der Expressionsverhältnisse beobachtet bzw. ermittelt werden. 


\subsection{Charakteristische Gene für B. licheniformis}

Ein weiterer Ansatz zur Identifizierung charakteristischer Gene wurde mit der Methode des bidirektionalen BLASTs verfolgt. Zum Einsatz kam hierbei das bioinformatische Softwaretool BiBag (Wollherr et al., in Bearbeitung). In einem ersten Schritt werden bei dieser komparativen Methode die Aminosäuresequenzen aller proteinkodierenden Gene eines Query-Organismus mit den Aminosäuresequenzen einer beliebigen Anzahl von Subject-Organismen mittels BLASTP-Analyse (Altschul et al., 1990) miteinander verglichen. Im zweiten Schritt erfolgt die Umkehrung dieses BLASTs, d.h. die Aminosäuresequenzen der Subject-Organismen werden gegen die des Query-Organismus geblastet. Beim letzten Schritt dieser Methode werden die besten bidirektionalen Treffer zwischen Query- und Subject-Organismus herausgefiltert. Zur Validierung der Ergebnisse werden im Anschluss daran die Trefferpaare des bidirektionalen BLASTs mit Hilfe des Needleman-Wunsch-Algorithmus (Needleman \& Wunsch, 1970) aligned um globale Sequenzähnlichkeitswerte zu erhalten.

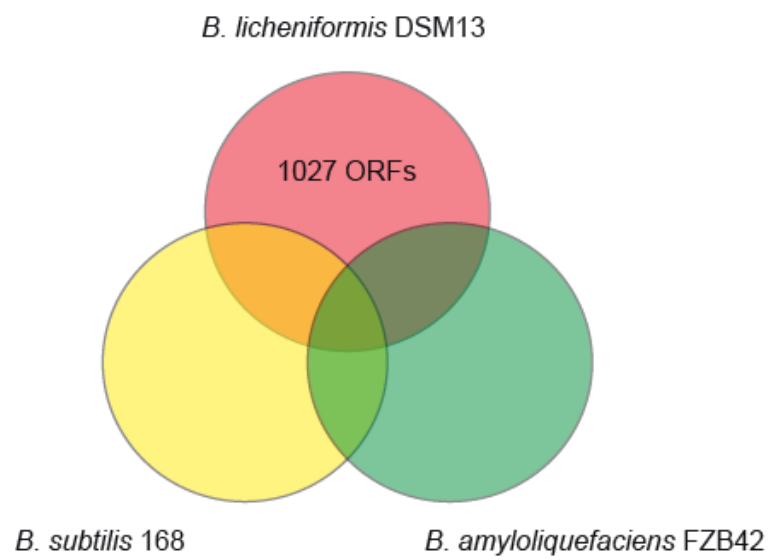

Abbildung 4.31: Schematische Darstellung des Vergleichs der Genome von B. licheniformis DSM13, B. subtilis 168 und B. amyloliquefaciens FZB42. Hervorgehoben sind dabei nur die Anzahl der ORFs, welche nur in DSM13 vorhanden sind.

Zunächst wurde unter Verwendung des bidirektionalen BLASTs B. licheniformis DSM13 mit weiteren Vertretern der Bacillus subtilis Gruppe verglichen (Abb. 4.31). Im Einzelnen waren dieses B. subtilis 168 und B. amyloliquefaciens FZB42. Der sogenannte „Heubacillus“ B. subtilis kommt in den oberen Schichten des Bodens vor und gehört zu den am besten charakterisierten Gram-positiven Bakterien (Kunst et al., 
1997; Barbe et al., 2009). B. amyloliquefaciens FZB42 ist ein mit Pflanzen assoziiertes Bakterium, welches das Potential zur Bildung von Sekundärmetaboliten wie den Polyketiden Bacillaene und Difficidin hat (Chen et al., 2007). Diese vergleichenden Untersuchungen ergaben, dass 1027 ORFs unique für B. lichenformis sind, d. h. keine Orthologe sowohl in B. subtilis 168, als auch in B. amyloliquefaciens FZB42 vorhanden sind. Ausgehend hiervon wurde anschließend die Anzahl von ORFs ermittelt, welche beim Wachstum mit einzelnen Aminosäuren als Stickstoff- und Kohlenstoffquelle eine signifikante Erhöhung des Expressionsverhältnisses zeigten (Tab. 4.28). Auch in diesem Zusammenhang wurde eine Änderung des ratio of medians um mindestens einen Faktor 3 als signifikant eingestuft. Logarithmiert zur Basis 2 entspricht dies 1,5849 bzw. $-1,5849$.

Tabelle 4.28: Anzahl der charakteristischen Gene für DSM13, welche beim Wachstum auf den angegebenen Aminosäuren eine signifikante Erhöhung der Expression zeigten.

\begin{tabular}{lc}
\hline Aminosäure & $\begin{array}{c}\log \text { Expressionsverhältnis } \\
>\end{array}$ \\
\hline L-Alanin & 31 \\
L-Arginin & 98 \\
L-Asparagin & 56 \\
L-Aspartat & 35 \\
L-Glutamin & 90 \\
L-Glutamat & 59 \\
L-Prolin & 54 \\
\hline
\end{tabular}

In einem nächsten Schritt wurde durch vergleichende Darstellung der in Tabelle 4.28 ermittelten ORFs eine Schnittmenge von Genen gebildet, welche eine signifikant erhöhte Expression beim Wachstum mit Aminosäuren zeigten. Um, wie unter 4.3.1.2.2. bereits beschrieben, den Effekt auszuschließen, dass eine Katabolitrepression auf Glucose gewachsenen Zellen als erhöhte Expression bei Aminosäure gewachsenen Zellen interpretiert wird, wurden auch hier Daten von Transkriptionsanalysen Gluconat gewachsener Zellen vergleichend mit einbezogen. Die daraus resultierende Schnittmenge ist in Tabelle 4.29 dargestellt. Hierbei handelt es sich um ORFs, welche schon in der Schnittmenge der unter 4.3.1.2.2. bestimmten Gene mit gleicher 
Genexpression beim Wachstum mit einzelnen proteinogenen Aminosäuren enthalten waren. Neben dem ORF BLi02104, welcher für eine Methylmalonat-SemialdehydDehydrogenase kodiert, sind auch die zwei angrenzenden Gene upstream (BLi02105, BLi02106) und downstream (BLi02103, BLi02102) in dieser Schnittmenge enthalten. Des Weiteren sind noch die ORFs BLi03498 und BLi04275 zu nennen. Ersterer kodiert für eine putative Pectin-Methylesterase, letzterer hingegen für ein Homolog der AlaninDehydrogenase.

Tabelle 4.29: Darstellung der Schnittmenge von ORFs, welche beim Wachstum mit Aminosäuren als Stickstoff- und Kohlenstoffquelle eine signifikante Erhöhung der Expression zeigten. Des Weiteren sind die Expressionsverhältnisse dieser ORFs beim Wachstum mit Acetat bzw. 2,3-Butandiol im Vergleich zum Wachstum mit Glucose angegeben. Werte größer 1 bedeuten eine verstärkte Expression beim Wachstum mit Acetat bzw. 2,3-Butandiol, Werte kleiner -1 eine verstärkte Expression unter der Referenzbedingung. Die Tabelle enthält repräsentative Einzelmessungen.

\begin{tabular}{llcc}
\hline ID & Annotation & \multicolumn{2}{c}{ log Expressionsverhältnisse } \\
& & $\begin{array}{l}\text { Acetat / } \\
\text { Glucose }\end{array}$ & 2,3-Butandiol / \\
& & Glucose \\
\hline BLi02102 & putative Enoyl(3-hydroxyisobutyryl)- & 3,14 & 3,16 \\
& Coenzyme A-Hydratase & & \\
BLi02103 & putative Enoyl-CoA-Hydratase & 3,17 & 2,72 \\
BLi02104 & Methylmalonat-Semialdehyd- & 3,29 & 2,55 \\
& Dehydrogenase & & 3,71 \\
BLi02105 & putative 2-Hydroxy-3-Oxopropionat- & 3,56 & \\
& Reductase & & 3,18 \\
BLi02106 & putative Butyryl-CoA-Dehydrogenase & 3,30 & 3,48 \\
BLi03498 & putative Pectin-Methylesterase & 3,40 & $-1,30$ \\
BLi04275 & homolog zu Ald: L-Alanin- & $-1,42$ & \\
& Dehydrogenase & & \\
\hline
\end{tabular}

Weitere Untersuchungen zeigten, dass für ein Großteil dieser Gene auch beim Wachstum mit C2-Metaboliten, wie Acetat oder 2,3-Butandiol, eine signifikant erhöhte Expression im Vergleich zum Wachstum mit Glucose beobachtet werden konnte (Tab. 4.29). Diente Acetat als Kohlenstoffquelle, wurde nicht nur für die ORFs BLi02106 bis BLi02102, sondern auch für den ORF BLi03498 eine mehr als dreifache Erhöhung des 
$\log$ Expressionsverhältnisses ermittelt. Beim Wachstum mit 2,3-Butandiol konnte diese Steigerung ebenfalls für die ORFs BLi02102, BLi02105, BLi02106 und BLi03498 beobachtet werden. BLi02103 und BLi02104 hingegen zeigten eine mehr als zweifache Erhöhung des log Expressionsverhältnisses. Lediglich der ORF BLi04275 war sowohl beim Wachstum mit 2,3-Butandiol, als auch mit Acetat als Kohlenstoffquelle reprimiert.

Tabelle 4.30: Vergleichende Darstellung der durch BiBag ermittelten Sequenzähnlichkeiten.

\begin{tabular}{|c|c|c|c|}
\hline \multirow[t]{2}{*}{ ID } & \multirow[t]{2}{*}{ Annotation } & \multicolumn{2}{|c|}{ Sequenzähnlichkeit (\%) } \\
\hline & & $\begin{array}{c}\text { Bacillus weihen- } \\
\text { stephanensis } \\
\text { KBAB4 }\end{array}$ & $\begin{array}{c}\text { Bacillus cereus } \\
\text { ATCC } 14579\end{array}$ \\
\hline BLi02102 & $\begin{array}{l}\text { put. Enoyl(3-hydroxyisobutyryl)- } \\
\text { Coenzyme A-Hydratase }\end{array}$ & 78,8 & 78,8 \\
\hline BLi02103 & putative Enoyl-CoA-Hydratase & 0 & 0 \\
\hline BLi02104 & $\begin{array}{l}\text { Methylmalonat-Semialdehyd- } \\
\text { Dehydrogenase }\end{array}$ & 88,9 & 88,9 \\
\hline BLi02105 & $\begin{array}{l}\text { putative 2-Hydroxy-3- } \\
\text { Oxopropionat-Reductase }\end{array}$ & 80,1 & 79,1 \\
\hline BLi02106 & $\begin{array}{l}\text { putative Butyryl-CoA- } \\
\text { Dehydrogenase }\end{array}$ & 79,1 & 79,2 \\
\hline BLi03498 & putative Pectin-Methylesterase & 0 & 0 \\
\hline BLi04275 & $\begin{array}{l}\text { homolog zu Ald: L-Alanin- } \\
\text { Dehydrogenase }\end{array}$ & 84,4 & 84,9 \\
\hline
\end{tabular}

Anders als in B. subtilis und seinen nahen Verwandten konnten diese Gene, wiederum unter Verwendung des Bioinformatikprogramms BiBag, in Vertretern der Bacillus cereus Gruppe identifiziert werden (Tab. 4.30). Exemplarisch hervorgehoben werden sollen in diesem Zusammenhang B. weihenstephanensis KBAB4 und B. cereus ATCC 14579. B. weihenstephanensis ist ein fakultativ psychrophiler, vornehmlich im Boden vorkommender Organismus. Der Stamm KBAB4 zeichnet sich durch den Besitz von vier Plasmiden gegenüber anderen Bacillen aus (Lapidus et al., 2008). B. cereus hingegen ist ein mesophiles Bodenbakterium, welches mit Lebensmittelvergiftungen im Zusammenhang steht. Beim Stamm ATCC 14579 handelt 
es sich um den Typstamm von B. cereus (Ivanova et al., 2003). Mit Ausnahme der ORFs BLi02103 und BLi03498 konnten für die weiteren Produkte der Gene in beiden Organismen Sequenzähnlichkeiten von mehr als 78\% ermittelt werden. Für den ORF BLi04275 konnte eine mehr als 84\%ige und für BLi02104 sogar eine mehr als 88\%ige Sequenzähnlichkeit ermittelt werden.

Setzt man einen Schwellenwert von 75\% Sequenzähnlichkeit voraus, so können noch weitere 34 ORFs der insgesamt 1027 als unique in B. licheniformis ermittelten Gene sowohl in B. weihenstephanensis KBAB4, als auch in B. cereus ATCC 14579 identifiziert werden (Tab. 7.7 im Anhang). Darunter sind paraloge Gene der Arginase (BLi00198) und der Aspartase (BLi00528) zu finden, ebenso wie der ORF der putativen Formiat-Acetyltransferase (BLi02132) und dem im Genom angrenzenden Aktivierungsenzyms (BLi02131). Letztere beiden sind an der Umsetzung von Pyruvat zu Acetyl-CoA und Formiat beteiligt (vgl. 4.1.2.1.). Eine Sequenzähnlichkeit von mehr als 80\% zeigte das Gen der anaeroben Ribonukleotid-Reduktase (BLi03824). Für das Gen des potenziell dazugehörigen Aktivierungsenzyms, BLi03823, konnte eine Sequenzähnlichkeit von $67,4 \%$ in B. weihenstephanensis KBAB4 bzw. $68 \%$ in B. cereus ATCC 14579 bestimmt werden. Beide Enzyme sind an der Reduktion von Ribonukleotid-Triphosphaten zu den entsprechenden Desoxyribonukleotiden beteiligt (vgl. 4.1.2.1.). Des Weiteren konnten ORFs ermittelt werden, dessen Produkt Homologie zur Isocitrat-Lyase (BLi04207) und der Malat-Synthase (BLi04208) aufweisen. Diese bilden, gemeinsam mit weiteren Enzymen des Tricarbonsäurezyklus, den Glyoxylatzyklus (vgl. 4.2.). Im Gegensatz dazu konnte jedoch für 775 ORFs der insgesamt 1027 ORFs keine Sequenzähnlichkeit in B. weihenstephanensis KBAB4 und B. cereus ATCC 14579 mittels BiBag festgestellt werden.

\subsection{Transkriptionsanalysen im Vergleich: PCR-basierende Genomchips vs. Oligo-basierende Genomchips}

Zur Erstellung des PCR-basierenden Genomchips von B. licheniformis DSM13 wurden 300-500 bp große Fragmente jedes ORFs größer 300 bp amplifiziert. Hierbei gilt es anzumerken, dass 14,1\% aller 4286 ORFs von DSM13 kleiner als 300 bp sind und aufgrund einer Mindestgröße der probes von $300 \mathrm{bp}$ deshalb nicht für die 
Erstellung des Genomchips berücksichtigt wurden. Somit sind letztendlich 81,5\% aller in B. licheniformis DSM13 identifizierter ORFs auf dem PCR-basierenden Genomchip vertreten. Eine detailierte Beschreibung der Generierung von Primern und der Ampflifizierung der probes mittels PCR ist der Dissertation von Birgit Veith zu entnehmen (Veith, 2004). Nach dem Prinzip des Kontaktprintens erfolgte anschließend das Aufbringen der probes auf Aminosilan slides (Amersham Biosciences). Dieses so genannte Spotten erfolgte mit einem Lucidea Spotter (Amersham Biosciences) in Blöcken von Spots, wobei jeder Block zweimal auf den Chip aufgebracht wurde. Für die sich anschließende UV-Immobilisierung wurde der UVC500 UV-Crosslinker (Hoefer, San Francisco) verwendet. Die gespotteten Microarrays werden in einem Exsikkator bei Unterdruck über einem Trocknungsmittel gelagert.

Um Oligo-basierende Genomchips zu erstellen, wurden 5'-Amino-C6 modifizierte Oligonukleotide mit einer Länge von 60 bis 70 Basen von einem MicroGrid II Microarray Spotter (Zinsser Analytic, Frankfurt, Deutschland) auf CodeLink Microarray slides (SurModics, Eden Prairie, USA) gespottet. Das Spotten der 4177 Oligonukleotide erfolgte ebenfalls in Blöcken, wobei auch hier die Spots als Duplikat auf dem Genomchip vorlagen. Um eine einheitliche Hybridisierung sicherzustellen, wurden die Oligonukleotide so gewählt, dass ihre erwartete Schmelztemperatur bei etwa $66^{\circ} \mathrm{C}$ liegt und sie frei von so genannten Haarnadelstrukturen sind. Ihre Spezifität für das jeweilige target-Gen wurde mittels BLAST-Analyse gegen alle weiteren ORFs von DSM13 überprüft. Nachdem die Oligonukleotide kovalent an die slide-Oberfläche gekuppelt wurden, erfolgte die Immobilisierung durch Ethanolamin. Analog den PCR-basierenden Genomchips werden auch die Oligo-basierenden Genomchips in einem Exsikkator bei Unterdruck über einem Trocknungsmittel gelagert.

Die Umstellung von PCR-basierenden Chips auf sogenannte Oligochips für die Transkriptionsanalysen ging einher mit der Änderung bzw. Optimierung der Markierungs- und Hybridisierungsbedingungen. Im Rahmen der Markierung wurde dem Ansatz nun nicht mehr random nonamere, sondern hexamere zugefügt. Verkürzt werden konnte das Annealing der Primer. Dieses erfolgte nun für 10 min bei $70^{\circ} \mathrm{C}$ anstelle eines PCR-Laufes. Des Weiteren wurde für die reverse Transkription ein 4/10 dNTP Nukleotid Mix und kein dCTP Nukleotid Mix verwendet. Für die Hybridisierung wurde dem Ansatz nicht mehr der Microarray Hybridization Buffer und 
Formamid zugegeben, sondern der Tom Freeman Hybridization Buffer. Weitere Änderungen betrafen die Wasch- und Reinigungschritte der Hybridisierungskammern, ebenso wie die Hybrdisierung selbst. Diese erfolgt nun bei $55^{\circ} \mathrm{C}$ anstatt $42^{\circ} \mathrm{C}$ und verlängerte sich auf 15 Stunden (vgl. 3.8.).

Zunächst soll nun auf die Reproduzierbarkeit der durch Oligo-basierende DNAMicroarrays ermittelten Expressionsverhältnisse eingegangen werden. Hierzu wurde RNA aus B. licheniformis Zellen gewonnen, dessen Kultivierung zum einen in einem definierten Medium mit equimolarer Zugabe $(10 \mathrm{mM})$ der sieben proteinogenen Aminosäuren L-Alanin, L-Arginin, L-Asparagin, L-Aspartat, L-Glutamin, L-Glutamat und L-Prolin erfolgte und zum anderen in einem definierten Medium mit $50 \mathrm{mM}$ Xylose als Kohlenstoffquelle. In einer ersten Markierungsreaktion wurde die RNA der Aminosäure gewachsenen Zellen mit dem Farbstoff Cy5 markiert und die Xylose gewachsenen Zellen mit dem Farbstoff Cy3. Die daraus ermittelten Daten für Gene, welche mit der Verwertung von Aminosäuren im Zusammenhang stehen, sind in der ersten Spalte der log Expressionsverhältnisse der Tabelle 4.31 dargestellt. Für die zwei darauf folgenden Markierungsreaktionen, dessen Werte in Spalte zwei und drei dieser Tabelle dargestellt sind, erfolgte eine Umkehrung der Farbmarkierung, ein sogenannter dye-flip. Der Verständlichkeit halber sind die hieraus gewonnenen Expressionsverhältnisse als reziproke Werte dargestellt. Neben dem Gen der L-AlaninDehydrogenase (ald, BLi03382) und dem ORF BLi04275, welcher für ein Homolog der L-Alanin-Dehydrogenase kodiert, konnte in den Experimenten ebenfalls eine signifikant erhöhte Expression für die Gene, die im Zusammenhang mit der Verwertung von L-Arginin und L-Prolin stehen, verzeichnet werden. Namentlich sind dieses ycgMN, rocD und rocF. Anzumerken ist allerdings, dass für letzteres kein Wert im dritten Experiment ermittelt werden konnte. Für das Gen ybgJ (BLi00274), dessen Produkt Ähnlichkeit zur Glutaminase aufweist, konnte in allen drei Experimenten eine mehr als vierfache Änderung des logarithmierten Expressionsverhältnisses beobachtet werden. Auf der anderen Seite konnte unter den gewählten Versuchsbedingungen keine erhöhte Expression beim Wachstum mit Aminosäuren für die ORFs BLi04139 und BLi04140 ermittelt werden. Beide ORFs, welche die Umsetzung von L-Asparagin zu Fumarat katalysieren, sind unter diesen Kultivierungsbedingungen reprimiert. Analysen des Kulturüberstandes vergleichbarer Wachstumsexperimente von DSM13 ergaben, dass zum Zeitpunkt der Ernte für die Transkriptionsanalysen kein L-Asparagin mehr im 
Medium vorhanden war (Daten nicht gezeigt). Im Genom konnten vier ORFs identifiziert werden, dessen Produkt Ähnlichkeit zur Aspartat-Aminotransferase aufweist. Dieses Enzym ist in der Verwertung von L-Glutamat involviert. Nur für den ORF BLi01514 konnte beim Wachstum mit einem Gemisch von Aminosäuren eine erhöhte Expression ermittelt werden.

Tabelle 4.31: Expressionsverhältnisse von Genen, welche mit der Verwertung von Aminosäuren im Zusammenhang stehen. Werte größer 1 bedeuten eine verstärkte Expression beim Wachstum mit einem Gemisch von Aminosäuren, Werte kleiner -1 eine verstärkte Expression unter der Referenzbedingung. Die Tabelle enthält repräsentative Einzelmessungen. AS-Mix - equimolarer (10 mM) Aminosäuremix; n.b. - nicht bestimmt.

\begin{tabular}{|c|c|c|c|c|c|}
\hline \multirow[t]{2}{*}{ ID } & \multirow[t]{2}{*}{ Gen } & \multirow[t]{2}{*}{ Annotation } & \multicolumn{3}{|c|}{ log Expressionsverhältnisse } \\
\hline & & & $\begin{array}{l}\text { AS-Mix / } \\
\text { Xylose }\end{array}$ & $\begin{array}{l}\text { AS-Mix / } \\
\text { Xylose }\end{array}$ & $\begin{array}{l}\text { AS-Mix / } \\
\text { Xylose }\end{array}$ \\
\hline BLi00274 & $y b g J$ & ähnlich zur Glutaminase & 5,26 & 5,13 & 4,88 \\
\hline BLi00373 & $y c g M$ & ähnlich zur Prolin-Oxidase & 5,70 & 6,11 & 5,92 \\
\hline BLi00374 & $y c g N$ & $\begin{array}{l}\text { ähnlich zur } \Delta^{1} \text {-Pyrrolin-5- } \\
\text { Carboxylat-Dehydrogenase }\end{array}$ & 5,31 & 5,68 & 5,64 \\
\hline BLi00422 & rocD & Ornithin-Aminotransferase & 4,78 & 4,72 & 4,64 \\
\hline BLi00424 & $r o c F$ & Arginase & 4,18 & 3,74 & n.b. \\
\hline BLi01514 & $y k r V$ & $\begin{array}{l}\text { ähnlich zur Aspartat- } \\
\text { Aminotransferase }\end{array}$ & 1,79 & 1,52 & 1,63 \\
\hline BLi02372 & $a s p B$ & Aspartat-Aminotransferase & $-0,21$ & $-0,39$ & $-0,41$ \\
\hline BLi03382 & ald & L-Alanin-Dehydrogenase & 6,79 & 6,01 & 6,06 \\
\hline BLi03434 & yurG & $\begin{array}{l}\text { ähnlich zur Aspartat- } \\
\text { Aminotransferase }\end{array}$ & 0,23 & 0,08 & 0,09 \\
\hline BLi04139 & & homolog zur AnsB Aspartase & $-1,73$ & $-1,69$ & $-2,11$ \\
\hline BLi04140 & ans $A$ & Asparaginase & $-2,60$ & $-2,25$ & $-2,41$ \\
\hline BLi04237 & $y w f G$ & $\begin{array}{l}\text { ähnlich zur Aspartat- } \\
\text { Aminotransferase }\end{array}$ & $-0,82$ & $-0,40$ & $-0,49$ \\
\hline BLi04275 & & $\begin{array}{l}\text { homolog zur Ald Alanin- } \\
\text { Dehydrogenase }\end{array}$ & 8,06 & 7,64 & 7,97 \\
\hline
\end{tabular}


Tabelle 4.32: Vergleichende Darstellung von Expressionverhältnissen. Übersicht der Gene des Gluconat-Operons, ermittelt durch DNA-Microarray-Technologie unter Verwendung von PCRbasierenden bzw. Oligo-basierenden Chips. Werte größer 1 bedeuten eine verstärkte Expression beim Wachstum mit Gluconat, Werte kleiner -1 eine verstärkte Expression unter der Referenzbedingung. n.b. - nicht bestimmt

\begin{tabular}{|c|c|c|c|c|}
\hline \multirow[t]{4}{*}{ ID } & \multirow[t]{4}{*}{ Gen } & \multirow[t]{4}{*}{ Annotation } & \multicolumn{2}{|c|}{ log Expressionsverhältnisse } \\
\hline & & & Gluconat / & Gluconat / \\
\hline & & & Glucose & Glucose \\
\hline & & & PCR-Chip ${ }^{1)}$ & Oligo-Chip ${ }^{2)}$ \\
\hline \multirow[t]{2}{*}{ BLi04286 } & gntR & transkriptionaler Repressor des & 2,91 & 2,72 \\
\hline & & Gluconat-Operons & & \\
\hline BLi04287 & gntK & Gluconat-Kinase & 3,09 & 2,35 \\
\hline BLi04288 & gntP & Gluconat-Permease & 3,25 & 2,27 \\
\hline \multirow[t]{2}{*}{ BLi04289 } & gntZ & 6-Phosphogluconat- & n.b. & 2,65 \\
\hline & & Dehydrogenase, decarboxylierend & & \\
\hline
\end{tabular}

1) Veith, 2004
2) repräsentative Einzelmessungen

Im Folgenden soll nun auf die Reproduziebarkeit von Transkriptionsanalysen mit PCR-basierenden DNA-Microarrays durch Oligo-basierende DNA-Microarrays eingegangen werden. Hierzu wurden exemplarisch die Expressionsverhältnisse der Gene des Gluconat-Operons vergleichend dargestellt (Tab. 4.32). Sowohl für das Gen des transkriptionalen Repressors des Gluconat-Operons, gntR, als auch für die angrenzenden Gene gntK und gntP konnten die mittels PCR-basierenden DNAMicroarrays ermittelten Werte durch die Transkriptionsanalysen, in denen Oligobasierende DNA-Microarrays verwendet wurden, verifiziert werden. Für alle genannten Gene konnte eine mehr als zweifache, in zwei Fällen sogar mehr als dreifache, Erhöhung des logarithmierten Expressionsverhältnisses beobachten werden. Im Zusammenhang mit den Untersuchungen zum Gluconat-Operon lagen jedoch keine Daten der PCR-basierenden DNA-Microarrays zum Gen der 6-PhosphogluconatDehydrogenase, gntZ, vor. Aufgrund der ermittelten Werte der bereits beschriebenen Gene, kann für gntZ ein ähnliches Expressionsverhältnis angenommen werden. Diese Vermutung konnte durch die Transkriptionsanalysen der Oligo-basierenden DNAMicroarrays bekräftigt werden. Für letztere wurde RNA aus B. licheniformis Zellen gewonnen, welche in einem definierten Medium mit $50 \mathrm{mM}$ Gluconat als 
Kohlenstoffquelle in batch kultiviert wurden bzw. wie unter 3.3.5. beschrieben, als Referenzbedigung in kontinuierlicher Kultur.

\subsection{Erstellung und phänotypische Charakterisierung von Mutanten}

Neben Transkriptionsanalysen wurden auch molekularbiologische Arbeiten zur Erstellung von Mutanten durchgeführt, die die Ergebnisse der Transkriptionsanalysen experimentell untermauern sollten und weitere Einblicke in die Regulation das Zentralstoffwechsels von B. licheniformis ermöglichen sollen. Von besonderem Interesse waren hierbei Gene, welche eine signifikant erhöhte Expression im Zusammenhang mit der Verwertung von Aminosäuren zeigte. Wie bereits unter 4.3.1.2.4 beschrieben, zeigte das Gen $m m g D$, welches für die Citratsynthase III kodiert, eine erhöhte Expression im Zusammenhang mit dem Wachstum auf L-Alanin, L-Arginin, L-Glutamin, L-Glutamat und L-Prolin. Lokalisiert ist dieses Gen in direkter Nachbarschaft zu den Genen eines putativen Methylcitratzyklus. Benachbart liegt weiterhin der ORF BLi04093, welcher Homologie mit Transkriptionsregulatoren der GntR-Familie besitzt (Abb. 4.32).

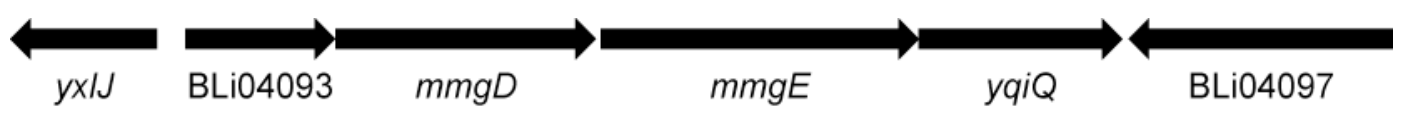

Abbildung 4.32: Organisation der kodierenden Gene eines putativen Methylcitratzyklus in B. licheniformis DSM13.

Überprüfungen der DNA-Microarray-Analysen ergaben, dass nicht nur $m m g D$, sondern auch die weiteren dem putativen Methylcitratzyklus zugeordneten ORFs beim Wachstum mit den oben angesprochenen proteinogenen Aminosäuren induziert sind (Tab. 4.33). Sowohl für den ORF des putativen transkriptionalen Regulators, als auch für die downstream lokalisierten Gene $m m g E$ und yqiQ konnte eine Erhöhung der Expression beim Wachstum mit diesen einzelnen Aminosäuren als Stickstoff- und Kohlenstoffquelle im Vergleich zum Wachstum mit Glucose ermittelt werden. 
Tabelle 4.33: Vergleichende Darstellung der Expressionsverhältnisse von Genen, welche im Zusammenhang mit einem putativen Methylcitratzyklus stehen. Werte größer 1 bedeuten eine verstärkte Expression beim Wachstum mit den angegebenen Aminosäuren im Vergleich zur Referenzbedingung. Die Tabelle enthält repräsentative Einzelmessungen.

\begin{tabular}{llllllll}
\hline ID & Gen & Funktion & \multicolumn{5}{c}{ log Expressionsverhältnisse } \\
& & & Ala / & Arg / & Gln / & Glu / & Pro / \\
& & & Glc & Glc & Glc & Glc & Glc \\
\hline BLi04093 & & putativer & 2,93 & 2,36 & 1,89 & 2,83 & 1,70 \\
& & Transkriptionsregulator & & & & & \\
BLi04094 & $m m g D$ & Citratsynthase III & 2,67 & 2,04 & 1,64 & 2,71 & 1,89 \\
BLi04095 & $m m g E$ & putative Methylaconitat- & 2,71 & 1,88 & 1,83 & 2,37 & 1,22 \\
& & Hydratase & & & & & \\
BLi04096 & $y q i Q$ & putative Methylisocitrat- & 2,78 & 1,62 & 1,56 & 2,27 & 1,21 \\
& & Lyase & & & & & \\
\hline
\end{tabular}

Ähnliches konnte auch beim Wachstum auf einem Gemisch aus 20 Aminosäuren beobachtet werden. $\mathrm{Zu}$ dem Zeitpunkten T2 bis T5, wenn kein L-Asparagin im Kulturüberstand mehr zu detektieren war (vgl. 4.3.2.4., Abb. 4.29), konnte eine erhöhte Expression der am putativen Methylcitratzyklus beteiligten Gene im Vergleich zum Wachstum mit Glucose beobachtet werden (Tab. 4.34). Lagen hingegen zum Zeitpunkt T1 noch alle Aminosäuren im Medium vor, waren diese Gene nicht induziert.

Weitere interessante Gene wären die verbleibenden Citratsynthasen I und II. Ergebnisse der Transkriptionsanalysen der durch die Gene citA und citZ kodierten Enzyme wurden im Rahmen der Untersuchungen $\mathrm{zu}$ den Citratsynthasen bereits vorgestellt (vgl. 4.3.1.2.4. Abb. 4.22, 4.3.2.2. Abb. 4.26 und 4.3.2.4. Abb. Abb.30). 
Tabelle 4.34: Expressionsverhältnisse von Genen, welche im Zusammenhang mit einem putativen Methylcitratzyklus stehen. Die Daten wurden zu den Zeitpunkten T1 bis T5 eines Wachstumsverlaufs in einem definierten Medium mit einem Gemisch von 20 Aminosäuren ermittelt (vgl. 4.3.2.4.). Werte größer 1 bedeuten eine verstärkte Expression beim Wachstum mit einem Gemisch von Aminosäuren zu den angegebenen Zeitpunkten im Vergleich zur Referenzbedingung. Die Tabelle enthält repräsentative Einzelmessungen.

\begin{tabular}{|c|c|c|c|c|c|c|c|}
\hline \multirow[t]{3}{*}{ ID } & \multirow[t]{3}{*}{ Gen } & \multirow[t]{3}{*}{ Funktion } & \multicolumn{5}{|c|}{ log Expressionsverhältnisse } \\
\hline & & & $\mathrm{T} 1 /$ & $\mathrm{T} 2 /$ & $\mathrm{T} 3 /$ & $\mathrm{T} 4 /$ & $\mathrm{T} 5 /$ \\
\hline & & & Glc & Glc & Glc & Glc & Glc \\
\hline \multirow[t]{2}{*}{ BLi04093 } & & putativer & $-0,44$ & 4,85 & 2,21 & 3,41 & 3,22 \\
\hline & & Transkriptionsregulator & & & & & \\
\hline BLi04094 & $m m g D$ & Citratsynthase III & $-0,86$ & 4,99 & 2,12 & 3,17 & 2,74 \\
\hline \multirow[t]{2}{*}{ BLi04095 } & $m m g E$ & putative Methylaconitat- & $-0,18$ & 4,60 & 2,43 & 3,17 & 2,79 \\
\hline & & Hydratase & & & & & \\
\hline \multirow[t]{2}{*}{ BLi04096 } & yqiQ & putative Methylisocitrat- & $-0,41$ & 4,21 & 2,01 & 2,59 & 2,20 \\
\hline & & Lyase & & & & & \\
\hline
\end{tabular}

In diesem Zusammenhang gilt es anzumerken, dass interessanterweise auch unter anaeroben Kultivierungsbedingungen im Vergleich zum aeroben Wachstum Änderungen der Expressionsverhältnisse ermittelt werden konnten (Tab. 4.35). Nicht nur für das die Citratsynthase III kodierende Gen $m m g D$, sondern auch für den upstream angrenzenden ORF BLi04093 und die downstream liegenden ORFs BLi04095 und BLi04096 konnte eine signifikante Erhöhung der Expression unter anaeroben Wachstumsbedingungen beobachtet werden.

Tabelle 4.35: Expressionsverhältnisse von Genen, welche im Zusammenhang mit einem putativen Methylcitratzyklus stehen. Werte kleiner -1 bedeuten eine verstärkte Expression unter anaeroben im Vergleich zu aeroben Kultivierungesbedingungen. Die Tabelle enthält repräsentative Einzelmessungen.

\begin{tabular}{lllc}
\hline ID & Gen & Funktion & $\begin{array}{c}\text { log Expressionsverhältnisse } \\
\text { aerob / anaerob }\end{array}$ \\
\hline BLi04093 & & putativer Transkriptionsregulator & $-2,48$ \\
BLi04094 & $m m g D$ & Citratsynthase III & $-2,93$ \\
BLi04095 & $m m g E$ & put. Methylaconitat-Hydratase & $-2,70$ \\
BLi04096 & \multirow{2}{*}{$y q i Q$} & putative Methylisocitrat-Lyase & $-2,93$ \\
\hline
\end{tabular}


Zur Erstellung von markerfreien in frame Deletionsmutanten sollte das Zielgen durch ein stark verkürztes Fragment des gleichen Gens in B. licheniformis mittels doppelter homologer Rekombination ausgetauscht und somit inaktiviert werden. Vorgehensweise zur Erstellung des Deletionskonstruktes, der Konjugation und anschließender Selektion sind unter 3.5 in dieser Arbeit beschrieben. Die abschließende Überprüfung auf das Vorhandensein des Deletionsvektors erfolgte mittels Southern-Blot (3.4.4.4.) Wie in Abbildung $4.33 \mathrm{zu}$ sehen, bindet die Sonde spezifisch an die mitgeführte DNA des Vektors pKVM1. Sowohl beim Vektor pKVM1, als auch beim Vektor pMAD sind unspezifische Banden auf gleicher Höhe zu erkennen. Es sind jedoch keinerlei Banden bei den Mutanten bzw. Wildtyp zu beobachten.

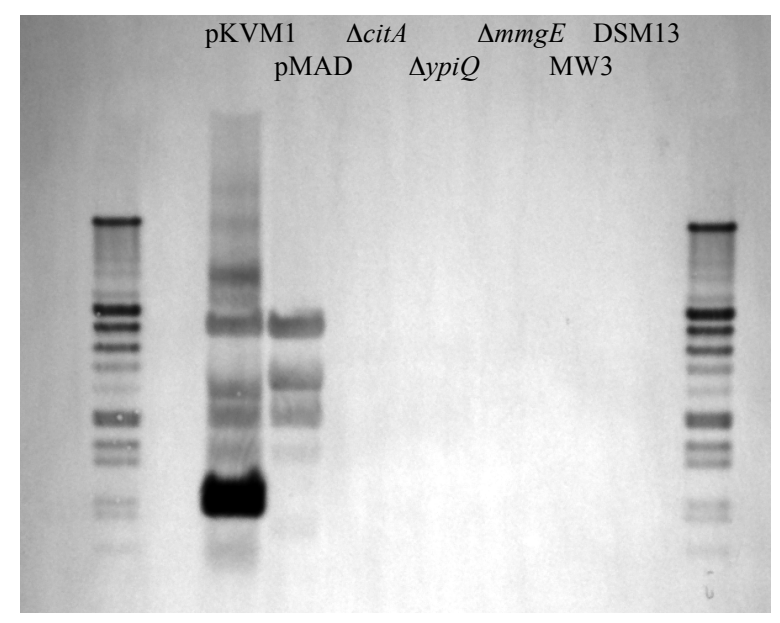

Abbildung 4.33: Darstellung eines Southern-Blots zur Überprüfung auf den Deletionsvektor.

Für eine erste phänotypische Charakterisierung lagen folgende Mutanten von B. licheniformis MW3 vor: $\triangle \mathrm{BLi} 04093, \Delta m m g D, \Delta m m g E, \Delta y q i Q$ und $\Delta c i t A$. In einem ersten Schritt wurden die Mutanten in einem definierten Medium mit einem Gemisch aus sieben Aminosäuren, welches der Sojabohne nachempfunden war, kultiviert (vgl. 3.2.2.). Um auszuschließen, dass sich Beobachtungen im Rahmen der nachfolgenden Untersuchungen auf die Deletion der beiden Typ I Restriktions-Modifikations-Systeme (Typ I RMS) von B. licheniformis MW3 zurückführen lassen, wurde dieser vergleichend mit dem Wildtyp DSM13 mitgeführt. Das Augenmerk lag zunächst auf den Mutanten der Citratsynthasen. Bei diesen Experimenten konnte kein signifikanter Wachstumsunterschied der Mutante $\Delta c i t A$ im Vergleich zu DSM13 bzw. MW3 
beobachtet werden. Die Mutante $\triangle m m g D$ hingegen zeichnete sich durch ein etwas langsameres diauxieähnliches Wachstum aus. Mit dem Einschwenken in die stationäre Phase erreichte sie aber eine ähnliche optische Dichte wie die anderen drei Stämme (Abb. 4.34).

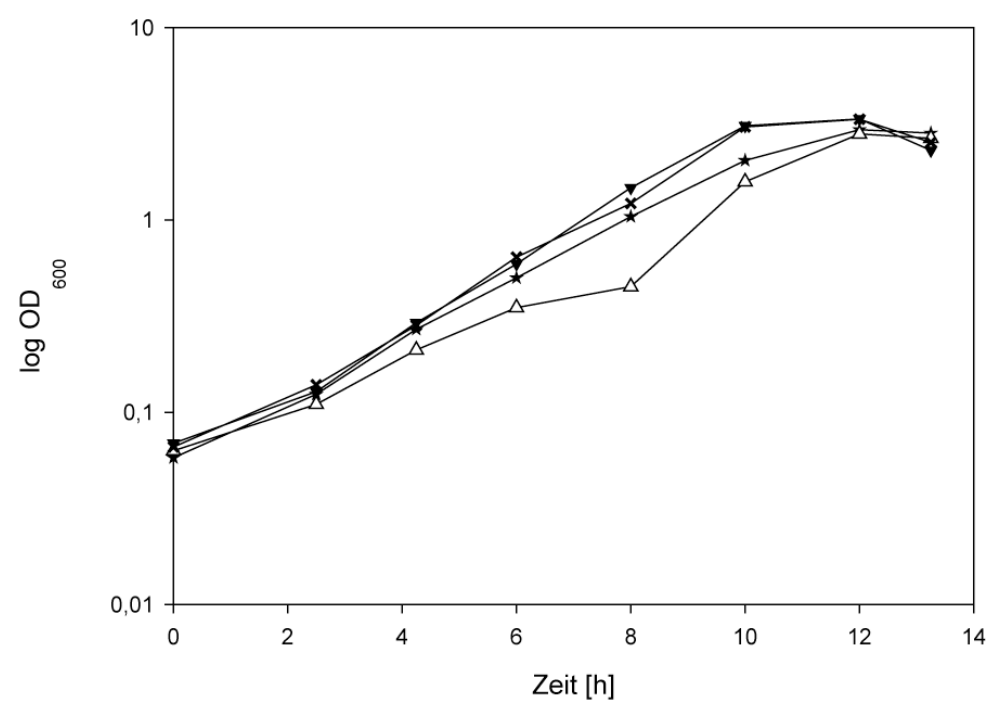

Abbildung 4.34: Vergleichende Wachstumskurven. Dargestellt ist das Wachstum von DSM13 ( $\star$ ), MW3 $(\boldsymbol{\nabla}), \Delta c i t A(\mathbf{x})$ und $\triangle m m g D(\Delta)$ auf einem definierten Medium mit einem Gemisch aus sieben Aminosäuren. Die Abbildung zeigt repräsentative Einzelmessungen.

Anhand von Analysen des Kulturüberstandes konnte dieses diauxieähnliche Wachstum mit der Verwertung von Aminosäuren in Verbindung gebracht werden (Abb. 4.35). Ebenso wie der Wildtyp DSM13 verstoffwechselte auch die Mutante $\Delta m m g D$ zunächst L-Asparagin. Ein Verbrauch der verbleibenden sechs proteinogenen Aminosäuren war erst zu beobachten, als L-Asparagin in geringer Konzentration bzw. nicht mehr im Kulturüberstand zu detektieren war. Im letzteren Fall war reproduzierbar ein stark verlangsamtes Wachstum $\mathrm{zu}$ beobachten. Mit dem sich anschließenden signifikanten Verbrauch der sechs proteinogenen Aminosäuren ging eine zunehmende Bildung von Zellmasse einher. 


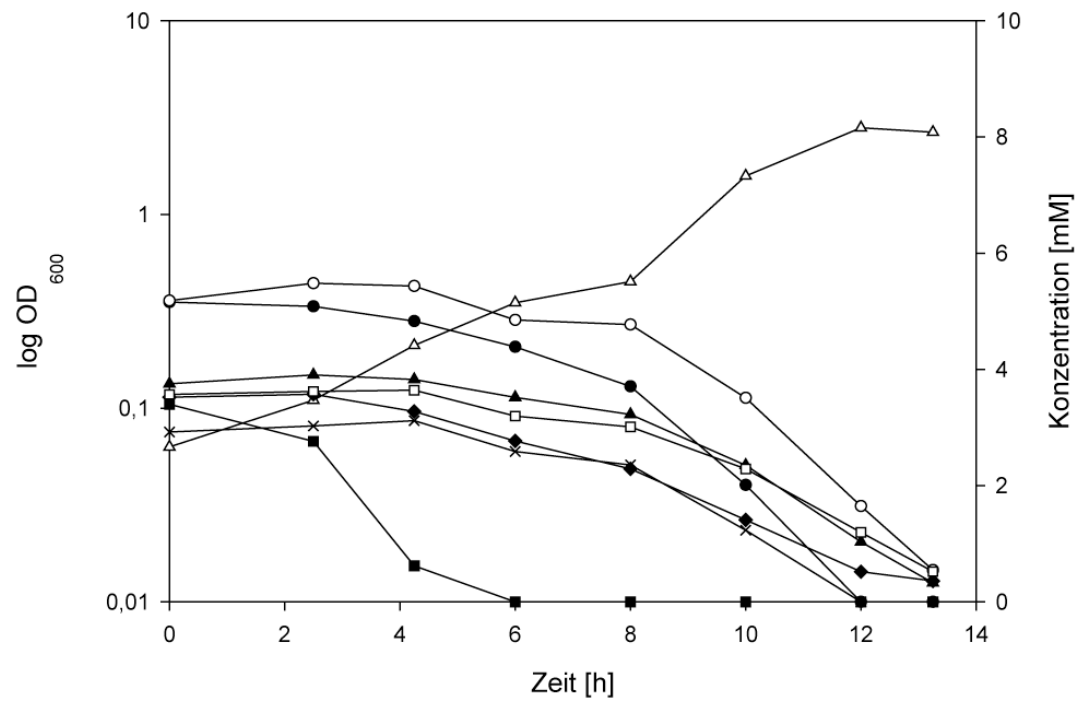

Abbildung 4.35: Wachstumsverlauf von $\triangle m m g D$ auf einem definierten Medium mit einem Gemisch aus sieben Aminosäuren. Dargestellt ist das Wachstum von $\Delta m m g D(\Delta)$ und der Verbrauch der

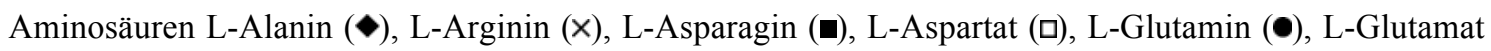
(O) und L-Prolin (ム). Die Abbildung zeigt repräsentative Einzelmessungen.

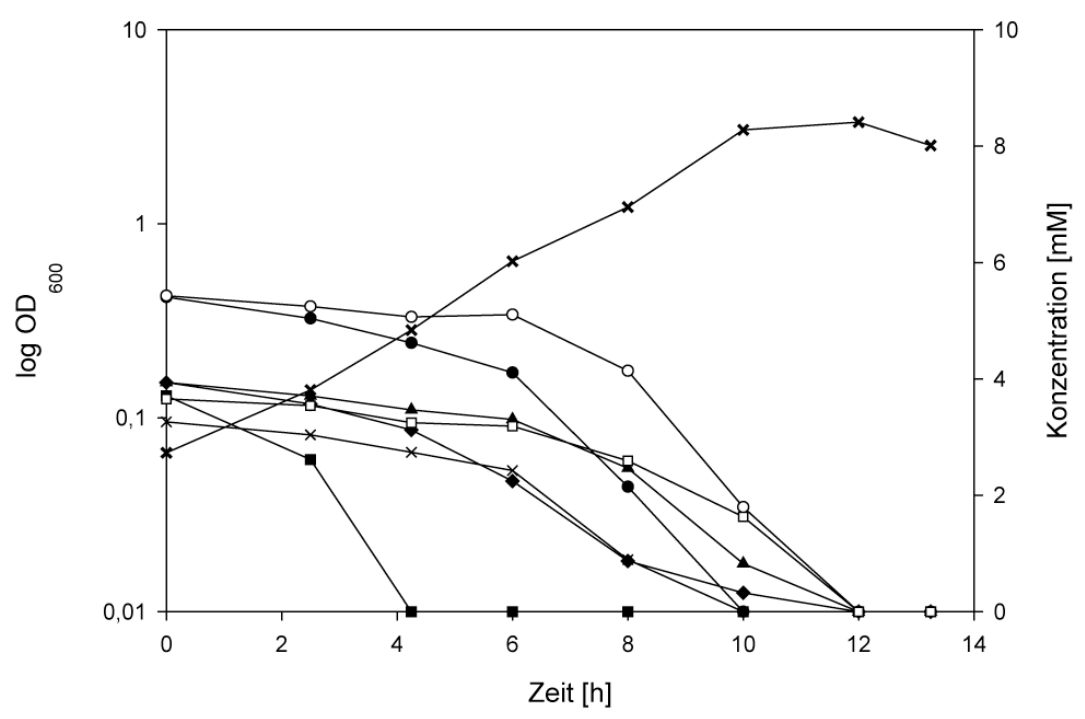

Abbildung 4.36: Wachstumsverlauf von $\Delta$ citA auf einem definierten Medium mit einem Gemisch aus sieben Aminosäuren. Dargestellt ist das Wachstum von $\Delta$ citA (x) und der Verbrauch der Aminosäuren L-Alanin (•), L-Arginin (×), L-Asparagin (ロ), L-Aspartat (ם), L-Glutamin (•), L-Glutamat (○) und L-Prolin (৯). Die Abbildung zeigt repräsentative Einzelmessungen. 
Eine Deletion des für die Citratsynthase I kodierenden Gens citA zeigte bei diesen Experimenten in einem definierten Medium mit einem Gemisch aus sieben Aminosäuren keinen Phänotyp. Sowohl die Daten der Wachstumskurve, als auch die Analysen der Kulturüberstände zeigten keinen signifikanten Unterschied zum Wildtyp DSM13 (Abb. 4.36).

Neben den Citratsynthasen waren die Gene im Zusammenhang mit dem putativen Methylcitratzyklus von Interesse. Bei der Kultivierung der verbleibenden Mutanten $\triangle \mathrm{BLi} 04093, \Delta m m g E$, und $\triangle y q i Q$ konnte kein verändertes Wachstumsverhalten in einem definierten Medium mit einem Gemisch aus sieben Aminosäuren im Vergleich zu DSM13 beobachtet werden (Abb. 4.37).

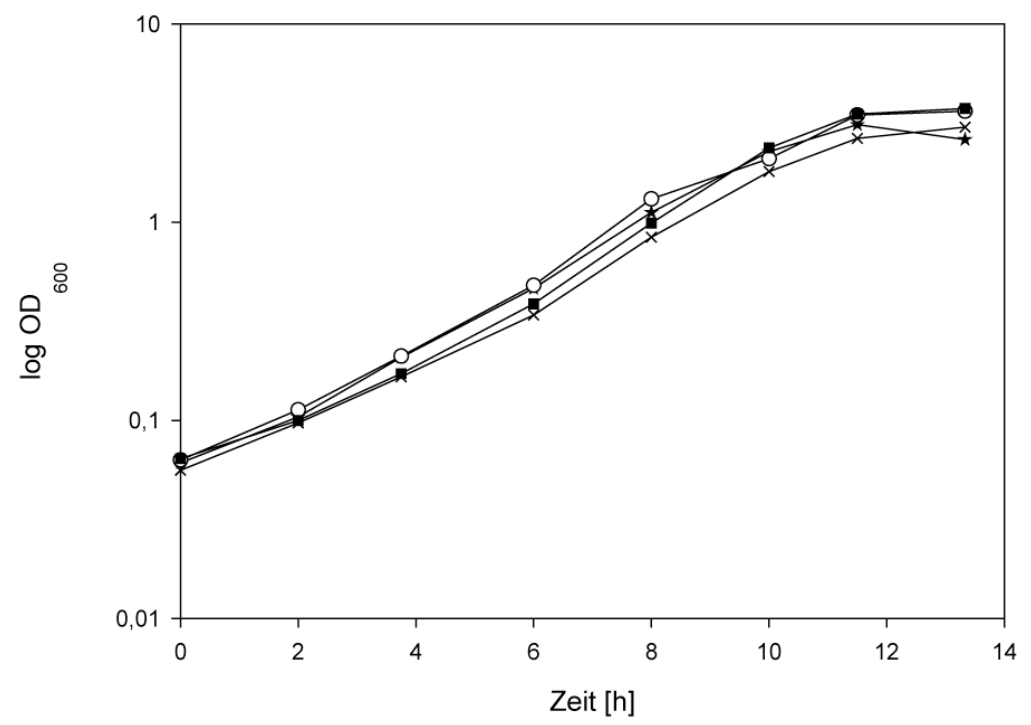

Abbildung 4.37: Vergleichende Wachstumskurven. Dargestellt ist das Wachstum von DSM13 ( $\star$ ), $\triangle \mathrm{BLi04093}(\times), \Delta m m g E(\mathrm{O})$ und $\Delta y q i Q(\mathbf{\square})$ auf einem definierten Medium mit einem Gemisch aus sieben Aminosäuren. Die Abbildung zeigt repräsentative Einzelmessungen.

In einem weiteren Experiment wurden die Mutanten in einem definierten Medium mit $50 \mathrm{mM}$ Glucose als Kohlenstoffquelle und $10 \mathrm{mM}$ Ammoniumchlorid als Stickstoffquelle kultiviert. Diese Untersuchungen zeigten, dass sowohl $\Delta c i t A$, als auch $\triangle \mathrm{BLi04093,} \Delta m m g E$ und $\triangle y q i Q$ keinen Wachstumsunterschied im Vergleich zu DSM13 bzw. MW3 aufwiesen (Abb. 4.38). Die Mutante der Citratsynthase III, $\Delta m m g D$, konnte hingegen weder auf Festmedium (Abb. 4.38), noch in Flüssigkultur (Daten nicht gezeigt) kultiviert werden. Ergänzend soll in diesem Zusammenhang noch erwähnt werden, das die Mutante $\triangle y q i Q$ im Gegensatz zu DSM13 bzw. MW3 nicht 
mehr in einem definierten Medium mit $60 \mathrm{mM}$ Propionat zu kultivieren ist (Daten nicht gezeigt).
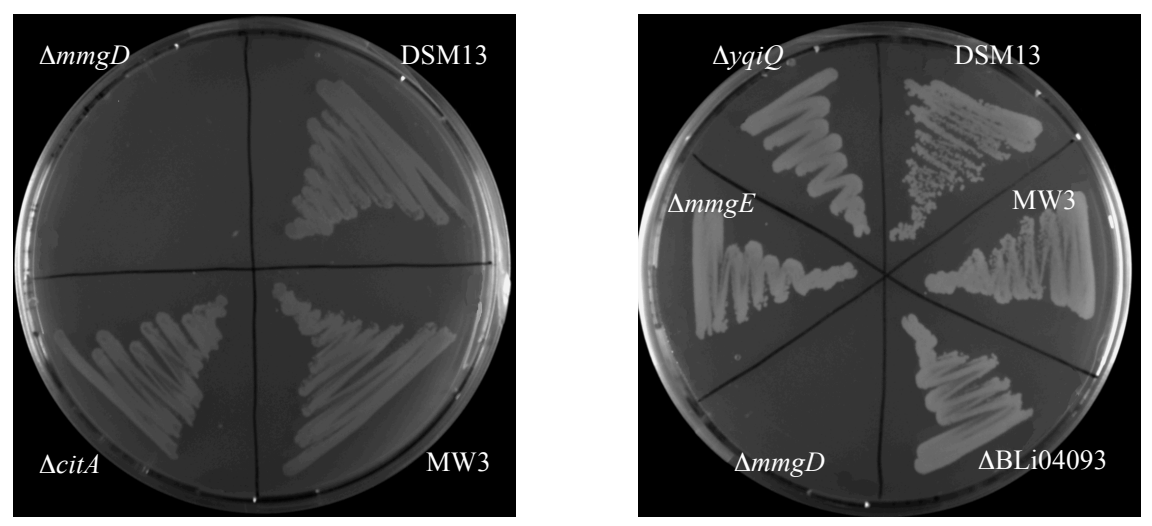

Abbildung 4.38: Vergleichende Darstellung des Wachstum von Wildtyp und Mutanten. Übersicht des Wachstums des Wildtyps und der in dieser Arbeit vorliegenden Mutanten auf einem definierten Festmedium mit $50 \mathrm{mM}$ Glucose als Kohlenstoffquelle. Lediglich für die Mutante $\Delta m m g D$ konnte in diesem Zusammenhang ein Phänotyp beobachtet werden. 


\section{Diskussion}

\subsection{Wachstum von B. licheniformis DSM13 unter anaeroben Kultivierungsbedingungen}

\section{Anaerobe Verwertung von Zuckern}

Wie bereits beschrieben, wurden im Rahmen dieser Arbeit die Untersuchungen zum fermentativen Wachstum von DSM13 erneut aufgegriffen. Im Unterschied zu den vorangegangenen Arbeiten (Schwarzer, 2005) wurde das definierte Medium unter anaeroben Wachstumsbedingungen mit Thiamin supplementiert.

Die weiterführenden Untersuchungen dieser Arbeit zum anaeroben Wachstum von $B$. licheniformis DSM13 ergaben, dass dieser keine der verwendeten Pentosen verwerten kann. Beim Wachstum in einem definierten Medium mit Hexosen konnte neben Glucose auch Fructose als Kohlenstoffquelle dienen. Des Weiteren konnte ein anaerobes Wachstum bei der Kultivierung mit Maltose und Saccharose beobachtet werden. Hierbei gilt es anzumerken, dass DSM13 in dem untersuchten Zeitraum von 50 Stunden ein schlechtes Wachstum auf Maltose zeigte (vgl. 4.1.1.).

Auf der anderen Seite ist es DSM13 möglich alle getesteten Zucker aerob als Kohlenstoffquelle zu nutzen. Daneben konnte bereits gezeigt werden, dass DSM13 unter aeroben Wachstumsbedingungen sowohl Gluconat, als auch Sorbitol verwerten kann. Im Gegensatz dazu konnte DSM13 aber weder Sorbitol, noch Gluconat vergären, wobei auch die gleichzeitige Zugabe der reduzierten und der oxidierten Verbindung nicht zum Wachstum unter anaeroben Bedingungen führte (Schwarzer, 2005). Dieses wiederum ließ vermuten, dass $B$. licheniformis DSM13 Probleme hat, die Redox-Bilanz unter fermentativen Bedingungen auszugleichen und deckt sich mit den Beobachtungen wie sie für den B. licheniformis Stamm NCIB 6346 (Shariati et al., 1995) gemacht wurden.

Gemeinsam ist den unter anaeroben Kultivierungsbedingungen als alleinige Kohlenstoffquelle dienenden Hexosen Glucose und Fructose und dem Disaccharid Saccharose, dass sie $\mathrm{zu}$ den sogenannten PTS-Zuckern gehören. Bei dem Phosphotransferase-System (PTS) handelt es sich um ein komplexes Enzymsystem, welches neben der Detektion und dem Transport auch für die Phosphorylierung verschiedener Zucker zuständig ist. Es besteht im Wesentlichen aus drei Komponenten. 
Zusätzlich zu den generellen Komponenten HPr und Enzym I kommt eine für den jeweiligen Zucker spezifische Komponente, das Enzym II, hinzu. Das Glucosespezifische Enzym II wird in DSM13 durch das Gen ptsG (BLi001598) kodiert. Direkt daneben im Genom lokalisiert sind die Gene ptsH (BLi01599) und ptsI (BLi01600). Ersteres kodiert für das HPr-Protein und letzteres für das Enzym I. Um die Flexibilität von DSM13, dass dieser neben Glucose, noch weitere Zucker anaerob zum Wachstum nutzen kann, näher zu beleuchten, soll im Weiteren auf mögliche Abbauwege dieser Zucker eingegangen werden.

In B. subtilis sind für die Aufnahme von Fructose zwei Wege bekannt (Steinmetz, 1993). Die beteiligten Gene des ersten Aufnahmeweges sind fruAB. Dieser scheint auch als Hauptweg zur Aufnahme von Fructose zu dienen, da Mutationen in diesen Genen zu schlechterem Wachstum auf Fructose führen (Gay \& Delobbe, 1977). Am zweiten Aufnahmeweg ist das Gencluster levDEFG beteiligt (Martin-Verstraete et al., 1990), welches für eine Fructose-spezifische PTS-Permease kodiert. Auch für B. licheniformis DSM13 konnten im Rahmen der Genomanalyse diese ORFs identifiziert werden. Hierbei kodiert fruA (BLi01654) für das PTS Fructose-spezifische Enzym II und fruK (BLi01653) für eine Fructose-1-Phopsphat-Kinase. Upstream hiervon ist das Gen des zugehörigen transkriptionalen Repressors, fruR (BLi01652), lokalisiert. Das kodierende Gencluster levDEFG (BLi02831, BLi02830, BLi02829, BLi02828) des PTS Fructosespezifische Enzyms II ist in DSM13 hingegen von dem Gen eines transkriptionalen Aktivators (levR, BLi02832) flankiert. Ebenfalls mit diesem Gencluster assoziiert ist das für eine Levanase kodierende Gen sacC (BLi02827).

Wie für Fructose, so sind auch für Saccharose zwei Aufnahmesysteme in B. subtilis beschrieben. Die am Transport und Phosphorylierung bzw. anschließender Hydrolyse beteiligten Gene des ersten Weges sind $s a c A$ und $s a c P$. Ersteres kodiert hierbei für eine Phosphosucrase (Fouet et al., 1986) und letzteres für eine Untereinheit der Saccharose-spezifischen PTS-Permease (Fouet et al., 1987). Eine weitere Möglichkeit des Saccharose Metabolismus in B. subtilis kann über das Exoenzym Lvs, kodiert durch $s a c B$, erfolgen. Hierbei kommt es durch den Transfer der FructosylGruppe der Saccharose zu einer Mischung aus Glucose, Fructose und Levan (Steinmetz, 1993). Die soeben beschriebenen Gene im Zusammenhang mit der Aufnahme und Umsetzung von Saccharose sind ebenfalls in DSM13 $\mathrm{zu}$ finden. In direkter Nachbarschaft zu den die Sucrase-6-Phosphat-Hydrolase bzw. PTS Saccharose- 
spezifischen Enzyme II Komponente kodierenden Gene sacA (BLi04016) und sacP (BLi04017) ist das Gen eines zugehörigen transkriptionalen Antiterminors (sacT, BLi04018) lokalisiert. Weiter downstream hiervon befindet das die Levansucrase kodierende Gen $s a c B$ (BLi03706).

In Abbildung 5.1 sind einmal zusammenfassend die einleitenden Schritte für die Aufnahme und Verwertung bzw. die daran beteiligten Gene für Glucose, Fructose und Saccharose schematisch dargestellt. Wie soeben erörtert, lassen sowohl die genetische Ausstattung von DSM13, als auch seine Fähigkeit diese Zucker aerob, wie auch anaerob zum Wachstum nutzen zu können, vergleichbare Funktionen, wie sie für B. subtilis beschrieben sind, vermuten.

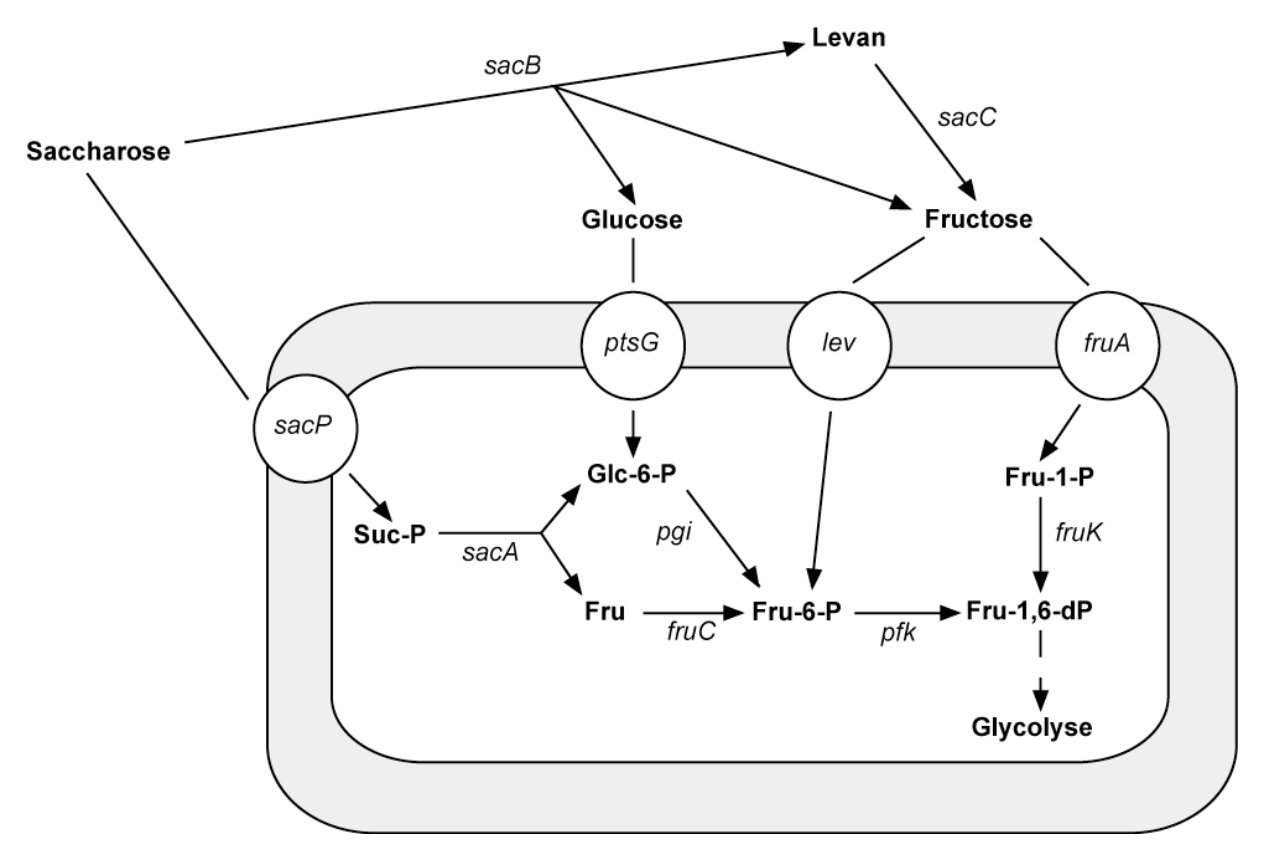

Abbildung 5.1: Schematischer Abbau von Hexosen und Saccharose in DSM13 (adaptiert und modifiziert nach B. subtilis, Steinmetz, 1993). Erläuterungen sind dem Text zu entnehmen.

Fru - Fructose; Fru-1-P - Fructose-1-Phopsphat; Fru-1,6-dP - Fructose-1,6-Diphopsphat;

Fru-6-P - Fructose-6-Phopsphat; Glc-6-P - Glucose-6-Phopsphat; Suc-P - Saccharose-Phopsphat

\section{Anaerobe Ribonukleotidreduktase}

Im vorangegangenen Abschnitt wurden eine Reihe von Gemeinsamkeiten von B. licheniformis DSM13 mit seinem nahen Verwandten B. subtilis herausgestellt. Im Gegensatz zu DSM13 benötigt dieser aber zum anaeroben fermentativen Wachstum die zusätzliche Zugabe von Pyruvat (Nakano et al., 1997) oder Desoxyribonukleotiden 
(Folmsbee et al., 2004). Letztere sind für die Synthese von DNA essentiell. Katalysiert wird ihre Bildung durch Ribonukleotidreduktasen, welche sich wiederum in drei Klassen einteilen lassen. Enzyme der Klasse I benötigen Sauerstoff, die der Klasse II agieren unabhängig vom Sauerstoff und auf Enzyme der Klasse III wirkt Sauerstoff toxisch (Torrents et al., 2000). Für die katalytische Aktivität der anaeroben Ribonukleotidreduktase ist ein Sauerstoff-sensitives Glycyl-Radikal notwendig, an dessen Generierung ein spezifisches Aktivierungsenzym beteiligt ist (Sun et al., 1995). Durch die Sequenzierung des Genoms von DSM13 konnten die Gene einer putativen anaeroben Ribonukleotidreduktase der Klasse III (BLi03824) und zwei potenziell zugehöriger Aktivierungsenzyme (BLi03823, BLi04172) identifiziert werden. Basierend auf Resultaten von Transkriptionsanalysen konnte das Aktivierungsenzym (BLi03823) der anaeroben Ribonukleotidreduktase zugeordnet werden (vgl. 4.1.2.1.). Im Genom von DSM13 ist der kodierende ORF dieses Enzyms in direkter Nachbarschaft zum Gen der Ribonukleotidreduktase lokalisiert. Des Weiteren konnte die für das Gen der anaeroben Ribonukleotidreduktase ermittelte erhöhte Expression unter fermentativen Bedingungen durch real-time RT-PCR verifiziert werden (vgl. 4.1.2.2.). In diesem Zusammenhang ist es erwähnenswert, dass via BLAST-Analyse keine anaerobe Ribonukleotidreduktase der Klasse III für B. subtilis ermittelt werden konnte (Folmsbee et al., 2004). Dieses steht im Einklang mit der zuvor beschriebenen Beobachtung, dass B. subtilis eine zusätzliche Supplementierung von Desoxyribonukleotiden für das anaerobe Wachstum benötigt. Im Gegensatz hierzu lassen die in dieser Arbeit geschilderten Experimente für DSM13 eine Aktivität der anaeroben Ribonukleotidreduktase in vivo vermuten.

\section{Pyruvat-Formiat-Lyase}

Dieses sehr gut in E. coli untersuchte Glycyl-Radikalenzym katalysiert unter Sauerstoffausschluss die Umsetzung von Pyruvat zu Acetyl-CoA und Formiat. Die Pyruvat-Formiat-Lyase (PFL) kann wechselseitig in einer aktiven oder inaktiven Form vorliegen. Die nur anaerob eintretende Aktivierung der PFL zur Radikaltragenden Form wird durch ein monomeres Protein, dem PFL Aktivierungs-Enzym, katalysiert (Kessler \& Knappe, 1996). Die Regulation auf transkriptioneller Ebene erfolgt unter anderem durch den Redox-Regulator Fnr (Sawers \& Suppmann, 1992; Kaiser \& Sawers, 1995). 
In B. licheniformis DSM13 konnten zwei ORFs identifiziert werden, welche für eine putative Pyruvat-Formiat-Lyase (BLi02132) und einem zugehörigen putativen Aktivierungsenzym (BLi02131) kodieren. Wie bereits unter 4.1.2.1. erläutert wurde das Produkt des ORFs BLi02132 als putative Formiat-Acetyltransferase annotiert. Beide ORFs sind nebeneinander im Genom von DSM13 lokalisiert und vergleichende Expressionsanalysen mittels DNA-Microarrays ergaben eine mehr als 8fache Steigerung des log Expressionverhältnisses unter fermentativen Kultivierungsbedingungen im Vergleich $\mathrm{zu}$ aeroben Wachstumsbedingungen (vgl. 4.1.2.1., Tab. 4.7). Diese Steigerung konnte für den ORF der putativen Formiat-Acetyltransferase durch real-time RT-PCR bestätigt werden (vgl. 4.1.2.2.). Aufgrund des Fehlens der PFL nutzt B. subtilis die Pyruvat-Dehydrogenase (PDH) zum fermentativen Wachstum und produziert auch kein Formiat. Eine Mutante, welcher die Aktivität der PDH fehlt, ist nicht mehr fähig fermentativ zu wachsen (Nakano et al., 1997). Es gilt in diesem Zusammenhang darauf hinzuweisen, dass unter strikt fermentativen Kultivierungsbedingungen von einem sehr schwach ausgeprägten Wachstum von B. subtilis zu sprechen ist. Im Gegensatz hierzu konnte eine Induktion der kodierenden Gene für die Untereinheiten dieses Enzyms in Verbindung mit anaeroben Wachstumsbedingungen für DSM13 nicht beobachtet werden (vgl. 4.1.2.1., Tab. 4.7). Dieses lässt den Schluss zu, dass B. licheniformis DSM13, wie auch E. coli, zum fermentativen Wachstum die PFL nutzt. Gestützt wird dieses durch die zunehmende Konzentration an Formiat im Kulturüberstand während des anaeroben Wachstums (vgl. 4.1.3., Abb. 4.7). Einen Hinweis zur Regulation dieses Enzyms in B. licheniformis ist in der Tatsache begründet, dass eine hoch konservierte putative Fnr binding site über virtual footprint gefunden werden konnte (vgl. 4.1.2.1., Tab. 4.6). Dieses geht ebenfalls mit den Beobachtungen für E. coli konform. Ergänzend soll noch hinzugefügt werden, dass die Umwandlung der aktiven PFL in die nichtradikale Form in $E$. coli durch das Alkohol-Dehydrogenase-Enzym AdhE katalysiert wird (Kessler et al., 1991 \& 1992), wobei jedoch diese Deaktivase-Aktivität der AdhE durch erneute Untersuchungen nicht reproduziert werden konnte (Nnyepi et al., 2007).

\section{Regulation des fermentativen Wachstums}

Als Bestandteile des Regulationssystems der Adaption an das anaerobe Wachstum sind bereits das Zwei-Komponenten-System ResDE, der anaerobe Regulator Fnr und 
der transkriptionale Modulator ArfM in B. subtilis bekannt. Hierbei kodieren resE für eine Histidin-Sensor-Kinase und resD für den zugehörigen Response-Regulator (Sun et al., 1996). Das Gen fnr steht im Zusammenhang mit dem Nitrat-Metabolismus unter anaeroben Wachstumsbedingungen (Cruz Ramos et al., 1995). Die Transkription von $r e s D E$ und $f n r$ sind unter anaeroben Wachstumsbedingungen in B. subtilis induziert (Nakano et al., 1996).

Auch im Rahmen der durchgeführten Transkriptionsanalysen zum fermentativen Wachstum in B. licheniformis DSM13 konnte eine erhöhte Expression für die Gene resDE, wie auch fnr beobachtet werden (vgl. 4.1.2.1., Tab. 4.5). Ebenfalls induziert war das Gen $\operatorname{arfM}$, welches in B. subtilis an der anaeroben Induktion von den Genen der Häm-Biosynthese (hemN und hemZ) beteiligt ist (Homuth et al., 1999).

ResD und ResE sind in die Regulation von Genen der anaeroben Nitratatmung, wie nasDEF (Nitrit-Reduktase Operon) oder $f n r$, aber auch von Genen der Fermentation in B. subtilis involviert (Nakano et al., 1998; Nakano et al., 1996; Cruz Ramos et al., 2000; Nakano et al., 1997). Fnr wiederum induziert unter anaeroben Bedingungen die Transkription von narGHIJ (Nitrat-Reduktase, Cruz Ramos et al., 1995), narK (Nitrit Export, Cruz Ramos et al., 1995) und dem Gen des anaeroben Modulators ArfM (Marino et al., 2001) (Abb. 5.2). Wie bereits erläutert konnte mittels virtual footprint in DSM13 upstream von narG, narK und arfM potenzielle Fnr binding sites identifiziert werden (vgl. 4.1.2.1.). Dieses steht im Einklang mit den in B. subtilis gemachten Beobachtungen (Cruz Ramos et al., 1995). Es gilt anzumerken, dass die potenzielle binding site upstream von narK in DSM13 hoch konserviert vorliegt, wohingegen die upstream der Gene arfM und narG lokalisierten binding sites jeweils einen Basenaustausch enthalten (vgl. 4.1.2.1., Tab. 4.6). Im Zusammenhang mit dem anaeroben Wachstum konnten neben den Genen narGHIJ auch für narK und, wie schon beschrieben, auch für $\operatorname{arf} M$ eine erhöhte Expression ermittelt werden (vgl. 4.1.2.1., Tab. 4.5). Eine Induktion der Nitrat-Reduktase unter anaeroben Kultivierungsbedingungen, auch in Abwesenheit von Nitrat, konnte bereits 1970 für B. licheniformis gezeigt werden (Schulp \& Stouthamer, 1970).

Wie soeben erörtert, spielt das ResDE Zwei-Komponenten-System und der Redox-Regulator Fnr beim Übergang vom aeroben zum anaeroben Wachstum in B. subtilis eine wichtige Rolle (Nakano \& Zuber, 1998). Die Expression der Gene cydABCD hingegen sind in B. subtilis unter anaeroben Wachstumsbedingungen 
unabhängig von der Regulation sowohl durch ResDE, als auch von Fnr (Ye et al., 2000). Diese Gene kodieren bzw. werden für die Expression der Cytochrom bd Oxidase, eine der drei großen terminalen Oxidasen, benötigt (Winstedt et al., 1998). Unter fermentativen Kultivierungsbedingungen konnte im Rahmen dieser Arbeit eine Induktion aller vier beteiligten Gene für DSM13 ermittelt werden (vgl. 4.1.2.1., Tab. 4.4). Daneben wurden keine signifikante Änderung der für die Cytochrom $\mathrm{caa}_{3}$ Oxidase kodierenden Gene $c t a C D E F$ beobachtet. Die kodierenden Gene der dritten terminalen Oxidase, der Cytochrom $a a_{3}$ Quinol-Oxidase (qoxABCD), waren unter anaeroben Wachstumsbedingungen reprimiert. Diese Ergebnisse stehen für die Gene $c y d A B C D$ im Einklang mit DNA-Microarray-Analysen, welche in B. subtilis durchgeführt wurden (Ye et al., 2000). Anzumerken gilt es jedoch, dass die durchgeführten Transkriptionsanalysen in B. subtilis, nicht wie in dieser Arbeit in einem definierten Medium, sondern in einem komplexen Medium durchgeführt wurden. Wie eingangs erwähnt, haben die Wachstumsbedingungen bzw. Änderung dieser Bedingungen einen direkten Einfluss auf den Biosyntheseapparat eines Organismus. Aus diesem Grund können sich unterschiedliche Ergebnisse der Analysen auf unterschiedliche Versuchsbedingungen zurückführen lassen. In diesem Kontext soll nicht unerwähnt bleiben, dass Untersuchungen in B. subtilis gezeigt haben, dass ResD an der Expression von $c y d A$ unter aeroben Bedingungen involviert ist (Puri-Taneja et al., 2007).

Zusammenfassend lassen die ermittelten Ergebnisse der Genexpressionsanalyse und die Identifikation möglicher konserviert vorliegender Fnr binding sites darauf schließen, dass in DSM13 eine ähnliche Regulation des fermentativen Wachstums vorliegt, wie für B. subtilis beschrieben (Abb. 5.2). Der unter anderem aus B. subtilis bekannte transkriptionale Repressor Rex (ehemals YdiH; Gyan et al., 2006; Wang et al., 2008) ist ebenfalls in DSM13 zu finden. Lokalisiert ist der kodierende ORF BLi00618 in direkter Nachbarschaft zum Gen moaC, dessen Produkt Ähnlichkeit zu einem Vorläufer der Molybdopterin-Biosynthese hat und Genen (tatACY), welche für putative bzw. Komponenten des Twin-Arginin-Translokalisationspfads kodieren. Im Wesentlichen passt Rex die Transkription in Abhängigkeit des NADH/NAD ${ }^{+}$ Redoxzustandes an. Untersuchungen in B. subtilis lassen den Schluss zu, dass Rex ebenso als negativer Regulator der Expression von $c y d A B C D$ dient (Schau et al., 2004) wie auch als Repressor für die Gene $l d h$ und $y w c J$ (Larsson et al., 2005). Hierbei kodiert $l d h$ für die bereits erwähnte Lactat-Dehydrogenase und $y w c J$ für einen putativen 
Formiat-Nitrit-Transporter. Mithilfe der durchgeführten DNA-Microarrays konnte keine signifikante Änderung des Expressionsverhältnisses in DSM13 ermittelt werden. Die Intensität der einzelnen Kanäle lassen jedoch den Schluss zu, dass das Gen dieses Regulators sowohl unter aeroben, als auch unter anaeroben Kultivierungsbedingungen induziert ist (Daten nicht gezeigt). Die Rolle des Regulatorproteins Rex im Zusammenhang mit dem fermentativen Wachstum von DSM13 wurde im Rahmen dieser Arbeit nicht näher beleuchtet.

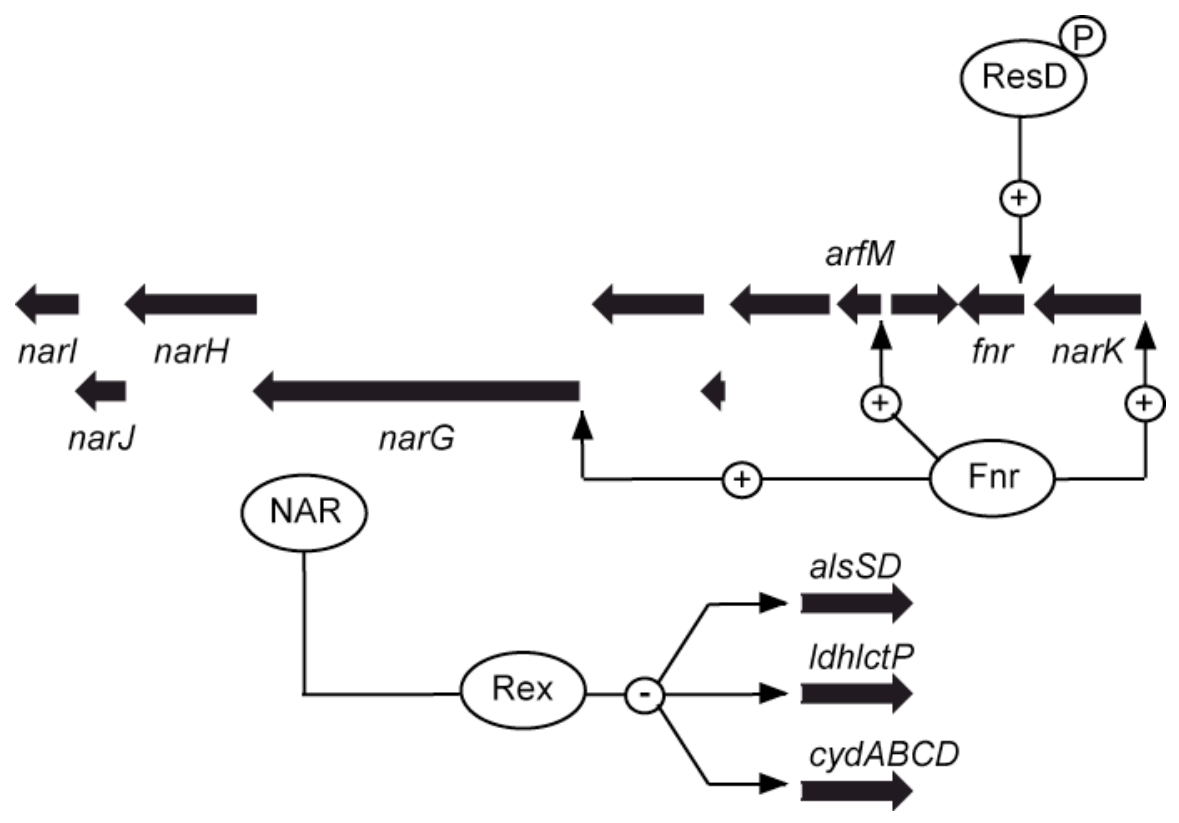

Abbildung 5.2: Vereinfachte schematische Übersicht der Regulationskaskade von Fnr für B. subtilis (nach Reents et al., 2006). Unter anaeroben Kultivierungsbedingungen induziert Fnr direkt die Transkription von arfM, narKfnr und narG. Durch die Regulation der Bildung der Nitrat-Reduktase, vermittelt Fnr unter anderem die Repression von alsSD, ldh lctP und $c y d A B C D$ durch Rex. Die Expression dieser Gene ist somit aber nicht direkt von Fnr abhängig.

\section{Genexpression und Fermentationsendprodukte}

Im Rahmen der Untersuchungen zum fermentativen Wachstum von DSM13 konnten eine Reihe von Genen aufgrund ihrer Expressionswerte der Bildung von Fermentationsendprodukten zugewiesen werden (vgl. 4.1.2.1., Tab. 4.8, 4.9 und 4.10). Eine Schlüsselaufgabe des fermentativen Wachstums besteht in der Reoxidation des während der Glykolyse gebildeten NADH. Dieses ist notwendig, da sonst die Oxidation der Glucose und damit verbunden die Bildung von ATP abbrechen würde. Die Regeneration des nur in geringen Mengen in der Zelle vorhandenen $\mathrm{NAD}^{+}$ist an verschiedene Reaktionen gekoppelt. Zum einen kann $\mathrm{NAD}^{+}$durch die Umwandlung 
von Pyruvat $\mathrm{zu}$ Lactat regeneriert werden. Katalysiert wird die Reaktion durch die Lactat-Dehydrogenase. Für das kodierende Gen dieses Enzyms, ldh, konnte die mittels DNA-Microarray ermittelte gesteigerte Expression unter anaeroben Wachstumsbedingungen durch real-time RT-PCR bestätigt werden (vgl. 4.1.2.2.). In diesem Zusammenhang ist es erwähnenswert, dass eine Mutation in der Lactat-Dehydrogenase in B. subtilis $\mathrm{zu}$ schlechtem Wachstum unter anaeroben Bedingungen führt (Cruz Ramos et al., 2000).

Eine weitere Möglichkeit der Regeneration ist an die Bildung von 2,3-Butandiol gekoppelt. Wiederum ausgehend vom Pyruvat wird dieses zunächst durch die $\alpha$-Acetolactat-Synthase (alsS) und $\alpha$-Acetolactat-Decarboxylase (alsD) zu Acetoin umgesetzt. Die anschließende Reduktion von Acetoin zu 2,3-Butandiol wird durch die Acetoin-Reduktase katalysiert. Sowohl für die Gene als $S D$, als auch für den ORF der putativen Acetoin-Reduktase BLi02066 konnte eine erhöhte Expression bei fermentativen Wachstum von DSM13 beobachtet werden (vgl. 4.1.2.1., Tab. 4.8). Mittels real-time RT-PCR konnte dieses am Beispiel der Gens alsD verifiziert werden (vgl. 4.1.2.2.). Eine Mutation in alsSD hat, im Gegensatz zu der bereits erwähnten Mutation der Lactat-Dehydrogenase, keine Auswirkung auf das Wachstum von B. subtilis unter anaeroben Bedingungen (Cruz Ramos et al., 2000). Eine Disruption des Gens des zugehörigen transkriptionalen Regulators, alsR, führt hingegen dazu, dass das alsSD Operon nicht mehr exprimiert wird (Renna et al., 1993).

Die zwei wesentlichen Syntheseswege von Glycerol beginnen mit dem glycolytischen Intermediat Dihydroxyacetonphosphat, unterscheiden sich jedoch in der Dephosphorylierung und Reduktion (Skraly \& Cameron, 1998). Involviert in diese katalytischen Schritte sind Glycerol-Dehydrogenasen. Im Genom von DSM13 konnten vier Gene identifiziert werden, dessen Produkte in Verbindung mit GlycerolDehydrogenasen annotiert wurden. Anhand der durchgeführten DNA-MicroarrayAnalysen wurden nur für die ORFs BLi00996 und BLi04259 eine erhöhte Expression beim Wachstum unter anaeroben Kultivierungsbedingungen im Vergleich zum aeroben Wachstum beobachtet (vgl. 4.1.2.1., Tab. 4.9). Eine Verifizierung der ermittelten Daten für den ORF BLi00996 erfolgte via real-time RT-PCR (vgl. 4.1.2.2.). Im Genom von B. licheniformis DSM13 ist der ORF BLi00996 ( $g l p D)$ mit Genen ( $g l p P F K)$ assoziiert, welche wiederum in B. subtilis mit der Verwertung von Glycerol in Verbindung stehen (Lindgren \& Rutberg, 1975). Unter den gegebenen fermentativen Versuchsbedingungen 
konnte für B. licheniformis keine erhöhte Expression dieser Gene ermittelt werden (vgl. 4.1.2.1., Tab. 4.9). Dieses lässt vermuten, dass sowohl die Gene glpPFK, ebenso wie $g l p D$, auch in DSM13 primär an der Verwertung von Glycerol beteiligt sind.

In direkter Nachbarschaft zum obig erwähnten ORF BLi04259 ist ein ORF lokalisiert, dessen Produkt für eine putative D- $\alpha$-Glycerophosphatase kodiert. Ein solches Enzym konnte bereits in B. licheniformis aufgereinigt und charakterisiert werden (Skraly \& Cameron, 1998). Es katalysiert den finalen Schritt zur Bildung von Glycerol, indem es D-Glycerolphosphat zu Glycerol dephosphoryliert. Der komplette biosynthetische Weg zum Glycerol ist in B. licheniformis nicht bekannt (Skraly \& Cameron, 1998). Die im Rahmen dieser Arbeit ermittelten gesteigerten Expressionswerte für DSM13 beim Wachstum unter fermentativen Kultivierungsbedingungen lassen vermuten, dass sowohl der für eine putative Glycerol-1-PhosphatDehydrogenase kodierende ORF BLi04259, als auch der für eine putative D- $\alpha$-Glycerophosphatase kodierende ORF BLi04260 in die Biosynthese von Glycerol involviert sind (vgl. 4.1.2.1., Tab. 4.9).

Wie bereits beschrieben, katalysiert die PFL, ausgehend von Pyruvat, die Umsetzung zu Formiat und Acetyl-CoA, ohne dabei, wie die Pyruvat-Dehydrogenase, nochmals zwei NADH zu produzieren. Acetyl-CoA kann anschließend einerseits, unter Bildung von ATP, zu Acetat umgewandelt oder andererseits zu Ethanol reduziert werden. Durch die Bildung von Ethanol in zwei Reduktionsschritten können zwei Moleküle $\mathrm{NAD}^{+}$regeneriert werden. Typischerweise werden diese Reduktionen von zwei verschiedenen Enzymen, der Acetaldehyd-Dehydrogenase und der AlkoholDehydrogenase katalysiert, wobei jedoch Untersuchungen in E. coli gezeigt haben, dass ein großes Hybridenzym beide Reaktionen katalysieren kann (Goodlove et al., 1989; Kessler et al., 1991). Hierbei handelt es sich um die bereits im Zusammenhang mit der Pyruvat-Formiat-Lyase erwähnte Ethanol-Dehydrogenase, welche durch das Gen adhE kodiert wird. Im Rahmen der in dieser Arbeit durchgeführten Transkriptionsanalysen wurden die vergleichenden Genexpressionen von neun möglichen Kandidaten putativer Alkohol-Dehydrogenasen untersucht (vgl. 4.1.2.1., Tab. 4.10). Für zwei dieser ORFs, BLi01117 und BLi04290, konnte eine signifikante Expressionserhöhung unter anaeroben Wachstumsbedingungen im Vergleich zu aeroben Bedingungen ermittelt werden. Anders als der ORF BLi01117 kodiert BLi04290 für eine putative bifunktionale Acetaldehyd-CoA/Alkohol-Dehydrogenase. Eine auf Aminosäureebene 
durchgeführte BLAST-Analyse ergab eine mehr als 50\%ige Übereinstimmung mit der multifunktionalen AdhE aus E. coli K12 (Daten nicht gezeigt).

Neben der Reduktion zu Ethanol kann Acetyl-CoA aber auch zu Acetat umgesetzt werden. Zunächst wird hierbei Acetyl-CoA durch die Phosphotransacetylase (pta) zu Acetyl-Phosphat umgesetzt (Presecan-Siedel et al., 1999). In einem durch die Acetat Kinase (ackA) katalysierten Schritt wird dieses anschließend unter Bildung von ATP zu Acetat umgewandelt. Wie bereits für die Mutation der Lactat-Dehydrogenase beschrieben, kommt es auch bei einer pta-Mutante zu vermindertem Wachstum unter anaeroben Bedingungen bei B. subtilis (Cruz Ramos et al., 2000). Die in DSM13 durchgeführten vergleichenden Analysen der Genexpression ergaben, dass die an beiden Reaktionen beteiligten Gene, pta und ackA, unter anaeroben Wachstumsbedingungen reprimiert waren. Dieses konnte mittels real-time RT-PCR für das Gen der Acetat-Kinase bestätigt werden (vgl. 4.1.2.2.). Im Zuge der Analysen des Kulturüberstandes konnte jedoch Acetat sowohl qualitativ, als auch quantitativ nachgewiesen werden (vgl. 4.1.3.). Eine Erklärungsmöglichkeit dieser Beobachtung ist, dass die beteiligten Gene zwar unter aeroben Kultivierungs-bedingungen gesteigert, jedoch auch unter fermentativen Wachstumsbedingungen, transkribiert werden. DNAMicroarray-Analysen geben die Verhältnisse von Genexpressionen an, hierzu ist jedoch eine Transkription der $\mathrm{zu}$ untersuchenden Gene unter beiden gewählten Versuchsbedingungen notwendig. In diesem Zusammenhang gilt es zu erwähnen, dass die Synthese der $\alpha$-Acetolactat-Synthase (alsS) in B. subtilis durch Acetat im Medium induziert wird (Holtzclaw \& Chapman, 1975). Ebensolches ist auch für Enterobakterien beschrieben worden (Böck \& Sawers, 1996).

Zusammenfassend kann also noch mal erläutert werden, dass die Transkriptionsanalysen des fermentativen Wachstums in B. licheniformis DSM13 gezeigt haben, dass Gene, welche an der Synthese von Fermentationsprodukten beteiligt sind, unter anaeroben Bedingungen gesteigert transkribiert wurden. Lediglich die Gene pta und ackA, welche an der Bildung von Acetat beteiligt sind, bilden hier eine Ausnahme. Alle in diesem Zusammenhang beschriebenen möglichen Fermentationsendprodukte konnten im Kulturüberstand von anaerob kultivierten B. licheniformis Zellen detektiert werden. Neben der qualitativen Bestimmung von Acetoin und Ethanol, konnten sowohl die Hauptfermentationsprodukte 2,3-Butandiol und Formiat, wie auch Lactat, Glycerol und Acetat quantitativ bestimmt werden (vgl. 
4.1.3.). Basierend auf der Konzentration des am zweithäufigsten gebildeten Endproduktes neben 2,3-Butandiol können Organismen in diol- $\mathrm{H}_{2}$ Produzenten, diol-Glycerol Produzenten und diol-Formiat Produzenten eingeteilt werden (Böck \& Sawers, 1996). Aufgrund der Analysen der Kulturüberstände fermentativ kultivierter Zellen, kann man DSM13 letzterer Gruppe zuordnen.

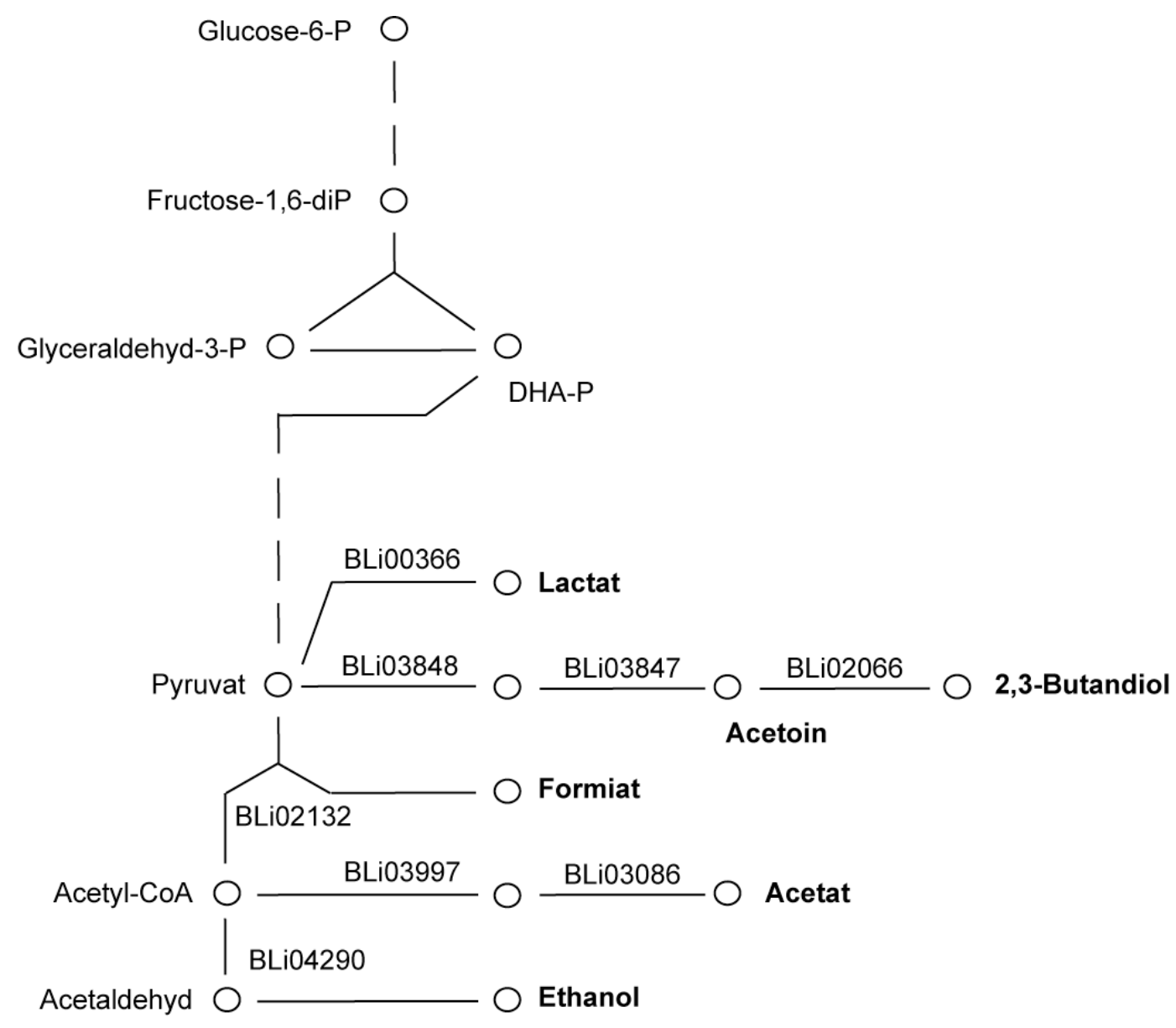

Abbildung 5.3: Darstellung von Genen, welche an der Produktion von Fermentationsendprodukten beteiligt sind. Die Zuordnung basiert auf den in den Transkriptionsanalysen ermittelten Genexpressionswerten. Fermentationsprodukte sind fett hervorgehoben. BLi00366, LactatDehydrogenase; BLi03848, $\alpha$-Acetolactat-Synthase; BLi03847, $\alpha$-Acetolactat-Decarboxylase; BLi02066, Acetoin-Reduktase; BLi02132, putative Formiat-Acetyltransferase / putative Pyruvat-Formiat-Lyase; BLi03997, Phosphotransacetylase; BLi03086, Acetat-Kinase; BLi04290, AlkoholDehydrogenase/Acetaldehyd-Dehydrogenase 
In Abbildung 5.3 sind einmal zusammenfassend alle an der Bildung von den im Rahmen dieser Arbeit detektierten Fermentationsprodukten beteiligten Gene dargestellt. Grundlage dieser Zuordnung bilden die in den vergleichenden Genexpressionsanalysen ermittelten Daten. Der genaue Reaktionsmechanismus zur Bildung von Glycerol bedarf noch weiterer Untersuchungen und ist aus diesem Grund hier nicht im Zusammenhang mit der gemischten Säuregärung abgebildet.

\subsection{Wachstum mit C2-Metaboliten}

Zusammen mit weiteren Enzymen des Tricarbonsäurezyklus bilden die putative Isocitrat-Lyase (BLi04207) und die putative Malat-Synthase (BLi04208) den anaplerotischen Glyoxylatzyklus, welcher Organismen dazu befähigt auf C2-Metaboliten zu wachsen. Die Isocitrat-Lyase spaltet zunächst Isocitrat zu Succinat und Glyoxylat. Durch die katalytische Aktivität der Malat-Synthase kondensiert letzteres mit einem weiteren Molekül Acetyl-CoA zu Malat (Abb. 5.4). Hieraus kann wiederum ein zusätzliches Molekül Oxalacetat gebildet werden, welches für biosynthetische Reaktionen zur Verfügung steht.

A

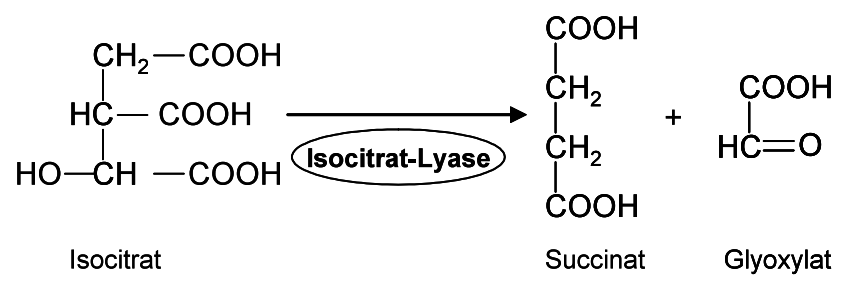

B

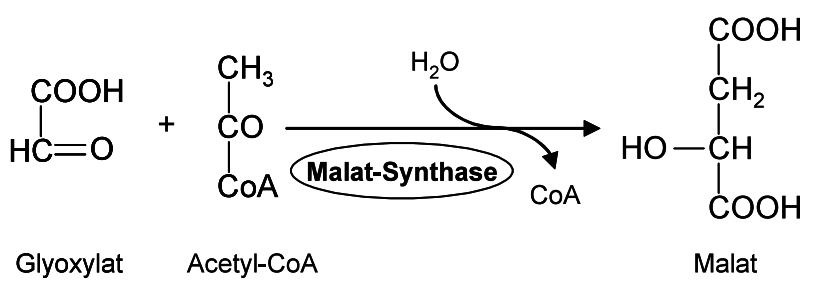

Abbildung 5.4: Anaplerotische Reaktionen des Glyoxylatzyklus. A Spaltung von Isocitrat durch die Isocitrat-Lyase in Succinat und Glyoxylat. B Synthese von Malat aus Glyoxylat und Acetyl-CoA durch die Malat-Synthase (Veith, 2004). 
Eine Induktion des Glyoxylatzyklus wird in Gram-negativen Organismen wie Rhodobacter capsulatus oder E. coli durch Acetat oder langkettige Fettsäuren als einziger C-Quelle beschrieben (Blasco et al., 1991; Vanderwinkel et al., 1963). Im Gegensatz zu diesen Beobachtungen konnte im Gram-positiven Organismus C. glutamicum eine Induktion der Isocitrat-Lyase und der Malat-Synthase durch Acetat als einziger C-Quelle, aber auch durch Acetat im Gemisch mit weiteren C-Quellen gezeigt werden (Reinscheid et al., 1994a; Reinscheid et al., 1994b). B. subtilis hingegen scheint keinen Glyoxylatzyklus zu besitzen, da entsprechende Gene nicht im Genom vorhanden sind und dieser nicht in der Lage ist mit Acetat als einziger C-Quelle zu wachsen. Des Weiteren konnte keine Aktivität der Isocitrat-Lyase und Malat-Synthase nachgewiesen werden (Sonenshein, 2002). Die Synthese dieser beiden Gene konnte hingegen für Bacillus stearothermophilus belegt werden (Chell \& Sundaram, 1975).

B. licheniformis DSM13 ist in der Lage sowohl mit Acetat, als auch mit 2,3-Butandiol als C-Quelle zu wachsen und im Rahmen der hierzu durchgeführten Transkriptionsanalysen konnten ähnliche Expressionsmuster für das Wachstum mit Acetat bzw. 2,3-Butandiol ermittelt werden (vgl. 4.2.). Im Vergleich zur Kultivierung mit Glucose waren neben den bereits angesprochen ORFs BLi04207 (Isocitrat-Lyase) und BLi04208 (Malat-Synthase) ebenfalls die Gene $p c k A$, acs $A$ und $c i t B$ sowohl beim Wachstum mit Acetat, als auch mit 2,3-Butandiol induziert.

Die Phosphoenolpyruvat-Carboxykinase (EC 4.1.1.49), kodiert durch pckA (BLi03197), katalysiert die Bildung von Phosphoenolpyruvat (PEP) aus Oxalacetat und ATP [5.1]. Alle Reaktionen der Glykolyse zwischen PEP und dem Fructose-1,6bisphoshat sind reversibel. Somit stellt PEP den Vorläufer der Gluconeogenese dar (Gottschalk, 1986), in welcher das Grundgerüst für die Synthese von Vitaminen oder Nukleinsäuren entsteht.

Oxalacetat + ATP $<=>$ Phosphoenolpyruvat $+\mathrm{ADP}+\mathrm{CO}_{2}$

In diesem Kontext gilt es zu erwähnen, dass zwei mögliche Wege zur Aktivierung von Acetat beschrieben wurden. Zum einen kann die Synthese von Acetyl-CoA, ausgehend vom Acetat, über das Zwischenprodukt Acetylphosphat von der AcetatKinase (AckA) und der Phosphotransacetylase (Pta) erfolgen. Der zweite, direkte Weg wird durch die Acetyl-CoA-Synthetase (AcsA) katalysiert (Abb. 5.5). Gemeinsam mit 
den Genen des Glyoxylatzyklus (aceA, aceB) werden in C. glutanicum ackA und pta induziert (Wendisch et al., 1997). Die in DSM13 durchgeführten Transkriptionsanalysen deuten hingegen auf eine Aktivierung des Acetats durch die Acetyl-CoASynthetase (AcsA) hin (vgl. 4.2.). Dieses deckt sich mit Beobachtungen die sowohl in E. coli, als auch in B. subtilis gemacht wurden. Die Acetataktivierung erfolgt in E. coli ebenfalls hauptsächlich durch die Acetyl-CoA-Synthetase (Brown et al., 1977; Oh et al., 2002). Auch wenn B. subtilis nicht in der Lage ist mit Acetat als einziger C-Quelle zu wachsen, so konnte dennoch durch Inaktivierung des kodierenden Gens acs $A$ gezeigt werden, dass die Acetyl-CoA-Synthetase in die Verwertung von Acetat involviert ist (Grundy et al., 1993b).

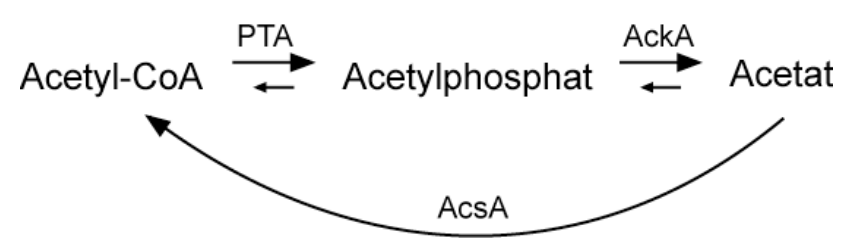

\begin{abstract}
Abbildung 5.5: Aktivierung von Acetat in DSM13. Basierend auf der komparativen Genexpressionsanalyse beim Wachstum mit Acetat bzw. Glucose. Erläuterung im Text (adaptiert von B. subtilis, Grundy et al., 1993a).
\end{abstract}

Die ersten drei Enzyme des Tricarbonsäurezyklus katalysieren die Kondensation von Oxalacetat und Acetyl-CoA zu Citrat und die anschließende Isomerisierung und Oxidation von letzterem zu 2-Oxoglutarat. Die Isomerisierung von Citrat zu Isocitrat wird hierbei von der Aconitat-Hydratase katalysiert. In B. subtilis wird dieses durch citB kodierte Enzym durch Citrat bzw. Vorläufern von Citrat, wie Aspartat, induziert (Ohné, 1974). Die synergistische Repression des Enzyms durch Glucose und Glutamat wird mit einer upstream des Promoters liegenden Region assoziiert (Fouet et al., 1990; Fouet \& Sonenshein, 1990; Rosenkrantz et al., 1985). Daneben lassen Untersuchungen vermuten, dass 2-Oxoglutarat bzw. N-Quellen, welche zu 2-Oxoglutarat umgewandelt werden können, ebenfalls in die Regulation des citB-Gens involviert sind (Blencke et al., 2006; Fisher \& Magasanik, 1984). Die Transkriptionsanalysen in DSM13 haben eine erhöhte Expression von citB beim Wachstum mit Acetat bzw. 2,3-Butandiol im Vergleich zur Kultivierung mit Glucose gezeigt (vgl. 4.2.). Es konnte jedoch noch nicht geklärt werden, ob diese Induktion auf Citrat zurückzuführen ist, da sowohl Acetat, als 
auch 2,3-Butandiol über Acetyl-CoA in den Tricarbonsäurezyklus einmünden, oder ob es sich um den Effekt der Repression unter Referenzbedingungen handelt. Ergänzend muss hinzugefügt werden, dass in vorangegangenen analogen Experimenten keine erhöhte Expression dieses Gens beobachtet wurde (Veith, 2004).

Der Katabolismus von Acetoin wurde in einer Reihe von Acetoinverwertenden Bakterien, wie Pelobacter carbinolicus (Oppermann et al., 1991; Oppermann \& Steinbüchel, 1994), Clostridium magnum (Krüger et al., 1994), Klebsiella pneumoniae (Deng et al., 1994) oder auch Alcaligenes eutrophus (Priefert et al., 1991) charakterisiert. Gemeinsam ist diesen Organismen, dass der Acetoin-Abbau durch das Acetoin-Dehydrogenase Enzymsystem (AoDH ES) katalysiert wird. Dieses besteht aus der Thiamin $\mathrm{PP}_{\mathrm{i}}$ abhängigen Acetoin-Dehydroganase (AoDH E1), der Dihydrolipoamid-Acetyltransferase (AoDH E2) und der Dihydrolipoamid-Dehydrogase (AoDH E3) (Oppermann et al., 1991; Oppermann \& Steinbüchel, 1994). Die strukturellen Gene des Acetoin-Dehydrogenase Enzymsystems acoA ( $\alpha$-Untereinheit von AoDH E1), $a c o B$ ( $\beta$-Untereinheit von AoDH E1), acoC (AoDH E2) und acoL (AoDH E3) sind in P. carbinolicus (Oppermann \& Steinbüchel, 1994), C. magnum (Krüger et al., 1994) und K. pneumoniae (Deng et al., 1994) in einem Gencluster angeordnet.

Unter den Genen, welche im Rahmen der in dieser Arbeit durchgeführten DNA-Microarray-Analysen ebenfalls beim Wachstum mit Acetat bzw. 2,3-Butandiol induziert waren, konnten eben diese Gene $a c o A B C L$ identifiziert werden. Im Genom von DSM13 ist auch noch das $а с u A B C$ Gencluster vorhanden, das am Acetoin-Abbau beteiligt zu sein scheint. Lokalisiert ist dieses in direkter Nachbarschaft zum Gen der Acetyl-CoA-Synthetase (acsA). Beide Gencluster weisen in B. subtilis keine Ähnlichkeit zueinander auf (Huang et al., 1999) und die Rolle von $a c u A$ scheint in einer Modifikation der Acetyl-CoA-Synthetase zu bestehen. Eine Inaktivierung von acuA führt zur schlechteren Verwertung von Acetoin (Grundy et al., 1993b), die Inaktivierung von aco $A$ hingegen bringt die Acetoinverwertung zum Erliegen. Diese führt zu der Schlussfolgerung, dass es sich bei der von den aco-Genen kodierte AcetoinDehydrogenase um das essentielle Enzym des Acetoin-Abbaus handelt (Huang et al., 1999). Weiterführende Studien haben gezeigt, dass die Transkription des aco-Operons in B. subtilis in Gegenwart von Acetoin induziert und abhängig von AcoR und dem Sigmafaktor L (SigL) ist (Ould Ali et al., 2001). In der DNA-Sequenz von 
B. licheniformis DSM13 konnte ebenfalls die Consensussequenz des SigL (BLi03678) Bindemotivs (Helmann \& Moran, 2002) vor dem Gen acoA ermittelt werden (Veith, 2004). Zusammenfassend lassen die erläuterten Untersuchungen einen ähnlichen Regulationsmechanismus wie er für B. subtilis beschrieben ist, auch in DSM13 vermuten.

Der einleitende Schritt zur Verwertung von 2,3-Butandiol wird durch die Butandiol-Dehydrogenase katalysiert. In früheren Untersuchungen wurden mögliche Kandidaten einer Butandiol-Dehydrogenase aufgrund ihrer Genexpression beschrieben (Veith, 2004). Es konnte jedoch keine Übereinstimmung mittels BLAST-Analyse sowohl auf Nukleotid- wie Aminosäureebene mit der in B. subtilis (Nicholson, 2008) beschriebenen Butandiol-Dehydrogenase in DSM13 ermittelt werden (Daten nicht gezeigt). Untersuchungen in Aerobacter aerogenes haben hingegen gezeigt, dass die Acetoin-Reduktase bei einem hohen $\mathrm{NAD}^{+} / \mathrm{NADH}-$ Verhältnis auch als ButandiolDehydrogenase agieren kann (Böck \& Sawers, 1996). Unter den gewählten Versuchsbedingungen für die Transkriptionsanalysen in DSM13 konnte keine Induktion des ORFs der Acetoin-Reduktase (BLi02066) beim Wachstum mit 2,3-Butandiol beobachtet werden (vgl. 4.2.4., Abb. 4.12). Analysen des Kulturüberstandes vergleichbarer Experimente lassen vermuten, dass DSM13 zum Zeitpunkt der Zellernte für die RNA-Präparation kein bzw. nur geringe Mengen 2,3-Butandiol zur Bildung von Zellmasse nutzt. Es konnte hingegen ein Verbrauch des zuvor akkumulierten Acetoin detektiert werden (vgl. 4.2.3., Abb. 4.11). Hiermit geht die bereits erläuterte Induktion der Gene des aco-Operons und des zugehörigen transkriptionalen Aktivators beim Wachstum mit 2,3-Butandiol konform.

Ergänzend soll in diesem Zusammenhang noch erwähnt werden, dass die anhand von vorangegangenen PCR-basierenden Transkriptionsanalysen ermittelte erhöhte Expression, sowohl beim Wachstum mit Acetat, als auch beim Wachstum mit 2,3-Butandiol, im Rahmen dieser Arbeit in vergleichbar durchgeführten Experimenten, in denen Oligo-basierende DNA-Microarrays zum Einsatz kamen, für eine Auswahl an Genen reproduziert werden konnten (siehe Tab. 7.10 im Anhang, vgl. Veith, 2004). In diesem Kontext wurden lediglich die Ergebnisse des für die Aconitat-Hydratase kodierende Gen citB nicht bestätigt. Diese Ergebnisse unterstreichen nochmals die bereits unter 4.5. beschriebene Reproduzierbarkeit von DNA-Microarray-Analysen. Die qualitativ deutliche Erhöhung der Genexpression der Isocitrat-Lyase und der Malat- 
Synthase wurde bereits unter Einsatz der real-time RT-PCR für das Wachstum mit Acetat im Vergleich zum Wachstum mit Glucose verifiziert (Veith, 2004).

\subsection{Wachstum mit Aminosäuren}

Aminosäuren bzw. Gemische von diesen können unter verschiedenen Bedingungen als Stickstoff-, Kohlenstoff- und Energiequelle für das bakterielle Wachstum dienen. Der Verbrauch der einzelnen Aminosäure ist von verschiedenen Parametern, wie der Verfügbarkeit weiterer Energiequellen oder des Kohlenstoff/Stickstoff-Verhältnisses abhängig. Um diese Thematik näher zu beleuchten wurde ein definiertes Medium zusammengestellt, welches in der Zusammensetzung der Aminosäuren der Sojabohne nachempfunden war. Zuvor wurde jedoch untersucht, welche proteinogenen Aminosäuren als Stickstoff- und Kohlenstoffquelle dienen können. Wachstumsexperimente haben gezeigt, dass B. licheniformis DSM13 sieben der 18 untersuchten proteinogenen Aminosäuren als Stickstoff- und Kohlenstoffquelle verwenden kann (vgl. 4.3.1.1.). Diese waren im Einzelnen L-Alanin, L-Arginin, L-Asparagin, L-Aspartat, L-Glutamin, L-Glutamat und L-Prolin. Weiterhin war es DSM13 möglich die nicht-proteinogene Aminosäure L-Ornithin als Stickstoff- und Kohlenstoffquelle zu nutzen (Daten nicht gezeigt). Anhand von Transkriptionsanalysen beim Wachstum mit diesen einzelnen Aminosäuren bzw. Gemischen von Aminosäuren wurden erhöhte Expressionswerte von Genen die im Zusammenhang mit ihrer Verwertung stehen verzeichnet. Basierend hierauf wurden die Aminosäuren bezüglich ihres Einmündens in den Zentralstoffwechsel in Gruppen eingeteilt. Die erste Gruppe enthält L-Alanin, die zweite Gruppe besteht aus L-Asparagin und L-Aspartat. Aminosäuren, welche wiederum über L-Glutamat in den Zentralmetabolismus einmünden, können in einer dritten Gruppe zusammengefasst werden. Unter Berücksichtigung der proteinogenen Aminosäuren sind dieses L-Glutamin, L-Glutamat, L-Arginin und L-Prolin. Letztere beiden nehmen aufgrund ihres gemeinsamen Intermediaten $\Delta^{1}$-Pyrrolin-5-Carboxylat eine Sonderstellung ein. 


\section{L-Alanin}

Der Abbau von L-Alanin zu Pyruvat und Ammoniak wird von der L-AlaninDehydrogenase (ald) katalysiert. Induziert wird diese in B. subtilis und B. licheniformis durch die Zugabe von Alanin zum Medium (Berberich et al., 1968, McCowen \& Phibbs, 1974, Schreier et al., 1982). Daneben können aber noch zusätzlich 10 weitere L-Aminosäuren, sowie 11 D-Aminosäuren dieses Enzym in B. subtilis induzieren. Unter diesen 10 L-Aminosäuren sind neben den verzweigtkettigen Aminosäuren Isoleucin, Leucin und Valin, auch Threonin und Methionin $\mathrm{zu}$ finden. Nach Berberich et al. resultiert die Induktion von ald durch die weiteren Aminosäuren dabei durch die Umwandlung dieser entweder zu L-Alanin oder D-Alanin durch Transamination (Berberich et al., 1968). Die eigentliche Induktion scheint jedoch durch D-Alanin zu erfolgen, da nur durch D-Alanin und die weiteren D-Aminosäuren die Expression von ald in einer Alanin-Racemase Mutante induziert wird (Fisher, 1993). Das Enzym Alanin-Racemase wandelt Alanin von der L- in die D-Konfiguration um. Salmonella typhimurium kann L-Alanin sowohl als alleinige Kohlenstoffquelle, als auch als alleinige Stickstoffquelle nutzen. E. coli hingegen kann sowohl L-Alanin, als auch D-Alanin als Kohlenstoff- und Energiequelle nutzen (McFall \& Newman, 1996). L-Alanin wird zunächst durch eine spezifische Racemase zu D-Alanin umgewandelt und letzteres, katalysiert durch eine D-Aminosäure-Dehydrogenase, zu Pyruvat und Ammonium umgesetzt (McFall \& Newman, 1996).

Auch für $B$. licheniformis DSM13 konnte eine erhöhte Expression von ald im Zusammenhang mit der Verwertung von L-Alanin beobachtet werden. Daneben konnte durch die DNA-Microarray-Analysen zusätzlich noch eine Induktion dieses Genes beim Wachstum mit L-Asparagin, L-Arginin, L-Prolin und L-Ornithin ermittelt werden (vgl. 4.3.1.2.1., Tab. 4.14). Beim Wachstum mit einem Gemisch aus 20 Aminosäuren konnte ebenfalls eine Induktion von ald in Verbindung mit einem gesteigerten Verbrauch von L-Alanin beobachtet werden. Der für ein Homolog der L-Alanin-Dehydrogenase kodierender ORF BLi04275 hingegen war konstitutiv induziert. Es konnte nicht nur beim Wachstum mit einzelnen Aminosäuren, sondern auch zu allen gewählten Zeitpunkten bei der Kultivierung mit einem Gemisch von 20 Aminosäuren eine erhöhte Expression im Vergleich zum Wachstum mit Glucose bestimmt werden (vgl. 4.3.1.2.1., Tab. 4.14 und 4.3.2.4., Tab. 4.23). Mitarbeiter um R. W. Bernlohr haben durch Messungen des intrazellularen Aminosäure-Pools in B. licheniformis gezeigt, dass 
Glutamat und Alanin 60 - 90\% der gesamten freien intrazellulären Aminosäuren ausmachen. Einschränkend muss hinzugefügt werden, dass die Produktion freier Aminosäuren der Zelle abhängig von der Zusammensetzung des Mediums und der Wachstumsphase ist (Clark et al., 1972). Eine signifikante Änderung der Expression des für die D-Alanin-Racemase kodierenden Gens alr (BLi00551) konnte beim Wachstum mit L-Alanin im Vergleich zum Wachstum mit Glucose für DSM13 nicht ermittelt werden (Daten nicht gezeigt).

\section{L-Asparagin und L-Aspartat}

Das Enzym L-Asparaginase katalysiert die Bildung von L-Aspartat aus L-Asparagin. E. coli synthetisiert zwei verschiedene L-Asparaginasen (Campbell et al., 1967). Bei der Asparaginase I handelt es sich um ein zytoplasmatisches Enzym, welches von dem Gen ansA kodiert wird (Spring et al., 1986; McFall \& Newman, 1996). Das Produkt des Gens ansB, die L-Asparaginase II, hingegen wird in das Periplasma sekretiert und auch nur unter anaeroben Kultivierungsbedingungen synthetisiert (Cedar \& Schwartz, 1967). In B. subtilis ist das kodierende Gen der L-Asparaginase (ansA) zusammen mit dem Gen der L-Aspartase $(a n s B)$ in einem Operon organisiert (Sun \& Setlow, 1991). Letzteres Enzym katalysiert die Umsetzung von L-Aspartat zu Fumarat. Eine Disruption des Gens ansA führte dazu, dass B. subtilis Asparagin nicht als Stickstoffquelle nutzen konnte (Sun \& Setlow, 1991). Die Expression von ansA wird sowohl durch die Anwesenheit von Asparagin oder Aspartat, als auch durch Stickstofflimitation induziert (Sun \& Setlow, 1991; Atkinson \& Fisher, 1991). Weiterführende Untersuchungen haben gezeigt, dass neben ans $A$ auch das Gen ans $Z$ (ehemals $y c c C$ ) für eine funktionale L-Asparaginase in B. subtilis kodiert (Fisher \& Wray, 2002). Die Expression dieser beiden Gene wird jedoch unterschiedlich reguliert. Beim Wachstum mit Asparagin wird das ans $A B$ Operon nicht mehr durch AnsR, dem Repressor des ans-Operons (Sun \& Setlow, 1993), reprimiert und AnsA wird exprimiert. Im Gegensatz dazu wird die Expression von ansZ während stickstofflimitierendem Wachstum durch den Stickstoff-Regulationsfaktor TnrA aktviert (Fisher \& Wray, 2002). TnrA gehört, wie auch GlnR, zur MerR-Familie der transkriptionalen Regulatoren (Fisher \& Débarbouillé, 2002).

Wie für B. subtilis beschrieben ist auch in B. licheniformis DSM13 das Gen der Asparaginase (ansA, BLi04140) mit den Genen der Aspartase (BLi04139) und dem 
Repressor AnsR (BLi04141) assoziiert (vgl. 4.3.1.2.1., Abb. 4.16). Für alle drei Gene konnte sowohl beim Wachstum mit L-Asparagin, als auch mit L-Aspartat eine signifikant erhöhte Expression ermittelt werden. Für die weiteren getesteten Aminosäuren konnte dieses nicht beobachtet werden und steht im Einklang mit den durchgeführten Experimenten zum Wachstum mit Gemischen von Aminosäuren. Nicht nur beim Wachstum mit einem Gemisch aus sieben Aminosäuren, sondern auch mit einem Gemisch aus 20 Aminosäuren konnte bei Anwesenheit von L-Asparagin im Kulturmedium eine Induktion der Gene $a n s A B$ und $a n s R$ bestimmt werden (vgl. 4.3.2.2., Tab. 4.21 und 4.3.2.4., Tab. 4.24). Eine Induktion der yccC Gene (BLi02777 und BLi02778), dessen Produkte ebenfalls Ähnlichkeiten zu Asparaginasen aufweisen, konnte im Zusammenhang mit dem Wachstum auf L-Asparagin nicht beobachtet werden (vgl. 4.3.1.2., Tab. 4.14). Gleiches gilt für die weiteren sieben getesteten Aminosäuren. $\mathrm{Ob}$ die $y c c C$ Gene dennoch für eine funktionale L-Asparaginse in DSM13 kodieren, wurden in dieser Arbeit nicht eingehend untersucht.

Als charakteristisch im Zusammenhang mit der Verwertung von L-Asparagin konnten neben weiteren Genen auch die für die Untereinheiten der PyruvatDehydrogenase kodierenden Gene ermittelt werden (vgl. 4.3.1.2.3., Abb. 4.21). Der Multienzymkomplex der Pyruvat-Dehydrogenase verbindet durch seine katalytische Aktivität die Glykolyse mit dem Tricarbonsäurezyklus. Durch drei enzymatische Reaktionen wird Pyruvat, mit $\mathrm{NAD}^{+}$als Co-Faktor, zu Acetyl-CoA und Kohlendioxid umgesetzt [5.2].

Pyruvat $+\mathrm{CoA}+\mathrm{NAD}^{+}<=>$Acetyl-CoA $+\mathrm{CO}_{2}+\mathrm{NADH}+\mathrm{H}^{+}$

Kodiert werden die Komponenten des Enzymkomplexes von insgesamt vier Genen, wobei $p d h A$ und $p d h B$ für die $\alpha$ - bzw. $\beta$-Untereinheit der Komponente E1, $p d h C$ für die Komponente E2 und $p d h D$ für die Komponente E3 kodieren. Von den acht getesteten Aminosäuren, welche als Stickstoff- und Kohlenstoffquelle dienen können, konnte nur beim Wachstum mit L-Asparagin eine erhöhte Expression dieser Gene beobachtet werden. Gleiches konnte auch beim Wachstum mit einem Gemisch aus sieben Aminosäuren zu einem Zeitpunkt beobachtet werden, wenn L-Asparagin noch im Kulturüberstand nachzuweisen war (vgl. 4.3.2.2., Tab. 4.20). Bestätigt wurden diese Ergebnisse für das Gen $p d h D$ durch real-time RT-PCR. Von den sieben getesteten 
proteinogenen Aminosäuren konnte nur für das Wachstum mit L-Asparagin eine erhöhte Transkription bestimmt werden (vgl. 4.3.1.3.).

Untersuchungen in $B$. licheniformis haben gezeigt, dass im Gegensatz zur Arginase (Simon \& Stalon, 1976) und der Alanin-Dehydrogenase (McCowen \& Phibbs, 1974) die Synthese der Asparaginase in B. licheinformis unter der Kontrolle der Stickstoff-Katabolitrepression steht (Schreier et al., 1982; Golden \& Bernlohr, 1985). Die Arginase und Alanin-Dehydrogenase, sowie die Histidase stehen hingegen in Bacillus spp. unter der Kontrolle der Kohlenstoff-Katabolitrepression (Schreier et al., 1982). Dieses steht im Einklang mit den in dieser Arbeit gemachten Beobachtungen. Beim Wachstum von B. licheniformis DSM13 mit einem Gemisch aus sieben bzw. 20 Aminosäuren wird zunächst L-Asparagin verstoffwechselt. Ein gesteigerte Verbrauch der verbleibenden Aminosäuren ist erst zu ermitteln, wenn kein L-Asparagin mehr im Kulturüberstand zu detektieren ist (vgl. 4.3.2.1. und 4.3.2.3.). Weitere Untersuchungen im Zusammenhang mit der Verwertung von Aminosäuren haben gezeigt, dass die höchste Wachstumsrate von DSM13 in einem definierten Medium mit L-Asparagin als Stickstoff- und Kohlenstoffquelle erzielt wird (Ochieng, 2007). Daneben zeigten die zum Wachstum in einem Gemisch von 20 Aminosäuren durchgeführten Transkriptionsanalysen, dass die Gene der Alanin-Dehydrogenase (ald) und der Arginase $(r o c F)$ in Anwesenheit von L-Asparagin im Medium reprimiert waren (vgl. 4.3.2.4., Tab. 4.23 und Tab. 4.25). Hieraus lässt sich der Schluss ziehen, dass nicht nur die Stickstoff-Katabolitrepression, sondern auch die Kohlenstoff-Katabolit-repression eine Rolle in der Verwertung von L-Asparagin spielt.

\section{L-Glutamin und L-Glutamat}

Die Umwandlung von L-Glutamin zu L-Glutamat kann durch verschiedene Enzyme erfolgen. Zum einen katalysiert die Glutaminase eine Hydrolase-Reaktion, in welcher L-Glutamin zu L-Glutamat und Ammoniak umgesetzt wird. Zum anderen katalysiert die aus zwei Untereinheiten bestehende Glutamatsynthase die Bildung von L-Glutamat. Annotiert wurden zugehörige Gene in DSM13 als gltA (BLi02162) und gltB (BLi02161). Zusammen mit der Glutaminsynthetase $(g \ln A)$ bildet die Glutamatsynthase den sogenannten GOGAT-Zyklus, welcher der Assimilation von Ammonium unter anderem in B. subtilis dient (Wacker et al., 2003). Sowohl die 
Glutamatsynthase, als auch die Glutaminsynthetase konnten bereits in B. licheniformis aufgereinigt werden (Donohue \& Bernlohr, 1981; Schreier \& Bernlohr, 1984).

In den Transkriptionsanalysen für DSM13 beim Wachstum mit einzelnen Aminosäuren konnte keine gesteigerte Expression der kodierenden Gene $g \ln A$ und glt $A B$ verzeichnet werden. Neben weiteren Aminosäuren wie L-Arginin, L-Prolin und L-Ornithin sind diese Gene beim Wachstum mit L-Glutamin reprimiert (vgl. 4.3.1.2.1., Tab. 4.14). Diese unter Referenzbedingungen beobachtete erhöhte Expression lässt sich durch die Zusammensetzung des Mediums der Referenzbedingung erklären. Die Kultivierung erfolgte hierfür in einem definierten Medium mit Glucose als Kohlenstoffund Ammoniumchlorid als Stickstoffquelle. Daraus lässt sich schließen, dass Gene, welche mit der Stickstoffassimilation im Zusammenhang stehen, unter der Referenzbedingung induziert sind. Daneben ist für B. subtilis eine drastisch reduzierte Expression von gltAB beim Wachstum Arginin, Prolin oder Ornithin beschrieben (Belitsky \& Sonenshein, 2004), welches ein weiterer Grund für die in DSM13 ermittelten Expressionsdaten sein kann. Demgegenüber wurde in dieser Arbeit im Rahmen der Untersuchungen mit einzelnen Aminosäuren als Stickstoff- und Kohlenstoffquelle für das Gen $y b g J$ im Zusammenhang mit der Verwertung von Glutamin eine erhöhte Expression ermittelt. Das Produkt dieses Gens weißt Ähnlichkeiten mit einer Glutaminase in DSM13 auf. Frühere Untersuchungen für B. licheniformis hatten gezeigt, dass die Aktivität der Glutamininase von L-Glutamin induziert wird (Cook et al., 1981). In B. subtilis konnte das Gen ybgJ ebenfalls in Verbindung mit der Nutzung von L-Glutamin gebracht werden (Satomura et al., 2005). Basierend auf den in der vorliegenden Arbeit durchgeführten Transkriptionsanalysen lässt sich schließen, dass auch in DSM13 das Gen ybgJ für eine Glutaminase kodiert.

L-Glutamat nimmt eine zentrale Rolle im Stoffwechsel einer Zelle ein. Zum einen im Rahmen der Stickstoffassimilation und zum anderen als Donor der Aminogruppe in der Biosynthese anderer stickstoffhaltiger Komponenten (McFall \& Newman, 1996). Hiermit geht die bereits erläuterte Beobachtung konform, dass Glutamat und Alanin $60-90 \%$ der gesamten freien intrazellulären Aminosäuren von B. licheniformis ausmachen (Clark et al., 1972). Daneben wurde Glutamat als Osmo- und Thermoprotektivum unter anderem für B. subtilis beschrieben (Holtmann \& Bremer, 2004). Der Abbau von L-Glutamat in Enterobakterien kann über verschiedene Wege erfolgen. Zum einen besteht die Möglichkeit L-Glutamat über die Glutamat- 
Dehydrogenase zu 2-Oxoglutarat umzusetzen. Die primäre Funktion dieses Enzyms scheint aber biosynthetischen Zwecken zu dienen (McFall \& Newmann, 1996). Dieses konnte auch für $B$. licheniformis und $B$. cereus beobachtet werden. In zellfreien Extrakten von beiden Organismen konnte spezifische Aktivität einer NADP-abhängigen Glutamatdehydrogenase nachgewiesen werden, jedoch keine NAD-abhängige Aktivität, wie sie für eine ,katabole“ Glutamatdehydrogenase zu erwarten wäre (Phibbs \& Bernlohr, 1971). Ein weiterer und der bevorzugte Weg des Abbaus von L-Glutamat in E. coli erfolgt über Transaminierung (Marcus \& Halpern, 1969). Hierbei werden zunächst L-Glutamat und Oxalacetat durch die Aspartat-Aminotransferase zu 2-Oxoglutarat und L-Aspartat umgesetzt. Letzteres kann im Weiteren, katalysiert durch die Aspartase, zu Fumarat umgewandelt werden.

Im Rahmen der durchgeführten DNA-Microarray-Analysen wurde für B. licheniformis DSM13 beim Wachstum mit L-Glutamat keine signifikante Änderung der Expression für das Gen der Aspartat-Aminotransferase ( $\operatorname{spp} B$ ) beobachtet. Die in Verbindung mit den Transkriptionsanalysen ermittelten Intensitäten der einzelnen Kanäle lassen jedoch den Schluss zu, dass das Gen der Aspartat-Aminotransferase unter beiden Kultivierungsbedingungen, d.h. sowohl beim Wachstum mit L-Glutamat, als auch mit Glucose induziert ist (Daten nicht gezeigt). Dieses wiederum ist ein Hinweis darauf, dass auch in B. licheniformis DSM13 das Gen aspB in den Abbau von Glutamat involviert ist.

\section{L-Arginin und L-Prolin}

In B. licheniformis sind unterschiedliche Wege zum Abbau von L-Arginin bekannt (Cunin et al., 1986). Zum einen kann L-Arginin über L-Ornithin zu GlutamatSeminaldehyd bzw. $\Delta^{1}$-Pyrrolin-5-Carboxylat und im Weiteren zu Glutamat umgesetzt werden (Abb. 5.6). 


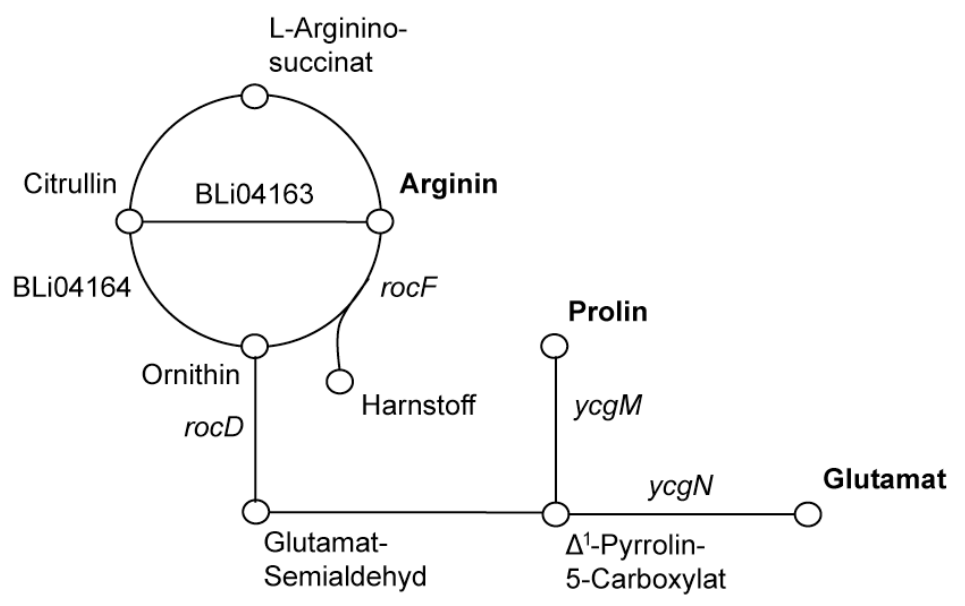

Abbildung 5.6: Darstellung des Harnstoffzyklus und beteiligter Enzyme. Die proteinogenen Aminosäuren sind fett hervorgehoben. Die Zuordnung der Gene erfolgte auf Basis der mittels DNAMicroarray-Analysen ermittelten Genexpressionsverhältnissen. BLi04163, Arginin-Deiminase; BLi04164, Ornithin-Carbamoyltransferase; $r o c F$, Arginase; rocD, Ornithin-Aminotransferase; $y c g N$, $\Delta^{1}$-Pyrrolin-5-Carboxylat-Dehydrogenase; ycgM, Prolin-Oxidase.

Katalysiert werden die ersten beiden Reaktionen durch die Enzyme Arginase und Ornithin-Transaminase. Eine Induktion dieser beiden Enzyme kann sowohl durch Arginin, als auch Ornithin erfolgen (Laishley \& Bernlohr, 1968). Es wurde in diesem Zusammenhang ebenfalls beobachtet, dass Prolin nicht nur die Prolin-Oxidase, sondern auch die Arginase induziert. Arginin wiederum induziert auch die Prolin-Oxidase. Diese Beobachtungen stehen im Einklang mit den für das Wachstum mit einzelnen Aminosäuren durchgeführten Transkriptionsanalysen dieser Arbeit. Sowohl bei der Kultivierung von DSM13 Zellen mit L-Arginin, als auch mit L-Prolin und L-Ornithin konnte eine signifikant erhöhte Expression der Gene ycgMN und rocDF im Vergleich zum Wachstum mit Glucose ermittelt werden (vgl. 4.3.1.2.1., Tab. 4.14). Hierbei kodieren $y c g M N$ für ORFs, welche Ähnlichkeiten zur Prolin-Oxidase ( $y c g M)$ und $\Delta^{1}$-Pyrrolin-5-Carboxylat-Dehydrogenase $(y c g N)$ zeigen und $r o c D F$ für eine OrnithinAminotransferase $(r o c D)$ und eine Arginase $(r o c F)$. Zwischen $r o c D$ und $r o c F$ ist das für eine Aminosäurepermease kodierende Gen rocE im Genom von DSM13 lokalisiert. Upstream von rocDEF befindet sich das Gen rocR (Abb. 5.7), welches für den zugehörigen transkriptionalen Aktivator kodiert. 


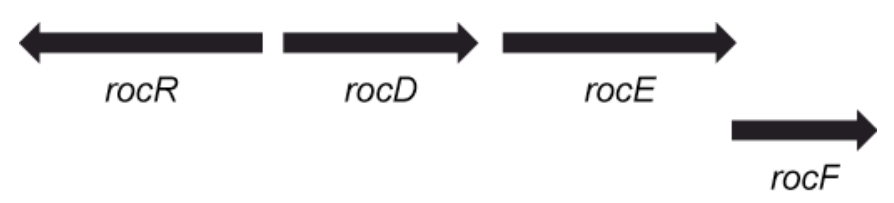

\begin{abstract}
Abbildung 5.7: Genetische Anordnung, der im Zusammenhang mit der Verwertung von Arginin stehenden Gene. Im Genom von DSM13 sind die kodierenden Gene der Ornithin-Aminotransferase $(r o c D)$ und der Arginase (rocF) zusammen mit dem Genen einer Aminosäurepermease (rocE) und einem transkriptionalen Aktivator (rocR) lokalisiert.
\end{abstract}

Neben den Genen rocABC, rocDEF und $\operatorname{roc} G$ (Belitsky \& Sonenshein, 1998; Calogero et al., 1994; Gardan et al., 1995) ist auch der transkriptionale Regulator RocR in der Verwertung von Arginin in B. subtilis involviert (Calogero et al., 1994, Ould Ali et al., 2003). Die Expression von rocDEF wird durch Arginin, Ornithin oder Prolin induziert und ist vom Sigmafaktor L abhänging. Eine Mutation in $\operatorname{roc} D$, aber auch in rocF führt dazu, dass Arginin nicht mehr durch B. subtilis verwertet werden kann. Durch eine Null-Mutation in rocR wird das rocDEF-Operon nicht mehr transkribiert. Des Weiteren konnte gezeigt werden, dass rocR nicht durch Arginin induziert wird (Gardan et al., 1995). In diesem Kontext ist es erwähnenswert, dass sich sowohl upstream des Promotors von $\operatorname{roc} A B C$, als auch von rocDEF ähnliche inverted repeats (UAS1 und UAS2) befinden, welche als Bindungstellen für RocR dienen (Gardan et al., 1995). Wie bereits für das rocDEF-Operon beschrieben, so wird auch das putative rocABC-Operon durch Arginin induziert und ist Sigma L abhängig (Calogero et al., 1994). Aktivitätsmessungen haben gezeigt, dass es sich bei dem Produkt von rocA um eine Pyrrolin-5-Carboxylat-Dehydrogenase handelt. Upstream von rocA ist das Gen der katabolen Glutamat-Dehydrogenase, $r o c G$, lokalisiert (Belitsky \& Sonenshein, 1998 \& 1999).

Wie soeben für $B$. subtilis erörtert, konnte auch anhand der Transkriptionsanalysen in $B$. licheniformis keine Induktion von rocR durch L-Arginin, daneben aber auch keine Induktion durch L-Prolin ermittelt werden. Reprimiert hingegen war das Gen $\operatorname{roc} G$, nicht nur beim Wachstum mit L-Arginin, sondern auch mit L-Prolin oder L-Ornithin. In diesem Zusammenhang gilt es zu erwähnen, dass auch in DSM13 vor dem Gen rocD ein SigL Bindemotiv gefunden wurde (Veith, 2004). Im Unterschied $\mathrm{zu}$ B. subtilis sind in DSM13 die Gene der katabolen Glutamat- 
Dehydrogenase und der $\Delta^{1}$-Pyrrolin-5-Carboxylat-Dehydrogenase nicht im Genom nebeneinander lokalisiert (vgl. 4.3.1.2.1., Abb. 4.19). Ob es sich dennoch um ähnliche Regulationsmechanismen handelt müssen weitere Experimente zeigen. Mit Hinblick auf eine möglichen Rolle von $\sigma^{\mathrm{L}}$ in der Regulation der Verwertung von Aminosäuren, sollte kurz erläutert werden, dass die Transkription von $\sigma^{54}$ abhängigen Promotoren die $\sigma^{54}$-Form der RNA-Polymerase und ein enhancer Protein, welches mit einer upstream liegenden Aktivierungssequenz (UAS) interagiert, benötigt (Fisher \& Débarbouillé, 2002). Unter den in B. subtilis beschriebenen $\sigma^{\mathrm{L}}$ abhängigen Aktivatoren sind neben LevR (Débarbouillé et al., 1991), RocR (Calogero et al., 1994), AcoR (Huang et al., 1999, Ould Ali et al., 2003), auch BkdR (Débarbouillé et al., 1999) zu finden. Im Gegensatz zu dem transkriptionalen Aktivatorprotein NtrC der Enterobakterien vermitteln die SigL transkriptionalen Aktivatoren von B. subtilis eine Substratabhängige Induktion (Fisher \& Débarbouillé, 2002). Eine Sigma L-defizite Mutante in B. subtilis kann weder Arginin, noch Ornithin verwerten (Calogero et al., 1994).

Der eben geschilderte Abbauweg des L-Arginins über die Arginase wird unter aeroben Wachstumsbedingungen von $B$. licheniformis bevorzugt. Der zweite für diesen Organismus beschriebene Weg der Verwertung von L-Arginin erfolgt über die ArgininDeiminase (Broman et al., 1978). Dieses Enzym setzt zunächst L-Arginin zu L-Citrullin um, welches anschließend, katalysiert durch die Ornithin-Carbamoyltransferase, zu L-Ornithin und Carbamoylphosphat umgewandelt wird. In einem letzten durch die Carbamat-Kinase katalysierten Schritt kann die Phosphat-Gruppe des Carbamoylphosphats ein ADP zu ATP phosphorylieren. Eine Induktion dieses Abbauweges erfolgt unter anaeroben Kultivierungsbedingungen in Anwesenheit von Arginin. Die Klonierung und Sequenzierung der zugehörigen Gene ergab, dass diese in einer operonähnlichen Struktur in B. lichenformis vorliegen (Maghnouj et al., 1998). Dieses konnte während der Analysen des Genoms von B. licheniformis bestätigt werden. Anders als die veröffentlichten ORF-Bezeichnungen des Göttinger Genomlabors (BLi04162 bis BLi04166) sind bei der von Novozymes Biotech Inc parallel durchgeführten Sequenzierung von DSM13 die von Maghnouj et al. beschriebenen Genbezeichnungen zu finden (Abb. 5.8). 


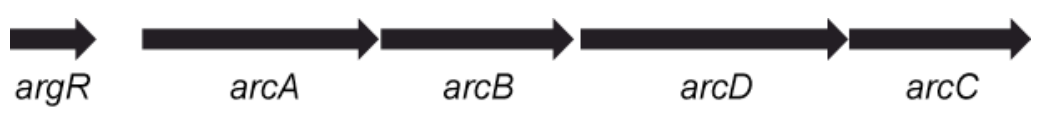

\begin{abstract}
Abbildung 5.8: Genregion der Arginin-Deiminase in B. licheniformis. Erläuterungen der Genprodukte nach Maghnouj et al. (1998). $\arg R$ (BLi04162) - Arginin-Repressor, $\operatorname{arcA}$ (BLi04163) - ArgininDeiminase, $\operatorname{arcB}$ (BLi04164) - Ornithin-Carbamoyltransferase, $\operatorname{arcD}$ (BLi04165) - putativer ArgininOrnithin-Antiporter, $\operatorname{arcC}$ (BLi04166) - Carbamat-Kinase
\end{abstract}

Im Zusammenhang mit dem in dieser Arbeit durchgeführten Untersuchungen zum Wachstum auf einzelnen Aminosäuren als Stickstoff- und Kohlenstoffquelle konnte, wie zu vermuten war, keine erhöhte Expression für die ORFs der Arginin-Deiminase ( $\operatorname{arcA}, \mathrm{BLi04163)}$ und der Ornithin-Carbamoyltransferase $(\operatorname{arcB}, \mathrm{BLi} 04164)$ beim Wachstum mit L-Arginin ermittelt werden (vgl. 4.3.1.2.1., Tab. 4.14). In diesem Kontext zeigte auch das Gen des putativen Arginin-Ornithin-Antiporters $(\operatorname{arc} D$, BLi04165) keine signifikante Änderung des Expressionsverhältnisses (Daten nicht gezeigt). Des Weiteren konnten weder für das kodierende Gen des Arginin-Repressors $(\arg R$, BLi04162), noch für das Gen der Carbamat-Kinase ( $\operatorname{arcC}, \mathrm{BLi04166)}$ Expressionsdaten ermittelt werden. Im Gegensatz hierzu konnten bei der Kultivierung von DSM13 Zellen mit einem Gemisch aus 20 Aminosäuren für diese Gene zu verschiedenen Zeitpunkten Änderungen der Genexpression ermittelt werden. Der ORF der Arginin-Deiminase war zu allen fünf gewählten Zeitpunkten induziert. Eine signifikant erhöhte Expression für die ORFs des putativen Arginin-Ornithin-Antiporters und der Carbamat-Kinase konnte für die Zeitpunkte T2 und T3 und im Fall der Ornithin-Carbamoyltransferase sogar zusätzlich zum Zeitpunkt T5 ermittelt werden. Für den ORF des Arginin-Repressors konnte für die Zeitpunkte T2 bis T5 eine erhöhte Expression verzeichnet werden (vgl. 4.3.2.4., Tab. 4.25). DNase I footprinting Daten haben gezeigt, dass das gereinigte Protein des Repressors ArgR an eine Sequenz upstream vom arcA Promoter bindet (Maghnouj et al., 1998). Unter Sauerstoffausschluss und in Gegenwart von Arginin können $\operatorname{argR}$ Mutanten den Abbauweg über die Arginin-Deiminase nicht induzieren. Diese Beobachtungen lassen vermuten, dass es sich bei ArgR um den Aktivator dieses Abbauweges handelt (Maghnouj et al., 1998). Der Grund, weshalb unter den in dieser Arbeit gewählten 
Versuchsbedingungen die Gene des Abbauweges über die Arginin-Deiminase induziert waren, konnte bisher nicht geklärt werden.

Anders als für B. subtilis beschrieben (Cruz-Ramos et al., 1997), konnte im Rahmen des Genomprojektes für B. licheniformis DSM13 keines der strukturellen Gene der Urease (ure $A B C$; Mobley et al., 1995) identifiziert werden. Die Urease katalysiert die Umsetzung von Harnstoff zu Ammoniak und Carbamat. Letzteres wird spontan zu einem weitern Molekül Ammoniak und Kohlensäure abgebaut. Gebildet wird Harnstoff unter anderem in der durch die Arginase katalysierten Abbaureaktion von Arginin zu Ornithin. Zur experimentellen Überprüfung wurde DSM13 in einem definierten Medium mit Harnstoff als Stickstoff- und Kohlenstoffquelle kultiviert. Um zu ermitteln, ob DSM13 Harnstoff als Stickstoffquelle nutzen kann, wurde B. licheniformis in einem definierten Medium mit Glucose bzw. Xylose kultiviert. Wie zu erwarten, konnte Harnstoff weder als Stickstoff-, noch als Kohlenstoffquelle von DSM13 genutzt werden (Daten nicht gezeigt). Dieses geht mit der Beobachtung konform, dass sowohl beim Wachstum mit einem Gemisch aus sieben Aminosäuren, als auch mit einem Gemisch aus 20 Aminosäuren eine Akkumulation von Harnstoff im Kulturüberstand zu detektieren war (vgl. 4.3.2.1. und 4.3.2.3.).

Der Abbau von L-Prolin erfolgt über zwei enzymatische Schritte. Zunächst wird L-Prolin zu $\Delta^{1}$-Pyrrolin-5-Carboxylat und im Anschluss daran zu L-Glutamat umgesetzt. In DSM13 wurden zwei Gene identifiziert, welche an diesen Schritten beteiligt sind. Das Produkt von ycgM weißt Ähnlichkeiten zu einer Prolin-Oxidase auf und das von $y \operatorname{cgN}$ zu einer $\Delta^{1}$-Pyrrolin-5-Carboxylat-Dehydrogenase. Im Genom von DSM13 sind diese nebeneinander lokalisiert. In S. typhimurium werden die beiden enzymatischen Aktivitäten von einem einzelnen Gen, putA, kodiert (Ratzkin \& Roth, 1978). Die Aufnahme von L-Prolin in E. coli und S. typhimurium erfolgt hauptsächlich über eine induzierbare L-Prolin-Permease. Das kodierende Gen, putP, ist angrenzend zu putA lokalisiert (McFall \& Newman, 1996; Wood, 1981). Auch in DSM13 ist downstream von ycgMN ein Gen ycgO lokalisiert, dessen Produkt Ähnlichkeit mit einer Prolin-Permease aufweist. Beim Wachstum mit den proteinogenen Aminosäuren L-Arginin bzw. L-Prolin wurde neben ycgMN auch für $y c g O$ eine erhöhte Expression ermittelt. Gleiches konnte auch beim Wachstum mit L-Ornithin beobachtet werden (Tab. 7.4 im Anhang). Die Transkriptionsanalysen beim Wachstum in einem definierten Medium mit einem Gemisch aus 20 Aminosäuren lassen eine Induktion für $y c g O$ in 
Abhängigkeit von L-Prolin vermuten. Eine erhöhte Expression dieses Gens konnte nicht mehr ermittelt werden, wenn nur noch geringe Mengen von L-Prolin im Kulturüberstand zu detektieren waren (vgl. 4.3.2.4.)

Neben der Verwertung von L-Prolin als Kohlenstoff- und Stickstoffquelle kann dieses auch als Osmoprotektant dienen (Wood, 1988). Der Transport von Prolin als osmoprotektive Substanz erfolgt in B. subtilis durch das OpuE-Transportsystem (von Blohn et al., 1997). Beim Wachstum von DSM13 mit den drei oben genannten Aminosäuren war der kodierende ORF BLi00728 im Vergleich zum Wachstum mit Glucose reprimiert (Daten nicht gezeigt). Wie bereits erläutert, laufen die Abbauwege von L-Arginin und L-Prolin zusammen und haben den gemeinsamen Intermediaten $\Delta^{1}$-Pyrrolin-5-Carboxylat. Untersuchungen zur Regulation der Verwertung von Arginin und Prolin lassen den Schluss zu, dass dieser Intermediat beide Abbauwege induziert (Laishley \& Bernlohr, 1968). Basierend auf den durchgeführten Transkriptionsanalysen, unter Berücksichtigung der Analysen der Kulturüberstände, konnte in dieser Arbeit auch für DSM13 eine Beteilung der Gene ycgMNO am Abbau von L-Prolin und im weiteren auch von L-Arginin und L-Ornithin beobachtet werden.

\section{Siderophore}

Bei der Kultivierung von B. licheniformis DSM13 in einem definierten Medium wurde mit zunehmender Kulturdichte eine rotbraune Färbung des Mediums beobachtet. In vorangegangenen Untersuchungen wurde dieses bereits in Verbindung mit der Biosynthese von Siderophoren gebracht (Veith, 2004). Siderophore sind Chelatkomplexe, welche mit hoher Affinität unlösliches Eisen komplexieren und anschließend über spezielle Aufnahmesysteme in die Zelle transportieren. Eisen ist eine essentielle Komponente von Cytochromen und Eisen-Schwefel-Proteinen, die in den Elektronentransport involviert sind. Unter Eisenmangelbedingungen bildet B. subtilis das Siderophor Bacillibactin (May et al., 2001). Die Expression von EisenAufnahmesystemen wird in B. subtilis durch das Enzym FUR (ferric uptake repressor) in Abhängigkeit der Verfügbarkeit von intrazellularem Eisen reguliert (Baichoo \& Helmann, 2002). In die Aufnahme des Eisen-Bacillibactin-Komplexes ist der FeuABCTransporter involviert. Die Freisetzung des Eisens in die Zelle wird durch das Protein BesA (ehemals Yuil), einer Trilacton-Hydrolase, vermittelt (Miethke et al., 2006). Weiterhin konnte gezeigt werden, dass die transkriptionelle Induktion des Eisen- 
Bacillibactin-Aufnahmesystems durch YbbB erfolgt (Gaballa \& Helmann, 2007). In B. subtillis sind die an der Bildung des Siderophores Bacillibactin beteiligten Gene $(d h b A C E B F)$ getrennt von den Genen organisiert, welche an der Aufnahme des EisenBacillibactin-Komplexes bzw. der anschließenden Freisetzung des Eisens in die Zelle beteiligt sind (Abb. 7.2 im Anhang).

Orthologe Gene, welche Homologien zu der an Biosynthese, Aufnahme und Freisetzung von Bacillibactin bzw. des Eisens beteiligten Gene zeigen, sind auch in B. licheniformis vorhanden. Im Gegensatz zu B. subtilis sind diese Gene in DSM13 zusammen organisiert (Abb. 7.3 im Anhang). Bei der Kultivierung von DSM13 in einem definierten Medium mit einem Gemisch von 20 Aminosäuren konnte für diese Gene eine Änderung der Expressionsverhältnisse verzeichnet werden (vgl. 4.3.2.4., Tab. 4.27). $\mathrm{Zu}$ den Zeitpunkten $\mathrm{T} 2$, $\mathrm{T} 4$ und $\mathrm{T} 5$ waren die Gene $d h b A C E B F$ bei auf Aminosäuren gewachsenen Zellen induziert. Eine erhöhte Expression unter diesen Kultivierungsbedingungen konnte hingegen zu allen fünf Zeitpunkten für die Gene feuABC und yuiI ermittelt werden. Die Zeitpunkte T4 und T5 gehen mit der gesteigerten rotbraunen Färbung des Mediums konform. Die Thematik, weshalb die Gene dhbACEBF zum Zeitpunkt T2 induziert waren und zum Zeitpunkt T3 wiederum nicht, wurde in dieser Arbeit nicht näher beleuchtet.

\section{Bacteriophagen}

Im Rahmen der Genomsequenzierung von DSM13 wurden vier Prophagen identifiziert. Drei der vier Prophagen sind dabei in Bereichen des Genoms lokalisiert, welche geringe bis keine Homologien zu ORFs aus B. subtilis aufweisen. Des Weiteren waren für diese Bereiche deutliche Abweichungen des lokalen $\mathrm{G}+\mathrm{C}$ Gehaltes zu vermerken. Ausgehend vom Transkriptionsstartpunkt im Uhrzeigersinn sind dieses der zweite, dritte und vierte Prophage im Genom von DSM13. Im Bereich des ersten Phagen hingegen konnten Gene identifiziert werden, welche hohe Homologien mit Genen des PBSX Prophagen von B. subtilis aufweisen. Ergänzend kann noch angeführt werden, dass dieser Bereich, anders als die der weiteren drei Prophagen, keine Auffälligkeiten bezüglich der codon usage im Vergleich zur codon usage des Genoms von DSM13 aufwies (Veith, 2004). Im Zusammenhang mit dem Wachstum von DSM13 mit einem Gemisch von 20 Aminosäuren konnte in den hierzu durchgeführten Transkriptionsanalysen zu verschiedenen Zeitpunkten eine Induktion von Genen der 
Prophagenbereiche verzeichnet werden (vgl. Tab. 7.8 im Anhang). Es konnten für einen Großteil der ORFs, welche dem PBSX Phagenbereich zugeordnet wurden, reproduzierbar zum Zeitpunkt T3 eine erhöhte Expression beim Wachstum mit Aminosäuren ermittelt werden. Daneben konnte für eine Anzahl der ORFs des zweiten Phagenbereiches zwischen den Zeitpunkten T1 und T4 eine erhöhte Expression verzeichnet werden. Für phagenassoziierte ORFs, welche im dritten bzw. vierten Bereich lokalisiert sind, wurden im Gegensatz dazu keine gesteigerten Änderungen der Expressionsverhältnisse beobachtet bzw. keine ermittelt. Ob und welche Auswirkungen eine mögliche Induktion der beiden Prophagen auf die Verwertung von Aminosäuren hat, wurde im Rahmen dieser Arbeit nicht eingehend untersucht. Es ist jedoch interessant, dass in B. licheniformis NRS 243 durch Mitomycin C induzierbare Bacteriophagenhagen charakterisiert wurden (Huang \& Marmur, 1970). In dem Zusammenhang wurden zwei morphologisch unterschiedliche Phagen gefunden, wobei der erste Phage Ähnlichkeiten zum PBSX Phagen aus B. subtilis zeigte. Der zweite hatte hingegen morphologische Ähnlichkeit zum temperenten Phagen $\phi 105$ aus B. subtilis. Daneben konnte auch in B. licheniformis DSM13 ein Phage mittels Mitomycin C induziert werden (Rachinger, 2010). Um welchen Bacteriophagen es sich handelt, konnte nicht eindeutig geklärt werden. Eine Deletion des Bereiches, welcher Homologien zum PBSX Phagen aus B. subtilis aufwies, führte jedoch dazu, dass sich in der Mutante kein Phage durch Mitomycin C induzieren ließ.

\section{Gemeinsam exprimierte Gene beim Wachstum mit Aminosäuren}

Im Rahmen dieser Arbeit konnte mit Hilfe der Transkriptionsanalyse eine Gruppe von Genen identifiziert werden, welche offensichtlich konstitutiv beim Wachstum von B. licheniformis mit Aminosäuren induziert waren (vgl. 4.3.1.2.2.). Neben acoR, konnte außerdem für die Genregion BLi02106 bis BLi02102 und der ORF BLi04275 eine erhöhte Expression beim Wachstum mit Aminosäuren im Vergleich zur Kultivierung mit Glucose verzeichnet werden. Ebenfalls unter diesen Versuchsbedingungen induziert waren die ORFs BLi01143 und BLi03498. Sowohl für acoR, als auch für den ORF BLi02104 (mmsA) wurde diese erhöhte Genexpression für das Wachstum mit proteinogenen Aminosäuren mittels real-time RT-PCR verifiziert (vgl. 4.3.1.3.). Lediglich im Zusammenhang mit dem Wachstum auf L-Asparagin konnte das Resultat der DNA-Microarray-Analysen für $a c o R$ nicht bestätigt werden. Dieses Gen kodiert für 
den transkriptionalen Regulator des Acetoin-Dehydrogenase Operons. Wie bereits erläutert, wurde dieser in B. subtilis als $\sigma^{\mathrm{L}}$ abhängiger Aktivator beschrieben (Huang et al., 1999; Ould Ali et al., 2003). Eine erhöhte Expression der Gene des AcetoinDehydrogenase-Operons wurde beim Wachstum mit einem Gemisch aus 20 Aminosäuren zu den Zeitpunkten T4 und T5, also beim Übergang in die stationäre Phase verzeichnet. Eine Akkumulation von Acetoin im Kulturüberstand wurde unter den gewählten Versuchsbedingungen nicht detektiert (Daten nicht gezeigt). Der ORF BLi01143 (melA) kodiert für eine $\alpha$-D-Galaktosid-Galaktohydrolase und ist augenscheinlich mit der Verwertung von Zuckern, genauer dem Disaccharid Melibiose, assoziiert. Eine Induktion von MelA konnte in B. subtilis während der Adaption an anaerobe Wachstumsbedingungen beobachtet werden (Marino et al., 2000). Im Genom von DSM13 ist melA in direkter Nachbarschaft zu Genen (amyCD) lokalisiert, welche in den Transport von Zuckern involviert sind. Ergänzend muss noch hinzugefügt werden, dass eine signifikant erhöhte Expression der ORFs BLi01143 und BLi03498 beim Wachstum mit L-Ornithin als einzige C- und N-Quelle nicht verzeichnet werden konnte. Hingegen waren acoR, die ORFs BLi02106 bis BLi02102 und BLi04275 auch bei der Kultivierung mit dieser nicht-proteinogenen Aminosäure induziert (Tab. 7.9 im Anhang).

Unter Verwendung des bioinformatischen Softwaretools BiBag (vgl. 4.4.) konnte gezeigt werden, dass die weiteren der gemeinsam exprimierten Gene unique für B. licheniformis DSM13 im Vergleich zu B. subtilis 168 und B.amyloliquefaciens FZB42 sind. D. h. es konnten keine Orthologe in diesen beiden Organismen identifiziert werden. Der ORF BLi03498 kodiert für eine putative Pectin-Methylesterase. Pectine sind pflanzliche Polysaccharide und daher ist auch dieser ORF augenscheinlich in die Verwertung von Zuckern involviert. Ein Ortholog konnte jedoch auch nicht in B. weihenstephanensis KBAB4 und B. cereus ATCC14579 identifiziert werden (vgl. 4.4., Tab. 4.30). Lokalisiert ist dieser ORF in DSM13 in Nachbarschaft zu sogenannten Y-ORFs. Dieses sind allgemein gesprochen Gene, deren Produkte bisher nicht näher charakterisiert wurden bzw. kaum Homologien mit anderen Genen aufweisen. Der ORF BLi04275 kodiert für ein Homolog der L-Alanin-Dehydrogenase. Im Gegensatz zu den weiteren charakteristischen Genen für DSM13 konnte für dieses Gen keine erhöhte Expression beim Wachstum mit Acetat, wie auch mit 2,3-Butandiol ermittelt werden (vgl. 4.4., Tab. 4.29). Daneben konnte im Rahmen der Untersuchungen des 
extrazellularem Proteoms von DSM13 das Produkt des ORFs BLi04275 beim Wachstum mit dem komplexen LB-Medium identifiziert werden, nicht jedoch unter Glucose-, Phosphat- und Stickstoffmangelbedingungen (Voigt et al., 2006). L-Alanin löst in vielen Bacillen die Keimung von Sporen aus (Powell \& Hunter, 1955). Untersuchungen in B. subtilis haben die Anwesenheit von zwei Arten von L-Aminosäure-Dehydrogenasen in ruhenden Sporen gezeigt. Im Gegensatz zu ersteren, welche spezifisch für L-Alanin war, handelt es sich bei der zweiten um eine nicht-spezifische Dehydrogenase, welche neben L-Alanin auch die verzweigtkettigen Aminosäuren L-Valin, L-Isoleucin und L-Leucin als Substrate nutzt (Nitta et al., 1974). Dies könnte ein Hinweis auf eine mögliche Funktion des ORFs BLi04275 in DSM13 sein.

Der ORF BLi02104 ist in der bereits angesprochenen Genregion BLi02106 bis BLi02102 lokalisiert und kodiert für eine Methylmalonat-Semialdehyd-Dehydrogenase. DSM13 besitzt zwei paraloge Gene, welche für eine Methylmalonat-SemialdehydDehydrogenase kodieren, wobei der zweite ORF, BLi04251, im Genom von DSM13 mit Genen assoziiert ist, welche Homologien zu Genen des Myo-Inositol-Abbaus in B. subtilis aufweisen (Stines-Chaumeil et al., 2006; Yoshida et al., 2008). Sowohl der upstream, als auch downstream gelegene ORF der Genregion BLi02106 bis BLi02102 zeigte keine signifikant erhöhte Expression beim Wachstum von DSM13 mit einzelnen Aminosäuren als C- und N-Quelle (Daten nicht gezeigt). Basierend auf Transkriptionsanalysen lässt dies eine operonähnliche Struktur dieser Genregion vermuten. Die ORFs BLi02102 und BLi02103 kodieren für putative Enoyl-CoAHydratasen. Ergänzend gilt es noch zu erwähnen, dass für den ORF BLi02103 kein Ortholog, sowohl in B. weihenstephanensis KBAB4, als auch in B. cereus ATCC14579 identifiziert werden konnte (vgl. 4.4., Tab. 4.30). Enoyl-CoA-Hydratasen sind in E. coli mit dem Multienzymkomplex der Fettsäureoxidation assoziiert (Pawar \& Schulz., 1981; Pramanik et al., 1979). Wie bereits erläutert, kodiert der ORF BLi02104 für eine Methylmalonat-Semialdehyd-Dehydrogenase. Dieses Enzym katalysiert in B. subtilis die NAD-abhängige Oxidation von Methylmalonat-Semialdehyd und MalonatSemialdehyd zu Propionyl-CoA und Acetyl-CoA (Stines-Chaumeil et al., 2006). Letztere wiederum stellen die Vorläufer des Methylcitrat- bzw. Tricarbonsäurezyklus dar. Der ORF BLi02105 kodiert für eine putative 2-Hydroxy-3-OxopropionatReduktase. Ein weiterer Name dieses Enzyms lautet Tartronat-Semialdehyd-Reduktase 
und ist in den Metabolismus von C2-Komponenten involviert (Gotto \& Kornberg, 1961). Der ORF BLi02106 dieses putativen Operons kodiert für eine putative ButyrylCoA-Dehydrogenase. Hierbei handelt es sich um eine Oxidoreduktase, welche zur Familie der Acyl-CoA-Dehydrogenasen gehört. Letztere wiederum sind mit dem bereits erwähnten Multienzymkomplex der Fettsäureoxidation assoziiert (Pramanik et al., 1979). Die genaue Rolle und Funktion dieses putativen Operons im Aminosäure- bzw. C2-Metabolismus muss in weiteren Untersuchungen noch näher beleuchtet werden.

\section{Tricarbonsäurezyklus}

Beim Wachstum mit Aminosäuren wie Asparagin, Aspartat, Glutamin, Glutamat, Arginin, Prolin oder Ornithin als einzige Kohlenstoffquelle werden diese Substrate zu Oxalacetat umgesetzt. Durch die PEP-Carboxykinase kann unter Verbrauch von ATP aus Oxalacetat Phosphoenolpyruvat (PEP), der Vorläufer der Gluconeogenese, synthetisiert werden (vgl. 5.2; Sonenshein, 2002). In E. coli sind verschiedene Wege, ausgehend von C4-Dicarbonsäuren, für die Bildung von PEP bekannt (Hansen \& Juni, 1974, 1975). Zum einen kann Malat durch die Malat-Dehydrogenase zu Oxalacetat oxidiert und anschließend, wie eben erläutert, zu PEP umgesetzt werden. Daneben kann Malat, katalysiert durch ein Malat-Enzym, oxidativ zu Pyruvat decarboxyliert und im weiteren durch die PEP-Synthetase zu Phosphoenolpyruvat umgewandelt werden. Auch in B. subtilis konnte die Aktivität des Malat-Enzyms gezeigt werden (Diesterhaft \& Freese, 1973). Weiterführende Untersuchungen in B. subtilis lassen vermuten, dass neben anderen Enzymen des Tricarbonsäurezyklus sowohl die Pyruvat-Dehydrogenase, als auch das Malat-Enzym durch Substratinduktion reguliert wird. Wie bereits unter 5.2. erläutert, unterliegen die ersten drei Enzyme des TCA-Zyklus der sogenannten feedback Repression (Ohné, 1975), wobei die Aconitat-Hydratase durch die Citrat vermittelte Induktion eine Sonderstellung einnimmt.

Wie unter 4.3.1.2.3. bzw. 4.3.1.2.4. beschrieben, konnte beim Wachstum von DSM13 mit L-Asparagin als alleinige C- und N-Quelle eine erhöhte Expression der Gene des Multienzymkomplexes der Pyruvat-Dehydrogenase ( $p d h A B C D)$ und eines möglichen Malo-Lactat-Enzyms (mleA) ermittelt werden. Enzymatische Untersuchungen in B. subtilis haben gezeigt, dass es sich bei MleA nicht um ein MaloLactat-Enzym handelt (Lerondel et al., 2006). In dem Kontext konnte diesem Enzym jedoch keine eindeutige physiologische Bedeutung zugeordnet werden, da lediglich in 
der exponentialen Wachstumsphase in einem komplexen Medium eine erhöhte Transkription von mleA beobachtet wurde. Dieses geht mit den in dieser Arbeit gemachten Untersuchungen zum Wachstum mit Gemischen von Aminosäuren konform (vgl. 4.3.2.2., Tab. 4.21 und 4.3.2.4., Tab. 4.24). Im Gegensatz zu den Untersuchungen in B. subtilis konnte in der vorliegenden Arbeit für B. licheniformis DSM13 eine Induktion dieses Gens in Verbindung mit L-Asparagin gebracht werden. Sowohl beim Wachstum in einem definierten Medium mit einem Gemisch aus sieben Aminosäuren, als auch mit einem Gemisch aus 20 Aminosäuren wurde eine erhöhte Expression für mleA zu Zeitpunkten ermittelt, in welchen L-Asparagin im Kulturüberstand nachzuweisen war. Gleiches gilt für das in direkter Nachbarschaft im Genom von DSM13 lokalisierte Gen mleN. Dessen Produkt wurde als Malat- $\mathrm{H}^{+} / \mathrm{Na}^{+}-\mathrm{Lactat}$ Antiporter annotiert. Zu Zeitpunkten in denen kein L-Asparagin mehr detektiert wurde, konnte unter beiden Kultivierungsbedingungen auch keine erhöhte Expression dieser Gene verzeichnet werden. Wie bereits unter 4.3.1.2.1. erläutert, sind upstream dieser beiden ORFs die Gene des ansAB Operons lokalisiert und kodieren für eine Asparaginase (ansA, BLi04140) bzw. Aspartase (ansB, BLi04140). Sowohl für diese Gene, als auch für das upstream gelegene ansR, welches für den transkriptionellen Repressor des ans $A B$ Operons kodiert, konnte das gleiche Expressionsmuster beobachtet werden. Neben diesen Genen konnte auch eine Induktion des für die PEPCarboxykinase kodierenden Gens $p c k A$ für DSM13 ermittelt werden. Im Gegensatz zu den zuvor erläuterten Genen wurde nicht nur in Verbindung mit L-Asparagin (Tab. 7.11 im Anhang), sondern auch beim Wachstum mit allen getesteten Aminosäuren bzw. zu allen Zeitpunkten beim Wachstum mit Gemischen von Aminosäuren eine erhöhte Expression verzeichnet (Daten nicht gezeigt). 


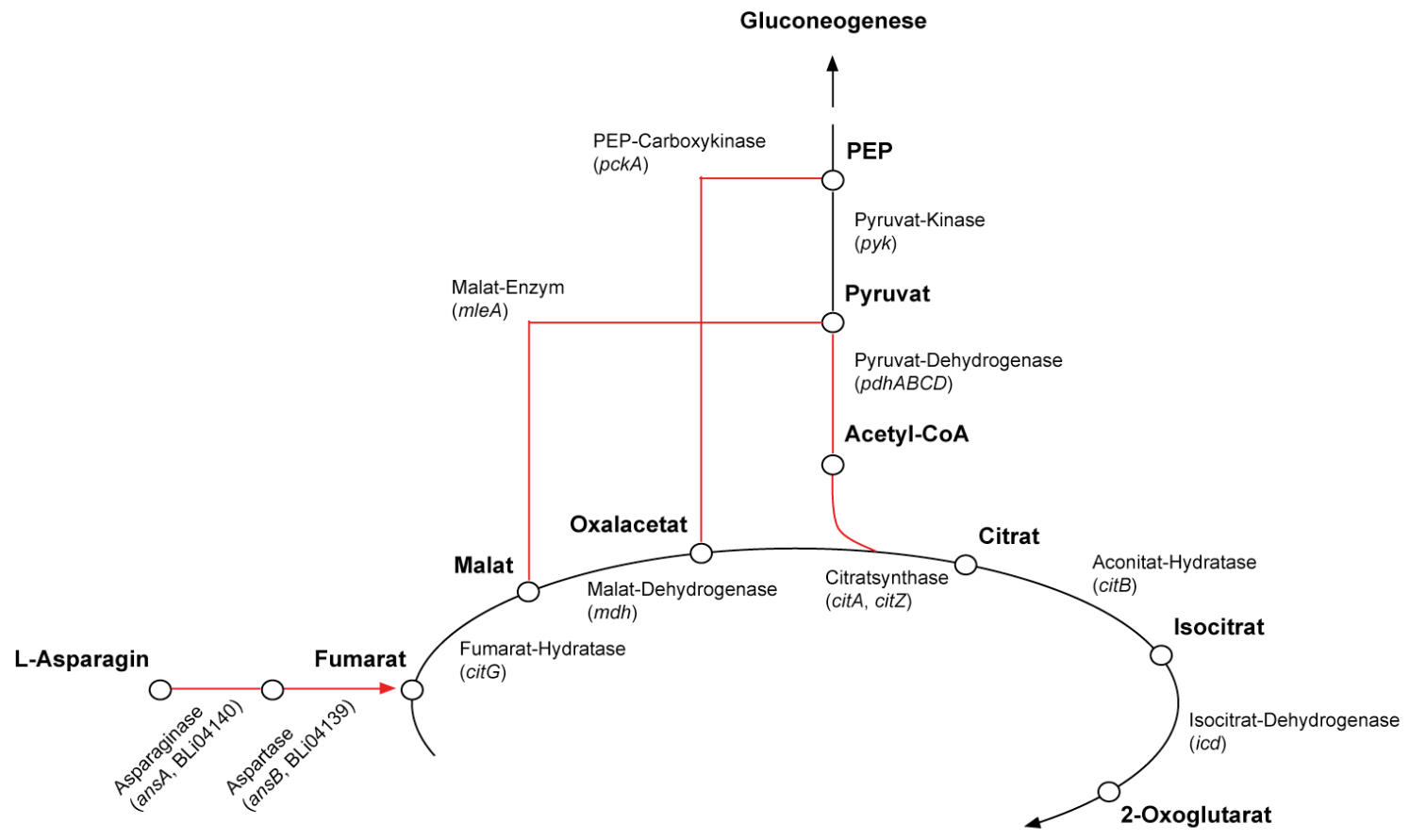

Abbildung 5.9: Schematische Übersicht des Einmündens von Asparagin in den Tricarbonsäurezyklus (adaptiert nach Lerondel et al., 2006). Basierend auf Transkriptionsanalysen sind in rot mögliche enzymatische Umsetzungen dargestellt.

Die in diesem Kontext ermittelten Expressionsverhältnisse lassen die Schlussfolgerung zu, dass Asparagin zunächst, katalysiert durch die Enzyme AnsA und AnsB, zu Fumarat umgesetzt wird. Letzteres kann wiederum über Malat zu Oxalacetat und im Anschluss daran weiter, katalysiert durch die PEP-Carboxykinase, zu Phosphoenolpyruvat umgesetzt werden und somit der Gluconeogenese dienen. Daneben könnte das Gen mleA eine analoge Rolle des Malat-Enzyms, wie es eingangs für E. coli beschrieben wurde, einnehmen und Malat zu Pyruvat umsetzen. Dieses kann im Weiteren, neben anderen biosynthetischen Zwecken, zu Acetyl-CoA umgesetzt und in den TCA-Zyklus eingeschleust werden (Abb. 5.9). Diese Vermutung steht im Einklang mit der bereits beschriebenen gesteigerten Expression der Gene des Multienzymkomplexes der Pyruvat-Dehydrogenase beim Wachstum von DSM13 mit L-Asparagin. Ergänzend soll in diesem Zusammenhang darauf hingewiesen werden, dass Phosphoenolpyruvat in E. coli aktivierend auf die Pyruvat-Dehydrogenase wirkt. Ein weiteren Hinweis auf eine gesteigerte Aktivität der Enzyme des TCA-Zyklus lässt die im Zusammenhang mit L-Asparagin ermittelte erhöhte Expression des für die 
Citratsynthase I kodierenden Gens citA vermuten. Diese auf Transkriptionsanalysen basierende Hypothese muss jedoch noch durch weiterführende molekularbiologische und biochemische Experimente überprüft werden.

\section{Citratsynthasen}

Citratsynthasen katalysieren die Kondensation von Acetyl-CoA und Oxalacetat zu Citrat und stellen somit das erste Enzym des Tricarbonsäurezyklus dar. Generell betrachtet werden die Citratsynthasen in Gram-positiven Bakterien durch ATP und im Gegensatz dazu in Gram-negativen Bakterien durch NADH inhibiert (Jin \& Sonenshein, 1994a). Während der Genomsequenzierung von DSM13 konnten drei Citratsynthasen identifiziert werden. Hierbei ist anzumerken, dass es sich bei der Citratsynthase III vermutlich um eine Methylcitratsynthase handelt. Wie für $B$. subtilis beschrieben ist auch in DSM13 das für die Citratsynthase I kodierende Gen citA mit citR im Genom assoziiert. Hierbei kodiert citR für den transkriptionalen Repressor von citA. Das Gen der Citratsynthase II, citZ, ist in beiden Organismen in direkter Nachbarschaft zu den Genen der Isocitrat-Dehydrogenase (icd) und der Malat-Dehydrogenase ( $m d h$ ) lokalisiert. Eine Mutation in citA hat nur einen geringen Effekt auf das Wachstum und die Citratsynthase-Aktivität in B. subtilis (Jin \& Sonenshein, 1994a; Jin \& Sonenshein, 1996). Als Folge einer Mutation von citZ wurde im Gegensatz dazu ein erheblicher Verlust der Citratsynthase-Aktivität, Glutamat-Auxotrophie und ein Defekt in der Sporulation beschrieben (Jin \& Sonenshein, 1994a). Zusammen mit vergleichenden Messungen der mRNA Level von citA und citZ wurde daraus geschlossen, dass citZ für die eigentliche Citratsynthase in B. subtilis kodiert (Jin \& Sonenshein, 1994b; Jin \& Sonenshein, 1996).

Ähnliches konnte im Rahmen dieser Arbeit auch für eine Mutation in citA beobachtet werden. Transkriptionsanalysen haben gezeigt, dass citA beim Wachstum mit L-Asparagin bzw. L-Aspartat als einzige C- und N-Quelle induziert war (vgl. 4.3.1.2.4., Abb. 4.22). In diesem Kontext konnte für die verbliebenen fünf proteinogenen Aminosäuren eine erhöhte Expression des für die (Methyl-) Citratsynthase III kodierenden Gens $m m g D$ ermittelt werden. Im Weiteren konnte diese erhöhte Expression von citA im Zusammenhang mit L-Asparagin ebenfalls beim Wachstum mit Gemischen von Aminosäuren beobachtet werden (vgl. 4.3.2.2., Abb. 4.26 und 4.3.2.4., Abb. 4.30). Wurde L-Asparagin noch im Kulturüberstand detektiert, 
war zu diesen Zeitpunkten citA induziert. Für die weiteren Zeitpunkte beim Wachstum mit einem Gemisch aus 20 Aminosäuren konnte eine erhöhte Expression für $m m g D$ ermittelt werden. Für den Zeitpunkt T3 bei der Kultivierung mit einem Gemisch aus sieben Aminosäuren wurde lediglich beobachtet, dass citA nicht mehr induziert war. Im Gegensatz zu den soeben geschilderten Beobachtungen konnte für das Gen der Citratsynthase II, citZ, unter keiner der gewählten Versuchsbedingungen eine signifikante Steigerung der Expression beim Wachstum mit Aminosäuren im Vergleich zum Wachstum mit Glucose ermittelt werden.

Aufgrund der ermittelten Genexpressionsdaten für die Citratsynthasen wäre ein schlechteres Wachstum einer citA-Mutante im Zusammenhang mit L-Asparagin zu vermuten. Dieses konnte jedoch anhand der bisher durchgeführten Kultivierungsexperimente und Analysen der Kulturüberstände nicht beobachtet werden (vgl. 4.6.). In einem definierten Medium mit einem Gemisch aus sieben Aminosäuren wurde kein Wachstumsunterschied von $\Delta c i t A$ im Vergleich zum Wildtyp DSM13 oder dessen Derivat MW3 beobachtet. Auch die Analysen der Kulturüberstände lieferten keine weiteren Erkenntnisse. Wie der Wildtyp, so verwertete auch die citA-Mutante zunächst L-Asparagin und erst im Anschluss daran war ein gesteigerter Verbrauch der verbliebenen proteinogenen Aminosäuren zu beobachten. Des Weiteren konnte auch anhand der durchgeführten Plattentests zum Wachstum in einem definierten Medium mit Glucose kein Unterschied zum Wildtyp beobachtet werden.

Diese bisher im Rahmen zur phänotypischen Charakterisierung durchgeführten Experimente lassen auf eine ähnliche Funktion von citA in DSM13 schließen, wie sie für B. subtilis beschrieben wurde. Einen weiteren Hinweis auf diese Vermutung liefern die durchgeführten Transkriptionsanalysen. Auch wenn mithilfe dieser keine signifikante Änderung des Expressionsverhältnisses für das Gen der Citratsynthase II (citZ) in DSM13 ermittelt werden konnte, so lassen die starken Intensitäten der einzelnen Kanäle jedoch den Schluss zu, dass dieses Gen sowohl beim Wachstum mit einzelnen Aminosäuren, als auch unter Kultivierungsbedingungen mit Glucose induziert ist (Daten nicht gezeigt). Ergänzend soll noch hinzugefügt werden, dass eine Mutation von citA in B. subtilis keinen Effekt auf die Transkription von citZ hat und umgekehrt (Jin \& Sonenshein, 1994b). 


\section{Methylcitratzyklus}

Wie bereits im vorangegangenen Abschnitt erläutert konnte im Rahmen der Transkriptionsanalysen eine erhöhte Expression des Gens der putativen (Methyl-) Citratsynthase III $(m m g D)$ im Zusammenhang mit den proteinogenen Aminosäuren L-Alanin, L-Arginin, L-Glutamin, L-Glutamat und L-Prolin beobachtet werden. Das kodierende Gen dieser (Methyl-) Citratsynthase III ist im Genom von B. licheniformis DSM13 mit weiteren Genen eines putativen Methylcitratzyklus assoziiert.

Besonders gut ist der Methylcitratzyklus in S. typhimurium LT2 untersucht. Die notwendigen Gene für den Abbau von Propionat in diesem Organismus sind in zwei transkriptionalen Einheiten organisiert, prpR und $p r p B C D E$. Die Gene prpBCDE sind in einem Operon organisiert und kodieren für die 2-Methylisocitrat-Lyase ( $\operatorname{rp} B)$, die 2-Methylcitratsynthase ( $\operatorname{rp} \mathrm{C})$, die 2-Methylcitrat-Dehydratase ( $p r p D)$ und die Propionyl-CoA-Synthethase (prpE) (Horswill \& Escalante-Semerena, 1997). Im Gegensatz zu den anderen Produkten dieses Operons ist PrpE nicht für das Wachstum mit Propionat in S. typhimurium LT2 notwendig (Horswill \& Escalante-Semerena, 1999a, 1999b). Das Gen prpR kodiert für einen $\sigma^{54}$ abhängigen transkriptionalen Aktivator, welcher für die Transkription des prpBCDE-Operons notwendig ist (Palacios \& Escalante-Semerena, 2000, 2004). Weitere Untersuchungen haben gezeigt, dass der Propionat-Metabolismus, sowohl von E. coli, als auch von Salmonella enterica serovar Typhimurium LT2, der Katabolit-Repression unterliegt (Lee et al., 2005).

B. subtilis kann nicht mit Propionat als einziger Kohlenstoffquelle wachsen (Sonenshein, 2002). Dennoch besitzt dieser Gene, welche Sequenzähnlichkeiten zu Genen des Methylcitratzyklus aufweisen (Bryan et al., 1996; Sonenshein, 2002). Diese sind in einem Operon zusammen mit Genen des Fettsäuremetabolismus ( $m m g A B C$ ) lokalisiert (Abb. 7.4 im Anhang; Bryan et al., 1996). Hierbei kodiert $m m g A$ für eine degradative Acetoacetyl-CoA-Thiolase (Reddick \& Williams, 2008), $m m g B$ für eine 3-Hydroxybutruryl-CoA-Dehydrogenase und $m m g C$ für eine Acyl-CoADehydrogenase. Induziert wird dieses Operon in den mittleren Stadien der Sporulation und steht unter der Kontrolle eines $\sigma^{\mathrm{E}}$-abhängigen Promotors (Bryan et al., 1996). Des Weiteren wird vermutet, dass B. subtilis verzweigtkettige Fettsäuren über den Methylcitratzyklus zu Pyruvat und Succinat abbauen kann (Koburger et al., 2005). 
Im Genom von B. licheniformis sind die Gene $m m g A B C$ nicht zusammen mit den Genen des putativen Methylcitratzyklus organisiert (Abb. 7.5 im Anhang). Begrenzt werden erstere downstream von dem Gen einer Acyl-CoA-Dehydrogenase ( $a c d A)$ und upstream von ywjF. Dessen Produkt weist Ähnlichkeiten zu Eisen-Schwefel-bindenden Reduktasen auf. In vorangegangenen Untersuchungen konnte durch Northern-BlotAnalysen gezeigt werden, dass die Gene des putativen Methylcitratzyklus ( $m m g D$, $m m g E$, yqiQ) in DSM13 zusammen mit dem ORF des putativen transkriptionalen Regulator (BLi04093) ein Operon bilden. Daneben konnte die Funktionalität des Methylcitratzyklus durch Wachstumsversuche mit Propionat und Transkriptionsanalyse beobachtet werden (Wülfing, 2006).

Anders als für eine Mutation des Gens der Citratsynthase I (citA) beschrieben, konnte im Zusammenhang mit einer Mutation der kodierenden Einheit der (Methyl-) Citratsynthase III ( $m m g D)$ ein Phänotyp beobachtet werden (vgl. 4.6.). Beim Wachstum mit einem Gemisch aus sieben Aminosäuren zeigte die $m m g D$-Mutante, im Gegensatz zum Wildtyp DSM13 bzw. dessen Derivat MW3, ein diauxieähnliches Wachstum. Dieses konnte mit der Verwertung von Aminosäuren in Verbindung gebracht werden. Analysen der in diesem Zusammenhang entnommenen Kulturüberstände ergaben, dass die $m m g D$-Mutante in Anwesenheit von L-Asparagin das gleiche Wachstumsverhalten wie der Wildtyp zeigte. Nachdem L-Asparagin nicht mehr bzw. nur in geringen Konzentrationen im Kulturüberstand zu detektieren war, konnte eine starke Reduktion der Wachstumsrate für diese Mutante beobachtet werden. Im Anschluss daran ging eine Zunahme der optischen Dichte mit dem gesteigerten Verbrauch der sechs verbliebenen Aminosäuren einher. Weitere Experimente zeigten außerdem, dass $\Delta m m g D$ nicht mehr in einem definierten Medium mit Glucose als Kohlenstoff- und Ammoniumchlorid als Stickstoffquelle wachsen konnte (vgl. 4.6.). Eine Deletion der weiteren im Zusammenhang mit dem putativen Methylcitratzyklus stehenden Gene in DSM13 hatte keine offensichtliche Auswirkung auf das Wachstum in einem definierten Medium, sowohl mit einem Gemisch aus sieben Aminosäuren, als auch mit Glucose und Ammoniumchlorid (vgl. 4.6.). Weder für $\Delta$ BLi04093, noch für $\triangle m m g E$ und $\triangle y q i Q$ konnte in diesen Medien ein signifikanter Wachstumsunterschied, oder sogar Wachstumsdefekt, im Vergleich zum Wildtyp beobachtet werden. In ersten Experimenten in einem definierten Medium mit Propionat als Kohlenstoffquelle konnte eine yqiQ-Mutante nicht kultiviert werden (Daten nicht gezeigt). Das Gen yqiQ kodiert 
für eine putative Methylisocitrat-Lyase, welche die Umsetzung von Methylisocitrat zu Succinat und Pyruvat katalysiert. Diese Beobachtung unterstützt die Beteiligung des Operons am putativen Methylcitratzyklus in B. licheniformis DSM13.

\section{Analysen der Kulturüberstände beim Wachstum mit sieben bzw. 20 Aminosäuren}

Im Gegensatz zu einem komplexen Medium, wie zum Beispiel nutrient broth, welches zusätzlich noch Oligopeptide enthält, ist ein Vorteil eines definierten Mediums, dass dieses analytisch besser zugänglich ist. Im Rahmen dieser Arbeit wurde ein definiertes Medium zusammengestellt, welches der Aminosäure-Zusammensetzung der Sojabohne nachempfunden ist. Durch Probenentnahmen zu verschiedenen Zeitpunkten des Wachstums wurde der Verbrauch von Aminosäuren und die Bildung von Produkten analytisch überprüft. In diesem Kontext konnten viele Gemeinsamkeiten beim Wachstum von B. licheniformis DSM13 mit einem Gemisch aus sieben und aus 20 Aminosäuren beobachtet werden (vgl. 4.3.2.1. und 4.3.2.3.). Die Untersuchungen deuten darauf hin, dass es eine Reihenfolge des Verbrauchs der Aminosäuren gibt. So wird in beiden Gemischen zunächst L-Asparagin verstoffwechselt und erst im Anschluss daran konnte ein gesteigerter Verbrauch der weiteren sechs proteinogenen Aminosäuren verzeichnet werden. Ausgehend von diesen sechs Aminosäuren ist L-Glutamat die letzte Aminosäure in beiden Gemischen, die noch im Kulturüberstand zu detektieren war. Wurde auch diese Aminosäure limitierend, so konnte beim Wachstum von DSM13 ein Übergang in die stationäre Phase beobachtet werden. Des Weiteren wurde, unabhängig vom Gemisch der Aminosäuren, eine Akkumulation und der anschließende Verbrauch von Ornithin in Abhängigkeit von L-Arginin ermittelt. Ebenfalls im Zusammenhang mit dem Verbrauch von L-Arginin konnte in beiden Medien ein Anstieg von Harnstoff im Kulturüberstand beobachtet werden. Daneben wurde ebenfalls eine Akkumulation von Ammonium und Acetat detektiert. Wie bereits im Zusammenhang mit der Verwertung von C2-Metaboliten erläutert, ist DSM13 in der Lage, Acetat als C-Quelle zu nutzen. Ein signifikanter Verbrauch von Acetat und Ammonium konnte jedoch unter den bisher gewählten Versuchsbedingungen nicht ermittelt werden.

Beim Wachstum von DSM13 mit einem Gemisch von 20 Aminosäuren konnte ein Verbrauch der verzweigtkettigen Aminosäuren L-Isoleucin, L-Leucin und L-Valin beobachtet werden. In einer Konzentration von jeweils $30 \mathrm{mM}$ in einem definierten 
Medium konnte DSM13 diese einzeln nicht als Stickstoff- und Kohlenstoffquelle nutzen (vgl. 4.3.1.1.). Mit einem äquimolaren Gemisch (25 mM) dieser drei proteinogen Aminosäuren konnte eine geringe Zunahme der Zelldichte ermittelt werden. Wurde diesem Medium 0,04\% Casein-Hydrolysat zugefügt, konnte ein gesteigertes Wachstum im Vergleich mit nur 0,04\% Casein-Hydrolysat, ohne die weitere Zugabe von Aminosäuren, beobachtet werden (Wülfing, 2006). Diese Experimente stehen im Einklang mit dem beim Wachstum mit 20 Aminosäuren gemachten Beobachtungen, dass es DSM13 möglich ist die verzweigtkettigen Aminosäuren zu verwerten. Ob diese Aminosäuren in diesem Zusammenhang als N-Quelle und/oder als C-Quelle dienen, konnte jedoch nicht ermittelt werden.

\section{4 Ausblick}

Im Rahmen dieser Arbeit konnte für eine Reihe von Genen eine erhöhte Genexpression unter verschiedenen Kultivierungsbedingungen ermittelt werden. Eine erhöhte Expression bekannter Gene in einem gemeinsamen Kontext mit uncharakterisierten Genen gestattet eine hypothetische funktionelle Zuordnung der letzteren. Deren genaue Rolle muss anschließend über molekularbiologische Techniken eingehend überprüft werden. Im Zusammenhang mit dem fermentativen Wachstum wären neben anderen die Pyruvat-Formiat-Lyase (BLi02132) ein interessanter Kandidat, um deren Funktion und Rolle in B. licheniformis näher zu beleuchten. Gleiches gilt für das in Verbindung mit der Verwertung von Aminosäuren beschriebene putative Operon um das Gen einer putativen Methylmalonat-SemialdehydDehydrogenase.

Beim Wachstum von B. licheniformis DSM13 in einem definierten Medium mit Gemischen von Aminosäuren können letztere sowohl als Stickstoff-, wie auch als Kohlenstoffquelle dienen. Um die Komponenten verwerten zu können, welche eine optimale Wachstumsrate ermöglichen, wird die Expression der an den Abbauwegen beteiligten Gene durch globale Regulatoren kontrolliert. In diesem Zusammenhang gilt es in weiteren Untersuchungen die Rolle des Regulatorproteins des C-Stoffwechsels, CcpA, aber auch von Proteinen, welche die Genexpression in Abhängigkeit der Verfügbarkeit von Stickstoff regulieren, zu untersuchen. $\mathrm{Zu}$ letzteren zählen die Proteine GlnR, TnrA und CodY. 


\section{Literaturverzeichnis}

Altschul, S. F., W. Gish, W. Miller, E. W. Myers, and D. J. Lipman. 1990. Basic local alignment search tool. J. Mol. Biol. 215:403-410.

Arnaud, M., A. Chastanet, and M. Débarbouillé. 2004. New Vector for Efficient Allelic Replacement in Naturally Nontransformable, Low-GC-Content, Gram-Positive Bacteria. Appl. Environ. Microbiol. 70:6887-6891.

Atkinson, M. R., and S. H. Fisher. 1991. Identification of genes and gene products whose expression is activated during nitrogen-limited growth in Bacillus subtilis. J. Bacteriol. 173:23-27.

Baichoo, N., and D. Helmann. 2002. Recognition of DNA by Fur: a Reinterpretation of the Fur Box Consensus Sequence. J. Bacteriol. 184:5826-5832.

Barbe, V., S. Cruveiller, F. Kunst, P. Lenoble, G. Meurice, A. Sekowska, D. Vallenet, T. Wang, I. Moszer, C. Médigue, and A. Danchin. 2009. From a consortium sequence to a unified sequence: the Bacillus subtilis 168 reference genome a decade later. Microbiology. 155:1758-1775.

Belitsky, B. R., and A. L. Sonenshein. 1998. Role and regulation of Bacillus subtilis glutamate dehydrogenase genes. J. Bacteriol. 180:6298-6305.

Belitsky, B. R., and A. L. Sonenshein. 1999. An enhancer element located downstream of the major glutamate dehydrogenase gene of Bacillus subtilis. Proc. Natl. Acad. Sci. USA. 96:10290-10295.

Belitsky, B. R., and A. L. Sonenshein. 2004. Modulation of Activity of Bacillus subtilis Regulatory Proteins GltC and TnrA by Glutamate Dehydrogenase. J. Bacteriol. 186:3399-3407.

Berberich, R., M. Kaback, and E. Freese. 1968. D-Amino Acids as Inducers of L-Alanine Dehydrogenase in Bacillus subtilis. J. Biol. Chem. 243:1006-1011.

Blalock, E. 2003. A beginner's guide to microarrays. Kluwer Academy Publishers; Boston/ New York/ Dordrecht/ London.

Blasco, R., J. Cárdenas, and F. Castillo. 1991. Regulation of isocitrate lyase in Rhodobacter capsulatus E1F1. Curr. Microbiol. 22:73-76.

Blencke, H.-M., I. Reif, F. M. Commichau, C. Detsch, I. Wacker, H. Ludwig, J. Stülke. 2006. Regulation of citB expression in Bacillus subtilis: integration of multiple metabolic signals in the citrate pool and by the general nitrogen regulatory system. Arch. Microbiol. 185:136-146. 
Blomqvist, K., M. Nikkola, P. Lehtovaara, M.-L. Suihko, U. Airaksinen, K. B. Straby, J. K. C. Knowles, and M. E. Penttilä. 1993. Characterization of the genes of the 2,3-butanediol operons from Klebsiella terrigena and Enterobacter aerogenes. J. Bacteriol. 175:1392-1404.

Böck, A. and G. Sawers. 1996. Fermentation. In F. C. Neidhardt, R. Curtiss III, J. L. Ingraham, E. C. C. Lin, K. B. Low, B. Magasanik, W. S. Reznikoff, M. Riley, M. Schaechter, and H. E. Umbarger (ed.), Escherichia coli and Salmonella: Cellular and Molecular Biology. American Society for Microbiology, Washington, D. C., pp.262282.

Box, G. 2006. Herstellung rekombinanter Clostridien-Sporen zur Therapie nekrotisierender Tumore. Dissertation zur Erlangung des Doktorgrades der Fakultät für Naturwissenschaften der Universität Ulm.

Brämer, C. O., and A. Steinbüchel. 2001. The methylcitric acid pathway in Ralstonia eutropha: new genes identified involved in propionate metabolism. Microbiology. 147:2203-2214.

Broman, K., N. Lauwers, V. Stalon, and J.-M. Wiame. 1978. Oxygen and Nitrate in Utilization by Bacillus licheniformis of the Arginase and Arginine Deiminase Routes of Arginine Catabolism and Other Factors Affecting Their Syntheses. J. Bacteriol. 135:920-927.

Brown, T. D. K., M. C. Jones-Mortimer, and H. L. Kornberg. 1977. The enzymic interconversion of acetate and acetyl-coenzyme A in Escherichia coli. J. Gen. Microbiol. 102:327-336.

Bryan, E. M., B. W. Beall, and C. P. Moran, Jr. 1996. A $\sigma^{\mathrm{E}}$-Dependent Operon Subject to Catabolite Repression during Sporulation in Bacillus subtilis. J. Bacteriol. 178:4778-4786.

Buhrmester, J. 2004. Genomweite Analysen von Gen-Clustern zur ABC-Transportvermittelten Eisenaufnahme bei Sinorhizobium meliloti Stamm Rm1021.Dissertation zur Erlangung des Doktorgrades. Fakultät für Biologie der Universität Bielefeld.

Calogero, S., R. Gardan, P. Glaser, J. Schweizer, G. Rapoport, and M. Débarbouillé. 1994. RocR, a Novel Regulatory Protein Controlling Arginine Utilization in Bacillus subtilis, Belongs to the NtrC/NifA Family of Transcriptional Activators. J. Bacteriol. 176:1234-1241.

Campbell, H. A., L. T. Mashburn, E. A. Boyse, and L. J. Old. 1967. Two L-asparaginases from Escherichia coli B. Their separation, purification, and antitumor activity. Biochemistry. 6:721-730.

Cedar, H., and J. H. Schwartz. 1967. Localization of the Two L-Asparaginases in Anaerobically Grown Escherichia coli. J. Biol. Chem. 242:3753-3755. 
Chang, S., and S. N. Cohen. 1979. High Frequency Transformation of Bacillus subtilis Protoplasts by Plasmid DNA. Molec. gen. Genet. 168:111-115.

Chell, R. M., and T. K. Sundaram. 1975. Isolation and characterization of isocitrate lyase and malate synthase from Bacillus stearothermophilus. Biochem. Soc. Trans. 3:303-306.

Chen, X. H., A. Koumoutsi, R. Scholz, A. Eisenreich, K. Schneider, I. Heinemeyer, B. Morgenstern, B. Voss, W. R. Hess, O. Reva, H. Junge, B. Voigt, P. R. Jungblut, J. Vater, R. Süssmuth, H. Liesegang, A. Strittmatter, G. Gottschalk, and R. Borriss. 2007. Comparative analysis of the complete genome sequence of the plant growth-promoting bacterium Bacillus amyloliquefaciens FZB42. Nat. Biotechnol. 25:1007-1014.

Chung, T., D. J. Klumpp, and D. C. LaPorte. 1988. Glyoxylate bypass operon of Escherichia coli: cloning and determination of the functional map. J. Bacteriol. 170:386-392.

Claes, W. A., A. Pühler, and J. Kalinowski. 2002. Identification of Two prpDBC Gene Clusters in Corynebacterium glutamicum and Their Involvement in Propionate Degradation via the 2-Methylcitrate Cycle. J. Bacteriol. 184:2728-2739.

Clark, V. L., D. E. Peterson, and R. W. Bernlohr. 1972. Changes in Free Amino Acid Production and Intracellular Amino Acid Pools of Bacillus licheniformis as a Function of Culture Age and Growth Media. J. Bacteriol. 112:715-725.

Cook, W. R., J. H. Hoffman, and R. W. Bernlohr. 1981. Occurrence of an Inducible Glutaminase in Bacillus licheniformis. J. Bacteriol. 148:365-367.

Cruz Ramos, H., L. Boursier, I. Moszer, F. Kunst, A. Danchin, and P. Glaser. 1995. Anaerobic transcription activation in Bacillus subtilis: identification of distinct FNR-dependent and -independent regulatory mechanisms. EMBO J. 14:5984-5994.

Cruz Ramos, H., P. Glaser, L. V. Wray,Jr, and S. H. Fisher. 1997. The Bacillus subtilis ureABC Operon. J. Bacteriol. 179:3371-3373.

Cruz Ramos, H., T. Hoffmann, M. Marino, H. Nedjari, E. Presecan-Siedel, O. Dreesen, P. Glaser, and D. Jahn. 2000. Fermentative Metabolism of Bacillus subtilis: Physiology and Regulation of Gene Expression. J. Bacteriol. 182:3072-3080.

Cunin, R., N. Glansdorff, A. Piérard, and V. Stalon. 1986. Biosynthesis and Metabolism of Arginine in Bacteria. Microbiol. Mol. Biol. Rev. 50:314-352.

Débarbouillé, M., I. Martin-Verstraete, F. Kunst, and G. Rapoport. 1991. The Bacilius subtilis sigL gene encodes an equivalent of $\sigma^{54}$ from Gram-negative bacteria. Proc. Natd. Acad. Sci. USA. 88:9092-9096. 
Débarbouillé, M., R. Gardan, M. Arnaud, and G. Rapoport. 1999. Role of BkdR, a Transcriptional Activator of The SigL-Dependent Isoleucine and Valine Degradation Pathway in Bacillus subtilis. J. Bacteriol. 181:2059-2066.

Deng, W.-L., H.-Y. Chang, and H. L. Peng. 1994. Acetoin catabolic system of Klebsiella pneumoniae CG43: sequence, expression, and organization of the aco operon. J. Bacteriol. 176:3527-3535.

Diesterhaft, M. D., and E. Freese. 1973. Role of pyruvate carboxylase, phosphoenolpyruvate carboxykinase, and malic enzyme during growth and sporulation of Bacillus subtilis. J. Biol. Chem. 248:6062-6070.

Donohue, T. J., and R. W. Bernlohr. 1981. Properties of the Bacillus licheniformis A5 glutamine synthetase purified from cells grown in the presence of ammonia or nitrate. J. Bacteriol. 147:589-601.

Eckhardt, T. 1978. A rapid method for the identification of plasmid desoxyribonucleic acid in bacteria. Plasmid 1:584-588.

Ehrenreich, A. 2006. DNA microarray technology for the microbiologist: an overview. Appl. Microbiol. Biotechnol. 73:255-273.

Fiechter, A. 1992. Biosurfactants: moving towards industrial applications. Trends Biotechnol. 10:208-217.

Fisher, S. H. 1993. Utilization of Amino Acids and Other Nitrogen-Containing Compounds. In Bacillus subtilis and Other Gram-Positive Bacteria, A. L. Sonenshein, J. A. Hoch, and R. Losick, eds. (Washington, DC, Am. Soc. Microbiol.), pp.221-228.

Fisher, S. H., and M. Débarbouillé. 2002. Nitrogen Source Utilization and Its Regulation. In Bacillus subtilis and Its Closest Relatives, A. L. Sonenshein, J. A. Hoch, and R. Losick, eds. (Washington, DC, ASM Press), pp. 181-191.

Fisher, S. H., and B. Magasanik. 1984. 2-Ketoglutarate and the Regulation of Aconitase and Histidase Formation in Bacillus subtilis. J. Bacteriol. 158:379-382.

Fisher, S. H., and L. V. Wray, Jr. 2002. Bacillus subtilis 168 Contains Two Differentially Regulated Genes Encoding L-Asparaginase. J. Bacteriol. 184:2148-2154.

Fitzpatrick J. M., D. A. Johnston, G. W. Williams, D. J. Williams, T. C. Freeman, D. W. Dunne and K. F. Hoffmann. 2005. An oligonucleotide microarray for transcriptome analysis of Schistosoma mansoni and its application/use to investigate gender-associated gene expression. Molecular and Biochemical Parasitology 141:1-13.

Folmsbee, M. J., M. J. McInerney, and D. P. Nagle. 2004. Anaerobic growth of Bacillus mojavensis and Bacillus subtilis requires deoxyribonucleosides or DNA. Appl. Envir. Microbiol. 70:5252-5257. 
Fouet, A., and A. L. Sonenshein. 1990. A target for carbon source-dependent negative regulation of the citB promoter in Bacillus subtilis. J. Bacteriol. 172:835-844.

Fouet, A., A. Klier, and G. Rapoport. 1986. Nucleotide sequence of the sucrase gene of Bacillus subtilis. Gene. 45:221-225.

Fouet, A., M. Arnaud, A. Klier, and G. Rapoport. 1987. Bacillus subtilis sucrose-specific enzyme II of the phosphotransferase system: Expression in Escherichia coli and homology to enzymes II from enteric bacteria. Proc. Natl. Acad. Sci. USA. 84:8773-8777.

Fouet, A., S. Jin, G. Raffel, and A. L. Sonenshein. 1990. Multiple regulatory sites in the Bacillus subtilis citB promoter region. J. Bacteriol. 172:5408-5415.

Fox, D.K., and S. Roseman. 1986. Isolation and characterization of homogeneous acetate kinase from Salmonella typhimurium and Escherichia coli. J. Biol. Chem. 261:13487-13497.

Froyshov, O., and S. G. Laland. 1974. On the biosynthesis of bacitracin by a soluble enzyme complex from Bacillus licheniformis. Eur. J. Biochem. 46:235-242.

Gaballa, A., and J. D. Helmann. 2007. Substrate induction of siderophore transport in Bacillus subtilis mediated by a novel one-component regulator. Mol. Microbiol. 66:164173.

Gardan, R., G. Rapoport, and M. Débarbouillé. 1995. Expression of the rocDEF operon involved in arginine catabolism in Bacillus subtilis. J. Mol. Biol. 249:843-856.

Gay, P., and A. Delobbe. 1977. Fructose transport in Bacillus subtilis. Eur. J. Biochem. 79:363-373.

Golden, K. J., and R. W. Bernlohr. 1985. Nitrogen Catabolite Repression of the L-Asparaginase of Bacillus licheniformis. J. Bacteriol. 164:938-940.

Goodlove, P. E., P. R. Cunningham, J. Parker, and D.P. Clark. 1989. Cloning and sequence analysis of the fermentative alcohol-dehydrogenase-encoding gene of Escherichia coli. Gene. 85:209-214.

Gotto, A. M., and H. L. Kornberg. 1961. The Metabolism of C2 Compounds in Micro-Organisms. 7. Preparation and Properties of Crystalline Tartronic Semialdehyde Reductase. Biochem. J. 81:273-284.

Gottschalk, G. 1986. Bacterial Metabolism, Second Edition (New York, SpringerVerlag).

Grundy, F. J., D. A. Waters, S. H. G. Allen, and T. M. Henkin. 1993a. Regulation of the Bacillus subtilis Acetate Kinase Gene by CcpA. J. Bacteriol. 175:7348-7355. 
Grundy, F. J., D. A. Waters, T. Y. Takova, and T. M. Henkin. 1993b. Identification of genes involved in utilization of acetate and acetoin in Bacillus subtilis. Mol. Microbiol. 10:259-271.

Gyan, S., Y. Shiohira, I. Sato, M. Takeuchi, and T. Sato. 2006. Regulatory loop between redox sensing of the NADH/NAD ${ }^{+}$ratio by $\mathrm{Rex}(\mathrm{YdiH})$ and oxidation of NADH by NADH dehydrogenase Ndh in Bacillus subtilis. J. Bacteriol. 188:7062-7071.

Hanahan, D. 1983. Studies on transformation of Escherichia coli with plasmids. J. Mol. Biol. 166:557-580.

Hansen, E. J., and E. Juni. 1974. Two routes for synthesis of phosphoenol-pyruvate from C4-dicarboxylic acids in Escherichia coli. Biochem. Biophys. Res. Commun. 59:1204-1210.

Hansen, E. J., and E. Juni. 1975. Isolation of mutants of Escherichia coli lacking NAD- and NADP-linked malic enzyme activities. Biochem. Biophys. Res. Commun. 65:559-566.

Helmann, J. D., and C. P. Moran Jr. 2002. RNA Polymerase and sigma factors. In Bacillus subtilis and Its Closest Relatives, A. L. Sonenshein, J. A. Hoch, and R. Losick, eds. (Washington, DC, ASM Press), pp. 289-312.

Hemmilä, I. A., and P. I. Mäntsälä. 1978. Purification and properties of glutamate synthase and glutamate dehydrogenase from Bacillus megaterium. Biochem. J. 173:45-52.

Holtmann, G., and E. Bremer. 2004. Thermoprotection of Bacillus subtilis by Exogenously Provided Glycine Betaine and Structurally Related Compatible Solutes: Involvement of Opu Transporters. J. Bacteriol. 186:1683-1693.

Holtzclaw, W. D., and L. F. Chapman. 1975. Degradative Acetolactate Synthase of Bacillus subtilis: Purification and Properties. J. Bacteriol. 121:917-922.

Homuth, G., A. Rompf, W. Schumann, and D. Jahn. 1999. Transcriptional control of Bacillus subtilis hemN and hemZ. J. Bacteriol. 181:5922-5929.

Horswill, A. R., and J. C. Escalante-Semerena. 1997. Propionate Catabolism in Salmonella typhimurium LT2: Two Divergently Transcribed Units Comprise the prp Locus at 8.5 Centisomes, prpR Encodes a Member of the Sigma-54 Family of Activators, and the prpBCDE Genes Constitute an Operon. J. Bacteriol. 179:928-940.

Horswill, A. R., and J. C. Escalante-Semerena. 1999a. Salmonella typhimurium LT2 Catabolizes Propionate via the 2-Methylcitric Acid Cycle. J. Bacteriol. 181:5615-5623.

Horswill, A. R., and J. C. Escalante-Semerena. 1999b. The prpE gene of Salmonella typhimurium LT2 encodes propionyl-CoA synthetase. Microbiology. 145:1381-1388. 
Horton, R. M., H. D. Hunt, S. N. Ho, J. K. Pullen, and L. R. Pease. 1989. Engineering hybrid genes without the use of restriction enzymes: gene splicing by overlap extension. Gene. 77:61-68.

Huang, M., F. B. Opermann-Sanio, and A. Steinbüchel. 1999. Biochemical and Molecular Characterization of the Bacillus subtilis Acetoin Catabolic Pathway. J. Bacteriol. 181:3837-3841.

Huang, W. M., and J. Marmur. 1970. Characterization of Inducible Bacteriophages in Bacillus licheniformis. J. Virol. 5:237-246.

Ivanova, N., A. Sorokin, I. Anderson, N. Galleron, B. Candelon, V. Kapatral, A. Bhattacharyya, G. Reznik, N. Mikhailova, A. Lapidus, L. Chu, M. Mazur, E. Goltsman, N. Larsen, M. D.'Souza, T. Walunas, Y Grechkin, G. Pusch, R. Haselkorn, M. Fonstein, S. D. Ehrlich, R. Overbeek, and N. Kyrpides. 2003. Genome sequence of Bacillus cereus and comparative analysis with Bacillus anthracis. Nature. 423:87-91.

Jin, S., and A. L. Sonenshein. 1994a. Identification of Two Distinct Bacillus subtilis Citrate Synthase Genes. J. Bacteriol. 176:4669-4679.

Jin, S., and A. L. Sonenshein. 1994b. Transcriptional Regulation of Bacillus subtilis Citrate Synthase Genes. J. Bacteriol. 176:4680-4690.

Jin, S., and A. L. Sonenshein. 1996. Characterization of the Major Citrate Synthase of Bacillus subtilis. J. Bacteriol. 178:3658-3660.

Kaiser, M., and G. Sawers. 1995. Fnr activates transcription from the P6 promoter of the pfl operon in vitro. Mol. Microbiol. 18:331-342.

Klinger, A., J. Schirawski, P. Glaser, and G. Unden. 1998. The fnr of Bacillus licheniformis and the cysteine ligands of the C-terminal $\mathrm{FeS}$ cluster. J. Bacteriol. 180:3483-3485.

Knappe , J., F. A. Neugebauer, H. P. Blaschkowski, and M. Gänzler. 1984. Posttranslational activation introduces a free radical into pyruvate formate-lyase. Proc. Natl. Acad. Sci. USA. 81:1332-1335.

Kessler, D., and J. Knappe. 1996. Anaerobic Dissimilation of Pyruvate. In F. C. Neidhardt, R. Curtiss III, J. L. Ingraham, E. C. C. Lin, K. B. Low, B. Magasanik, W. S. Reznikoff, M. Riley, M. Schaechter, and H. E. Umbarger (ed.), Escherichia coli and Salmonella: Cellular and Molecular Biology. American Society for Microbiology, Washington, D. C., pp. 199-205.

Kessler, D., I. Leibrecht, and J. Knappe. 1991. Pyruvate-formate-lyase-deactivase and acetyl-CoA reductase activities of Escherichia coli reside on a polymeric protein particle encoded by adhE. FEBS Lett. 281:59-63. 
Kessler, D., W. Herth, and J. Knappe. 1992. Ultrastructure and pyruvate formatelyase radical quenching property of the multienzymic AdhE protein of Escherichia coli. J. Biol. Chem. 267:18073-18079.

Koburger, T., J. Weibezahn, J. Bernhardt, G. Homuth, and M. Hecker. 2005. Genome-wide mRNA profiling in glucose starved Bacillus subtilis cells. Mol. Gen. Genomics. 274:1-12.

Kunst, F., N. Ogasawara, I. Moszer, A. M. Albertini, G. Alloni, V. Azevedo, M. G. Bertero, P. Bessieres, A. Bolotin, S. Borchert, R. Borriss, L. Boursier, A. Brans, M. Braun, S. C. Brignell, S. Bron, S. Brouillet, C. V. Bruschi, B. Caldwell, V. Capuano, N. M. Carter, S. K. Choi, J. J. Codani, I. F. Connerton, and A. E. A. Danchin. 1997. The complete genome sequence of the Gram-positive bacterium Bacillus subtilis. Nature. 390:249-256.

Krüger, N., F. B. Oppermann, H. Lorenzl, and A. Steinbüchel. 1994. Biochemical and Molecular Characterization of the Clostridium magnum Acetoin Dehydrogenase Enzyme System. J. Bacteriol. 176:3614-3630.

Laishley, E. J., and R. W. Bernlohr. 1968. Regulation of Arginine and Proline Catabolism in Bacillus licheniformis. J. Bacteriol. 96:322-329.

Lander, E. S. 1999. Array of hope. Nat. Genet. 21:3-4.

Lapidus A, E. Goltsman, S. Auger, N. Galleron, B. Ségurens, C. Dossat, M. L. Landa, V. Broussolle, J. Brillard, M.-H. Guinebretiere, V. Sanchis, C. Nguen-The, D. Lereclus, P. Richardson, P. Wincker, J. Weissenbach, S. D. Ehrlich, and A. Sorokin. 2008. Extending the Bacillus cereus group genomics to putative food-borne pathogens of different toxicity. Chem. Biol. Interact. 171:236-249.

Larsson, J. T., A. Rogstam, and C. von Wachenfeldt. 2005. Coordinated patterns of cytochrome $b d$ and lactate dehydrogenase expression in Bacillus subtilis. Microbiology. 151:3323-3335.

Lederberg, E. M., and S. N. Cohen. 1974. Transformation of Salmonella typhimurium by Plasmid Deoxyribonucleic Acid. J. Bacteriol. 119:1072-1074.

Lee, S. K., J. D. Newman, and J. D. Keasling. 2005. Catabolite Repression of the Propionate Catabolic Genes in Escherichia coli and Salmonella enterica: Evidence for Involvement of the Cyclic AMP Receptor Protein. J. Bacteriol. 187:2793-2800.

Lerondel, G., T. Doan, N. Zamboni, U. Sauer, and S. Aymerich. 2006. YtsJ Has the Major Physiological Role of the Four Paralogous Malic Enzyme Isoforms in Bacillus subtilis. J. Bacteriol. 188:4727-4736.

Lindgren, V., and L. Rutberg. 1975. Glycerol Metabolism in Bacillus subtilis: GeneEnzyme Relationships. J. Bacteriol. 119:431-442. 
Maghnouj, A., T. Franco de Sousa Cabral, V. Stalon, and C. V. Wauven. 1998. The $\operatorname{arcABDC}$ Gene Cluster, Encoding the Arginine Deiminase Pathway of Bacillus licheniformis, and Its Activation by the Arginine Repressor ArgR. J. Bacteriol. 180:6468-6475.

Marcus, M., and Y. S. Halpern. 1969. The metabolic pathway of glutamate in Escherichia coli K12. Biochim. Biophys. Acta. 177:314-320.

Marino, M., H. Cruz Ramos, T. Hoffmann, P. Glaser, and D. Jahn. 2001. Modulation of Anaerobic Energy Metabolism of Bacillus subtilis by arfM (ywiD). J. Bacteriol. 183:6815-6821.

Marino, M., T. Hoffmann, R. Schmid, H. Möbitz, and D. Jahn. 2000. Changes in protein synthesis during the adaptation of Bacillus subtilis to anaerobic growth conditions. Microbiology. 146:97-105.

Martin-Verstraete, I., M. Débarbouillé, A. Klier, and G. Rapoport. 1990. Levanase operon of Bacillus subtilis includes a fructose-specific phosphotransferase system regulating the expression of the operon. J. Mol. Biol. 214:657-671.

Martinez, J. L., M. Herrero, and V. de Lorenzo. 1994. The organization of intercistronic regions of the aerobactin operon of pColV-K30 may account for the differential expression of the iucABCD iutA genes. J. Mol. Biol. 238:288-293.

May, J. J., T. M. Wendrich, and M. A. Marahiel. 2001. The dhb Operon of Bacillus subtilis Encodes the Biosynthetic Template for the Catecholic Siderophore 2,3-Dihydroxybenzoate-Glycine-Threonine Trimeric Ester Bacillibactin. J. Biol. Chem. 276:7209-7217.

McCowen, S. M., and P. V. Phibbs, Jr. 1974. Regulation of Alanine Dehydrogenase in Bacillus licheniformis. J. Bacteriol. 118:590-597.

McFall, E., and E. B. Newman. 1996. Amino Acids as Carbon Sources. In F. C. Neidhardt, R. Curtiss III, J. L. Ingraham, E. C. C. Lin, K. B. Low, B. Magasanik, W. S. Reznikoff, M. Riley, M. Schaechter, and H. E. Umbarger (ed.), Escherichia coli and Salmonella: Cellular and Molecular Biology. American Society for Microbiology, Washington, D. C., pp.358-379.

Miethke, M., O. Klotz, U. Linne, J. J. May, C. L. Beckering, and M. A. Marahiel. 2006. Ferri-bacillibactin uptake and hydrolysis in Bacillus subtilis. Mol. Microbiol. 61:1413-1427.

Morrison, D.A. 1977. Transformation in Escherichia coli: Cryogenic Preservation of Competent Cells. J. Bacteriol. 132:349-351.

Mobley, H. L. T., M. D. Island, and R. P. Hausinger. 1995. Molecular Biology of Microbial Ureases. Microbiol. Rev. 59:451-480. 
Münch, R., K. Hiller, A. Grote, M. Scheer, J. Klein, M Schobert, and D. Jahn. 2005. Virtual Footprint and PRODORIC: an integrative framework for regulon prediction in prokaryotes. Bioinformatics 21:4187-4189.

Nakano, M. M., and P. Zuber. 1998. Anaerobic growth of a "strict aerobe" (Bacillus subtilis). Annu. Rev. Microbiol. 52:165-190.

Nakano, M. M., P. Zuber, P. Glaser, A. Danchin, and F. M. Hulett. 1996. TwoComponent Regulatory Proteins ResD-ResE Are Required for Transcriptional Activation of fnr upon Oxygen Limitation in Bacillus subtilis. J. Bacteriol. 178:37963802 .

Nakano, M. M., Y. P. Dailly, P. Zuber, and D. P. Clark. 1997. Characterization of Anaerobic Fermentative Growth of Bacillus subtilis: Identification of Fermentation End Products and Genes Required for Growth. J. Bacteriol. 179:6749-6755.

Nakano, M. M., T. Hoffmann, Y. Zhu, and D. Jahn. 1998. Nitrogen and Oxygen Regulation of Bacillus subtilis nasDEF Encoding NADH-Dependent Nitrite Reductase by TnrA and ResDE. J. Bacteriol. 180:5344-5350.

Needleman, S. B., and C. D. Wunsch. 1970. A general method applicable to the search for similarities in the amino acid sequence of two proteins. J. Mol. Biol. 48:443-453.

Nicholson, W. L. 2008. The Bacillus subtilis ydjL (bdhA) Gene Encodes Acetoin Reductase/2,3-Butanediol Dehydrogenase. Appl. Envir. Microbiol. 74:6832-6838.

Nitta, Y., Y. Yasuda, K., Tochikubo, and Y. Hachisuka. 1974. L-Amino Acid Dehydrogenases in Bacillus subtilis Spores. J. Bacteriol. 117:588-592.

Nnyepi, M. R., Y. Peng, and J. B. Broderick. 2007. Inactivation of E. coli pyruvate formate-lyase: role of AdhE and small molecules. Arch. Biochem. Biophys. 459:1-9.

Ochieng, D. J. 2007. Comparative analysis of amino acid utilization in E.coli and Bacillus strains. Diplomarbeit. Institut für Mikrobiologie und Genetik, Georg-August Universität, Göttingen.

O'Connor, R. J., and H. O. Halvorson. 1960. Intermediate metabolism of aerobic spores. V. The purification and properties of L-alanine dehydrogenase. Arch. Biochem. Biophys. 91:290-299.

Oh, M. K., L. Rohlin, K. C. Kao, and J. C. Liao. 2002. Global expression profiling of acetate-grown Escherichia coli. J. Biol. Chem. 277:13175-13183.

Ohné, M. 1974. Regulation of Aconitase Synthesis in Bacillus subtilis: Induction, Feedback Repression, and Catabolite Repression. J. Bacteriol. 117:1295-1305.

Ohné, M. 1975. Regulation of the Dicarboxylic Acid Part of the Citric Acid Cycle in Bacillus subtilis. J. Bacteriol. 122:224-234. 
Oppermann, F. B., B. Schmidt, and A. Steinbüchel. 1991. Purification and characterization of acetoin: 2,6-dichlorophenolindophenol oxidoreductase, dihydrolipoamide dehydrogenase, and dihydrolipoamide acetyltransferase of the Pelobacter carbinolicus acetoin dehydrogenase enzyme system. J. Bacteriol. 173:757-767.

Oppermann, F. B., and A. Steinbüchel. 1994. Identification and molecular characterization of the aco genes encoding the Pelobacter carbinolicus acetoin dehydrogenase enzyme system. J. Bacteriol. 176:469-485.

Ould Ali, N., J. Bignon, G. Rapoport, and M. Débarbouillé. 2001. Regulation of the Acetoin Catabolic Pathway Is Controlled by Sigma L in Bacillus subtilis. J. Bacteriol. 183:2497-2504.

Ould Ali, N., J. Jeusset, E. Larquet, E. Le Cam, B. Belitsky, A. L. Sonenshein, T. Msadek, and M. Débarbouillé. 2003. Specificity of the interaction of RocR with the rocG-rocA intergenic region in Bacillus subtilis. Microbiology. 149:739-750.

Palacios, S., and J. C. Escalante-Semerena. 2000. prpR, ntrA, and ihf Functions Are Required for Expression of the prpBCDE Operon, Encoding Enzymes That Catabolize Propionate in Salmonella enterica Serovar Typhimurium LT2. J. Bacteriol. 182:905-910.

Palacios, S., and J. C. Escalante-Semerena. 2004. 2-Methylcitrate-dependent activation of the propionate catabolic operon ( $\operatorname{prpBCDE}$ ) of Salmonella enterica by the PrpR protein. Microbiology. 150:3877-3887.

Pawar, S., and H. Schulz. 1981. The Structure of the Multienzyme Complex of Fatty Acid Oxidation from Escherichia coli. J. Biol. Chem. 256:3894-3899.

Phibbs Jr, P. V., and R. W. Bernlohr. 1971. Purification, Properties, and Regulation of Glutamic Dehydrogenase of Bacillus licheniformis. J. Bacteriol. 106:375-385.

Powell, J. F., and J. R. Hunter. 1955. Spore germination in the genus Bacillus: the modification of germination requirements as a result of preheating. J. Gen. Microbiol. 13:59-67.

Pramanik, A., S. Pawar, E. Antonian, and H. Schulz. 1979. Five Different Enzymatic Activities Are Associated with the Multienzyme Complex of Fatty Acid Oxidation from Escherichia coli. J. Bacteriol. 137:469-473.

Presecan-Siedel, E., A. Galinier, R. Longin, J. Deutscher, A. Danchin, P. Glaser, and I. Martin-Verstraete. 1999. Catabolite Regulation of the pta Gene as Part of Carbon Flow Pathways in Bacillus subtilis. J. Bacteriol. 181:6889-6897.

Priefer, U. B., R. Simon, and A. Pühler. 1985. Extension of the Host Range of Escherichia coli Vectors by Incorporation of RSF1010 Replication and Mobilization Functions. J. Bacteriol. 163:324-330. 
Priefert, H., S. Hein, N. Krüger, K. Zeh, B. Schmidt, and A. Steinbüchel. 1991. Identification and molecular characterization of the Alcaligenes eutrophus H16 aco operon genes involved in acetoin catabolism. J. Bacteriol. 173:4056-4071.

Priest, F. G. 1993. Systematics and Ecology of Bacillus. In Bacillus subtilis and Other Gram-Positive Bacteria, A. L. Sonenshein, J. A. Hoch, and R. Losick, eds. (Washington, DC, Am. Soc. Microbiol.), pp. 3-15.

Puri-Taneja, A., M. Schau, Y. Chen, and F. M. Hulett. 2007. Regulators of the Bacillus subtilis cydABCD Operon: Identification of a Negative Regulator, CcpA, and a Positive Regulator, ResD. J. Bacteriol. 189:3348-3358.

Rachinger, M. 2010. Stammdesign in B. licheniformis. Dissertation zur Erlangung des Doktorgrades, Institut für Mikrobiologie und Genetik, Georg-August Universität, Göttingen.

Ratzkin, B., and J. Roth. 1978. Cluster of Genes Controlling Proline Degradation in Salmonella typhimurium. J. Bacteriol. 133:744-754.

Reddick, J. J., and J. K. Williams. 2008. The $m m g A$ gene from Bacillus subtilis encodes a degradative acetoacetyl-CoA thiolase. Biotechnol Lett. 30:1045-1050.

Reents, H., R. Münch, T. Dammeyer, D. Jahn, and E Härtig. 2006. The Fnr Regulon of Bacillus subtilis. J. Bacteriol. 188:1103-1112.

Reinscheid, D. J., B. J. Eikmanns, and H. Sahm. 1994a. Characterization of the isocitrate lyase gene from Corynebacterium glutamicum and biochemical analysis of the enzyme. J. Bacteriol. 176:3474-3483.

Reinscheid, D. J., B. J. Eikmanns, and H. Sahm. 1994b. Malate synthase from Corynebacterium glutamicum: sequence analysis of the gene and biochemical characterization of the enzyme. Microbiology. 140:3099-3108.

Renna, M. C., N. Najimudin, L. R. Winik, and S. A. Zahler. 1993. Regulation of the Bacillus subtilis alsS, alsD, and alsR Genes Involved in Post-Exponential-Phase Production of Acetoin. J. Bacteriol. 175:3863-3875.

Rey, M. W., P. Ramaiya, B. A. Nelson, S. D. Brody-Karpin, E. J. Zaretsky, M. Tang, A. Lopez de Leon, H. Xiang, V. Gusti, I. Groth Clausen, P. B. Olsen, M. D. Rasmussen, J. T. Andersen, P. L. Jørgensen, T. S. Larsen, A. Sorokin, A. Bolotin, A. Lapidus, N. Galleron, S. D. Ehrlich, and R. M. Berka. 2004. Complete genome sequence of the industrial bacterium Bacillus licheniformis and comparisons with closely related Bacillus species. Genome Biol. 5:R77.

Rosenkrantz, M. S., D. W. Dingman, and A. L. Sonenshein. 1985. Bacillus subtilis citB gene is regulated synergistically by glucose and glutamine. J. Bacteriol. 164:155-164. 
Sambrook, J., E. F. Fritsch, and T. Maniatis. 1989. Molecular cloning: a laboratory manual, Cold Spring Harbour Laboratory.

Sandeman, R. A., M. J. Hynes, J. R. Fincham, and I. F. Connerton. 1991. Molecular organisation of the malate synthase genes of Aspergillus nidulans and Neurospora crassa. Mol. Gen. Genet. 228:445-452.

Satomura, T., D. Shimura, K. Asai, Y. Sadaie, K. Hirooka und Y. Fujita. 2005. Enhancement of glutamine utilization in Bacillus subtilis through the GlnK-GlnL twocomponent regulatory system. J. Bacteriol. 187:4813-4821.

Sawers, G., and B. Suppmann. 1992. Anaerobic Induction of Pyruvate Formate-Lyase Gene Expression Is Mediated by the ArcA and FNR Proteins. J. Bacteriol. 174:3474-3478.

Schau, M., Y. Chen, and F. M. Hulett. 2004. Bacillus subtilis YdiH Is a Direct Negative Regulator of the $c y d A B C D$ Operon. J. Bacteriol. 186:4585-4595.

Schmidt, V. 2005. Untersuchungen zur Regulation des Glyoxylatzyklus in Bacillus licheniformis DSM13. Diplomarbeit, Institut für Mikrobiologie und Genetik, Georg-August Universität, Göttingen.

Schreier, H. J., and R. W. Bernlohr. 1984. Purification and Properties of Glutamate Synthase from Bacillus licheniformis. J. Bacteriol. 160:591-599.

Schreier, H. J., T. M. Smith, and R. W. Bernlohr. 1982. Regulation of Nitrogen Catabolic Enzymes in Bacillus spp. J. Bacteriol. 151: 971-975.

Schulp, J. A., and A. H. Stouthamer. 1970. The Influence of Oxygen, Glucose and Nitrate upon the Formation of Nitrate Reductase and the Respiratory System in Bacillus lichenifomis. Microbiology. 64:195-203.

Schwarzer, M. 2005. Untersuchungen zum anaeroben fermentativen Wachstum von Bacillus licheniformis DSM13. Diplomarbeit. Institut für Mikrobiologie und Genetik, Georg-August Universität, Göttingen.

Shariati, P., W. J. Mitchell, A. Boyd, and F. G. Priest. 1995. Anaerobic metabolism in Bacillus licheniformis NCIB 6346. Microbiology. 141:1117-1124.

Sharma, V., S. Sharma, K. Hoener zu Bentrup, J. D. McKinney, D. G. Russell, W.R. Jacobs, Jr., and J. C. Sacchettini. 2000. Structure of isocitrate lyase, a persistence factor of Mycobacterium tuberculosis. Nat. Struct. Biol. 7:663-668.

Simon, J. P., and V. Stalon. 1976. Purification and structure of arginase of Bacillus licheniformis. Biochimie. 58:1419-1421.

Skraly, F. A., and D. C. Cameron. 1998. Purification and Characterization of a Bacillus licheniformis Phosphatase Specific for D- $\alpha$-Glycerophosphate. Arch. Biochem. Biophys. 349:27-35. 
Sneath, P. H. A., N. S. Mair, M. E. Sharpe, and J. G. Holt. 1986. Bergey 's manual of sytematic bacteriology, Vol 2 (Baltimore, Williams \& Wilkins).

Sonenshein, A. L. 2002. The Krebs Citric Acid Cycle. In Bacillus subtilis and Its Closest Relatives, A. L. Sonenshein, J. A. Hoch, and R. Losick, eds. (Washington, DC, American Society for Microbiology), pp. 151-161.

Southern, E. M. 1975. Detection of specific sequences among DNA fragments separated by gel electrophoresis. J. Mol. Biol. 98:503-517.

Spring, K. J., P. G. Jerlström, D. M. Burns, and I. R. Beacham. 1986. L-asparaginase genes in Escherichia coli: isolation of mutants and characterization of the ans $A$ gene and its protein product. J. Bacteriol. 166:135-142.

Steinmetz, M. 1993. Carbohydrate Catabolism: Pathways, Enzymes, Genetic Regulation, and Evolution. In Bacillus subtilis and Other Gram-Positive Bacteria, A. L. Sonenshein, J. A. Hoch, and R. Losick, eds. (Washington, DC, Am. Soc. Microbiol.), pp. 157-170.

Stines-Chaumeil, C., F. Talfournier, and G. Branlant. 2006. Mechanistic characterization of the MSDH (methylmalonate semialdehyde dehydrogenase) from Bacillus subtilis. Biochem. J. 395:107-115.

Sun, D., and P. Setlow. 1991. Cloning, Nucleotide Sequence, and Expression of the Bacillus subtilis ans Operon, Which Codes for L-Asparaginase and L-Aspartase. J. Bacteriol. 173:3831-3845.

Sun, D., and P. Setlow. 1993. Cloning and Nucleotide Sequence of the Bacillus subtilis ansR Gene, Which Encodes a Repressor of the ans Operon Coding for L-Asparaginase and L-Aspartase. J. Bacteriol. 175:2501-2506.

Sun, G., E. Sharkova, R. Chesnut, S. Birkey, M. F. Duggan, A. Sorokin, P. Pujic, S. D. Ehrlich, and F. M. Hulett. 1996. Regulators of aerobic and anaerobic respiration in Bacillus subtilis. J. Bacteriol. 178:1374-1385.

Sun, X., R. Eliasson, E. Pontis, J. Andersson, G. Buist, B.-M. Sjöberg, and P. Reichard. 1995. Generation of the glycyl radical of the anaerobic Escherichia coli ribonucleotide reductase requires a specific activating enzyme. J. Biol. Chem. 270:2443-2446.

Tabuchi, T., and N. Serizawa. 1975. A Hypothetical Cyclic Pathway for the Metabolism of Odd-carbon n-Alkanes or Propionyl-CoA via Seven-carbon Tricarboxylic Acids in Yeasts. Agr. Biol. Chem. 39:1055-1061.

Talaat, A. M., S. T. Howard, W. Hale IV, R. Lyons, H. Garner, and S. A. Johnston. 2002. Genomic DNA standards for gene expression profiling in Mycobacterium tuberculosis. Nucleic Acids Research. 30:1-9. 
Textor, S., V. F. Wendisch, A. A. De Graaf, U. Müller, M. I. Linder, D. Linder, and W. Buckel. 1997. Propionate oxidation in Escherichia coli: evidence for operation of a methylcitrate cycle in bacteria. Arch. Microbiol. 168: 428-436.

Tschech, A., and N. Pfennig. 1984. Growth yield increase linked to caffeate reduction in Acetobacterium woodii. Arch. Microbiol. 137:163-167.

Torrents, E., G. Buist, A. Liu, R. Eliasson, J. Kok, I. Gibert, A. Gräslund, and P. Reichard. 2000. The anaerobic (class III) ribonucleotide reductase from Lactococcus lactis. Catalytic properties and allosteric regulation of the pure enzyme system. J. Biol. Chem. 275:2463-2471.

Vanderwinkel, E., P. Liard, F. Ramos, and J. M. Wiame. 1963. Genetic control of the regulation of isocitritase and malate synthase in Escherichia coli K 12. Biochem. Biophys. Res. Commun. 12:157-162.

Veith, B. 2004. Genom- und Transkriptionsanalyse von Bacillus licheniformis DSM13 - einem Organismus mit großem industriellem Potential. Dissertation zur Erlangung des Doktorgrades. Institut für Mikrobiologie und Genetik, Georg-August Universität, Göttingen.

Veith, B., C. Herzberg, S. Steckel, J. Feesche, K. H. Maurer, P. Ehrenreich, S. Bäumer, A. Henne, H. Liesegang, R. Merkl, A. Ehrenreich, and G. Gottschalk. 2004. The complete genome sequence of Bacillus licheniformis DSM13, an organism with great industrial potential. J. Mol. Microbiol. Biotechnol. 7:204-211.

Villafane, R., D. H. Bechhofer, C. S. Narayanan, and D. Dubnau. 1987. Replication Control Genes of Plasmid pEl94. J. Bacteriol. 169:4822-4829.

Voigt, B, T. Schweder, M. J. J. B. Sibbald, D. Albrecht, A. Ehrenreich, J. Bernhardt, J. Feesche, K. H. Maurer, G. Gottschalk, J. Maarten van Dijl, and M. Hecker. 2006. The extracellular proteome of Bacillus licheniformis grown in different media and under different nutrient starvation conditions. Proteomics. 6:268-281.

von Blohn, C., B. Kempf, R. M. Kappes, and E. Bremer. 1997. Osmostress response in Bacillus subtilis: characterization of a proline uptake system (OpuE) regulated by high osmolarity and the alternative transcription factor sigma B. Mol. Microbiol. 25:175-187.

von Wachenfeldt, C., and L. Hederstedt. 2002. Respiratory Cytochromes, Other Heme Proteins, and Heme Biosynthesis. In Bacillus subtilis and Its Closest Relatives, A. L. Sonenshein, J. A. Hoch, and R. Losick, eds. (Washington, DC, American Society for Microbiology), pp. 163-179.

Wacker, I., H. Ludwig, I. Reif, H.-M. Blencke, C. Detsch, and J. Stülke. 2003. The regulatory link between carbon and nitrogen metabolism in Bacillus subtilis: regulation of the gltAB operon by the catabolite control protein CcpA. Microbiology. 149:3001-3009. 
Wagner, A. F. V., M. Frey, F. A. Neugebauer, W. Schäfer, and J. Knappe. 1992. The free radical in pyruvate formate-lyase is located on glycine-734. Proc. Natl. Acad. Sci. USA. 89:996-1000.

Wang, E., M. C. Bauer, A. Rogstam, S. Linse, D. T. Logan, and C. von Wachenfeldt. 2008. Structure and functional properties of the Bacillus subtilis transcriptional repressor Rex. Mol. Microbiol. 69:466-478.

Waschkau, B., J. Waldeck, S. Wieland, R. Eichstädt, and F. Meinhardt. 2008. Generation of readily transformable Bacillus licheniformis mutants. Appl. Microbiol. Biotechnol. 78:181-188.

Wendisch, V. F., M. Spies, D. J. Reinscheid, S. Schnicke, H. Sahm, and B. J. Eikmanns. 1997. Regulation of acetate metabolism in Corynebacterium glutamicum: transcriptional control of the isocitrate lyase and malate synthase genes. Arch. Microbiol. 168:262-269.

Westerfeld, W. W. 1945. A colorimetric determination of blood acetoin. J. Biol. Chem. 161:495-502.

Winstedt, L., K. Yoshida, Y. Fujita, and C. von Wachenfeldt. 1998. Cytochrome $b d$ biosynthesis in Bacillus subtilis: characterization of the cydABCD operon. J. Bacteriol. 180:6571-6580.

Wood. J. M. 1981. Genetics of L-Proline Utilization in Escherichia coli. J. Bacteriol. 146:895-901.

Wood, J. M. 1988. Proline porters effect the utilization of proline as nutrient or osmoprotectant for bacteria. J. Membr. Biol. 106:183-202.

Wülfing, E. 2006. Expression und transkriptionelle Organisation der am Wachstum auf Acetat und Propionat bei Bacillus licheniformis beteiligten Gene. Diplomarbeit. Institut für Mikrobiologie und Genetik, Georg-August Universität, Göttingen.

Ye, R. W., W. Tao, L. Bedzyk, T. Young, M. Chen, and L. Li. 2000. Global Gene Expression Profiles of Bacillus subtilis Grown under Anaerobic Conditions. J. Bacteriol. 182:4458-4465.

Yoshida, K., M. Yamaguchi, T. Morinaga, M. Kinehara, M. Ikeuchi, H. Ashida, and Y. Fujita. 2008. myo-Inositol Catabolism in Bacillus subtilis. J. Biol. Chem. 283:10415-10424.

Yuuki, T., T. Nomura, H. Tezuka, A. Tsuboi, H. Yamagata, N. Tsukagoshi, and S. Udaka. 1985. Complete nucleotide sequence of a gene coding for heat- and pH-stable alpha-amylase of Bacillus licheniformis: comparison of the amino acid sequences of three bacterial liquefying alpha-amylases deduced from the DNA sequences. J. Biochem. (Tokyo) 98:1147-1156. 


\section{Anhang}

Tabelle 7.1: Expressionsverhältnisse von Genen, die an der Glycolyse beteiligt sind. Werte größer 1 bedeuten eine verstärkte Expression unter aeroben Bedingungen, Werte kleiner -1 eine verstärkte Expression unter anaeroben Bedingungen. Die Tabelle enthält repräsentative Einzelmessungen. n.b. - nicht bestimmt

\begin{tabular}{lclc}
\hline ID & Gen & Funktion & $\begin{array}{c}\log \\
\text { Expressionsverhältnis } \\
\text { (aerob/anaerob) }\end{array}$ \\
\hline BLi01598 & $p t s G$ & Untereinheit PTS-System & 1,53 \\
BLi01599 & $p t s H$ & Untereinheit PTS-System & 0,45 \\
BLi01600 & $p t s I$ & Untereinheit PTS-System & 0,43 \\
BLi02660 & $g l c K$ & Glucose-Kinase & $-0,08$ \\
BLi03052 & $g a p B$ & Glycerinaldehyd-3-Phosphat- & $n . b$. \\
& & Dehydrogenase & \\
BLi03067 & $p y k A$ & Pyruvat Kinase & $-0,90$ \\
BLi03068 & $p f k A$ & 6-Phosphofructokinase & $-0,42$ \\
BLi03314 & $p g i$ & Glucose-6-Phosphat-Isomerase & $-0,92$ \\
BLi03661 & eno & Enolase & 0,55 \\
BLi03662 & $p g m$ & Phosphoglycerat-Mutase & 0,48 \\
BLi03663 & $t p i A$ & Triosephosphat-Isomerase & 0,01 \\
BLi03664 & $p g k$ & Phosphoglycerat-Kinase & 0,73 \\
BLi03665 & $g a p A$ & Glycerinaldehyd-3-Phosphat- & $-0,52$ \\
& & Dehydrogenase & $-0,99$ \\
BLi03960 & fbaA & Fructose-1,6-bisphosphat-Aldolase &
\end{tabular}


Tabelle 7.2: Vergleichende Darstellung der Genregion des aco-Operons beim Wachstum mit Acetat bzw. 2,3-Butandiol. Werte größer 1 bedeuten eine verstärkte Expression beim Wachstum mit Acetat bzw. 2,3-Butandiol, Werte kleiner -1 eine verstärkte Expression unter der Referenzbedingung. Die Tabelle enthält repräsentative Einzelmessungen. put. - putativ

\begin{tabular}{|c|c|c|c|c|}
\hline \multirow[t]{2}{*}{ ID } & \multirow[t]{2}{*}{ Gen } & \multirow[t]{2}{*}{ Annotation } & \multicolumn{2}{|c|}{ log Expressionsverhältnisse } \\
\hline & & & $\begin{array}{l}\text { Acetat / } \\
\text { Glucose }\end{array}$ & $\begin{array}{c}\text { 2,3-Butandiol / } \\
\text { Glucose }\end{array}$ \\
\hline BLi00848 & & put. intrazellulare Protease & $-0,04$ & $-1,99$ \\
\hline BLi00849 & $a c o A$ & $\begin{array}{l}\text { Acetoin-Dehydrogenase } \\
\text { (TPP-abhängige } \\
\alpha \text {-Untereinheit) }\end{array}$ & 4,66 & 8,14 \\
\hline BLi00850 & $a c o B$ & $\begin{array}{l}\text { Acetoin-Dehydrogenase } \\
\text { (TPP-abhängige } \\
\beta \text {-Untereinheit) }\end{array}$ & 4,80 & 8,64 \\
\hline BLi00851 & $\operatorname{aco} C$ & $\begin{array}{l}\text { Acetoin-Dehydrogenase } \\
\text { (Dihydrolipoamid- }\end{array}$ & 3,54 & 7,99 \\
\hline BLi00852 & $a c o L$ & $\begin{array}{l}\text { Acetyltransferase) } \\
\text { Acetoin-Dehydrogenase } \\
\text { (Dihydrolipoamid- }\end{array}$ & 3,86 & 7,83 \\
\hline BLi00853 & acoR & $\begin{array}{l}\text { Dehydrogenase) } \\
\text { transkriptionaler Aktivator } \\
\text { des Acetoin-Dehydrogenase }\end{array}$ & 2,58 & 4,37 \\
\hline BLi00854 & $y f j F$ & $\begin{array}{l}\text { Operons } \\
\text { ähnlich zu unbekannten } \\
\text { Proteinen }\end{array}$ & 0,36 & $-1,43$ \\
\hline
\end{tabular}


Tabelle 7.3: Vergleichende Darstellung von Expressionsverhältnissen der Genregion um den ORF der Arginase. Werte größer 1 bedeuten eine verstärkte Expression beim Wachstum mit der angegeben Aminosäure, Werte kleiner -1 eine verstärkte Expression unter der Referenzbedingung. Die Tabelle enthält repräsentative Einzelmessungen. n.b. - nicht bestimmt

\begin{tabular}{|c|c|c|c|c|c|}
\hline \multirow[t]{2}{*}{ ID } & \multirow[t]{2}{*}{ Gen } & \multirow[t]{2}{*}{ Annotation } & \multicolumn{3}{|c|}{ log Expressionsverhältnisse } \\
\hline & & & $\begin{array}{c}\text { Arg / } \\
\text { Glucose }\end{array}$ & $\begin{array}{c}\text { Pro / } \\
\text { Glucose }\end{array}$ & $\begin{array}{c}\text { Orn / } \\
\text { Glucose }\end{array}$ \\
\hline BLi00418 & $y c k I$ & $\begin{array}{l}\text { ähnlich Glutamin ABC- } \\
\text { Transporter (ATP-bindendes } \\
\text { Protein) }\end{array}$ & $-1,08$ & 0,85 & 0,83 \\
\hline BLI00419 & $y c k J$ & $\begin{array}{l}\text { ähnlich Glutamin ABC- } \\
\text { Transporter (Permease) }\end{array}$ & $-1,55$ & 0,36 & 0,81 \\
\hline BLi00420 & $y c k K$ & $\begin{array}{l}\text { ähnlich Glutamin ABC- } \\
\text { Transporter } \\
\text { (Glutaminbindendes Protein) }\end{array}$ & $-1,19$ & 0,94 & 0,25 \\
\hline BLi00421 & rock & $\begin{array}{l}\text { transkriptionaler Aktivator } \\
\text { des Argininverwertenden } \\
\text { Operons }\end{array}$ & 0,44 & $-0,16$ & n.b. \\
\hline BLi00422 & rocD & Ornithin-Aminotransferase & 6,10 & 4,44 & 7,07 \\
\hline BLi00423 & rocE & Aminosäurepermease & 5,80 & 5,12 & 7,26 \\
\hline BLi00424 & $r o c F$ & Arginase & 5,29 & 4,87 & 6,58 \\
\hline BLi00425 & $y c l A$ & $\begin{array}{l}\text { ähnl. zu transkriptionalen } \\
\text { Regulator (LysR Familie) }\end{array}$ & $-0,41$ & 0,10 & 0,15 \\
\hline
\end{tabular}




\begin{tabular}{|c|c|c|c|}
\hline$g \ln T$ & 1 & ATGCAGCAATTCCTTCAAGAAGTCATTGGTGTCACAAATGATTTTCTTTGGTCAAAACTA & 60 \\
\hline DSM13 & 247258 & $\begin{array}{l}\text { ATGCAGCAATTCCTTCAAGAAGTCATTGGTGTCACAAATGATTTTCTTTGGTCAAAACTA } \\
\text {. }\end{array}$ & 247199 \\
\hline$g \ln T$ & 61 & TTGATTATTATGCTTCTTGCTTCGGGACTGTTTTTTACTTTTAAATCTAAGTTCTTTCAA & 120 \\
\hline DSM13 & 247198 & TTGATTATTATGCTTCTTGCTTCGGGACTGTTTTTTACTTTTAAATCTAAGTTCTTTCAA & 247139 \\
\hline$g \ln T$ & 121 & GTTCGCTTGCTGAAAGACATGTTCCGTGTTTTAAAGGAGGAACGCCCGACAAAAACGGA & 180 \\
\hline DSM13 & 247138 & GTTCGCTTGCTGAAAGACATGTTCCGTGTTTTAAAGGAAGGACGCCCGACAAAAACGGA & 247079 \\
\hline$g \ln T$ & 181 & 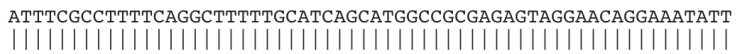 & 240 \\
\hline DSM13 & 247078 & ATTTCGCCTTTTCAGGCTTTTTGGATCAGCATGGCCGCGAGAGTAGGAACAGGAAATATT & 247019 \\
\hline$g \ln T$ & 241 & CGGGGATTGCGATCGCCATTGCCTTGGGCGGACCCGGCGCTATCTTTTGGATGTGGATC & 300 \\
\hline DSM13 & 247018 & ACGGGGATTGCGATCGCCATTGCCTTGGGCGGACCCGGCGCTATCTTTTGGATGTGGATC & 246959 \\
\hline gln $T$ & 301 & 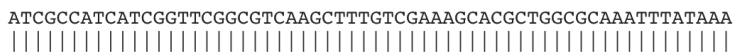 & 360 \\
\hline DSM13 & 246958 & ATCGCCATCATCGGTTCGGCGTCAAGCTTTGTCGAAAGCACGCTGGCGCAAATTTATAAA & 246899 \\
\hline gln $T$ & 361 & 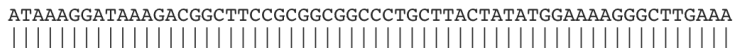 & 420 \\
\hline DSM13 & 246898 & ATAAAGGATAAAGACGGCTTCCGCGGCGGCCCTGCTTACTATATGGAAAAGGGCTTGAAA & 246839 \\
\hline$g \ln T$ & 421 & 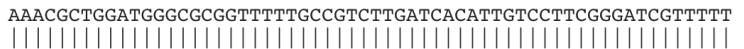 & 480 \\
\hline DSM13 & 246838 & AAACGCTGGATGGGCGCGGTTTTTGCCGTCTTGATCACATTGTCCTTCGGGATCGTTTTT & 246779 \\
\hline$g \ln T$ & 481 & 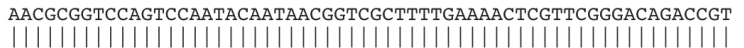 & 540 \\
\hline DSM13 & 246778 & AACGCGGTCCAGTCCAATACAATAACGGTCGCTTTTGAAAACTCGTTCGGGACAGACCGT & 246719 \\
\hline$g \ln T$ & 541 & CTCACACTGGGAATTATCATCACGATTGTTTTCGGCATCATTACF & 600 \\
\hline DSM13 & 246718 & CTCACACTGGGAATTATCATCACGATTGTTTTCGGCATCATTACATTCGGGGGAATCAAA & 246659 \\
\hline$g \ln T$ & 601 & 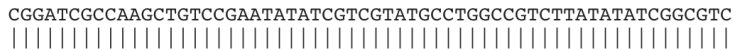 & 660 \\
\hline DSM13 & 246658 & CGGATCGCCAAGCTGTCCGAATATATCGTCGTATGCCTGGCCGTCTTATATATCGGCGTC & 246599 \\
\hline$g \ln T$ & 661 & 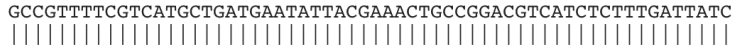 & 720 \\
\hline DSM13 & 246598 & GCCGTTTTCGTCATGCTGATGAATATTACGAAACTGCCGGACGTCATCTCTTTGATTATC & 246539 \\
\hline$g \ln T$ & 721 & 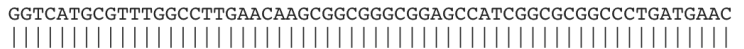 & 780 \\
\hline DSM13 & 246538 & GGTCATGCGTTTGGCCTTGAACAAGCGGCGGGCGGAGCCATCGGCGCGGCCCTGATGAAC & 246479 \\
\hline gln & 781 & 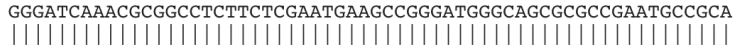 & 840 \\
\hline DSM13 & 246478 & GGGATCAAACGCGGCCTCTTCTCGAATGAAGCCGGGATGGGCAGCGCGCCGAATGCCGCA & 246419 \\
\hline$g \ln T$ & 841 & $\begin{array}{l}\text { GCCGCAGCCACTACGAGCCACCCTGTCAAACAGGGCCTTGTCCAGGCTTTAGGAGTCTTT } \\
\text { (1) }\end{array}$ & 900 \\
\hline DSM13 & 246418 & GCCGCAGCCACTACGAGCCACCCTGTCAAACAGGGCCTTGTCCAGGCTTTAGGAGTCTTT & 246359 \\
\hline $\operatorname{gln}$ & 901 & $\begin{array}{l}\text { GGCTTTTATCATTTTGTTTTCCGATGCGTAT } \\
\text { |||||||||||||||||||||||||||||| }\end{array}$ & 960 \\
\hline DSM13 & 246358 & ACGAGCACTTTGGTGATTTGTTCAAGCACGGCTTTTATCATTTTGTTTTCCGATGCGTAT & 246299 \\
\hline gln & 961 & 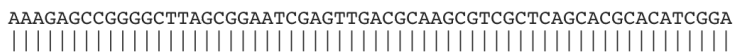 & 1020 \\
\hline DSM13 & 246 & AAAGAGCCGGGGCTTAGCGGAATCGAGTTGACGCAAGCGTCGCTCAGCACGCACATCGGA & 246239 \\
\hline $\operatorname{gln}$ & 1021 & $\begin{array}{l}\text { CCATTATGGTGTTCCTGTTTTCTTTCAGCACCTTGATC } \\
\text { ||l||l||l||l||l||l||l||l||l||l||l||l||l| }\end{array}$ & 1080 \\
\hline DSM13 & 246238 & GCATGGGCCTCAGGCTTTCTCGCCATTATGGTGTTCCTGTTTTCTTTCAGCACCTTGATC & 246179 \\
\hline gln & 1081 & 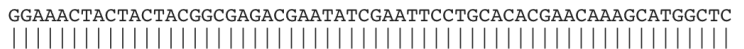 & 1140 \\
\hline DSM13 & 246178 & GGAAACTACTACTACGGCGAGACGAATATCGAATTCCTGCACACGAACAAAGCATGGCTC & 246119 \\
\hline$g \ln T$ & 1141 & $\begin{array}{l}\text { TCGGATCGGTATCAAAAGTCCAG } \\
|\||\||\||\||\||\||\|\mid\|\|\|\|\|\end{array}$ & 1200 \\
\hline DSM13 & 246118 & TTCATTTACCGGATCTGTGTGCTTGCGATGGTCATCTTCGGATCGGTATCAAAAGTCCAG & 246059 \\
\hline gln & 1201 & ETGATGGTCATCGTCAACCTGATTGCG & 1260 \\
\hline DSM13 & 246058 & CTTGTGTGGGACCTCGCCGATTTGTTCATGGGCCTGATGGTCATCGTCAACCTGATTGCG & 245999 \\
\hline & 1261 & 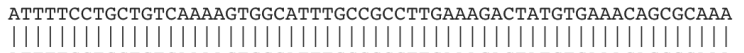 & 320 \\
\hline DSM13 & 245998 & АTTTTCCTGCTGTCAAAAGTGGCATTTGCCGCCTTGAAAGACTATGTGAAACAGCGCAAA & 245939 \\
\hline gln & 132 & $\begin{array}{l}\text { CCGGTCTTTTATAAAGATGTCATTAAAAACCATGAAGGCATCGAATGC } \\
|||||||||||||||||||||||||||||||||||||||||||||||||| \mid\end{array}$ & 1380 \\
\hline DSM13 & 245 & GGCATCGAATGC & 245879 \\
\hline gl. & 1381 & $\begin{array}{l}\text { TGGGAGCACTCCGGCACCGAACAAAAATCCGAAAGCAAAAATGCGATATAA } \\
|||||||||||||||||||||||||||||||||||||||||||||||||||| \mid\end{array}$ & \\
\hline DSM13 & 245878 & TGGGAGCACTCCGGCACCGAACAAAAATCCGAAAGCAAAAATGCGATATAA 245828 & \\
\hline
\end{tabular}

Abbildung 7.1: Ergebnis des Vergleichs mittels BLAST von der DNA Sequenz von $g \ln T$ (Rey et al., 2004) und DSM13 (Veith et al., 2004). 
Tabelle 7.4: Vergleichende Darstellung von Expressionsverhältnissen der Genregion der am Abbau von L-Prolin beteiligten ORFs. Werte größer 1 bedeuten eine verstärkte Expression beim Wachstum mit der angegeben Aminosäure im Vergleich zur Kultivierung unter der Referenzbedingung. Die Tabelle enthält repräsentative Einzelmessungen.

\begin{tabular}{lllccc}
\hline ID & Gen & Annotation & \multicolumn{3}{c}{ log Expressionsverhältnisse } \\
& & & Arg / & Pro / & Orn / \\
& & & Glucose & Glucose & Glucose \\
\hline BLi00372 & $y c g L$ & YcgL & 0,83 & 0,87 & 1,20 \\
BLi00373 & $y c g M$ & ähnlich zur Prolin-Oxidase & 3,44 & 3,78 & 5,01 \\
BLi00374 & $y c g N$ & ähnlich zur & 3,95 & 3,57 & 5,16 \\
& & $\Delta^{1}$-Pyrrolin-5-Carboxylat- & & & \\
& & Dehydrogenase & & & \\
BLi00375 & $y c g O$ & ähnl. zur Prolin-Permease & 2,99 & 5,66 & 5,01 \\
BLi00376 & $y c g P$ & YcgP & 2,20 & 3,55 & 1,22 \\
\hline
\end{tabular}

Tabelle 7.5: Vergleichende Darstellung von Expressionsverhältnissen beim Wachstum mit L-Asparagin bzw. L-Aspartat. Werte größer 1 bedeuten eine verstärkte Expression beim Wachstum mit der angegeben Aminosäure im Vergleich zur Kultivierung unter der Referenzbedingung. Die Tabelle enthält repräsentative Einzelmessungen.

\begin{tabular}{lllcc}
\hline ID & Gen & Annotation & \multicolumn{2}{c}{ log Expressionsverhältnisse } \\
& & & Asn / Glucose & Asp / Glucose \\
\hline BLi00227 & & putative Carboxylase & 3,75 & 2,43 \\
BLi01010 & citA & Citrat-Synthase I & 6,49 & 4,05 \\
BLi04137 & mleA & mögl. Malolactisches Enzym & 4,72 & 3,94 \\
BLi04138 & mleN & Malat-H ${ }^{+} / \mathrm{Na}^{+}$-Lactat & 4,32 & 3,47 \\
& & Antiporter & \\
BLi04139 & & homolog zur AnsB L- & 4,67 & 3,65 \\
& & Aspartase & & 4,67 \\
BLi04140 & ans $A$ & L-Asparaginase & 5,55 & 3,23 \\
BLi04141 & ans $R$ & transkriptionaler Repressor & 3,00 & \\
& & des ans $A B$ Operons & & 1,61 \\
BLi04214 & bglH & B-Glucosidase & 2,41 & \\
\hline
\end{tabular}




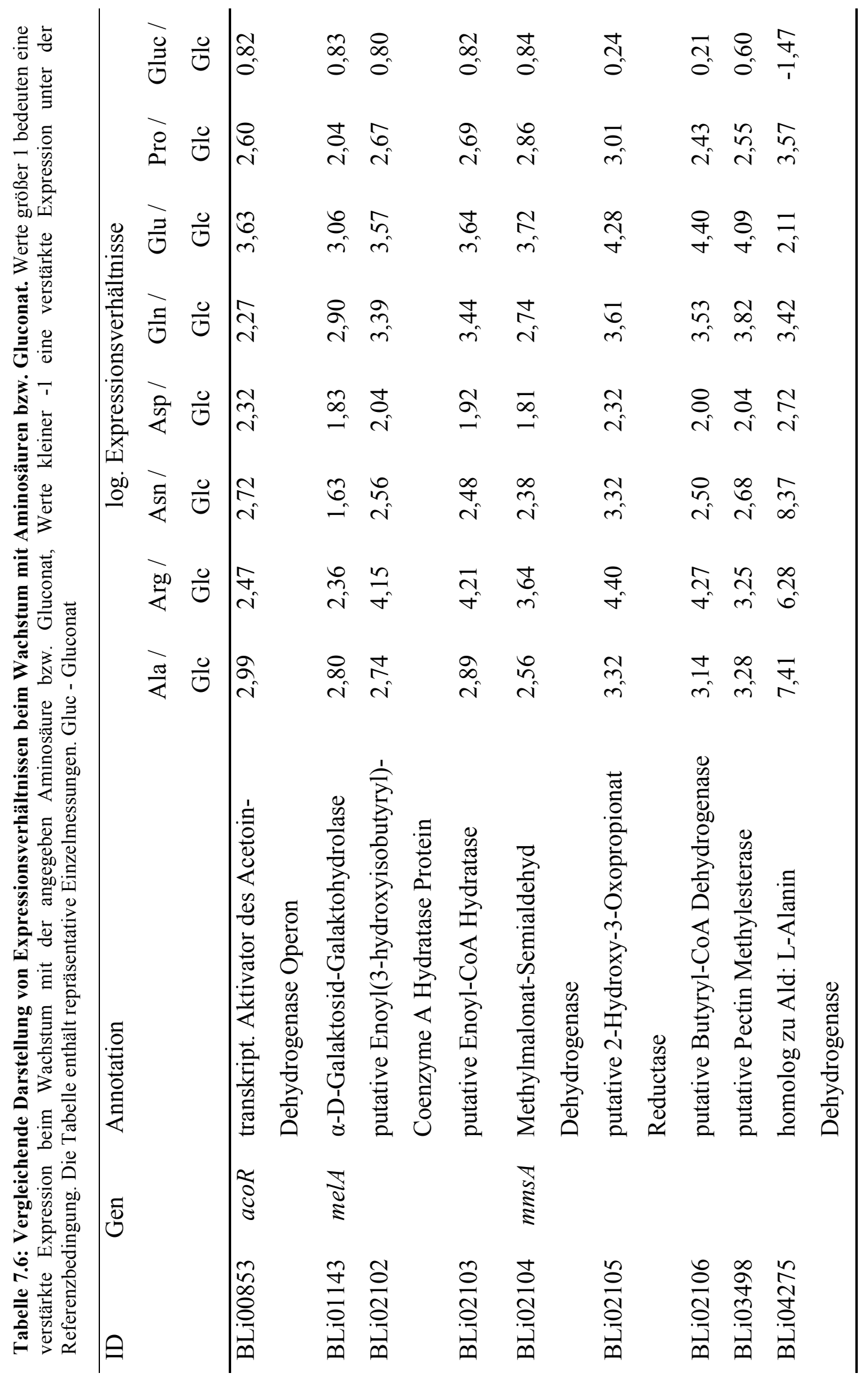


Tabelle 7.7: Vergleichende Darstellung der Ergebnisse des bioinformatischen Softwaretools BiBag bei einem gesetzten Schwellenwert der Sequenzähnlichkeit von 75\%. put. - putativ

\begin{tabular}{|c|c|c|c|}
\hline \multirow[t]{4}{*}{ ID } & \multirow[t]{4}{*}{ Annotation } & \multicolumn{2}{|c|}{ Sequenzähnlichkeit (\%) } \\
\hline & & Bacillus weihen- & Bacillus cereus \\
\hline & & stephanensis & ATCC 14579 \\
\hline & & \multicolumn{2}{|l|}{ KBAB4 } \\
\hline BLi00198 & homolog zur RocF Arginase & 82,2 & 82,2 \\
\hline \multirow[t]{2}{*}{ BLi00245 } & putativer Natriumabhängiger & 82,4 & 82,8 \\
\hline & Phosphattransporter & & \\
\hline \multirow[t]{2}{*}{ BLi00326 } & put. Cellobiose Phosphotransferase & 78,1 & 78,1 \\
\hline & System Enzym II & & \\
\hline BLi00327 & hypothetisches Protein & 76,4 & 77,5 \\
\hline BLi00528 & L-Aspartase & 87,1 & 86 \\
\hline BLi00536 & put. $\mathrm{H}^{+} /$Glutamat Symport Protein & 75,4 & 76,1 \\
\hline BLi00656 & $\alpha$-Amylase Vorläufer & 80,7 & 81,1 \\
\hline BLi00740 & hypothetisches Protein & 76,7 & 76 \\
\hline BLi00753 & putative Methyltransferase & 76 & 76,1 \\
\hline BLi00875 & hypothetisches Protein & 76,5 & 76,5 \\
\hline \multirow[t]{2}{*}{ BLi00972 } & putatives ABC Transporter & 80 & 79,7 \\
\hline & ATP-bindendes Protein & & \\
\hline \multirow[t]{2}{*}{ BLi01050 } & kleines säure-lösliches & 86,6 & 85,5 \\
\hline & Sporenprotein & & \\
\hline \multirow[t]{2}{*}{ BLi01192 } & putative 5-Methyltetrahydrofolat- & 77,8 & 78,5 \\
\hline & Homocystein-Methyltransferase & & \\
\hline BLi01213 & putative Undecaprenol-Kinase & 81,5 & 81,5 \\
\hline BLi01777 & hypothetisches Protein & 76,6 & 76,6 \\
\hline BLi02012 & putative Acetyltransferase & 82,8 & 81,7 \\
\hline BLi02013 & hypothetisches Protein & 76,3 & 79,7 \\
\hline BLi02055 & konserviert hypothetisches Protein & 79,1 & 79,1 \\
\hline \multirow[t]{2}{*}{ BLi02102 } & put. Enoyl(3-hydroxyisobutyryl)- & 78,8 & 78,8 \\
\hline & Coenzyme A-Hydratase & & \\
\hline BLi02104 & Methylmalonat-Semialdehyd-DH & 88,9 & 88,9 \\
\hline
\end{tabular}




\begin{tabular}{|c|c|c|c|}
\hline BLi02105 & putative 2-Hydroxy-3- & 80,1 & 79,1 \\
\hline BLi02106 & $\begin{array}{l}\text { Oxopropionat-Reductase } \\
\text { putative Butyryl-CoA- } \\
\text { Dehydrogenase }\end{array}$ & 79,1 & 79,2 \\
\hline BLi02114 & put. transkriptionaler Regulator & 75 & 75 \\
\hline BLi02131 & $\begin{array}{l}\text { putatives Aktivierungsenzym der } \\
\text { Pyruvat-Formiat-Lyase }\end{array}$ & 77,9 & 78,3 \\
\hline BLi02132 & putative Formiat-Acetyltransferase & 88,3 & 88,3 \\
\hline BLi02328 & $\begin{array}{l}\text { putative Formiat-Tetrahydrofolat- } \\
\text { Ligase }\end{array}$ & 77 & 79,8 \\
\hline BLi02797 & konserviert hypothetisches Protein & 88,1 & 88,5 \\
\hline BLi02810 & ähnlich zur Thioredoxin-Reduktase & 86,2 & 85,1 \\
\hline BLi02927 & put. transkriptionaler Regulator & 88,8 & 88,8 \\
\hline BLi02962 & $\begin{array}{l}\text { putative verzweigtkettige } \\
\text { Aminosäure-Aminotransferase }\end{array}$ & 81,2 & 81,6 \\
\hline BLi03657 & $\begin{array}{l}\text { putatives Eisen(III)-Transporter- } \\
\text { Bindungsprotein }\end{array}$ & 75,5 & 75,5 \\
\hline BLi03823 & $\begin{array}{l}\text { Aktivierungsenzym putative } \\
\text { anaerobe Ribonukleotidreduktase }\end{array}$ & 67,4 & 68 \\
\hline BLi03824 & $\begin{array}{l}\text { putative anaerobe } \\
\text { Ribonukleotidreduktase }\end{array}$ & 82,1 & 80,9 \\
\hline BLi03966 & Acyl-CoA-Dehydrogenase & 77,7 & 76,4 \\
\hline BLi04097 & put. Chromat-Transportprotein & 78,4 & 78,6 \\
\hline BLi04207 & putative Isocitrat-Lyase & 90,4 & 90,4 \\
\hline BLi04208 & putative Malat-Synthase & 79,6 & 79 \\
\hline BLi04269 & konserviert hypothetisches Protein & 84,8 & 85,2 \\
\hline BLi04275 & $\begin{array}{l}\text { homolog zu Ald: L-Alanin- } \\
\text { Dehydrogenase }\end{array}$ & 84,4 & 84,9 \\
\hline BLi04290 & $\begin{array}{l}\text { putative Alkohol-Dehydrogenase / } \\
\text { Acetaldehyd-Dehydrogenase }\end{array}$ & 84,2 & 84 \\
\hline
\end{tabular}


Tabelle 7.8: Expressionsverhältnisse von ORFs der Phagenbereiche. Werte größer 1 bedeuten eine verstärkte Expression beim Wachstum mit einem Gemisch von 20 Aminosäuren zu den angegebenen Zeitpunkten, Werte kleiner -1 eine verstärkte Expression unter der Referenzbedingung. Die Tabelle enthält repräsentative Einzelmessungen. In diesem Fall wurden die englischsprachigen Bezeichnungen der Annotation beibehalten. Die Phagenbereiche sind optisch getrennt. n.b. - nicht bestimmt

\begin{tabular}{|c|c|c|c|c|c|c|c|}
\hline \multirow[t]{3}{*}{ ID } & \multirow[t]{3}{*}{ Gen } & \multirow[t]{3}{*}{ Annotation } & \multicolumn{5}{|c|}{ log Expressionsverhältnisse } \\
\hline & & & $\mathrm{T} 1 /$ & $\mathrm{T} 2 /$ & $\mathrm{T} 3 /$ & $\mathrm{T} 4 /$ & $\mathrm{T} 5 /$ \\
\hline & & & Glc & Glc & Glc & Glc & Glc \\
\hline BLi01314 & none & none & 0,09 & $-1,26$ & $-0,91$ & $-0,80$ & $-2,35$ \\
\hline BLi01315 & yeeF & similar to unknown & $-0,17$ & $-1,60$ & $-1,16$ & $-1,11$ & $-2,38$ \\
\hline BLi01316 & $y j q B$ & $\begin{array}{l}\text { proteins from } B \text {. subtilis } \\
\text { similar to phage-related } \\
\text { replication protein }\end{array}$ & n.b. & 1,40 & n.b. & 0,80 & 0,88 \\
\hline BLi01317 & $x k d A$ & PBSX prophage & $-0,28$ & 0,99 & $-0,15$ & $-1,61$ & $-2,32$ \\
\hline BLi01318 & xre & $\begin{array}{l}\text { transcriptional repressor } \\
\text { of PBSX genes }\end{array}$ & 0,72 & 0,47 & $-0,94$ & $-0,84$ & $-1,78$ \\
\hline BLi01319 & none & putative repressor protein & n.b. & n.b. & 1,74 & n.b. & n.b. \\
\hline BLi01320 & none & none & 1,86 & 0,87 & n.b. & n.b. & $-0,47$ \\
\hline BLi01321 & $x k d B$ & PBSX prophage & n.b. & 0,37 & n.b. & n.b. & n.b. \\
\hline BLi01322 & $x k d C$ & PBSX prophage & n.b. & n.b. & n.b. & n.b. & $-0,19$ \\
\hline BLi01323 & none & none & 2,13 & 1,28 & 3,09 & $-1,10$ & $-2,03$ \\
\hline BLi01324 & $x k d D$ & PBSX prophage & 2,13 & 1,09 & 2,87 & $-1,02$ & $-1,40$ \\
\hline BLi01325 & $x \operatorname{tr} A$ & PBSX prophage & 1,72 & 0,99 & n.b. & n.b. & n.b. \\
\hline BLi01326 & $x p f$ & $\begin{array}{l}\text { RNA polymerase PBSX } \\
\text { sigma factor-like }\end{array}$ & 0,24 & n.b. & n.b. & n.b. & 0,11 \\
\hline BLi01327 & $x \operatorname{tm} A$ & $\begin{array}{l}\text { PBSX terminase } \\
\text { (small subunit) }\end{array}$ & 0,33 & n.b. & 1,88 & $-2,04$ & n.b. \\
\hline BLi01328 & $x \operatorname{tm} B$ & $\begin{array}{l}\text { PBSX terminase } \\
\text { (large subunit) }\end{array}$ & n.b. & 0,25 & 1,90 & $-0,70$ & $-1,50$ \\
\hline BLi01329 & $x k d E$ & PBSX prophage & 1,02 & 0,49 & 2,61 & $-1,96$ & $-2,55$ \\
\hline BLi01330 & $x k d F$ & PBSX prophage & 1,56 & 0,18 & 2,17 & $-2,52$ & n.b. \\
\hline BLi01331 & $x k d G$ & PBSX prophage & 0,42 & 0,44 & 2,61 & n.b. & n.b. \\
\hline BLi01332 & $y q b G$ & unknown & 1,06 & 0,28 & 2,56 & $-2,46$ & $-3,64$ \\
\hline
\end{tabular}




\begin{tabular}{|c|c|c|c|c|c|c|c|}
\hline BLi01333 & $y q b H$ & $\begin{array}{l}\text { unknown; similar to } \\
\text { phage-related protein }\end{array}$ & 0,75 & 0,26 & 2,61 & $-2,54$ & n.b. \\
\hline BLi01334 & $x k d I$ & PBSX prophage & 0,59 & 0,21 & 2,41 & $-2,47$ & $-3,01$ \\
\hline BLi01335 & $x k d J$ & PBSX prophage & 1,17 & 0,27 & 2,53 & $-2,47$ & n.b. \\
\hline BLi01336 & none & none & 1,49 & 0,40 & 2,71 & $-2,00$ & n.b. \\
\hline BLi01337 & $x k d K$ & PBSX prophage & 0,65 & 0,16 & 2,53 & $-2,87$ & n.b. \\
\hline BLi01338 & $x k d M$ & PBSX prophage & 0,51 & 0,55 & 2,71 & $-1,01$ & $-2,48$ \\
\hline BLi01339 & $x k d N 1$ & PBSX prophage & 0,58 & $-0,30$ & 1,95 & $-3,29$ & n.b. \\
\hline BLi01340 & $x k d N 2$ & PBSX prophage & 0,95 & 0,27 & 2,47 & $-3,02$ & $-4,44$ \\
\hline BLi01341 & $x k d O$ & PBSX prophage & 0,73 & 0,01 & 2,41 & $-1,74$ & $-2,32$ \\
\hline BLi01342 & $x k d P$ & PBSX prophage & 1,59 & 0,47 & 2,72 & $-2,01$ & $-2,55$ \\
\hline BLi01343 & $y q b Q$ & $\begin{array}{l}\text { unknown; similar to } \\
\text { phage-related protein }\end{array}$ & 1,04 & 0,29 & 2,34 & $-1,79$ & $-1,58$ \\
\hline BLi01344 & none & put. phage PBSX protein & 0,96 & 0,63 & 2,80 & $-1,40$ & n.b. \\
\hline BLi01345 & $x k d S$ & PBSX prophage & 0,41 & 0,10 & 2,52 & $-2,94$ & $-1,41$ \\
\hline BLi01346 & $y q b T$ & $\begin{array}{l}\text { unknown; similar to } \\
\text { phage-related protein }\end{array}$ & 1,02 & $-0,18$ & 2,23 & $-1,91$ & $-2,07$ \\
\hline BLi01347 & $x k d U$ & PBSX prophage & n.b. & n.b. & 1,20 & n.b. & 1,37 \\
\hline BLi01348 & none & none & 1,40 & 0,26 & 2,33 & $-1,97$ & $-3,43$ \\
\hline BLi01349 & none & put. phage PBSX protein & 0,99 & 0,03 & 2,21 & $-2,20$ & $-3,01$ \\
\hline BLi01350 & none & put. phage PBSX protein & 1,59 & 0,67 & 2,73 & $-1,80$ & $-2,39$ \\
\hline BLi01351 & $x h l A$ & $\begin{array}{l}\text { involved in cell lysis upon } \\
\text { induction of PBSX }\end{array}$ & 1,11 & 0,15 & 2,53 & $-0,94$ & n.b. \\
\hline BLi01352 & none & put. cell wall hydrolase & 1,46 & 0,42 & 1,86 & $-1,50$ & $-1,80$ \\
\hline BLi01427 & none & none & 0,60 & 1,00 & 0,52 & $-0,58$ & $-1,73$ \\
\hline BLi01428 & none & $\begin{array}{l}\text { putative integrase-phage } \\
\text { associated }\end{array}$ & 0,27 & 1,78 & $-0,02$ & $-2,02$ & $-2,84$ \\
\hline BLi01429 & $y q a B$ & $\begin{array}{l}\text { unknown; similar to } \\
\text { phage-related protein }\end{array}$ & $-0,56$ & 0,83 & $-0,67$ & $-2,06$ & $-2,32$ \\
\hline BLi01430 & none & none & n.b. & n.b. & n.b. & n.b. & $-3,44$ \\
\hline BLi01431 & none & none & $-0,05$ & $-0,86$ & $-0,38$ & $-2,82$ & $-3,77$ \\
\hline BLi01432 & none & none & 0,48 & -076 & $-0,89$ & $-1,91$ & $-3,87$ \\
\hline
\end{tabular}




\begin{tabular}{|c|c|c|c|c|c|c|c|}
\hline BLi01433 & $y q a E$ & $\begin{array}{l}\text { similar to transcriptional } \\
\text { regulator (phage-related) } \\
\text { (Xre family) }\end{array}$ & 0,40 & $-0,47$ & $-1,63$ & $-1,59$ & $-2,69$ \\
\hline BLi01434 & none & none & 3,73 & 0,86 & 2,66 & 0,58 & $-2,34$ \\
\hline BLi01435 & none & none & n.b. & 0,96 & 2,75 & 0,78 & $-1,95$ \\
\hline BLi01436 & none & putative phage protein & 3,67 & 0,60 & 2,44 & 0,35 & n.b. \\
\hline BLi01437 & none & putative phage protein & 4,13 & 1,22 & 2,92 & 0,00 & $-2,05$ \\
\hline BLi01438 & $y q a H$ & unknown & 4,19 & 1,36 & 3,12 & 0,29 & $-2,11$ \\
\hline BLi01439 & none & none & 4,33 & 1,53 & 3,10 & 0,79 & n.b. \\
\hline BLi01440 & yqaJ & $\begin{array}{l}\text { unknown; similar to } \\
\text { phage-related protein }\end{array}$ & 3,76 & n.b. & 2,49 & $-0,06$ & $-1,71$ \\
\hline BLi01441 & yqaK & $\begin{array}{l}\text { unknown; similar to } \\
\text { phage-related protein }\end{array}$ & 4,22 & 1,55 & 3,27 & 0,57 & $-0,91$ \\
\hline BLi01442 & $y q a L$ & unknown & n.b. & 1,14 & 2,69 & 0,30 & $-1,30$ \\
\hline BLi01443 & yqaM & $\begin{array}{l}\text { unknown; similar to } \\
\text { phage-related protein }\end{array}$ & 3,78 & 0,73 & 2,33 & 0,28 & $-1,16$ \\
\hline BLi01444 & $y q a O$ & $\begin{array}{l}\text { unknown; similar to } \\
\text { phage-related protein }\end{array}$ & 3,72 & 0,85 & 2,41 & 0,17 & $-1,49$ \\
\hline BLi01445 & none & none & 4,06 & 0,99 & 2,50 & 0,44 & $-1,39$ \\
\hline BLi01446 & none & none & 3,98 & 1,01 & 2,63 & 0,55 & $-1,72$ \\
\hline BLi01447 & none & none & n.b. & 1,50 & 2,53 & 0,54 & $-1,62$ \\
\hline BLi01448 & none & none & 4,34 & 1,03 & 2,67 & 0,36 & $-1,67$ \\
\hline BLi01449 & none & none & 3,95 & 0,97 & 2,48 & 0,22 & $-1,88$ \\
\hline BLi01450 & none & none & 2,97 & 0,82 & 2,68 & 0,46 & $-1,42$ \\
\hline BLi01451 & none & none & n.b. & 0,26 & 2,11 & $-0,50$ & $-0,72$ \\
\hline BLi01452 & $y q a N$ & unknown & n.b. & n.b. & n.b. & n.b. & $-1,31$ \\
\hline BLi01453 & none & $\begin{array}{l}\text { putative single-stranded } \\
\text { DNA-binding protein }\end{array}$ & 4,16 & 1,17 & 3,31 & 0,33 & $-1,73$ \\
\hline BLi01454 & none & none & 3,31 & 0,13 & 1,81 & $-0,34$ & 0,29 \\
\hline BLi01455 & none & none & n.b. & n.b. & n.b. & 1,43 & 1,95 \\
\hline BLi01456 & none & none & 3,59 & 1,13 & 2,85 & 1,74 & 2,07 \\
\hline BLi01458 & none & none & n.b. & n.b. & n.b. & 1,43 & n.b. \\
\hline
\end{tabular}




\begin{tabular}{|c|c|c|c|c|c|c|c|}
\hline BLi01460 & $y q a Q$ & $\begin{array}{l}\text { similar to unknown } \\
\text { proteins from } B \text {. subtilis }\end{array}$ & n.b. & n.b. & 3,25 & 1,65 & 0,19 \\
\hline BLi01461 & none & none & n.b. & n.b. & n.b. & n.b. & n.b. \\
\hline BLi01462 & none & none & n.b. & n.b. & n.b. & 1,01 & n.b. \\
\hline BLi01463 & yqaS & similar to phage-related & n.b. & n.b. & n.b. & n.b. & n.b. \\
\hline & & terminase small subunit & & & & & \\
\hline BLi01464 & none & putative multidrug & n.b. & n.b. & n.b. & n.b. & n.b. \\
\hline & & resistance protein & & & & & \\
\hline BLi01465 & none & putative portal protein & n.b. & n.b. & n.b. & n.b. & n.b. \\
\hline BLi01466 & none & putative phage protein & n.b. & n.b. & n.b. & n.b. & n.b. \\
\hline BLi01467 & none & none & n.b. & 1,77 & n.b. & n.b. & 0,08 \\
\hline BLi01468 & none & putative phage protein & n.b. & n.b. & 4,06 & 1,87 & n.b. \\
\hline BLi01469 & none & none & 4,05 & 3,34 & 5,02 & 2,84 & $-1,39$ \\
\hline BLi01470 & none & put. phage capsid protein & n.b. & 2,93 & 4,26 & 2,91 & n.b. \\
\hline BLi01471 & none & putative phage protein & 2,81 & 2,96 & 4,29 & 1,97 & $-0,17$ \\
\hline BLi01472 & none & none & 1,88 & 1,94 & 3,04 & 2,06 & 0,41 \\
\hline BLi01473 & none & putative phage protein & n.b. & 3,05 & n.b. & 2,03 & n.b. \\
\hline BLi01474 & none & putative phage protein & n.b. & n.b. & n.b. & 0,73 & 0,77 \\
\hline BLi01475 & none & putative phage protein & n.b. & n.b. & n.b. & 1,25 & n.b. \\
\hline BLi01476 & none & putative phage tail protein & 3,59 & n.b. & 3,61 & 2,00 & $-0,22$ \\
\hline BLi01477 & none & putative phage tail protein & 3,64 & 2,43 & 3,48 & 2,58 & 0,72 \\
\hline BLi01478 & none & putative phage protein & n.b. & n.b. & n.b. & n.b. & n.b. \\
\hline BLi01479 & none & putative phage protein & 1,43 & 1,61 & 2,90 & 1,23 & n.b. \\
\hline BLi01480 & none & putative phage protein & 2,85 & n.b. & 3,24 & 0,91 & n.b. \\
\hline BLi01481 & none & none & n.b. & 1,97 & 3,09 & 1,14 & $-0,30$ \\
\hline BLi01482 & none & putative phage protein & n.b. & n.b. & n.b. & 1,00 & n.b. \\
\hline BLi01483 & none & none & n.b. & 2,56 & n.b. & 2,61 & n.b. \\
\hline BLi01484 & none & putative phage protein & n.b. & n.b. & n.b. & 1,92 & n.b. \\
\hline BLi01485 & $x h l B$ & $\begin{array}{l}\text { hydrolysis of 5-bromo 4- } \\
\text { chloroindolyl phosphate }\end{array}$ & 3,18 & n.b. & n.b. & 1,60 & $-0,36$ \\
\hline BLi01486 & none & $\begin{array}{l}\text { upon induction of PBSX } \\
\text { putative glycosyl } \\
\text { hydrolase/lysozyme }\end{array}$ & n.b. & 1,46 & n.b. & 0,44 & n.b. \\
\hline
\end{tabular}




\begin{tabular}{|c|c|c|c|c|c|c|c|}
\hline BLi01540 & none & none & n.b. & $-0,31$ & n.b. & 0,31 & 0,07 \\
\hline BLi01542 & none & putative phage protein & n.b. & n.b. & n.b. & n.b. & $-0,23$ \\
\hline BLi01543 & none & none & n.b. & n.b. & n.b. & n.b. & n.b. \\
\hline BLi01544 & none & none & n.b. & n.b. & n.b. & n.b. & n.b. \\
\hline BLi01545 & none & none & n.b. & 0,41 & n.b. & n.b. & n.b. \\
\hline BLi01546 & none & none & n.b. & n.b. & n.b. & $-0,55$ & 0,14 \\
\hline BLi01547 & none & $\begin{array}{l}\text { putative terminase-small } \\
\text { subunit }\end{array}$ & 0,33 & n.b. & n.b. & $-0,01$ & $-0,18$ \\
\hline BLi01548 & none & putative terminase & n.b. & n.b. & n.b. & n.b. & n.b. \\
\hline BLi01549 & none & $\begin{array}{l}\text { putative phage head portal } \\
\text { protein }\end{array}$ & n.b. & n.b. & n.b. & n.b. & n.b. \\
\hline BLi01550 & none & $\begin{array}{l}\text { put. phage pi3 protein } 23 \text {, } \\
\text { ATP dependent Clp } \\
\text { protease }\end{array}$ & n.b. & n.b. & n.b. & n.b. & n.b. \\
\hline BLi01551 & none & none & n.b. & n.b. & n.b. & n.b. & n.b. \\
\hline BLi01552 & none & none & n.b. & n.b. & n.b. & n.b. & n.b. \\
\hline BLi01553 & none & none & n.b. & n.b. & n.b. & n.b. & n.b. \\
\hline BLi01554 & none & putative phage protein & n.b. & n.b. & n.b. & n.b. & 1,30 \\
\hline BLi01555 & none & none & n.b. & n.b. & n.b. & n.b. & n.b. \\
\hline BLi01556 & none & putative phage tail protein & n.b. & n.b. & n.b. & n.b. & n.b. \\
\hline BLi01557 & none & putative phage protein & n.b. & n.b. & n.b. & n.b. & n.b. \\
\hline BLi01558 & none & none & n.b. & n.b. & n.b. & n.b. & n.b. \\
\hline BLi01559 & $y q b O$ & $\begin{array}{l}\text { unknown; similar to } \\
\text { phage-related protein }\end{array}$ & n.b. & n.b. & n.b. & n.b. & n.b. \\
\hline BLi01560 & none & none & n.b. & n.b. & n.b. & n.b. & n.b. \\
\hline BLi01561 & none & putative phage protein & n.b. & n.b. & n.b. & n.b. & n.b. \\
\hline BLi01562 & none & putative phage protein & n.b. & n.b. & n.b. & n.b. & n.b. \\
\hline BLi01563 & $p B S X$ & prophage ORF xkdV & n.b. & n.b. & n.b. & n.b. & n.b. \\
\hline BLi01564 & none & putative phage protein & n.b. & n.b. & n.b. & $-0,30$ & 0,00 \\
\hline BLi01565 & yomP & $\begin{array}{l}\text { unknown; similar to } \\
\text { phage-related protein }\end{array}$ & n.b. & n.b. & n.b. & n.b. & $-0,14$ \\
\hline BLi01566 & none & put. phosphodiesterase & $-1,45$ & $-0,82$ & $-1,77$ & $-1,56$ & $-1,88$ \\
\hline BLi01567 & bhlA & holin-like protein & n.b. & n.b. & n.b. & n.b. & \\
\hline
\end{tabular}




\begin{tabular}{|c|c|c|c|c|c|c|c|}
\hline BLi01568 & $x l y B$ & $\begin{array}{l}\text { N-acetylmuramoyl-L- } \\
\text { alanine amidase (PBSX } \\
\text { prophage-mediated lysis) }\end{array}$ & n.b. & n.b. & n.b. & n.b. & n.b. \\
\hline BLi01569 & none & putative holin & 1,59 & 0,22 & $-0,22$ & $-1,98$ & $-2,59$ \\
\hline BLi01570 & none & none & 0,56 & $-0,37$ & $-0,46$ & 1,07 & $-2,78$ \\
\hline BLi01571 & none & none & $-0,27$ & 1,10 & 0,33 & 1,07 & 0,70 \\
\hline BLi01572 & none & none & n.b. & n.b. & n.b. & n.b. & n.b. \\
\hline BLi01573 & none & none & 0,40 & 4,50 & 0,85 & 1,17 & 0,82 \\
\hline BLi01574 & none & putative integrase-phage & $-0,50$ & 2,21 & $-0,59$ & $-0,35$ & 0,36 \\
\hline & & associated & & & & & \\
\hline BLi01575 & none & none & 0,38 & 1,47 & $-0,30$ & $-0,78$ & $-1,05$ \\
\hline BLi03598 & blyA & $\begin{array}{l}\text { N-acetylmuramoyl-L- } \\
\text { alanine amidase cwlL } \\
\text { precursor (EC 3.5.1.28) } \\
\text { (Cell wall hydrolase) } \\
\text { (Autolysin) }\end{array}$ & n.b. & n.b. & n.b. & n.b. & 0,47 \\
\hline BLi03599 & none & putative phage protein & 0,86 & n.b. & n.b. & n.b. & n.b. \\
\hline BLi03600 & none & putative phage protein & n.b. & n.b. & n.b. & n.b. & n.b. \\
\hline BLi03601 & yomQ & unknown & $-0,30$ & 0,57 & 0,95 & 1,82 & 1,19 \\
\hline BLi03602 & none & put. phage PBSX protein & n.b. & n.b. & n.b. & n.b. & n.b. \\
\hline BLi03603 & none & none & n.b. & n.b. & n.b. & n.b. & n.b. \\
\hline BLi03604 & none & $\begin{array}{l}\text { putative phage autolysin } \\
\text { (amidase) homolog }\end{array}$ & n.b. & n.b. & n.b. & n.b. & n.b. \\
\hline BLi03605 & none & none & n.b. & n.b. & n.b. & n.b. & n.b. \\
\hline BLi03606 & none & putative phage tail protein & n.b. & n.b. & n.b. & n.b. & n.b. \\
\hline BLi03607 & none & none & n.b. & n.b. & n.b. & n.b. & n.b. \\
\hline BLi03608 & none & none & n.b. & n.b. & n.b. & n.b. & n.b. \\
\hline BLi03609 & none & none & n.b. & n.b. & n.b. & n.b. & n.b. \\
\hline BLi03610 & none & none & n.b. & n.b. & n.b. & n.b. & n.b. \\
\hline BLi03611 & none & none & n.b. & n.b. & n.b. & n.b. & n.b. \\
\hline BLi03612 & none & none & n.b. & n.b. & n.b. & n.b. & 0,35 \\
\hline BLi03613 & none & none & n.b. & n.b. & $-1,04$ & $-0,52$ & 0,74 \\
\hline BLi03614 & none & putative phage protein & n.b. & n.b. & n.b. & n.b. & n.b. \\
\hline
\end{tabular}




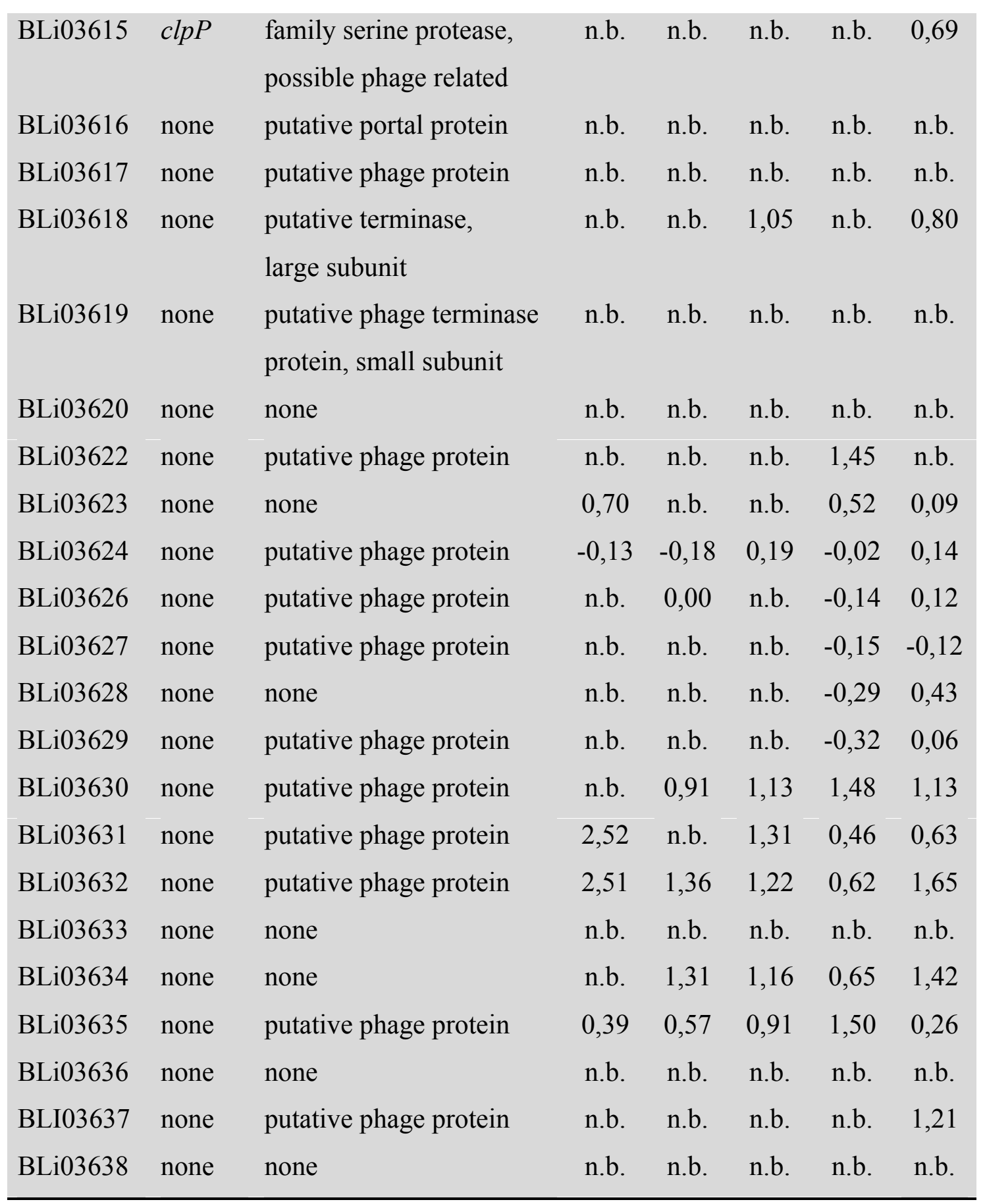


Tabelle 7.9: Übersicht von Genen, welche beim Wachstum mit proteinogen Aminosäuren eine erhöhte Expression zeigten. Werte größer 1 bedeuten eine verstärkte Expression beim Wachstum mit L-Ornithin im Vergleich zur Kultivierung unter der Referenzbedingung.

\begin{tabular}{|c|c|c|c|}
\hline ID & Gen & Funktion & $\begin{array}{c}\text { log } \\
\text { Expressionsverhältnis } \\
\text { L-Ornithin / Glucose }\end{array}$ \\
\hline BLi00853 & acoR & $\begin{array}{l}\text { transkriptionaler Aktivator des } \\
\text { Acetoin-Dehydrogenase Operons }\end{array}$ & 1,54 \\
\hline BLi01143 & melA & $\alpha$-D-Galaktosid-Galaktohydrolase & 1,00 \\
\hline BLi02102 & & $\begin{array}{l}\text { putative Enoyl(3-hydroxyisobutyryl)- } \\
\text { Coenzyme A Hydratase Protein }\end{array}$ & 2,70 \\
\hline BLi02103 & & putative Enoyl-CoA Hydratase & 2,02 \\
\hline BLi02104 & $m m s A$ & $\begin{array}{l}\text { Methylmalonat-Semialdehyd } \\
\text { Dehydrogenase }\end{array}$ & 2,43 \\
\hline BLi02105 & & $\begin{array}{l}\text { putative 2-Hydroxy-3-Oxopropionat } \\
\text { Reductase }\end{array}$ & 1,85 \\
\hline BLi02106 & & putative Butyryl-CoA-Dehydrogenase & 2,45 \\
\hline BLi03498 & & putative Pectin-Methylesterase & 1,41 \\
\hline BLi04275 & & $\begin{array}{l}\text { homolog zur Ald: L-Alanin- } \\
\text { Dehydrogenase }\end{array}$ & 5,09 \\
\hline
\end{tabular}


Tabelle 7.10: Vergleichende Darstellung der via PCR-basierenden bzw. Oligo-basierenden DNAMicroarrays ermittelten Expressionsverhältnisse. Abgebildet sind Expressionswerte beim Wachstum mit Acetat bzw. 2,3-Butandiol (2,3-B.) im Vergleich zum Wachstum mit Glucose. Werte größer 1 bedeuten eine verstärkte Expression beim Wachstum mit Acetat bzw. 2,3-Butandiol im Vergleich zur Kultivierung unter der Referenzbedingung. Die Tabelle enthält repräsentative Einzelmessungen. n.b. - nicht bestimmt

\begin{tabular}{|c|c|c|c|c|c|c|}
\hline \multirow[t]{4}{*}{ ID } & \multirow[t]{4}{*}{ Gen } & \multirow[t]{4}{*}{ Funktion } & \multicolumn{4}{|c|}{ log Expressionsverhältnisse } \\
\hline & & & \multicolumn{2}{|c|}{ PCR-Chip ${ }^{1)}$} & \multicolumn{2}{|c|}{ Oligo-Chip $^{2)}$} \\
\hline & & & Acetat / & 2,3-B. / & Acetat / & 2,3-B. / \\
\hline & & & Glc & Glc & Glc & Glc \\
\hline \multirow[t]{3}{*}{ BLi00849 } & $a \operatorname{co} A$ & Acetoin-Dehydrogenase & 2,68 & 8,11 & 4,66 & 8,14 \\
\hline & & (TPP-abhängige & & & & \\
\hline & & $\alpha$-Untereinheit) & & & & \\
\hline \multirow[t]{3}{*}{ BLi00850 } & $a c o B$ & Acetoin-Dehydrogenase & 4,08 & 7,49 & 4,80 & 8,64 \\
\hline & & (TPP-abhängige & & & & \\
\hline & & $\beta$-Untereinheit) & & & & \\
\hline \multirow[t]{3}{*}{ BLi00851 } & $\operatorname{acoC}$ & Acetoin-Dehydrogenase & 2,59 & 7,66 & 3,54 & 7,99 \\
\hline & & (Dihydrolipoamid- & & & & \\
\hline & & Acetyltransferase) & & & & \\
\hline \multirow[t]{3}{*}{ BLi00852 } & $a c o L$ & Acetoin-Dehydrogenase & n.b. & 4,26 & 3,86 & 7,83 \\
\hline & & (Dihydrolipoamid- & & & & \\
\hline & & Dehydrogenase) & & & & \\
\hline \multirow[t]{2}{*}{ BLi00853 } & $a c o R$ & transkript. Aktivator des & n.b. & 2,92 & 2,58 & 4,37 \\
\hline & & aco-Operons & & & & \\
\hline BLi02047 & $\operatorname{cit} B$ & Aconitat-Hydratase & 1,26 & 0,58 & 2,00 & 2,27 \\
\hline BLi03119 & $a \operatorname{cs} A$ & Acetyl-CoA-Synthetase & 4,11 & 3,56 & 3,90 & 3,76 \\
\hline BLi03197 & $p c k A$ & PEP-Carboxykinase & 5,77 & 4,07 & 6,43 & 6,04 \\
\hline BLi04207 & & Isocitrat-Lyase & 6,78 & 6,73 & 6,83 & 7,33 \\
\hline BLi04208 & & Malat-Synthase & 7,01 & 7,24 & 7,32 & 8,07 \\
\hline
\end{tabular}


A
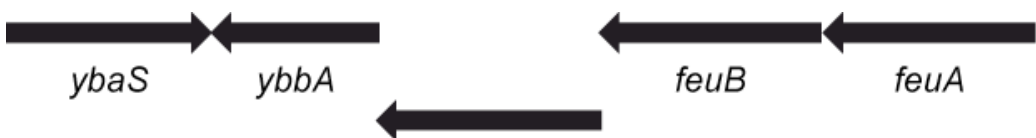

feuB

feuA

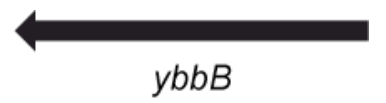

feuC

B

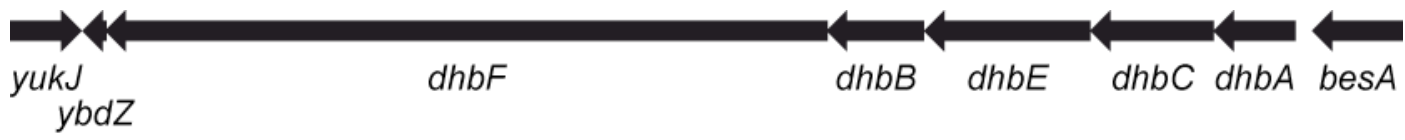

Abbildung 7.2: Darstellung der an der Biosynthese und Transport von Bacillibactin beteiligter feu-(A) und dhb-Regionen (B) bzw. angrenzender Gene in B. subtilis. Die Relationen der Genomabschnitte sind nicht in Relation zueinander dargestellt. Der Genomabschnitt in A hat eine Größe von etwa $6,5 \mathrm{~kb}$ und der Genomabschnitt in B eine Größe von etwa $14 \mathrm{~kb}$.

A $y b a S$, putativer natriumabhängiger Transporter; $y b b A$, putative Eisen-Chelat-Esterase; $f e u C$, Eisenaufnahmeprotein; $f e u B$, Eisenaufnahmeprotein; feuA, Eisen-Hydroxamatbindendes Protein; $y b b B$, putativer transkriptionaler Regulator; B $y u k J$, hypothetisches Protein; $y b d Z$, hypothetisches Protein; $d h b F$, Siderophor 2,3-Dihydroxybenzoat-Glycin-Threonin Trimere-Ester-Bacillibactin-Synthetase; $\quad \operatorname{dhbB}$, Isochorismatase; $d h b E, \quad 2,3$-Dihydroxybenzoat-AMP-Ligase; $d h b C$, Isochorismat-Synthase; $d h b A$, 2,3-Dihydroxybenzoat-2,3-Dehydrogenase; besA, Bacillibactin-Trilacton-Hydrolase

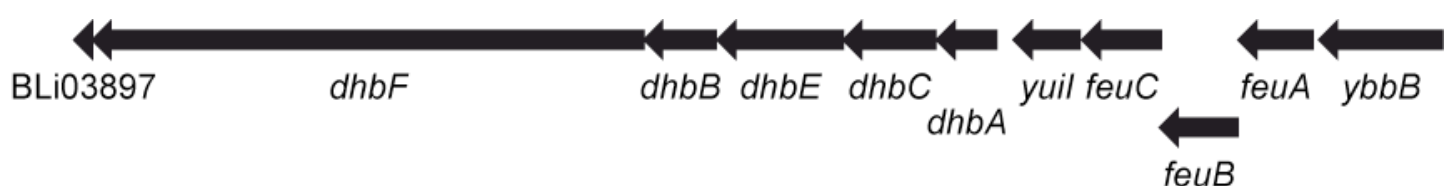

Abbildung 7.3: Anordnung von Genen, welche mit der möglichen Biosynthese von Bacillibactin in B. licheniformis im Zusammenhang stehen. BLi03897, hypothetisches Protein; $d h b F$, putative Siderophor 2,3-Dihydroxybenzoat-Glycin-Threonin Trimere-Ester-Bacillibactin-Synthetase; $\quad d h b B$, Isochorismatase; $d h b E, 2,3-D i h y d r o x y b e n z o a t-A M P-L i g a s e ; ~ d h b C$, Isochorismat-Synthase; $d h b A$, 2,3-Dihydroxybenzoat-2,3-Dehydrogenase; yuiI, YuiI; feuC, Eisenaufnahmesystem (Membranprotein); $f e u B$, Eisenaufnahmesystem (Membranprotein); feuA, Eisenaufnahmesystem (bindendes Protein); $y b b B$, ähnlich transkriptionaler Regulator 


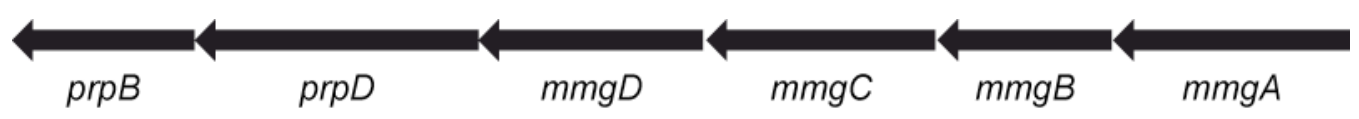

Abbildung 7.4: Darstellung des mmg-Operons in B. subtilis. Die Gene des Fettsäuremetabolismus sind zusammen mit den Genen des Methylcitratzyklus in einem Operon organisiert. prpB, 2-MethylisocitratLyase; $\operatorname{prpD}$, 2-Methylcitrat-Dehydratase; $m m g D$, Citratsynthase III; $m m g C$, Acyl-CoA-Dehydrogenase; $m m g B, 3-H y d r o x y b u t y r y l-C o A-D e h y d r o g e n a s e ; ~ m m g A$, Acetoacetyl-CoA-Thiolase

A

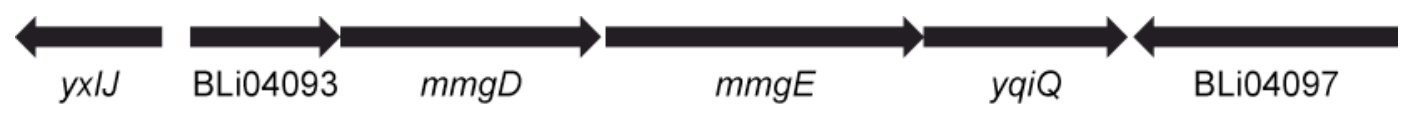

B

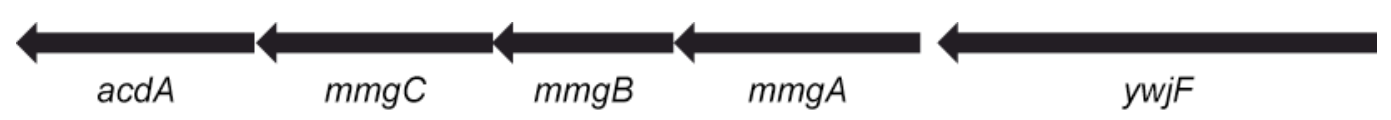

Abbildung 7.5: Vergleichende Darstellung der Genregionen des putativen Methylcitratzyklus (A) und $m m g A B C$ (B) für B. licheniformis DSM13. A yxlJ, ähnlich zu DNA-3-Methyladenin-Glycosidase; BLi04093, putativer transkriptionaler Regulator; $m m g D$, Citratsynthase III / putative Methylcitratsynthase; $m m g E$, 2-Methylcitrat-Dehydratase; yqiQ, putative Methylisocitrat-Lyase; BLi04097, putatives Chromattransportprotein; B acdA, Acyl-CoA-Dehydrogenase; mmgC, Acyl-CoADehydrogenase; $m m g B, 3$-Hydroxybutyryl-CoA-Dehydrogenase; $m m g A$, Acetyl-CoA-Acetyltransferase; $y w j F$, ähnlich zu Eisen-Schwefel-bindenden Reduktasen 
Tabelle 7.11: Übersicht von Expressionsverhältnissen von Genen des Tricarbonsäurezyklus. Werte größer 1 bedeuten eine verstärkte Expression beim Wachstum mit L-Asparagin im Vergleich zur Kultivierung unter der Referenzbedingung. Mit einem Stern gekennzeichnete Werte konnten in einem zweiten biologischen Experiment nicht reproduziert werden. Die Tabelle enthält repräsentative Einzelmessungen.

\begin{tabular}{|c|c|c|c|}
\hline ID & Gen & Funktion & $\begin{array}{c}\log \\
\text { Expressionsverhältnis } \\
\text { L-Asparagin / Glucose }\end{array}$ \\
\hline BLi01010 & $\operatorname{citA}$ & Citratsynthase I & 6,49 \\
\hline BLi01677 & $p d h D$ & $\begin{array}{l}\text { Pyruvat-Dehydrogenase / } \\
\text { 2-Oxoglutarat-Dehydrogenase } \\
\text { E3-Untereinheit }\end{array}$ & 2,09 \\
\hline BLi01829 & sucC & $\begin{array}{l}\text { Succinyl-CoA-Synthetase } \\
\text { ( } \beta \text {-Untereinheit) }\end{array}$ & $1,95^{*}$ \\
\hline BLi01830 & sucD & $\begin{array}{l}\text { Succinyl-CoA-Synthetase } \\
\text { ( } \alpha \text {-Untereinheit) }\end{array}$ & 1,69 \\
\hline BLi02047 & citB & Aconitat-Hydratase & $-0,59$ \\
\hline BLi02259 & $o d h B$ & $\begin{array}{l}\text { 2-Oxoglutarat-Dehydrogenase } \\
\text { (E2 Untereinheit) }\end{array}$ & 1,19 \\
\hline BLi02260 & odhA & $\begin{array}{l}\text { 2-Oxoglutarat-Dehydrogenase } \\
\text { (E1 Untereinheit) }\end{array}$ & $-0,19$ \\
\hline BLi02992 & $s d h B$ & $\begin{array}{l}\text { Succinat-Dehydrogenase (Eisen- } \\
\text { Schwefelprotein) }\end{array}$ & 1,18 \\
\hline BLi02993 & $s d h A$ & $\begin{array}{l}\text { Succinat-Dehydrogenase } \\
\text { (Flavoprotein-Untereinheit) }\end{array}$ & 0,45 \\
\hline BLi02994 & $s d h C$ & $\begin{array}{l}\text { Succinat-Dehydrogenase } \\
\text { (Cytochrom b558-Untereinheit) }\end{array}$ & 0,47 \\
\hline BLi03060 & $m d h$ & Malat-Dehydrogenase & 0,94 \\
\hline BLi03061 & icd & Isocitrat-Dehydrogenase & 0,66 \\
\hline BLi03062 & $\operatorname{cit} Z$ & Citratsynthase II & 0,96 \\
\hline BLi03197 & pckA & Phosphoenolpyruvat-Carboxykinase & 6,66 \\
\hline BLi03486 & $\operatorname{cit} G$ & Fumarat-Hydratase & 0,64 \\
\hline BLi04094 & $m m g D$ & Citratsynthase III & 0,25 \\
\hline
\end{tabular}




\section{Danksagung}

An dieser Stelle möchte ich nun die Gelegenheit nutzen, um an einige Personen meinen Dank zu richten. Zunächst möchte ich mich bei Herrn Prof. Dr. W. Liebl für die Ermöglichung des selbständigen Arbeitens und im Weiteren für die Übernahme des Referats bedanken. Ein sehr großer Dank richtet sich an Dr. Armin Ehrenreich für die Überlassung dieses Themas, seiner Diskussionsbereitschaft und seines Ideenreichtums. Vielen Dank für die Gelegenheit, auch mal über den „Tellerrand“ hinausschauen zu können.

Herrn PD. Dr. R. Daniel danke ich für die freundliche Übernahme des Korreferats.

Ich möchte ebenfalls die Gelegenheit nutzen und mich bei unseren Kooperationspartnern der Firma Henkel, Prof. Maurer, Dr. Bongaerts und Herrn Evers, für die Zusammenarbeit zu bedanken.

Ein besonderes Dankeschön richtet sich an Anja und Désirée für die freundliche Aufnahme in Freising. Es war eine Erfahrung wert. Darüber hinaus möchte ich aber nicht die weiteren jetzigen und früheren Mitglieder der Arbeitsgruppe vergessen. Vielen Dank für die gute Zusammenarbeit. Es war schön mit Euch, sowohl in Göttingen, als auch in Freising. Im Weiteren möchte ich mich bei Antje und Hedwig bedanken, welche mir durch ihre Einführungen in die Programmiersprachen sehr weitergeholfen haben. Nicht zu vergessen Christina, welche immer mit Rat und Tat zur Seite stand. Ich bin Dir zu großem Dank verpflichtet.

Bei meinen Eltern möchte ich mich für Ihre stetige Hilfsbereitschaft und Unterstützung bedanken. Ein Dankeschön richtet sich ebenso an meine Schwester samt Familie, ebenso wie an meine Schwiegereltern, meinen Schwager und Schwägerin, welche mich nicht nur während meines Studiums, sondern auch darüber hinaus in meinem Tun bestärkt haben.

Mein größter Dank gebührt aber den drei wichtigsten Personen in meinem Leben, meiner Frau Tanja und meinen Töchtern Lea Marie und Pia Sophie. Vielen Dank für Eure Liebe, Zuneigung und Euer Verständnis. 


\section{Lebenslauf}

\section{Persönliche Daten}

Geburtsdatum

08. Juni 1976

Geburtsort

Langenhagen

Familienstand

verheiratet, zwei Kinder (10 und 3 Jahre alt)

Nationalität

deutsch

\section{Naturwissenschaftliche Ausbildung}

03/2009 - heute

$06 / 2006-02 / 2009$

$12 / 2005-05 / 2006$

$10 / 1997-10 / 2005$

\section{Wehrdienst}

09/1996 - 06/1997

\section{Schulabschluss}

21.05.1996

Matthias-Claudius-Gymnasium Gehrden

Allgemeine Hochschulreife, Abiturnote: 3,0

\section{Weiterbildung}

25. -26.09 .2007$
Arbeiten zur Anfertigung der Dissertation am Lehrstuhl für Mikrobiologie der Technischen Universität München

Lehrstuhl Prof. W. Liebl, Arbeitsgruppe Dr. A. Ehrenreich

Arbeiten zur Anfertigung der Dissertation am Institut für Mikrobiologie und Genetik der Georg-August-Universität Göttingen

Lehrstuhl Prof. W. Liebl, Arbeitsgruppe Dr. A. Ehrenreich

Wiss. Mitarbeiter am Institut für Mikrobiologie und Genetik Göttingen

Lehrstuhl Prof. W. Liebl, Arbeitsgruppe Dr. A. Ehrenreich

\section{Studium der Naturwissenschaften an der Georg-August-Universität Göttingen}

Prüfungsfächer : Mikrobiologie, Immunologie, Betriebswirtschaftslehre

(Schwerpunkt Handelsbetriebslehre)

Thema der Diplomarbeit: Untersuchungen zum anaeroben fermentativen Wachstum von Bacillus licheniformis DSM13

Hochschulgrad Diplom-Biologe, Gesamtnote: Gut

Grundwehrdienst in Breitenburg und Wildeshausen 